\title{
CATÁLOGO
}

\section{DE LAS EXPOSICIONES DE ARTE EN 1969}

SUPLEMENTO AL NÜM. 39 DE LOS

ANALES DEL INSTITUTO DE INVESTIGACIONES ESTÉTICAS

MÉXICO, 1970 
DOI: http://dx.doi.org/10.22201/iie.18703062e.1970.sup1

Primera edición: 1970

DR (C) 1970, Universidad Nacional Autónoma de México

Ciudad Universitaria. México 20, D. F.

Dirección General de Publicactones

Impreso y hecho en México 
Cuando era de esperarse que el número de exposiciones de arte decreciera exageradamente, después de las que tuvieron Iugar durante la Olimpiada Cultural de 1968, en verdad apenas si disminuyó. Es interesante comparar las cifras estadísticas de los últimos años: 1966, 250 exposiciones; 1967, 310 exposiciones; 1968, 373 exposiciones; 1969,356 exposiciones.

En general las principales instituciones han mantenido un equilibrio en el número de exposiciones presentadas; el Instituto Nacional de Bellas Artes unas 80 anuales; la Universidad Nacional Autónoma de México unas veintitantas; el Organismo de Promoción Internacional de Cultura unas veinte. De los Institutos Culturales extranjeros se distinguieron: el Instituto Mexicano-Norteamericano de Relaciones Culturales con 25 exposiciones y el Instituto Francés de América Latina con 15 . Ahora bien, el resto de las exposiciones se distribuye entre ofras instituciones y galerías particulares en la ciudad de México.

E.l Instituto Nacional de Bellas Artes presentó, en el Palacio de Bellas Artes, las siguientes exposiciones: Mauricio Lasansky, excelente grabador norteamericano; Zdenek Rada; Johannes Gutenberg; Albert Tucker; Waldemar Sjölander; Exposición del Libro Argcntino; Rudolf Ray; Primera Exposición Internacional de Instrumentos Musicales; Alfredo Hlito; Luis Bolland; Richard Upton; la de Hon1enaje a Alfredo Ramos Martínez; Miguel Cervantes; Francisco Coello; Ejemplos de Simbiosis Plásticas en pintura; Colette Holder de Marcillac; Ken Nishi; Gustavo Aranguren; El paisaje en la palabra y en la pintura; Betty Schneider; George Loomer; Contribución a la X Bienal de São Paulo; Rodolfo Nieto; Enrique Mónaco; York Wilson; Copias de Maestros Europeos por pintores mexicanos; El Arte del futuro; Sociedad Mexicana de Grabadores, A. C.; Fitzia; Pedro Banda y Luis Macías; Jean-Jacques Morvan; Gita Segerskog.

Otras dependencias del Instituto Nacional de Bellas Artes se consideran a continuación, con las exposiciones que presentaron:

Museo de Arte Moderno, en Chapultepec: Ricardo Martínez; Homenaje a Angel Zárraga; IV Bienal Nacional de Escultura; Dibujos y pequeñas esculturas de Rodin a nuestros días; Plástica Moderna del Japón; Fsculturas de Francisco Zúñiga.

Salón de la Plástica Mexicana: Sofía Bassi; Beatriz Caso de Solórzano; Carlos Antonio Chávez; Carlos García Estrada; Angel Boliver; Gerardo Cantú; Fernando Vilchis; Joaquín Martínez Navarrete; Enrique Climent; María Teresa Toral; Salón de grabado 1969; Salón de pintura 1969; Raúl Anguiano; Mario Orozco Rivera; Mexiac; Venta de Navidad. 
Galería Chapultepec: Rosa María Sustaeta; Hugo Chávez; Alizandro Valencia; Octavio Ochoa; José Zúniga; Mazón; José Montiel; Juan Reyes; José Lazcarro; Iesús Contreras Peña; Herminio Alvarez; Gildardo Úribe; Jesús Escalera; Luis Torreblanca; Artores; Octavio Bajonero; Humberto Peraza; Jorge Quiroz; Colectiva de Invierno.

Galcria José Maria l'elasco: Carlos Páramo; Luis Torreblanca; Grabado en México; lrene Becerril; Mathias Goeritz y Manuel Montiel Blancas; Hugo Chávez; José Padilla Carlin; Ofrendas; Alberto Sedas; Xavier Lavalle.

Las siguientes dependencias de la Universidad Autónoma de México presentaron cxposiciones :

Escuela Nacional de Artes Plásticas: 70 obras de la Escuela de Diseño y Artesanías de Colonia, R. F. A.; Grabado Chino Contemporáneo; Luis García Robledo; Grabado Soviético; Antonio Berni; Aldo Biglione; Francisco Moyao; Esteban Ramos; Oliverio Diaz; Egresados recientes de San Carlos.

Museo Universitario de Cicncias y Arte: El grabado internacional, siglos xvir y xIx; El grabado internacional, siglo $\mathrm{xx}$; Arte inclustrial de Finlandia; Akira Kirakawa; Thonas Mann; Las artes plásticas al servicio de la arquitectura.

Casa del Lago, Chapultepec: Alfredo Metueses.

Galeria Unizersitaria Aristos: Marilyn; Jacobo Glantz; Los animales en el arte poptular.

Dirección General de Jifusión (ultural: Rostros 1900.

Biblioteca Nacional de México: Francisco Mújica y Dícz de Bonilla.

Escuela Nacional do Arquitectura: Prefabricación de arquitectura.

El Organisno de Promoción Internacional de Culturas presentó las siguientes exposiciones: Enrique Miguel de la Vega; Visión fotográfica de la República de Corea; Grabado Soviético; Augusto Degois; Francisca Durán; Reynals; Luis Federico Trama; Carlos Sconnapieco; Shuzo Wakiya; Voroshilov Vazante; Nueva Tmagen Plástica; Grupo 65; Nueva visión sobre la cultura Precolombina de Amoreno; Rina Lazo; Adolfo Menclaca; 17 obras de Baya; Jaime Villa; Eugenio Brito; Graciela Mariscal; Esteban Ramos.

Tos museos dependientes de la Secretaría de Educación Pública presentaron las exposiciones siguientes:

Musco Nacional de Antropología c Historia: Exploraciones en el Cenote Sagrado de Chichén Itzá; Cerámica Maya.

Museo de las Culturas: Arte popular de la URSS; Escultura clásica; Etnografia de Polonia; Exposición de trajes del extranjero; Artesanías de Israel; Ayako Tsuri; Arigón; Artesanías populares de Clecoslovaquia; Exposición final de Artesanías. 
El Comité Ejecutivo Nacional dei Partido Revolucionario Institucional presentó dos exposiciones, una sobre la Historia de la pintura mural mexicana; otra titulada: Exposición Nacional de Grabado.

La Escuela Nacional de Artes Gráficas presentó la exposición de Alberto de Trinidad Solís.

El Colegio de Arquitectos expuso obras de Ignacio Barrios y de Fernando Casas.

La Constructora Move, S. A., instaló una Exposición Colectiva.

La Escuela de Diseño y Artesauías presentó las siguientes exposiciones: Exposición de Trabajos realizados en el ciclo escolar 1968-1969; $1^{\text {a }}$ Exposición de Maestros; VII Gran Concurso Nacional de Piñatas.

Las Galerías de la ciudad de México, clependientes de la Dirección General de Acción Social, del Departamento del Distrito Federal, presentaron las siguientes exposiciones: 16 pintores mexicanos; Joaquín Martínez Navarrete; Bernice Kolko; Tacho; Guillermo Maqueo; La mujer en las artes plásticas de México; Pintura, escultura y grabado; Taku Hon; Acuarela y dibujo del Japón; Luis Torreblanca; David Pimentel; Retrospectiva del Taller de Gráfica Popular; María Teresa Toral; Beatriz Zamora; Marco Chilet; Chirrey; Rina Lazo; Pintura impresionista.

Los institutos culturales extranjeros presentaron exposiciones, que se consignan a continuación :

Instituto Mexicano Nortemericano de Relaciones Culturales, $A$. C.: Mra ie Cosindas; Elizabeth Jones Langmuir; Honore Guilbeau Cooke; Kristel Guma; Adrián Silva; 20a exposición anual del Centro de Arte de la Universidad de las Américas; Clara Klinglıoffer; Suzanne Diorio; Antonio liménez Núñez; Claire Evangelista; Joseplı Hogan; Héctor Xavier; Verna Ringer; Kitty Kanpp; Miguel Hernández Urrbán; Charles Douglas; Jones; Helen Lvitjens; Llizabeth Millioud; Michaei Carver; Grupo Arte Fotográfico, $6^{a}$ exposición; Allen Carter; Antonio Gutiérrez Mendoza; Susana Smith; Los Acuarelistas; Gregorio Gutiérrez.

Instituto Francés de la América Lafina: Rafael Zepeda; María Lagunes; José de Jesús Martínez Álvarez; Jesús Martínez; Julio Montes; Salvador Ortiz; Hernández Suárez (Hersua); Goulven Elies; Colectiva; Antragne; Las artes plásticas en la arquitectura moderna; Esteban Cruz; Andree Burg de Genovés; Cecile Martial; Fnrique Bryant.

Instituto Cultural Hispano Mcricano, S. A.: Homenaje a laime Nunó; Ligia Urvina Dávila; Carlos A. Guerrero B.; Luis G. Guerrero B.

Instituto Cultural Mericano Israeli, A. C.: Antonio Serna; Luis López Loza; Coen.

Instituto Cultural Alemán: Yolanda Savin. 
A continuación se agrupan las galerías particulares y las exposiciones que presentaron:

Galería de Arte Mexicano: Feliciano Peña, Gabriel Fernández Ledesma, Roberto Donis, Luis López Loza, Alfredo Castañeda, Olga Costa, Leonora Carrington, Cristina Bremer, Kishio Murata, Antonio Rodríguez Luna, Juan Soriano, Alfredo Zalce, Mario Rangel, Jorge Wilmont.

Galeria de Arte Misrachi: Peyri, Clemente Lococo H., Juan Luis Buñuel, Toni Sbert, Mario Pérez Orona, Rufino Tamayo, Pintura en movimiento, María Lagunes, Los animales de Marta Adams, Arévalo, Jaime Saldivar.

Galerias del Centro Deportivo Israelita: Tanya Kohn de Salzberger, Israel a través de imágenes, 10 pintores mexicanos, Shoshana Li-On, Edgardo Coghlan, Carlos KohnKagan, Julio Prieto, Luis García Robledo, Zipora Ascalón, $11^{\circ}$ Salón de Nuevos Valores.

Instituto de Arte de México: La mujer en la plástica, Treinta obras de Jesús Tello, Fidel Corpus, J. Martínez Saucedo.

Galerías Mer-Kup: Delgadillo '69, Marcelo Grassmann, Miguel Hernández Urbán, Alexander Bogen, Lior Roth, Moshe Gat, Rodolfo Nieto, Héctor Xavier, Silvia H. González, Lorraine Pinto, Byron Gálvez, Danielle Wolfowitz, Ernesto Carreón, Diego Rivera, Willi Gutmann, Pablo Picasso.

Galería Pecanins: Paul Antragne, María Teresa Toral, Alice Rahon, Nissen, Myra Landau, Peter Knigge, Judith Gutiérrez, Felipe Orlando, Luis Jasso, Tovar, Sí sólo 3 dias, Francisco Icaza.

Galería Edvard Munch: José Hernández Delgadillo, Armando Villagrán, Alfredo Meneses, 100 miniaturas, Dibujo-1969, Juan José Arreola, Apocalipsis, 16 voces de la plástica, Dolor y violencia, Torneo de mentiras, Manuel Alvarez Bravo Martínez.

Galería Juan Martín: Coen, Orlando, Szyszlo, Vicente Rojo, Manuel Felguérez, Gabriel Ramírez, Toledo, Roger von Gunten.

Plástica de México: Gildardo Uribe, Fanny Rabel, Colectiva, Santos, Froylán Ojeda, José Manuel Schmill, Dibujos y grabados, Nicolás Moreno, Trinidad Osorio, Venta de Navidad.

Galeria Antonio Sousa: Hagan, Melesio Galván, Jody Mc Grath.

Sala Revolución: José Clemente Orozco y la Mujer.

Galeria de Arte Arvil: Feliciano Béjar, José García Ocejo.

Galería Pablo Picasso: Exposición Colectiva, Grabado Internacional, Pal Kepenyes, Colectiva, El hombre en el espacio, Minipinturas.

Galeria 33: Pablo Picasso.

Galerias Escudero: Raxim, Colectiva anual, María Elena Delgado.

Galería San José: Enrique Estrada.

Alianca Francesa: Grabadores.

Calle de Horacio, núm. 1703: Exposición del Grupo de amigos de las Bellas Artes. Centro Cultural Provisional: Leni de Servin y su arte.

Galeria de Artes Plásticas: René Villanueva, Brecht y el teatro de la República Denocrática Alemana. 
Club de Periodistas: R.D.A., 20 años de construcción del Estado Democrático y Antifascista.

Calle de Pedro Luis Ogazón, núm. 98: Salvador Valdés Galindo.

Galeria Kusak: Leni de Servin; Denelly Fabre, Valetta, Nuevos Valores, Antonio Ramirez, Grupo Espiral.

Galeria de Edith Quijano: Irene Arias.

Galeria de Arte Nieto: Trinidad Osorio, Patricia Padilla de Corcuera.

Galería Selene: Pintura y escultura.

Molino de Santo Domingo: Exposición de pintura.

Galería Marcos Fastlicht, S. A.: Antonio Roca.

Taller de Gráfica Popular: Zapata, 50 años en el arte de México.

En las galerías de algunos Estados de la República se presentaron las siguientes exposiciones:

Cuernavaca, Mor. Taller de Siqueiros: Siqueiros,

Casino de la Selva: Carlos Jurado, David Alfaro Siqueiros,

Palacio de Cortés: Irma René Koen, Carmen Cook.

Salón de la Plástica Morelense: Raxim.

Monterrey, N. L., Instituto Mexicano-Norteamericano de Relaciones Culturales de Nuevo León, A. C.: Witford Carter.

Durango, Dgo.; Universidad Juárez del Estado de Durango: Exposición Anual. Guadalajara, Jal., Salón de Otoño 1969: Plástica Contemporánea de Guadalajara.

Acapulco, Gro., Tasende's Gallery: Humberto Peraza, Julio Montes, Trinidad Osorio, Roberto Montenegro, Francisco Zúñiga, Benito Messeguer, José Luis Cuevas, Romero Tabuena, José García Ocejo.

Algunas exposiciones presentadas en el extranjero por artistas mexicanos:

Center of Inter-American Relations (New York): Nuevas pinturas y esculturas Latinoamericanas.

Katia Granoff Gallerie (Paris): Leonardo Nierman.

The College Art Gallery (New York) : José Luis Cuevas.

The Graphic Gallery (San Francisco, Cal.): José Luis Cuevas.

Se han incluido en este catálogo algunos textos que acompañan a las exposiciones para salvarlos del olvido, puesto que vienen a ser documentos de interés histórico. También se incluyen los datos biográficos esenciales de los artistas, cuando aparecen en los catálogos. Esperamos la benevolencia de los interesados por tratarse de reunir informaciones que de otra manera sería muy difícil reunir por los historiadores en el futuro, de esa manera pretendemos contribuir a los estudios que se hagan más adelante. 
DOI: http://dx.doi.org/10.22201/iie.18703062e.1970.sup1 
DOI: http://dx.doi.org/10.22201/iie.18703062e.1970.sup1

ENERO

TaNya koHn de Salzberger. Exposición de óleos y dibujos, presentada por el Comité de Actividades Generales del Centro Deportivo Israelita, Boulevard Manuel Avila Camacho ním. 620, Lomas de Sotelo, el 5 de enero.

paul antragne. Exposición presentada por la Galería Pecanins, Hamburgo 103, el 7 de enero.

marie cosinnas. Exposición de fotografías, presentada por el Instituto MexicanoNorteamericano de Relaciones Culturales, A. C., Sala Nabor Carrillo, Hamburgo 115, el 9. de enero.

rafael zepeda. Exposición de grabados, presentada por el Instituto Francés de América Latina, Nazas 43, el 9 de enero.

rosa maría sustaeta. Exposición presentada por la Galería Chapultepec, Insurgentes Sur núm. 11, el 10 de enero.

sofía Bassi. Exposición de obras recientes, presentada por el Instituto Nacional de Bellas Artes (SEP), Salón de la Plástica Mexicana, Havre núm. 7, del 10 al 30 de enero.

Esta exposición de Sofía Bassi está inspirada en el tema del huevo. Connota tal vez la potencialidad de ese germen en el que ya está inscrito un Cristo, un Buda futuro. El huevo es a la vez la forma congelada o tangible del futuro; el seno inframaterno de los universos duplicados de fécula y de clara de huevo de nueva existencia claustral; formas geométricas de una prisionía de la visión; es decir: del mundo.

Hay, sorprendentemente, en este universo ovoide, la implicación de un infierno, de una oquedad que informa a la vez una imagen de resonancias musicales y de resquicios óseos, como en el infierno musical de Bosco, pero hay también la idea de armoría que toda forma que implica a la música, y también al silencio - como una de sus formas supremas-, invoca.

Hay también en él la formación de una misteriosa perspectiva ovoidal del mundo; como si ésta fuera un espacio cerrado; pero cerrado de acuerdo a su orden bifocal; de acuerdo al orden que impcra con la misma rigidez en la oología y en la lógica recurrente de todas las formas cerradas rítmicas. 
Ia dialéctica del huevo, por su carácter bifocal y circular implica la persecución de los perros, figura reiterada de los mandalas, idea simbólica de todo afán artístico, expresión concreta de la bifocalidad con que somos capaces de imaginarnos la esfera platónica como cosa vista por nosotros con dos ojos, y sólo por virtud de que cada uno de esos esferoides imaginados a partir de la noción de un círculo con dos centros proyectado en torno a su diámetro mayor, es visto dos veces cada vez que es visto.

Lo de menos sería suponer que el huevo es la perfecta conjunción de dos secciones cónicas diferentes; un proyecto necesariamente improbable en una geometria euclidiana. Esto se debe tal vez a que el hecho más interesante que aquí se plantea es el del espacio; un espacio consubstancial al artista, que se refleja en el espejo de la pintura, y al espacio real en que está contenido.

\section{Salvador Elizondo}

mauricio tasansky. Exposición de dibujos nazis, presentada por el Instituto Nacional de Bellas Artes, Salas 3 y 4, del 14 de enero al mes de febrero.

Sólo en raras ocasiones puede un artista captar en el medio que le es propio, una visión imaginativamente madura de su época, una visión que no sólo nazca de su experiencia personal sino que además resuma activamente la experiencia de millones de sus contemporáneos. Cuando ese arte se da, se advierte en él algo especial, como también se siente algo especial en la respuesta que suscita. Sea lo que fuere en cualquier terreno, ese arte es un acto de partidarismo, pero de un partidarismo nuly personal. Sin embargo, en cuanto documento, atiza los sentimientos partidaristas del espectador. Bosch, Goya, Daumier y Picasso crearon vigorosos documentos artísticos de esta especie, potenciados con el más personal y maduro lenguaje del artista.

En cuanto sus contemporáneos que somos, no deberíamos sentirnos tranquilos ante la obra de Mauricio Lasansky, aunque sólo fuera por el hecho de que el tema de Los dibujos nazis es una parte de nuestro pasado que nos inquieta todavia. Podemos pasar ante ellos y luego desviar la mirada hacia otra parte, o bien podemos clavar en ellos las pupilas y estudiarlos con fascinación. Hagamos lo que hagamos, los dibujos seguirán perturbándonos. $\mathrm{Y}$ no debe extrañarnos, puesto que componen una aterradora interpretación de nuestra época : nuestras peores experiencias históricas reducidas a sus términos básicos de hecatombe, suplicio de inocentes, demonismo erótico y religioso, y todo ello recogido con los medios más simples que un pintor puede utilizar: lápiz de plomo, colores de tierras, solución de trementina y un papel comercial común.

Al mirar con ojos vidriosos de espanto estos dibupos, he aqui que caemos en la ctenta de ser los observadores lascivos, los espectadores culpables que sobrevivieron a esos terrores de la historia humana. Hemos sobrevivido, sí ¿pero a qué precio?, ¿ cố cuál saber y cuál comprensión del modo como participamos en acontecimientos ya momificados en la pesadilla del pasado? Ahora que esos acontecimientos se han trocadis en puros notivos de curiosidad para los seres humanos nacidos en el ínterin, no podemos menos de preguntarnos cómo fue posible que persistiéramos durante todos estos años en silenciosa angustia como supervivientes de aquel periodo.

No hay respuesta. Sólo se puede decir que para los jóvenes, que siguen viniendo al mundo, somos las reliquias vivientes de la era de los campos nazis de concentra- 
ción. Lil modo como sonreimos, nuestros gestos y giros de lenguaje incluso las arrugas de la cara, siguen dando testimonio del terror, la congoja $\mathrm{y}$ la culpa (inclusive el alivio del terror, la congoja y la culpa) que culminaron con los nazis. Lo que estos dibujos registran es una parte de nuestra vida, de nuestro pasado. ¿Cómo esperar que el artista sea tierno y nos consuele, si ha de ser honesto, es decir, si ha de representar lo que sucedió, lo que sigue visible en mosotros, con la imaginación total de lo que se requiere para ser hombre?

Estos dibujos fueron trazados por un ser humano comprometido, un artista que aboga por la verdad de la imaginación total. Esto significa que su arte es ilustrativo porque representa la verdad, y representativo porque es moral y dramático.

Del primero al último, los dibujos representan un drama que presupone algo como una serie de acontecimientos que realmente se efectuaron. Son los mismos que vuelven a efectuarse cuando observamos los dibujos. La realidad se convierte en lo que unos seres humanos están haciendo a otros seres humanos - no el porqué lo están hacienclo- en los dibujos. Desde nuestra perspectiva crítica se saca en conclusión que, el hacer lo que se está haciendo supone la pérdida de todos los valores espirituales y humanos. Como en cualquier drama, aferrar el sentido de la acción nos exige situarnos detrás de las pupilas no ya de los actores sino del creador, viendo y sintiendo lo que su lenguaje nos dice que él ha visto y sentido.

Lasansky es un superviviente que en sus dibujos aún está ahí, en los campos nazis, de manera que su obra se nos presenta como un ensayo continuo del drama de lo que significa haber sobrevivido a esa experiencia. La vemos junto con él a la demoniaca media luz entre la vida y la muerte -y ésta es la condición medular de todos los dibujos-, donde no hay gran diferencia entre el estar vivo y el estar muerto.

Conprender los dibujos significa precisamente descubrir lo que está sucediendo en ellos, es decir, contemplarlos como un drama pictórico de muerte y privación humanas - del cual apenas acabamos de recuperarnos- que se desarrolla escena por escena, en el orden numérico en que el artista las ha dispuesto. Además, debemos comprender sus dimensiones, porque casi todos los dibujos son bastante grandes (aproximadamente 180 centímetros de altura por 120 de anchura). Se exceptían los primeros cuatro retratos (de asesinos nazis) y un grupo final de cinco retratos (de niños en agonia). En todos ellos Lasansky insiste en la escala huinana, por lo cual sus modelos son literalmente de tamaño natural. De ese modo, la escala física contribuye a dar cuerpo a la dignidad y el horror que el artista se comprometió a dramatizar en los dibujos.

Los cuatro primeros dibujos sirven como introducción de la serie y forman una galería de bustos cabezudos representados sobre todo de perfil y tocados con yelmos en forma de cráneo humano. En los dibujos posteriores, estas figuras se asocian con las de los verdugos de los inocentes. En el primero, el yelmo-cráneo sugiere la gorra alemana de campana con visera. Por otra parte, el cuello, los hombros y el pecho de la figura, embutidos como un salchichón, sugieren algo así como un estar sepultado en la ropa, la condición de hallarse medio enterrado en vida. Los mismos motivos se repiten en el segundo dibujo, en que el yelmo-cráneo está levantado un poco y ha perdido los dientes. Aqui se observa también el principio de una caracteristica maraña de líneas de lápiz oscuro que envuelven la cara y trazan una condecoración en el pecho sobre la silueta de una mano inerte cual una araña muerta. En el tercer dibujo reaparece el hombre pletórico, de cuello de salchicha. $\mathrm{Si}$ se exceptúan las grotes- 
cas proporciones de la cabeza y el cuello, el tratamiento de la figura es deliberadamente abocetado, aun cuando empiezan a aparecer nuevos detalles, tales como el torvo, cadavérico rostro inedio tapado, la nariz de cuchillo y las sombras de lápiz en torno a los ojos: signos del homicida. En el cuarto dibujo hay más detalles porque la cabeza se ve de tres cuartos. Aquí aparece además otro motivo: el papel cortado y vuelto a pegar justo bajo el cuello del uniforme medio militar, medio clerical. Flotando libremente en el margen izquierdo hay algo que parece el cráneo de un niño de perfil; apenas visible sobre el frente del uniforme del nazi se perciben los contornos de una figura religiosa o desnudo.

Pictóricamente, el quinto dibujo es el más desarrollado de los vistos liasta ahora. La figura, de cuerpo entero - un nazi tieso, con el peclo cubierto de medallas pero sin pantalones-, es grotesca, a respecho de su cómica actitud humillada. Vemos sus piernas desnudas, levanta el brazo en el saludo nazi y lleva un extraño sombrero, casi coino para protegerse del sol (el uniforme, irónicamente abreviado, sugiere el trópico), consistente en un enorme cráneo bovino cuyos enormes dientes le sombrean la frente. Una mancha de tierra color sangre tiñe la suástica que lleva al brazo, así como el puño izquierdo apretado por detrás de la espalda, mientras el mismo líquido seroso chorrea de la mano derecha rígidamente alzada.

En el sexto dibujo se acentúa la tendencia hacia una mayor pictorialización. Aquí vemos cómo al ya multiforme e intrincado yelmo-cráneo le brotan esqueléticas cxtremidades. La parte superior da la apariencia de alas cerradas que brotan de un costillar como un capullo, al paso que los miembros inferiores cabalgan airosos la figura vestida de uniforme y botas. Por su parte, la figura inisma es apenas visible, exceptuando la cara, de tres cuartos, torvamente capturada en el fondo de la tronera que forman el paladar y los dientes del cráneo. Sólo el esqueleto está coloreado.

En el dibujo siguiente los motivos precedentes culminan poderosamente en la representación de una mujer semidesnuda, representada de cuerpo entero y de perfil. GrueSas líneas curvas de lápiz ciñen la cabeza cubierta con el yelmo-cráneo - como un sombrero de inujer con dientes en vez de flores- y el cabello femenil se ha convertido en un espeso nido revuelto de donde surge la cara fofa con el ojo en sombra. El melón de un seno desnudo descansa sobre la tela transparente de una camisa arrugada, sostenida por las manos de la figura, ceñidas sobre el vientre desnudo. Una de las nuanos y el antebrazo correspondiente están igualmente marcadas por gruesos trazos de lápiz para representar el tejido de un guante largo. Este tema vuelve a reaparecer en el mechón de pelos pubianos y en las osadamente incongruentes medias $y$ en los zapatos de tacón alto. Se advierte que el dibujo ha sido cortado y vuelto a pegar en tres secciones, como para acentuar el carácter ficticio y charro de lo que se muestra.

En los doce dibujos siguientes - la parte central y más altamente gráfica de la serie-- hay una creciente profusión de notivos complejos. El octavo nos muestra de frente a otra prostituta a medio vestir, quizás la misma que acabamos de ver. La casa pelada y redonda sonríe leve, casi con lascivia, los ojos perdidos en una nube de lineas de lápiz. Los brazos y las manos, levantados en el gesto apropiado, nos recuerdan la actitud de una mujer que se prueba un sombrero. Sobre los hombros tiene una especie de telaraña que se funde con la desmesurada chaqueta de hombre bajo la cual asoman apenas los pequeños pechos. Al igual que antes, las secciones de papel están toscamente cortadas y vueltas a pegar a la altura del tórax. Estos 
detalles, reforzados por el grosor de la parte alta de los muslos, que contrasta con la delgadez de las piernas a la altura de las rodillas, con las bien modeladas pantorrillas y con los tacones altos, dan la impresión de un taimado hermafrodita que posa ostentando narcisisticamente sus atributos profesionales.

En el noveno dibujo reaparece la prostituta de la cara redonda abrazando la silueta truncada de un sargento. Sonriente, gira sobre sí misma, casi como arrastrada por el peso del soldado que, tocado con el yelmo-cráneo, lleva sujeto entre los brazos. Los trazos densos y rítmicos de lápiz se repiten ahora de manera evidente en el cabello y en el ojo en sombra que se ve bajo el sombrero-cráneo, así como en el guante largo, la faja, las medias y los zapatos de tacón alto. El sostén, que se ha deslizado hacia arriba y se ve desde atrás, así como los brochazos color de sangre que le chorrean de la faja contribuyen a precisar las zonas cruciales donde el cuerpo ha sido truncado.

En el siguiente dibujo, el sargento ha desaparecido para dejar el sitio a un esqueleto curiosamente plegado sobre sí mismo. No sólo se ha montado en la prostituta por detrás, sino que al mismo tiempo que le muerde la cara, le apoya un brazo en el hombro y le aferra el pubis con un brazo extendido. Una serie de brochazos tubulares, dados con un color castaño diluido en trementina, invaden también las zonas complementarias claras y oscuras.

E1 undécimo dibujo nos muestra a la prostituta, aún sonriente, pero casi totalmente oscurecida y envuelta en algo que parece gruesa hilaza negra. Tiene las piernas cruzadas y extendidas sobre el huesudo regazo de tres esqueletos fundidos entre sí, todos ellos embutidos como espectrales salchichas. En torno a las caras desvanecidas se entrelazan líneas de bien definidos dientes y costillares que suben y bajan como arpeggios. Un motivo complementario es el de los manojos de dedos y manos, dibujados con más ligereza, que parecen separar entre sí a las apretujadas figuras. Un incongruente antebrazo cuelga de lo alto, con los dedos de la mano recatadamente extendidos sobre un billete de banco.

En el duodécimo dibujo la misma prostituta, en una pose más severa y con nalgas y senos enormemente protuberantes, contrasta con el esqueleto que, denso, negro, corcovado, de extremidades de araña, la estruja y, furiosamente, le muerde la carne. mientras con un brazo y una mano le hunde en la cabeza, en parte para apoyarse, en parte llevado por la pasión, el sombrero-cráneo que le oculta a medias la cara torcida, la cabeza coquetamente vuelta hacia un lado.

Llegado este punto, se advierte que los dibujos están dispuestos de modo de ser "leídos" como se haría con una serie de "caricaturas cómicas". Visto así, el dibujo decimotercero, además de la mayoría de los motivos contenidos en los anteriores, presenta otros nuevos. También aqui domina la figura de la prostituta de los últimos seis dibujos, ahora patéticamente colgada como una canal de res, mostrando desnudos las caderas, la espalda y los muslos, mientras levanta juntas, quizás en oración, las manos por encima de la cabellera revuelta, que se ve desde atrás como un nido deshecho. La camisa, míseramente caída sobre las piernas de la mujer, es recogida con gesto distraído por una negra figura embutida de verdugo. Esta figura, por su parte, concentra en sí los motivos precedentes: el esqueleto abrazado, el yelmo-cráneo cubierto por una especie de torrecilla de fortín dentro de la cual brillan los dientes, la cara apenas visible. A esto se agrega un motivo nuevo: un ambiguo pájaro posado en lo alto del verdugo. En la parte inferior del dibujo aparecen otros pares de manos 
y antebrazos, uno de los cuales al parecer sostiene un segundo cráneo entre las piernas colgantes de la prostituta. Otro cráneo asona a la izquierda, sonriendo al espectador bajo los imprecisos trazos de otra figura femenina colgada a la izquierda de la primera y que acaso sugiere una serie ad-infinitum del mismo tipo de víctima. En la parte inferior del dibujo parece brillar por transparencia una tracería de cabezas y cráneos de niños, que comunican un vago sentimiento de vidas abandonadas y extinguidas. La actitud de las figuras recuerda de manera muy insistente el lenguaje gráfico de Los desastres de la guerra de Goya.

Partiendo de una particularmente macabra disposición de las figuras, el dibujo decimocuarto logra su efecto mediante los contrastes de claroscuro observados antes y una intensificación de los ya familiares motivos del yelmo-cráneo (aqui sumido sobre la cabeza del verdugo hasta que sólo deja asomar la barbilla), el esqueleto agazapado y exhausto (o quizás devorante) que baja la bulbosa cabeza, con acrobática soltura, entre los huesos de los colgantes brazos, sobre la espalda del verdugo, y, por último, el niño medio muerto cuyos ojos y cabeza están siendo mísera, irrevocable y desesperadamente aplastados entre las espesas manos del verdugo. Acaso es la voluminosa densidad de las figuras, su espesor físico, lo que nos comunica el sentimiento de horror que emana del grupo, no obstante la simplicidad de su ejecución.

Si el espectador es capaz de distinguir entre sueño y pesadilla, el siguiente dibujo probablemente le parezca, por contraste con los otros, el más onírico. La niña que baila o salta en primer plano es la figura base de una pirámide de cuatro, rematada por un esqueleto encorvado, bajo cuyo maxilar superior se ve incrustada, como un camafeo, la cara de la oscura figura maternal que ocupa con su vestido la mayor parte del dibujo. Sobre el hombro derecho lleva un tumefacto cadáver de niño conı la barriga hinchada y las piernecillas rotas extendidas rigidamente hacia la izquierda. El grupo tiene los ojos clavados no muy lejos - con qué expresión, imposible adivinarlo-, mientras detrás se perciben los postes de la cerca de un campo de concentración.

Si el motivo del yelmo-cráneo no fuera ya tan familiar, se diría una ilusión de óptica el descubrir que el cráneo del esqueleto se apoya en el honbro del verdugo que se inclina sobre la nujer muerta (o niña, o prostituta), o, por mejor decir, que el esqueleto y el verdugo comparten una misma cabeza. En el decimosexto dibujo el claroscuro basta una vez más para subrayar dramáticamente el horror y la crueldad de la imagen.

Reaparece la figura ahorcada o ejecutada mediante gas. De liecho se trata de la misma figura muerta del decimosexto dibujo. Pero el número de víctimas se ha multiplicado por cinco y el grotesco esqueleto, encaramado en los verdugos, suena sobre ellas, sardónicamente, una campanilla turibularia. La ironía de haber duplicado el yelmo-cráneo en el esqueleto y en el negro verdugo, se refuerza en el hecho de que ambos llevan, colgantes, como trompas, tubos de máscaras de gas. Al igual que la figura del quinto dibujo, el verdugo se muestra aquí con los pantalones caídos (en realidad, se los han bajado) lo que vuelve a ser un comentario ridículo y bufo sobre el sanguinario absurdo que es el maniático homicida. También empieza a destacar aquí, en el decimoséptimo dibujo, como visto en transparencia, el efecto de travesaños, antes discernibles como postes de cerca o como prolongaciones de los hombros y brazos del esqueleto agazapado.

En el collage del decimoctavo dibujo, burdamente embarrado de sangre, predomina 
el motivo cruciforme que se impone al ojo con fuerza inexplicable. No se trata sólo de la figura maternal evidentemente empalada en la cruz de papel de periódico, sino que también hay un brazo, el suyo o sin cuerpo, visible bajo su terrificante cabeza, que tira de la cuerda con que la desorbitada figura está siendo izada a la cruz. Al mismo tiempo como ajeno al horror, un niño pequeño yace sobre el vientre de la madre, dormido o muerto, es imposible saberlo. En otro refinamiento del motivo es de señalar que el travesaño de la cruz es un collage de periódicos, inclusive sin recorte referente a un asesino de los SS llamado Kaduk.

El decimonoveno es otro dibujo terrorífico y complejo donde se emplea con gran destreza el efecto de claroscuro. Una pululante presencia demoniaca lleria la parte superior del dibujo con protuberantes dientes de calavera y brazos ceñidos sobre el travesaño de una cruz, que sostiene una mujer consumida, apenas más visible que el número de campo de concentración tatuada en su piel. Posados o aleteantes, un grupo de halcones está devorando a la crucificada y en este caso se comportan más como pájaros carniceros que como las curiosas palonias que aparentan ser en dibujos anteriores. Los pájaros han anidado en el cuerpo de la muerta y le picotean los órganos corporales de los que sorben los jugos. El pálido color que llena diagonalmente la sección hasta el borde inferior del dibujo deja emerger, incisivo, el trazo de un fondo cruciforme.

En el vigésimo dibujo acontece un nuevo tipo de proliferación temática: los números de campo de concentración repetidos en dibujo tras dibujo. El collage de papel de periódico, a través del cual ha sido lanzada la desnuda víctima, está compuesto con páginas del Libro de Samuel. Y las sombras que proyecta la figura, junto con las sombras que se proyectan sobre ella, muestran una escala claramente graduada de variaciones del claroscuro básico - algo así como una escala monocromática-, efecto que no se explota de manera completa hasta llegar a este dibujo. Lo que asi emerge con tanto vigor es una clásica representación de la dignidad del cuerpo humano brutalizado por la perversidad del hombre, algo como los espectadores acorneados en una estampa de Goya. Esta dolorosa figura de una mujer, violada y empalada, en el último instante de la agonía, de manos y pies retorcidos y tiesos, con las articulaciones nudosas y protuberantes del cuerpo consumido por la desnutrición, se convierte en imagen no sólo de los inocentes degollados y de los mártires de otrora, sino también del hombre común de hoy, a un tiempo víctima y victimario, que es realmente cada uno de nosotros.

En el dibujo vigésimo primero tenemos lo que paradójicamente podría llamarse la apoteosis de lo demoniaco. Una criptica figura de pesadilla, flojamente envuelta en una piel humana que muestra delante, tatuado, un número del campo de concentración. Detrás de esta reliquia humana, la reconcentrada silueta monolítica trata afanosamente de levantar el plúmbeo yelmo-cráneo que se le ha caído sobre la cara. Al mismo tiempo, las filacterías que lleva en los antebrazos sugieren al judío en la oración ritual de la mañana. El frente punteado, el vello pubiano, los gruesos muslos color de tierra, sugieren una superposición de realidad y de sueños, acaso un segundo momento de silencio, cuando el horror de lo acontecido empieza a aflorar a la conciencia y hay un primer intento estupefacto de hacerle frente.

Empezando con el vigésimo segundo y siguiendo hasta el penúltimo dibujo, Lasansky enfoca la irreconciliabilidad de la matanza de los inocentes con la inmóvil actitud de la iglesia establecida. La superposición de elementos colindantes en la 
composición forman un comentario sobre el tema. Otro comentario es la figura del obispo que, de frente al espectador, domina el dibujo con su expresión obsesionada -producto del terror o, el remordimiento- la cara y la mitra oscurecidas con lineas de lápiz. Apenas visibles en la capa pluvial se advierten imágenes convencionales, como de vitral, del Salvador y de la Virgen, que representan a la iglesia, mientras aquí y allá sobre la tela se ven impresas huellas sanguinolentas de manos. 'Tras de la capa pluvial aparece una cruz, de donde penden el torso y los miembros estigmatizados cle un hombre crucificado. En el hombro derecho del obispo, fundido con el crucificado, hay malamente apoyado un cadáver de niño, de enorme cabeza con un fragmento de su número de campo de concentración todavía visible en el pecho. De lá orilla superior izquierda del dibujo surge, como nota consoladora, una segunda mano estigmatizada que sostiene dulcemente, desde atrás, la cabeza infantil.

E1 momento siguiente al sacrificio, como en una pesadilla, magnifica silenciosamente el acto, incrustándolo en la conciencia y haciendo volver a las mismas figuras. Así las vemos reaparecer en el vigésimo tercer dibujo: el obispo con el horror borrándosele poco a poco de la cara para dejar el sitio a una incredulidad donde el remordimiento se evapora, el paso que sujeta contra el pecho, como si fuera un escudo, el cadáver de un niño. Evidentemente, el niño muerto, que tiene la cara cubierta por un yelmo-cráneo, se identifica con la figura de Cristo a la que estaba fundido en el dibujo anterior. Los halcones han vuelto y se han posado simétrica y anenazadoramente en cuatro ángulos de los travesaños. La capa pluvial del obispo es un collage de páginas del Exodo, las mismas que ornan la mitra. Las imágenes de sexo, muerte y religión, tan viscosamente mezcladas en los demás dibujos, vuelven a aparecer aquí. Los ojos quedan aprisionados en la distorsión del pubis, bajo la barriga hinchada del niño muerto, y en el pequeño desnudo femenino bosquejado en el travesaño superior, justamente debajo del pájaro.

Con el vigésimo cuarto dibujo empieza una serie final de retratos que son como la contraparte de las solemnes, mortiferas, embutidas figuras de homicidas que, tocados con sus yelmos-cráneos, vimos en los primeros cuatro dibujos. Aquí, los niños están captados en una aflicción y un sufrimiento tan terribles como definitivos, con las cabezas hinchadas en contraste con las manos pequeñas, inútiles, desproporcionadas, como si ellas mismas se hubieran convertido en la personificación de la pesadilla que se les ha infligido. La incesante repetición del mismo número tatuado cle campo de concentración parece perforar cada uno de estos dibujos, excepto el vigésimo quinto, que no lleva número alguno, acaso porque es la encarnación de un grito sin palabras. Collages, sombras dadas con la punta del lápiz, labios contraídos sobre dientes destemplados del horror, el yelmo-cráneo deslizándose otra vez hacia abajo en el vigésimo séptimo dibujo, donde se ven los dientes del niño: los motivos reiterados se reúnen aquí en un crescendo de una soledad elemental, a la que nada puede responderse.

"Ya está, se ha consumado, pero resistimos" es lo que parecen decir las manos unidas y las expresiones faciales del vigésimo noveno dibujo. De la cara oscura y devastada del obispo surge una mirada fija en un reto insano, que contrasta violenta con las imágenes religiosas de la capa, es decir, menos con la representación de un billete de banco. La sombra de la cara del obispo se extiende a la vestidura del asistente a la izquierda. La oscura tela de esta vestidura nos inquieta momentáneamente la memoria, hasta que se cae en la cuenta de que es igual a la 
te la ropa del verdugo en los dibujos anteriores. Luego, como para confirmat la asociación, se advierte que los clérigos están de pie sobre un friso de cadáveres de niños apilados. La composición se tiñe así de una trágica ironía al evocar las majes: Wosas representaciones medievales de santos y padres de la iglesia parados sobre min frontón de leones y bestias silvestres ; la iglesia triunfante! Aqui la púrpura de la iaja del sacerdote chorrea sobre los cuerpos de los niños.

Un grotesco abiter dictum cierra la serie con la invención por Lasansky de una ulltima ironía: una figura de Hitler en el acto de castrarse, montado por un esqueleto, se enfrenta al espectador. Es como sorprender al diablo amputándose la cola. Ahora la sangre que chorrea es la del máximo verdugo: sombrío, egocéntrico, diestro, mecanicísticamente sacrificado a su propia ideologia, medio agazapado, cortándose las partes viriles mientras el espectro de la muerte le empuja - semejante a la de un ataúd- la tapa de un cráneo (el último yelmo-cráneo), con el gesto decidido de alguien que cubre una lata de basura demasiado llena. La firma del artista, puesta al revés, al pie grupo, subraya la áspera visión personal del holocausto tan conmovedoramente descrito a lo largo de los treinta dibujos.

Catálogo: los dibujos no llevan títulos individuales. Se dan los tamaños en centímetros; la altura precede a la anclura. $1.58 \times 58-58 \times 59-59 \times 56-66 \times 49$ $174 \times 55-180 \times 58-195 \times 55-175 \times 65-181 \times 63-185 \times 114-188 \times 114-183$ $\times 114-193 \times 115-185 \times 114-165 \times 114-185 \times 114-190 \times 114-192 \times 115=$ $193 \times 114-190 \times 116-193 \times 89-188 \times 115-170 \times 117-110 \times 100-109 \times$ $108-115 \times 109-117 \times 117-208 \times 114-198 \times 114-142 \times 76$. Los dibujos están hechos a lápiz. El rojo es una tierra con agıa. El castaño está diluido en trementina.

Mauricio Lasansky nació en Argentina en 1914 y es ciudadano de los Estados Unidos desde 1943. Dirige actualmente el Departamento de Gráficas de la Universidad de Iowa, uno de los más influyentes talleres de estampa en el mundo.

En su país de origen recibió 18 primeros premios y en los Estados Unidos ha sido galardoneado con cerca de un centenar de distinciones entre primeros y segundos prenios de adquisición, menciones honoríficas, menciones especiales. Ha tenido también unas noventa exposiciones individuales y ha participado, por invitación, en cerca de 85 exposiciones colectivas. Su obra figura en más de 75 colecciones públicas de los Estados Unidos y otros países, y ha sido comentada en unos ocho libros y en dos tesis universitarias.

Dedico estos dibujos como homenaje a los hombres buenos de ayer que con amor fraternal y coraje salvaron vidas de las masacres nazis.

A los jóvenes de hoy con la esperanza de que no olviden los momentos tristes en la historia del hombre del siglo $\mathrm{xx}$.

Y a Austin y Bodine Lamont amigos de mi hogar.

MARÍA teresa tORAL. Exposición de tintas y grabados, presentada por la Galería Pecanins, Hamburgo 103, el 14 de enero.

ZDENEK RADA. Exposición obra pictórica, presentada por el Instituto Nacional de Bellas Artes. Sala Internacional, el 15 de enero.

Dulus biográficos: Zdenek Rada, nació en Checoslovaquia en 1922, pasó sus primeros años en los Estados Unidos de Norteamérica y después regresó a su país 
de origen donde continuó sus estudios, empezó a exponer en Australia; en 1962 fue invitado por los Estados Uunidos de América, para que expusiera en San Francisco y Los Angeles, Cal.

16 pintores mexicanos. Exposición presentada por el Departamento del Distrito Federal, Dirección General de Acción Social, Galerias de la ciudad de México (en el centro social popular "Leandro Valle", Av. Sur 8 y Oriente 241, col. Agrícola Oriental), del 21 de enero al 21 de febrero.

Expositores: Ignacio Aguirre, David Alfaro Siqueiros, Raúl Anguiano, Luis $Y$. Aragón, Dr. Atl, Alberto Beltrán, Arturo Bustos, Humberto Carrillo Gil, Joaquín Clausell, José Luis Cuevas, Felipe Ehrenberg, Arturo Estrada, Juan O'Gorman, Pablo O'Higgins, Froylán Ojeda, Fermin Revueltas.

DELgadillo '69. Exposición de 35 obras recientes, presentada por la Galeria Mer-Kup, Moliere 328-C, el 22 de enero.

Esclela DE PARís. Exposición de obras originales, presentada por el Instituto Francés de América Latina. Foyer de la Sala Molière, Nazas 43, el 22 de enero.

Elizaneth JONES LANGMUIR. Exposición de textiles y diseños abstractos para proyección, presentada por el Instituto Mexicano Norteamericano de Relaciones Culturales, A. C., Hamburgo 115 , el 23 de enero.

HONORE GUILBEAU COOKE. Exposición de textiles y diseños abstractos para proyección, presentada por el Instituto Mexicano Norteamericano de Relaciones Culturales, A. C. Hamburgo 115, el 23 de enero.

Datos biográficos: Honore Guilbeau Cooke, nació en Baton Rouge, Louisiana, es graduada del Instituto de Arte de Chicago.

JOHANNES GUtenBerg (1400-1468). El Arte de imprimir transforma el mundo. Exposición presentada por el Instituto Nacional de Bellas Artes y la Embajada de Alemania, Sala Verde, el 23 de enero.

70 ObRas DE LA ESCUEla dE diseño y ARTESANías DE Colonia, R. F. D. (Kolner Werkschulen). Exposición presentada por la Escuela Nacional de Artes Plásticas, Sala de Exposiciones, Academia 22, el 24 de enero.

gRabado chino contemporáneo. Exposición presentada por la Escuela Nacional de Artes Plásticas (UNAM), Sala de Exposiciones, Academia 22, el 24 de enero.

Martínez NAVARRETe, JoAquín. Exposición (la obra del metro, vista por un pintor), presentada por el Departamento del Distrito Federal. Dirección General de Acción Social (Alameda Central), Galerias de la ciudad de México, del 24 de enero al 14 de febrero.

JoSÉ HERNÁNDEZ delgadillo. Exposición presentada por la Galería Edvard Munch, Paseo de la Reforma 489, el 27 de enero (68 iracundia). 
covs. Exposición presentada por la Galería Juan Martín, Amberes 17, del 28 de enero al 15 de febrero.

alice rahon. Exposición de obras, presentada por la Galería Pecanins, Hamburgo 103 , el 28 de enero.

Siquerros. Exposición presentada en la Sala de Arte Público (extensión de la Escuela Taller Siqueiros en Cuernavaca, Morelos). Tres Picos núm. 29, el 29 de enero.

nEATRIz Caso DE solórsano. Exposición de esculturas, presentada por el Instituto Nacional de Bellas Artes (SEP), Salón de la Plástica Mexicana, Havre núm. 7, del 31 de enero al 20 de febrero.

Catálogo: Bronces: 1. continuidad 2. retrato de Carlos 3. retrato de una joven 4. hicevo 5. huevo 6. pensador 7. berrinche 8. hacha Alquimia: (bronce, resina y vidrio) 9. plexo solar, lente 10 . retrato de mi hijo, matraz 11. amantes, matraz 12. toloache, redoma 13. periscopio, botella 14. ventana 15. fertilización, matraz 16. intimidad 17. gravides, redoma.

gildardo Uribe. Exposición de grabado, presentada por la Galería de Arte, Plástica de México, Londres 139, el 31 de enero.

VISIÓN FotOGRÁFICA DE LA REPÚBLICA dE COREA. Exposición presentada por el Organismo de Promoción Internacional de Cultura, de la Secretaría de Relaciones Exteriores y la Embajada de la República de Corea en México, Sala de Arte OPlC, Av. Juárez 42, Edificio $C, 2^{a}$ Mezzanine, el 31 de enero.

raxim (Rafael Jiménez). Exposición de pintura, presentada por el Salón de la Plástica Morelense, Centro Cívico Cultural, Cuernavaca, Morelos, del 4 al 27 de enero.

Catálogo: 1. árbol de fuego 2. bordado espacial 3. azoro espectral 4. el adiós 5. callejón sin salida 6. crisálida 7. L'Emprise 8. vientos de muerte 9. mujer verde 10. ballet espacial 11. laguna azul 12. laguna rosa 13. laguna magenta 14. laguna verde 15. jaula de cristal 16. asceta 17. música sorda 18. eterno cautivo 19. Adán y Eva 20. marionetas 21. ligaduras 22. umbral del destino 23. autorretrato 24. genética solar 25. ascetismo alucinante 26. pesca etérea 27. mascarade 28. la cosecha 29 . las mariposas 30. la primavera 31. fatalismo pictórico 32. candelabro esotérico 33. resurrección 34. placenta espacial 35. espejo del tiempo 36. el dolor de envejecer 37. el mundo de mi ensueño 38. dinámica curvilinea 39. voracidad vegetal 40. ensueño creativo.

whitford CARTER. Exposición de pinturas, presentada por el Instituto Mexicano Norteamericano de Relaciones Culturales de Nuevo León, A. C., en Monterrey, N. L., el 14 de cnero.

julio MONTES. Exposición de obras recientes, presentada por el Consejo Nacional de Turismo en la Tasendes Gallery, Costera M. Alemán, y V. Yáñez Pinzón, Acapulco, Gro., durante el mes de enero.

TRINIDAD OSORIO. Exposición de obras recientes, presentada por el Consejo Nacional 
de Turisno, en la Tasende's Gallery, Costera M. Alemán y V. Yáñez Pinzón, Acapulco, Gro., del 2 al 17 de enero.

Datos biográficos: Trinidad Osorio, nació en México, D. F., el 26 de mayo de 1929. Recibió su grado de Maestro en Bellas Artes, de la Escuela Nacional de Artes Plásticas y de la Universidad Nacional de México. Desde 1954 ha sido maestro de pintura y Artes Plásticas, en la Escuela Nacional de Artes Plásticas.

romerto montenegro. Exposición de pintura, presentada por el Consejo Nacional de Turismo, en la Tasende's Gallery, Costera M. Alemán y V. Yáñez Pinzón, Acapulco, Gro., durante el mes de enero.

Francisco zúÑ̃ga. Exposición de escultura, presentada por el Consejo Nacional de Turismo, en la Tasende's Gallery, Costera M. Alemán y V. Yáñez Pinzón, Acapulco, Gro., durante el mes de enero.

Benito messeguer. Exposición presentada, por el Consejo Nacional de Turismo, en la Tasende's Gallery, Costera M. Alemán y V. Yáñez Pinzón, Acapulco, Gro, durante el mes de enero.

José LuIS cuevas. Exposición presentada por el Consejo Nacional de Turismo, en la Tasende's Gallery, Costera M. Alemán y V. Yáñez Pinzón, Acapulco, Gro., durante el mes de enero.

\section{FEBRERO}

ALFredo meneses. Exposición presentada por la Casa del Lago, Difusión Cultural (UNAM), Bosque de Chapultepec, Galería Chica, el 2 de febrero.

roberto Donis. Exposición de pinturas, presentada por la Galería de Arte Mexicano, Milán 18, del 3 de febrero al 28 del mismo.

Catálogo: 1. tierra-amor 2. scxo pétreo 3. manifestación radiante 4. vicnto inmemorial 5. herencia y semejanza 6. quimera 7. amaneció en la tarde 8. presagio 9. templo de la conciencia 10. como una música 11. dolor desconocido 12. herencia secreta 13. prisión invisible 14. encantamiento perpetuo 15. tiempo de la luz 16. un minuto más y se hace fucgo.

María LAgunes. Exposición de esculturas y dibujos, presentada por el Instituto Francés de América Latina, Nazas 43, del 4 al 27 de febrero.

Catálogo: Esculturas: 1. ranita, bronce, 1966 (cera directa), colección particular 2. variación num. 1, tala, 1967 (madera de nacastle) 3. imágenes del hombre núm. 7, bronce, 1968 (cera directa) 4. homenaje a André Bloc, bronce, 1968 (cera directa) 5. flor marina, bronce, 1968 (cera directa) 6. pareja, bronce, 1968 (cera directa) 7. el quinto sol, bronce, 1968 (cera directa) 8. boccto, bronce. 1968-1969 9. grupo, bronce, 1968-1969, talla en cedro. Dibujos: 10. dibujo, pluma, 1968 11. dibujo, pluma, 1968 12. dibujo, pluma y actarela, 1968 13. dibujo, pluma y acuarela, 1968 14. tinta, 1968 15. tinta, 1968 16. tinla, 196817. 
sirenitas, crayón, 1966, col. Part 18. Crayón, 64/Col. Dr. J. M. Gutiérrez V. 19. crayón, 1966 20. crayón, 1966 21. crayón, 1967 22. crayón, 1968 23. crayón. 1968 24. crayón, 1968 25. crayón, 1968, colección Arq. Enrique Segarra 26. crayón, 1968 27. ciudad num. 5, 1966, colección Emilio Carballido 28. ciudad núm. 6, colección Arq. Enrique Segarra 29. les tours du chateau, París, 1966, colección de la autora 30. ciudad núm. 10,1968 31. elipses, 1968, técnica mixta 32. Janine (estudio para un retrato), crayón, 1967 33. impresions d'une dame parisienne (Mme. Sennegon).

Las esculturas de María Lagunes, trabajadas "en hueco" son reflexionadamente elocuentes como lo son, en sí el rigor de su "constructivismo", sus dibujos, que nada tienen de edulcoramiento femenil...

\section{Margarita Nelken. 1965}

Si la escultura... es obra acabada y cargada de interés plástico, sus dibujos y acuarelas podrían ser ellos solos, la mejor carta de naturaleza para el sitio de honor que esta artista merece.

\section{Jorge Crespo de la Serna. 1965}

Por el grado de madurez de sus obras, por la valoración artística de ellas, pensamos, no obstante, que no se trata de improvisaciones, que es una obra que ha venido germinando hace tiempo, en esencia o en potencia, hasta florecer en esta serie de realizaciones de mucha belleza expresiva...

\section{Pahlo Fernández Márouez. 1965}

La exposición de María Lagunes muestra las dos caras de un propósito. Más que la oposición entre el individuo y la urbe está plasmando nuestra atmósfera un momento de hoy en marcha. Va fraguando un monólogo de reflexiones graves, formulado con sagaces recursos plásticos. Con ellos nos evoca mundos de música o de poesía verbal: algo como la introducción de El mandarín milagroso de Bartok, algo como el ambiente del Poeta en Nueva York (que es, en esencia, el Poeta en Babel, el Poeta en la ciudad).

\section{Emilio Carballido. 1965}

La expresividad de la materia es el mayor elcmento estético en su obra, al bronce lo obliga a convulsiones barrocas llenas de armonía, el cobre lo integra con el espacio para hacer delicadas transparencias, y en la piedra, logra expresar con un mínimo de líneas un máximo de forma.

\section{Berta Taracena. 1965}

... Cabe destacar, sin lugar a dudas, el retrato del arquitecto Segarra, en el que las perforaciones hechas al volumen de bronce es un hallazgo muy logrado en retrato contemporáneo, porque desctaca ese espacio dúctil y perforado que se aleja 
de la bidimensionalidad de los retratos dibujados o pintados y nos enmarca la cualidad escultórica en su prístina definición.

\section{Salyador Pinocelly}

ALBERT TUCKER. (Australia). Exposición obra pictórica, presentada por el Instituto Nacional de Bellas Artes, Sala Internacional y la Embajada de Australia el 4 de febrero.

Datos biográficos: Albert Tucker, nació en Melbourne, Australia, en 1914. Vivió y trabajó en Francia, Italia, Alemania y Estados Unidos en los años 1947-1960.

Catálogo: 1. instruso en Gippsland I 2. intruso en Gippsland II 3. explorador descansando 4. dos exploradores 5. joven colono $I$ 6. joven colono II 7. joven colono III 8. joven colono IV 9. joven colono $V$ 10. joven colono VI 11. Ibis en vuelo 12. explorador-atardecer 13. dos intrusos 14. canibal 15. explorador y cacatuas 16. arbusto y fauno 17. fauno atacado por papagayo $I 18$. intruso en el desieto 19. formas desérticas 20. explorador 21. intruso con cuer-

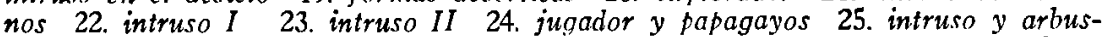
to 26. jinete en un pantano 27. explorador atacado por papagayos 28 . explorador y pájaro 29. fauno atacado por papagayo II 30. fauno atacado por papagayo III 31. intruso III 32. llegada a la rivera de los toneleros (tríptico) 33. cabeza I 34. cabeza II 35. intraso IV 36. explorador cruzando el río 37. oxplorador en el desierto 38. montaña de hierro 39. explorador y papagayo 40 . intrusos 41. fauno atacado por papagayos 42. explorador en el pantano.

JOSÉ DE JESús martínez Álvarez. Exposición de grabados presentada por el Instituto Francés de América Latina, Nazas 43, del 5 de febrero al 28 de marzo

Hưgo CHÁvez. Exposición de cobres, presentada por el Instituto Nacional de Bellas Artes, Galeria Chapultepec, Insurgentes Sur núm. 11 bis, el 7 de febrero.

WALDEMar stölander. Exposición (taller de pintura y escultura), presentada por el Instituto Nacional de Bellas Artes, Salas 1 y 2 , el 7 de febrero. (Taller de pintura y escultura.)

Datos biográficos: Waldemar Sjölander, nació el 6 de enero de 1908, en Gotenburgo, Suecia.

alizandro valencia. Exposición de óleos, presentada por el Instituto Nacional de Bellas Artes, Galería Chapultepec, Insurgentes Sur núm. 11 bis, el 7 de febrero.

CARLos pÁramo. Exposición de acrílicos y gouaches presentada por el Instituto Nacional de Bellas Artes (SEP) Galería José María Velasco, Peralvillo 55, el 7 de febrero.

Catálogo: 1. soy tiempo, acrílico/tela $.50 \times .60 \mathrm{~m}$. 2. alquimia de un pes, acrílico/ tela $.60 \times .90 \mathrm{~m}$. 3. Milena y Kafka, acrilico/tela $.60 \times .80 \mathrm{~m}$. 4. formas mudas, acrílico/tela $.70 \times .90 \mathrm{~m}$. 5. niña del prostíbulo, acrílico/tela $.60 \times .50 \mathrm{~m} .6$. Francisca, acrílico/tela $.80 \times .60 \mathrm{~m}$. 7. poeta de 7 años, acrílico/tela $.70 \times .50$ 
m. 8.paisaje, acrílico/tela $.60 \times .80 \mathrm{~m}$. 9. forma num. 1 óleo/tela $.70 \times .50 \mathrm{~m}$. 10. sin tierra prometida, acrílico/tela $.60 \times .50 \mathrm{~m} .11$. la jaula de Prometeo, acrílico/tela $.70 \times .50 \mathrm{~m}$. 12. mulhouse núm. 2, acrílico/tela $.90 \times .60 \mathrm{~m} .13$. tras del espejo, acrílico/tela $.80 \times .60 \mathrm{~m} .14$. las fiestas del dictador, acrílico/tela $.90 \times .60 \mathrm{~m}$. 15. lamento por Ravensbruck, acrílico/tela $1.00 \times .80 \mathrm{~m}$. 16 . incomunicación, acrílico/tela $.60 \times .80 \mathrm{~m} .17$. soneto para plumas, acrílico/tela $.60 \times .80 \mathrm{~m}$. 18. otro retrato de Francisca, acrílico/tela $.90 \times .70 \mathrm{~m}$. 19. mujeres nadando en el balcón, acrilico/tela $.50 \times .60 \mathrm{~m} .20$. crisis, acrílico/tela $.50 \times .70$ $\mathrm{m}$. 21. juegos antiguos, aguada/papel $.45 \times .60 \mathrm{~m}$. 22 . otra realidad, aguada/papel .45 y $.60 \mathrm{~m}$. 23. mujer amarilla, aguada/papel $.45 \times .60 \mathrm{~m}$. 24 . seriedad muerta, aguada/papel $.60 \times .45 \mathrm{~m}$. 25. 453881 , aguada/papel $.60 \times .45 \mathrm{~m}$. 26. secreto del grito, aguada/papel $.60 \times .45 \mathrm{~m}$. 27. fuga, aguada/papel $.45 \times .60 \mathrm{~m} .28$. brisqueda del silencio, aguada/papel $.60 \times .45 \mathrm{~m}$. 29 . composición en descomposición, aguada/papel $.45 \times .60 \mathrm{~m}$. 30. secuencia simultónea, aguada/papel $.60 \mathrm{x}$ $.45 \mathrm{~m}$.

LUis torreblanca. Exposición de esculturas, presentada por el Instituto Nacional de Bellas Artes (SEP) Galería José Maria Velasco, Peralvillo 55, el 7 de febrero.

Datos biográficos: nació el 3 de septiembre de 1938, en México, D. F. Estudió en la Escuela de diseño y artesanía del INBA, es maestro de metales. Premios por trabajos en metal $(1962,1963,1964$ y 1965) de la Escuela de diseño y artesanía del INBA.

Catálogo: 1. hombre cósmico, cobre 2. rueda saturnal, aluminio 3. bumpa, cobre y latón 4. eblis, hierro 5. gelon, hierro 6. pentaclo, hierro 7. mujer, hierro 8. arpa saulica, hierro y latón 9. abesi, estaño, plomo y latón, cuadro 10. metratón, piedra y hierro 11. tres, hierro 12 . balomati flecha, hierro.

GRABado Soviético. Exposición presentada por el Organismo de Promoción Internacional de Cultura de la Secretaria de Relaciones Exteriores, la Embajada de la URSS y el Instituto de Amistad e Intercambio Cultural México-URSS, Galería de Arte del Teatro "Casa de la Paz", Cozumel núm. 33, el 8 de febrero.

yolanda savín. Exposición de obras pictóricas, presentada por el Instituto Cultural Alemán, Tonalá núm. 43 , del 12 de febrero aì 12 de marzo.

KRISTEL GUMA. Exposición de obras recientes, presentada por el Instituto MexicanoNorteamericano de Relaciones Culturales, A. C., Hamburgo 115, del 13 de febrero al 11 de marzo.

ENRIQUE ESTRADA. Exposición de obras, presentada por la Galería San José, Insurgentes Sur 1888, del 14 al 28 de febrero.

Asombra la sinceridad con la que Enrique Estrada se desplaza por el mundo del arte. Justamente en estos momentos por los que atraviesa la pintura -mundo éste, si los hay, en crisis-; cuando por estar casi en un callejón sin salida, el pintor intenta lo indecible con tal de conseguir una originalidad no siempre, por desgracia, feliz; cuando el arte abstracto ofrece una salida peligrosa por aparentemente más sencilla; cuando esto ocurre, digo, Enrique Estrada permanece y subraya los valores de la figura humana con una lealtad amorosa, digna de la mayor meditación. ¿Qué 
ocurre en efecto? ¿Se trata de volver hacia atrás la mirada, de recorrer el mismo camino a la inversa para intentar la salvación? Tal parece como si sólo así -sin quitarse el espejo de enfrente, con todo el gozo y la tortura que la actitud implica-pudiera el hombre encontrar la coyuntura: redimirse. Así las cosas caen uno a uno los temas dentro de sus manos: la naturaleza, la muerte, un latente e inhibido mindo sexual, el ser humano como individuo, lo social actuante, particular, y, envolviéndolos a todos como una malla obligada y feroz, la libertad.

Por lo demás, si de alguna tónica tuviéramos que echar mano para aprehender la pintura de Enrique Estrada, seguramente pensaríamos en una forma de la violencia por más que la suya, atada, nos entregue tanto más el hecho mismo anterior a la caza, que la caza en sí misma. Dicho de otro modo él se nos presenta un segundo antes de saltar sobre un punto moral determinado y destrozarlo. En esta clase de momento previo, trágico, es posible acaso encontrar el sentido de una pintura que, como la suya, ofrece una sinceridad sinónimo de fuerza, paradójico vasallaje a lo que en el ser humano el artista podría considerar consustancial. De allí que, apartado de cánones abstractos sea, uno de los pocos -muy pocosmoradores románticos con los que aún contamos en nuestra convivencia estética.

Sergto Fernández

Catálogo: 1. esclavo 2. estudio de esclavo 3. hombre idiota 4. la muerte negra 5. el profeta 6. el juicio o recreación sobre Goya 7. estudio de cabcza del profeta 8 . retrat de mi amigo José Muro 9. elementos (paisaje) 10. paisaje 11. paisaje de Silos.

Carlos antonio chávez. Exposición de grabados en color, presentada por el Instituto Nacional de Bellas Artes (SEP), Salón de la Plástica Mexicana, Havre núm. 7, del 14 de febrero al 8 de marzo.

FELICIAno PEÑA. Exposición de paisajes, presentada por la Galería de Arte Mexicano, Florencia 35 , del 17 de febrero al 20 de marzo.

Catálogo: 1. vista del valle 2. paisaje dorado 3. el cráter 4. almiares 5. vista del Ixtaccínuatl 6. los toros 7. paisaje del pedregal 8. ruinas en la selva num. 19. ruinas en la selva núm. 2 10. troncos 11. magueyes 12. mube roja 13. la lluvia 14. cerro negro 15 . el pucblo sobre el monte.

ARMANdo villagrán. Exposición de obras recientes, presentada por la Galería Edvard Munch, Paseo de la Reforma 489-a, el 17 de febrero.

nissen. Exposición de obras, presentada por la Galería Pecanins, Hamburgo 103, el 18 de febrero.

oRlando. Exposición presentada por la Galería Juan Martín, Amberes 17, del 18 de febrero al 8 de marzo.

ADRIÁN SILVA. Exposición presentada por el Instituto Mexicano-Norteamericano de Relaciones Culturales, A. C., Galería Nuevos Valores, Hamburgo 115, el 20 de febrero. 
Datos biográficos del artista: Adrián Silva, nació en Querétaro en 1925.

Catálogo: 1. niño prodigio 2. bestia de sacrificio 3. diácono 4. sed de luz 5 . el snob de la zona rosa 6. vestigio indescifrable 7. mágico designio 8. cavidad del tiempo 9. personaje del ciclo perdido 10. fase de nuestro tiempo 11. fusión selectiva 12. el pecado de Darwin 13. el cazador de aves mecánicas 14. navegante en el ángulo 33 15. silogismo 16. germinal 17. el actuante 18. delito in prontus 19. mutante 20. materialización trascendente 21. arqueología intemporal 22. morada intima 23. observador nocturno 24. visitantes desconocidos.

la mujer eN la plástica. Exposición de pintura, escultura, dibujo y grabado, presentada por el Instituto de Arte de México, Puebla 141, el 21 de febrero.

ISRAEL A TRAVÉS DE IMÁGENES. Exposición fotográfica, presentada por el Centro Deportivo Israelita, Galerías C. D. I., Av. Manuel Ávila Camacho 620, Lomas de Sotelo, del 23 de febrero al 15 de marzo.

marcelo grassmann. Exposición de dibujos y grabados, presentada por la Galería Mer-Kup, Molière 328-C, del 24 de febrero al mes de marzo.

Datos biográficos: nació en São Paulo Brasil el año de 1925.

Catálogo: 1 al 8 grabados y del 9 al 16 dibujos.

MigUel HERnÁNDEZ URBÁN. Exposición presentada por la Galería Mer-Kup, Molière $328-\mathrm{C}$, el 24 de febrero.

BERNICE Kolko. Exposición fotográfica, presentada por el Departamento del Distrito Federal, Dirección General de Acción Social, Galerías de la ciudad de México, en el Centro Social Popular Leandro Valle de la Colonia Agrícola Oriental, del 25 de febrero al 15 de marzo.

Catálogo: 1. Diego Rivera, pintor, México 2. muchacha maya, Ticul, Yuc. 3. tejedora de Morelia, Mich. 4. procesión de Juchitán, Oaxaca 5. linda juchiteca, Oax. 6. torito, Chamula Chis. 7. vendedora de naranjas, Veracruz 8. alfarera de Metepec, D. F. 9. joven de Chamula, Chis. 10. mujer haciendo tortillas, Tizimín, Yuc. 11. canastas, ciudad de México 12. muchacha de Coyotepec, Oax. 13 vieja alegria, Milpa Alta, D. F. 14. pensador, Chamula, Chis. 15. alfarero de Lerma, Campeche 16. madre e hijo en la hamaca, Motul, Yuc. 17. en el mercado de Mezquital, Hgo. 18. muchacho de El Romerillo, Chis. 19. la familia de Oaxaca, Oax. 20. mujeres de Juchitán, Oax. 21. cuatro generaciones, Janitzio, Mich. 22. hombre con henequén, Yuc. 23. gobernador chamula, Chis. 24. jacal, Chamula, Chis. 25. campesinos. El Romerillo, Chis. 26. matrimonio. San Cristóbal Las Casas, Chis. 27. dos hermanas. El Romerillo, Chis. 28. hombre de Mérida, Yuc. 29. hombre cortando henequén, Yuc. 30. la calle de Papantla, Ver. 31. huichol de Santiago, Nay. 32. niños de Xochimilco, D. F, 33. mujeres de Toluca, Edo. de México 34. mujer de Amatinango, Chis. 35. Elena Noriega, bailarina, México 36. cocina mexicana. Erongorícuaro, Mich. 37. José Luis Cuevas, pintor, México 38. Dr. Angel María Garibay, escritor, México 39. Francisco Zúñiga, escultor, México 40. Juan José Arrcola, cuentista, México 41. mujer de Lerma, Camp. 42, surcos y arrugas, México 43. Frida Kalo, pintora, México 44. casamiento, Tacuba, México 45. Kinder Garden, Coyoacán, México 46. domingo, mercado de Actopan, Hgo. 47. paisaje humano núm. 1. Orizaba, Ver, 48. 
paisaje mumano núm. 2, Orizaba, Ver. 49. la danza, Papantla, Ver. 50. muchacha de Papantla. Ver. 51. domingo en la Lagunilla, México 52. niña alfarera. Amatinango, Chis, 53. doningo en el parque de Papantla, Ver. 54. mujer de Janitzio, Mich. 55. mujer hilandera. El Romerillo, Chis. 56. Margarita de Tikul, Yuc. 57. cruces. El Romerillo, Chis. 58. día de los muertos, Janitzio, Mich. 59. boda elegante, Coyoacán. Méx. 60. sábado de gloria con los judas, México 61. mujeres lavando ropa. Coyuca, Gro. 62. vendedora de mais, Juchitán, Oax. 63. mercado de palmas, Toluca, Edo. de México 64. la falda, Janitzio, Mich. 65. muchacha de Piste, Yuc. 66. madre e hijo de Ticul, Yuc. 67. vendedora de totopos, Juchitán, Oax. 68. mercado de Toluca, Edo. de México 69. pelo largo, Janitzio, Mich. 70. dos hermanas bordando, Juchitán, Oax. 71. el regateo, mercado de Zacualpan de las Milpas, Mor. 72. Ruth Rivera. Arquitecto, Méx.

CITA SEgErSkog. Exposición obra pictórica, presentada por el Instituto Nacional de Bellas Artes, Embajada de Dinamarca, Sala Internacional, del 26 de febrero al 18 de marzo.

Catálogo: 1. el diplomático $70 \times 120 \mathrm{col}$. Emb. Hans Von Haffner 2. autorretrato $50 \times 75$ col. del autor 3. Liza $70 \times 120 \mathrm{col}$. Bisgaard 4. Il cavalleri $60 \times 90 \mathrm{col}$. del autor 5. raices $80 \times 100 \mathrm{col}$. del autor 6 . Kirsten $90 \times 120 \mathrm{col}$. Gilmore 7 . el entierro de Alfonso Doninguez $70 \times 100 \mathrm{col}$. del autor 8. juego de la riolencia $62 \times 100$ club de columnistas 9. Ragnhild y la primavera $70 \times 108$ col. del autor 10. por el espejo $74 \times 91$ col. del autor 11. Christina $70 \times 120 \mathrm{col}$. Cortés 12 . isla mujeres $54 \times 83 \mathrm{col}$. del autor 13. el actor $58 \times 100 \mathrm{col}$. Wess 14. paraiso tropical $50 \times 66$ 15. caperucita roja $47 \times 62$ col. del autor 16. las 3 gracias $52 \times 62$ col. del autor 17. La Malapert $40 \times 50$ col. Gallardo 18 . la danza' $46 \times 70$ col. del autor 19. y yo qué? $58 \times 100 \mathrm{col}$. del autor 20. retrato de Dalí $100 \times 120 \mathrm{col}$. del autor 21. sic transit gloris mundit $59 \times 120$ col. del autor 22 . el rostro $103 \times 155 \mathrm{col}$. Gallardo 23. noche escandinava $80 \times 130 \mathrm{col}$. del autor 24. Katte $40 \times 54$ col. del autor 25 . Beatriz $60 \times 45$ col. Talladrid 26. Bernardette $22 \times 31$ col. Flatow 27. la Crucifixion amarillo de Richard Harris $88 \times 115$ col. del autor 28. Maria-Helena 82 × 100 col. Gallardo 29. bente $50 \times 70$ col. Cortés 30. la batalla de la pildora $100 \times 150$ col. del autor.

PEYRI. Exposición de 23 óleos y 35 dibujos, presentada por la Galería de Arte Mistachi, Génova 20 , el 27 de febrero.

Datos biográficos: Antonio Peyri, nació en Barcelona, España el 27 de abril de 1924. Educación primaria en el Instituto Escola, Barcelona, España. Educación secundaria, Lycée Hoche, Versalles, Francia. Educación preparatoria, Academia Hispano-Mexicana, México. Profesional, Escuela de Arquitectura de la Universidad Nacional Autónoma de México, es de nacionalidad mexicana.

Catálogo: 1. espiritus festizos $125 \times 200 \quad$ 2. vnelo de hadas $125 \times 200$ 3. fantasia para niños $130 \times 130$ 4. caminante perdido en el espacio $65 \times 1055$. bailarina I (dedicado a Pilar Rioja) $65 \times 105$ 6. bailarina II $65 \times 105.7$. revelación interior $65 \times 1058$. cadena erótica $65 \times 1059$. ilusiones perdidas $60 \times 5010$. mujer soñando $60 \times 50$ 11. imagen de un rostro desconocido $40 \times 5012$. imagen triste de un rostro desconocido $40 \times 50$ 13. amor nocturno entre las plantas $40 \times 5014$. paisaje de otro mundo $40 \times 5015$. pájaro mágico $40 \times 5016$. the fool on the hill $40 \times 50$ 17. revelación interior $I 40 \times 5018$. revelación interior $I I 40 \times 50$ 19. revelación interior III $40 \times 5020$. revelación interior IV $40 \times 5021$. efloraración $40 \times 5022$. el crepúsculo de las plantas $65 \times 10523$, una vida con otro sentido $360 \times 10524$. ilusiones afuera de las cavernas, triptico $30 \times 40 \times 325$. 
homenaje a Ingmar Bergman, tríptico $30 \times 40 \times 3$ 26. transfiguraciones de la imagen de una mujer, tríptico $30 \times 40 \times 327$. remembranzas nostálgicas, díptico. $20 \times 45 \times 228$. ser extraño caminando sobre horizontales desconocidos $25 \times 30$ 29. mujer i/usionada $25 \times 3030$. jucgo de niños entre dos mundos $30 \times 4031$. descubrimiento de un misterio $30 \times 40$ 32. mujer frivola $30 \times 4033$. aparición misteriosa en un espejo I $30 \times 40 \quad 34$. aparición misteriosa en un espejo II $30 \mathrm{x}$ 40 35. aparición de un sueño en un espejo $30 \times 40$ 36. revelación interior $I, 30$ $\times 40$ 37. revelación interior II $30 \times 40$ 38. fantasía coqueta $30 \times 4039$. aparición de una nujer detrás de las cortinas $30 \times 4040$. cortesana I $30 \times 4041$. cortesana II $30 \times 4042$. cortesana III $30 \times 4043$. cortesana IV 44 . trasfondo de un sueño $30 \times 4045$. dos figuras observando un desfile de árboles $30 \times 40$ 46. revelación interior III $30 \times 4047$. paisaje de otro mundo $30 \times 4048$. visión fantástica $30 \times 4049$. penumbras sensuales $30 \times 40 \quad 50$. enigma barroco $30 \times 40$ 51. figura inquietante $30 \times 40$ 52. imágenes de tres rostros desconocidos, tríptico $30 \times 40 \times 3$ 53. contento de vivir $30 \times 40$ 54. figura enigmática $30 \times 4055$. imagen de un rostro desconocido $30 \times 40$ 56. revelación interior $I V \quad 30 \times 40 \quad 57$. revelación interior $V 30 \times 40 \quad 58$. aparición misteriosa en un espejo III $30 \times 40$.

TACHo. Exposición presentada por el Departamento del Distrito Federal, Dirección General de Acción Social, Galerías de la ciudad de México, Sala Juárez, el 26 de febrero.

Catálogo: 1. judas entrega a Jesuis de Ixtapalapa 2. la caida de Jesús de Ixtapalapa 3. $2^{a}$ caida de Jesuis de Ixtapalapa 4. $3^{a}$ caída de Jesús de Ixtapalapa 5. camino al Calvario 6. la sentencia de Jesilis 7. los Nazarenos 8. divino rostro 9. Dimas y Gestas 10. Jesús es clavado en la Cruz 11. toma aérea 12. Jesús y los maladrones on la cruz 13. el cine 14. el desfile 15. los guerrilleros 16. procesión de negros 17. rezo indigena 18. libranos Señor 19. no nos desumpares 20. sodado negro 21. almuerzo 22. calaveras cábulas 23. algo brilla en el cielo 24. cruces en al espacio 25. el perdón 26. un sueño 27. mundo desconocido 28. yo te escucho 29. somos observados 30. de algo hay que vivir (el tragafuego) 31. el paria 32. el niño de las banderas 33. la extra 34. el bolero 35. biafra S.O.S. 36. hambre y lluvia 37. aventurera 38, el niño de los globos.

riCardo martínez. Exposición de pintura presentada por el Instituto Nacional de Bellas Artes, Museo de Arte Moderno, Galería de Exposiciones temporales, del 27 de febrero al mes de abril.

Catálogo: 1. dos figuras, óleo s/tela $1.75 \times 2.00 \mathrm{col}$. INBA 2. mujeres 1959 óleo $\mathrm{s} /$ tela 1.75 y $2.00 \mathrm{col}$. de la Sra. Bryna Prensky 3. madre $e$ hijo 1960 óleo s/tela $1.60 \times 1.00 \mathrm{col}$. del autor 4. madre de tres hijos 1960 óleo s/tela $1.75 \times 1.10 \mathrm{col}$. privada San Diego Calif., EUA. 5. pareja 1960 óleo s/tela $1.75 \times 2.10 \mathrm{col}$. del Banco de Comercio, S. A. 6. madre e hijo 1961 óleo s/tela $.895 \times 1.50 \mathrm{col}$. Mr. and Mrs. Chares H. Gross 7. pareja en verde 1962 óleo s/tela $1.10 \times 2.00 \mathrm{col}$. del Ing. Arturo Madrazo y Sra. 8. figura sentada 1963 óleo s/tela 1.30 q 1.50 col. dc. Sr. José Iturbe y Sra. 9. desnudo 1963 óleo s/tela $1.15 \times 8.85$ col. del Arq: Enrique Carral y Sra. 10. grupo de mujeres 1964 óleo s/tela $2.00 \times 1.75$ col. del autor 11. desmudo 1964 óleo s/tela $1.50 \times .75$ col. del Banco de Comercio, S. A. 12. figura sentada 1964 óleo s/tela $1.30 \times 1.5013$. desnudo arcaico 1965 óleo s/tela $1.50 \times .95 \mathrm{col}$ del autor 14. mujer con luz azul 1965 óleo s/tela $1.50 \times 1.30$ col. del autor 15 .padre $\mathfrak{E}$ hijo $1965 \mathrm{~s} /$ tela $1.50 \mathrm{x} .95 \mathrm{col}$. del Ing. Jorge Díaz Serrano 16. mujer con tres figuras 1965 óleo s/tela $2.10 \times 1.75$ col. del autor 17. padre e hijo 1965 óleo s/tela $1.50 \times .95 \mathrm{col}$. del autor 18. mujer con fruta 1965 óleo s/tela $1.50 \times .95 \mathrm{col}$. del Ing. Jorge Díaz Serrano 19. figura sentada 1965 óleo s/tela $1.30 \times 1.50 \mathrm{col}$. del Ing. Jorge Díaz Serrano 20. pareja dor- 
mida 1965 óleo s/tela $1.75 \times 2.10 \mathrm{col}$. del Sr. Wayne Williams y Sra. 21. madre e hijo 1966 óleo s/tela $1.60 \times 1.30 \mathrm{col}$. del autor 22. mujer con juncos 1966 óleo s/tela $1.60 \times .95 \mathrm{col}$. del autor 23. mujer con juncos 1966 óleo s/tela $1.60 \times 1.00 \mathrm{col}$. del autor 24. mujer con palma 1966 óleo s/tela $1.60 \times 1.00$ col. del autor 25. gran desnudo 1966 óleo s/tela $1.60 \times 1.30 \mathrm{col}$. del autor 26 . hijo pródigo I $1966 \mathrm{~s} /$ tela $2.00 \times 1.10 \mathrm{col}$. del Sr. Joaquín Shapiro y Sra. 27. hijo pródigo II 1966 óleo s/tela $2.10 \times 1.00 \mathrm{col}$. del autor 28. hombre con niño 1966 óleo s/tela 1.30 x $1.50 \mathrm{col}$. del Sr. Fernando Ortiz Monasterio y Sra. 29. mujer con agua 1966 óleo s/tela $1.50 \times .95$ col. del Sr. Joaquín Shapiro y Sra. 30. desnudo 1967 óleo s/tela $.90 \times 1.50 \mathrm{col}$. de la Galería de Arte Mexicano .31. figura sentada 1967 óleo s/tela $1.30 \times 1.50 \mathrm{col}$. del Ing. Arturo Madrazo y Sra. 32. figura yacente 1967 óleo s/tela $.70 \times 1.50$ col. del Ing. Arturo Madrazo y Sra. 33. guerrero arcaico 1968 óleo s/tela $1.10 \times 2.00 \mathrm{col}$. del autor 34. composición 1968 óleo s/tela $2.00 \times 1.75 \mathrm{col}$. del autor 35. pareja con paisaje 1968 óleo s/tela $1.75 \times 2.00 \mathrm{col}$. del autor 36 pareja antigua 1968 óleo s/tela $2.00 \times 1.75 \mathrm{col}$. del autor 37. hijo pródigo III 1968 óleo s/tela $2.00 \times 1.10$ col. del autor 38. mujeres y figura yacente 1968 óleo s/tela $3.00 \times 2.00 \mathrm{col}$. del autor 39. figura inclinada 1968 óleo s/tela $1.30 \times 1.50 \mathrm{col}$. del Sr. Samuel Kurian 40. grupo 1969 óleo s/tela $3.00 \times 2.00$ col. del autor.

Datos biográficos: Ricardo Martínez, nació en México, Distrito Federal, en el año de 1918.

La primera exposición individual de Ricardo Martínez, en 1944, dio comienzo a un desarrollo de su personalidad artistica que ha sido a la vez un constante percibir el mundo desde distintos puntos de vista. De una posición afín a lo barroco, desde la sinuosidad del dibujo delinitaba incisivamente los objetos, pasó a hacer descansar en el espacio colorido las cualidades estéticas de sus telas, a grado tal que en los últimos años el dibujo -a menudo apenas insinuado, en ocasiones reducido a la continuidad de una línea- se hermana con el color sólo para facilitarle el ámbito necesario en que éste ha de prevalecer. Tras el esmerado proceso por el cual ha transcurrido su sensibilidad, ha llegado a esta etapa de su labor en que, al afinar los procedimientos, acentúa su profundidad perceptiva.

Despojado lentamente de una variada gama, apreciable en la fase inicial de su pintura, Ricardo Martínez decidió eludir también el hacinamiento y la diversidad de los objetos, seducido casi exclusivamente por la figura humana. Aquella proliferación se convirtió entonces en el hallazgo de una sobriedad que abrió el pasó a descubrimientos de expresiones eminentemente plásticas cada vez más sumergidas en una atmósfera de ensueños. El paisaje, las naturalezas muertas, las perspectivas -admirablemente emanadas de su pincel-, se han desvanecido para acoger con sencillez los elementos que, según la tradición, deben asignarse a la naturaleza: la tierra, el agua, el aire y el fuego.

Desdeñando el riesgo de lo decorativo y de lo anecdótico, en franca resistencia a las aficiones descriptivas y al gusto de la narración, en sus telas adquieren preeminéncia esos materiales que él torna dúctiles mediante el discernimiento adecuado de los colores. En su pintura, la moderación de esos elementos no inhibe la vehemencia de las formas, porque tal sobriedad nunca desciende al hálito de la tibieza, ni tampoco se diluye en la frialdad de la monotonia. Vigilando por la inteligencia, el esplendor excede de las márgenes del cuadro y prolonga la vitalidad de su espacio. Del estricto manejo de la materia plástica, de la ordenación de los volúmenes, deriva el efecto que estas obras producen en el espectador. Basta con examinar la 
riqueza de sus matices, para advertir en seguida el fervoroso movimiento que les prestan los toques del pincel, atributo que sólo el artista verdadero suele otorgar a lo representado.

A los orígenes del hombre absorto en sus preocupaciones fundamentales, se entrega la imaginación de Ricardo Martínez. Para sugerir júbilos y sinsabores, no recurre a evocaciones de hombres o de mujeres insertos en su mundo inmediato, relacionados con un instante preciso de su vida diaria, a la hora de desempeñar una actividad determinada, sino que prefiere fundir en similar nivel, en unidad, la desnudez de los cuerpos y de las almas para que al mirarlos los reconozcamos situados ante el misterio de la existencia. Son hombres y mujeres próximos a nosotros, dueños de nuestros defectos y de nuestras virtudes, pero concebidos desde dentro a solas, casi a partir de la formación de su espíritu. Acaso los recuerdos atávicos los mantengan descansando en lo mítico, ceñidos a anhelos primordiales, subordinados a la aceptación de un universo cautivo en el fecundo juego de la magia. Nacidos de la tierra, identificados con ella, hechos de la arcilla que a todos nos pertenece, despiertan el deseo de abordar en algún momento el significado de la condición humana. Sus rostros impresionan por su soledad, antigua y melancólica como la ternura que los habita. Pareciera que el tiempo hubiese dejado caer en ellos un poco de su distancia con el propósito de inducirlos a sospechar que nada ha acontecido durante milenios y que aún esperan el cumplimiento del primer suceso. Alli el amor se corresponde con el reposo $y$ las tinieblas del alma se nutren con el resplandor que, en el centro de su corporeidad, se abre cauce a fin de iluminar su noche.

Al comparar algunas de las obras de Ricardo Martínez producidas en la primera etapa, por ejemplo En memoria de mi padre (1944), con las de épocas posteriores, confirmamos cómo esa estabilidad se hallaba reflexivamente prefigurada desde entonces. Nadie podrá acercarse a aquel rostro y a aquellas manos sin referirlos al sosiego de las nuevas figuras y notar en éstas cierta resonancia de esa actitud, lo cual indica un modo análogo de abordar el drama de nuestros semejantes. En el primero, la muerte se hace sensible por la gracia artistica y nos lleva hacia la serenidad enemiga de los cambios, convencida de que nunca tenderá a desaparecer. En los últimos, lo inmutable es signo de idéntica contención, y en todos el velo del aire se mueve pausadamente sobre la severidad de las imágenes. No obstante, en resumidas cuentas no se trata de una pintura cuyo valor se cifre en interpretar lo inerte, en detener el movimiento sólo por ser movimiento, ni mucho menos en el hecho de sugerir ambientes desolados o formas que en su seno arrastren su propia destrucción, porque la energía de sus rasgos se encuentra inscrita en figuras levantadas en vilo por el temblor de la luz y por la gradación de sus tonalidades. Así, esta pintura conserva el sitio que su autor le ha dispuesto, más allá de la naturaleza y la razón.

Entre el sueño y la acción, las imágenes de Ricardo Martínez perduran en el lugar intermedio en que quiso suspenderlas, fluctuando de la realidad a la invención, animadas con la idea de persuadirnos a creer que el prodigioso recinto de lo sensual, aquello que invade la conciencia al través del engaño de lo contiguo, se mezcla y se confunde con la naturaleza. Bajo la piel de esas mujeres que surgen como rocas o catedrales silenciosas, los sentidos presienten la exuberancia de lo 
sagrado, la prolongación del enigma, acordes con el equilibrio de su presencia en la composición. Al brotar de las sombras, defendidas por su interna magnitud y por la vivacidad de ciertas luces gratas a la violencia, se redimen por la levedad del misterio y se exteriorizan en visiones puras solazadas en el placer de las formas por las formas mismas. Solas o al lado del hijo o del compañero, las mujeres que Ricardo Martínez pinta son símbolos de lo terrenal. Engendradas por el secreto de quien sabe ver más allá de las apariencias, se manifiestan como un testimonio de lo humano. La majestad de su presencia, cercana al tacto y, sobre todo, a la mirada, es un resumen de las fuerzas y de la armonía preestablecida en la naturaleza.

Para penetrar la obra de Ricardo Martínez, no son suficientes las anteriores anotaciones. Indispensable es enfrentarse a sus telas armados con la mirada ingenua del que confia en los valores plásticos y no en sus "explicaciones", particularmente si se pretende comprender, más que el sentido de su temática, su significación estética. Bastaría con decir por ahora que este singular arte es la muestra de un pintor que, al cumplir con las exigencias que le impone su vocación, ha creado una de las obras de mayor relieve en la historia última del arte mexicano.

\section{Alf Chumacero}

RENÉ villanueva. Exposición de 25 obras (tintas y pinturas), presentada por la Galería de Artes Plásticas, en el Centro Cultural Coyoacán, Eleuterio Méndez nún. 11 , el 28 de febrero.

Catálogo: 1. hombre 2. mujer 3. que tu canto sea más fuerte que tu llanto 4. 2 de octubre 5. silencio 6. huichilobos 68 7. el silencio 8. al compañero 9. ante la historia 10 . noche de muertos 11. todo es posible en la paz 12. la lucha 13. contradicción 14. coloquio 15. la prueba 16. diálogo con una sombra, técnica mixta 17. la semilla del hambre, técnica mixta 18. monólogo, acrílico 19. el retorno de las bestias, técnica mixta 20 . surtidor de piedra..., acrílico 21 . Ins inombrables, acrílico 22. vencidos, acrílico 23. vidala para mi sombra, acrílico 24. pájaro nocturno, acrílico 25. en el eco del silencio, acrílico.

octavio ochoa. Exposición presentada por el Instituto Nacional de Bellas Artes, Galería Chapultepec, Insurgentes Sur 11-b, el 28 de febrero.

JosE zúÑ̃GA. Exposición presentada por el Instituto Nacional de Bellas Artes, Galería Chapultepec, Insurgentes Sur 11-b, el 28 de febrero.

guillermo Mąueo. Exposición de pintura dactilar, presentada por el Departamento del Distrito Federal, Dirección General de Acción Social, Galerías de la ciudad de México, Pérgolas de la Alameda, Sala Hidalgo, el 28 de febrero.

Catálogo: 1. el ser más amado de la tierra, col. del autor 2. autorretrato, col. del autor 3. Santa Prisca de Taxco, col. del autor 4. Lupe, col del autor 5. Graciela $H$. de Matus, col. del Lic. Carlos Matus 6. Celia, col. Celia Smith 7. Lucha, col. Lucha de Vivero 8. trilogía de Cristo 9. flores silvestres 10. ella y las rosas 11. la merte de un Presidente 12. nostalgia 13. Emiliano Zapata 
14. su última canción 15. Acapulco de noche 16. Mazatlán 17. la Ticuana de Janitzio 18. Janitzio 19. la casa colorada 20. caridad verdadera 21 . el arquéologo 22. el restaurador 23. el coleccionista 24. farallón 25 . paseo de la $R e$ forma 26. desmudo 27. Lirio, col. Lirio Rivero.

Grabadores. Exposición del taller de grabado de Mario Reyes, presentada por la Alianza Francesa de San Ángel 17 de julio núm. 26, del 28 de febrero al 21 de marzo.

Expositores: Raúl Anguiano, Hilda Campillo, Robin Gill, Cecile Martial, Juan Messmacher, Carmen Mones, Ana Pellicer, Gonzalo del Pozo, Mario Reyes, Ma. Isabel Rodríguez, Eleanore Romero, Ignacio Romero.

humberto peraza. Exposición presentada por la Tasende's Gallery, Calzada Costera M. Alemán y V. Yáñez Pinzón, Acapulco, Gro., el 6 de febrero.

\section{MARZO}

Historia DE la pintura mural mexicana. Exposición presentada por el Comité Ejecutivo Nacional del Partido Revolucionario Institucional, Edificio del CEN del PRI, Insurgentes Norte 59, el 4 de marzo.

JEsús MARTínez. Exposición obra gráfica, presentada por el Instituto Francés de América Latina, Nazas 43, del 5 al 28 de marzo.

Catálogo: Grabados: 1. calavera. 2. siglo $X X$ 3. raices 4. el prisionero 5. muro de la ciudadela 6. el puente 7. vestigios 8. reflejo 9. mimetismo 10. necrópolis 11. fragmentación 12, asfalto 13. Km. 13 14. homenaje al pintor anónimo 15. textural 16. asiste 17. acero y vidrio 18. estrellado 19. resquebrajamiento 20. la hida 21. coágulo 22. ulular 23. aullido 24. gemido 25. la noche 26. detritus 27. recuerdo 28. simbología 29. horadación 30. andrajo 31. terror 32. tríptico de la angustia.

LENI DE SERvíN. Exposición de óleos, acuarelas y dibujos, presentada por la Galería Kusak, Génova 2-J bis, del 5 de marzo al 2 de abril.

GABRIEl FERNÁNDEZ LEDESMA. Exposición retrospectiva, presentada por la Galería de Arte Mexicano, Milán 18, del 7 de marzo al 7 de abril.

Nada más apropiado para celebrar el trigésimo cuarto aniversario de la Galería de Arte Mexicano que la exposición retrospectiva de uno de sus artistas fundadores: Gabriel Fernández Ledesma. Integrante de esa generación que tanta gloria ha dado a México fue, con sus contemporáneos Francisco Díaz de León, Agustín Lazo, David Alfaro Siqueiros, Antonio Ruiz, Rufino Tamayo, Julio Castellanos, uno de los más entusiastas colaboradores de mi hermana, Carolina Amor de Fournier, en el momento de iniciarse nuestras labores el 7 de marzo de 1935.

No es necesario describir los múltiples aspectos de la carrera artística de Fernández Ledesma. Basta recordar sus trabajos en todas las técnicas pictóricas posibles: sus excelencias en el arte del grabado; su esmero y pulcritud en la edición 
de libros de arte; sus aciertos en escenografia; sus investigaciones sobre el arte popular mexicano $y$, sobre todo ello, su larga $y$ fructifera labor como maestro. Enemigo del autobombo, ha seguido trabajando infatigablemente en el ambiente recoleto de su casa casi provinciana de la Villa de Guadalupe.

Es el fruto de ese generoso trabajo que tenemos el honor de presentar ahora al público mexicano.

INÉS AMOR

Catálogo: Dibujos: 1. olinca 2. retrato desmudo 3. yalaltecas 4. desmudo 5 . barcas al garete 6. Chabela 7/8. dibujos a una linea (tinta). Col. Dr. David Mijangos 9 a 19. dibujos a una linea (tinta). Grabados 20. patos chinos 21. la guerra y la paz 22. la prueba platónica 23. hermanas 24. Nueza York 25. $N u e v a$ York de noche 26. IV Centenario de la imprenta en México 27. nazarenos 28. retrato de un obrero tallista 29. titiritero 30. música pastoril 31. Cuauhtémoc (camafeo) 32. calaveras del segundo frente 33. talla directa 34. composición musical 35. ofrenda en Janitzio 36. semana santa en Sevilla, gouaches 37. farmacopea 38. maternidad en amarillo 39. geometría 40. 2 de noviembre 41. desruidos 42. siesta 43. flautista 44. madre y niño 45. desnudo en violeta 46. caballero "tíguerc" 47. tameme 48. el clarinete 49. proyecto para pequeño mural, monotipos 50. cafetera y manzanas 51. cerámica 52. mujer y niña dormida, col. del Ing. Alberto J. Barocio 53. arrullo 54. bañista y niño, col. del Ing. Alberto J. Barocio 55. mujer peinándose 56. el mar 57. mijer y niña 58. estibadores 59. los guantes negros 60. Chabela 61. naturale $\approx a$ muerta con barco 62. interior sin personajes 63. poeta citrico 64. Chabela en verde 65. farmacopea, col, del Ing. Alberto J. Barocio 66. prematernal, acrílico 67. bañista 68. barcas en reparación 69 . Acapatzingo 70. juego de hilo 71 . mujer y niña desnudas 72. cabeza de toro 73. cargando caña 74. dos mujeres en rosa 75 . cargando losas, col. del Ing. Alberto J. Barocio 76. Eva calipisia 77. mujer arrodillada 78. éxodo 79. fuego 80. tendero escenográfico 81. danza nüm. 182. muchacha sentada 83. Occlotl 84. danza núm. II (acrílico y tinta) 85. busto de mujer 86. mujer y silla, col. del Ing. Alberto J. Barocio 87. sombra en los ojos, col. de la Sra. Sonia A. de Correa, piroxilinas 88. movimiento de danza 89. flautista 90. diálogo 91. desnudo con espejo 92. cabeza antigua 93. Patricia, col. del Dr. Armando Villaseñor 94. eterna lucha 95. mujer y niño con palma 96. después de la conquista, ruinas y muerte en pie quedaron 97. Casiopea, col. de la Sra. Sonia A. de Correa 98. retablo de la niña y la muerte 99. el vestido rosa, col. de la Dra. Margarita C. de García Jimeno 100. retrato, col. del Prof. Lucas Ortiz.

Carlos garcía estrada (el șol, grabados en color). Exposición presentada por el Instituto Nacional de Bellas Artes. (SEP), Salón de la Plástica Mexicana, Havre núm. 7 , del 10 al 30 de marzo.

$20^{2}$ EXPosición ANUAL DEL CENTRO DE ARTE DE LA UNIVERSDAD DE LAS AMÉriCAs. Exposición presentada por el Instituto Mexicano-Norteamericano de Relaciones Culturales, AC., Galerías Nabor Carrillo, Hamburgo 115, el 13 de marzo.

Estarán expuestas obras en las siguientes técnicas: pintura (óleo, plástica, encáustica, collage, proyectos murales) acuarela y gouache; artes gráficas (intaglio, grabado en madera, litografía, serigrafias, etc.); fotografías; dibujo (lápiz, tinta, conte, punto de plata, carbón, pastel, etc.); escultura (tradicional y experimental). 
szyszlo. Exposición presentada por la Galería Juan Martín, Amberes 17, del 13 al 29 de marzo.

MYRA LANDAU. Exposición presentada por la Galería Pecanins, Hamburgo 103, el 13 de marzo.

EL GRABAdo INTERNACIONAL, Siglos XVIII $y$ xix. Exposición presentada por la Dirección General de Difusión Cultural (UNAM), Departamento de Artes Plásticas, Museo Universitario de Ciencias y Arte (entre la Escuela de Arquitectura y terminal de camiones), del 11 de marzo al 12 de abril.

Catálogo: Lista de coleccionistas, artista y su correspondiente obra por orden alfabético de coleccionistas. Col. Francisco Diaz de León. Picheta. Reproducciones en papel japonés, obtenidas de las planchas de madera originales por el $\mathrm{Sr}$. Díaz de León. 1. ingeniosa invención que conserva entre los esposos el amor que se profesan $95 \times 99 \mathrm{~mm}$ 2. portada del periódico Bullebulle $185 \times 105 \mathrm{~mm}$ 3. Nini za por lana $y$ zuelve trasquilado $98 \times 104 \mathrm{~mm}$. 4. coronación de un marido por su mujer $y$ un amigo 81 x $97 \mathrm{~mm}$. Colección San Carlos. Christian Rugendas 5. fin de batalla, aguatinta. George A. Wolfgang 6. alegoría del Parnaso, aguafuerte $0.470 \times 0.725$. Francisco de Goya y Lucientes 7 . retrato de doña Margarita de Austria, aguafuerte $0.470 \times 0.725$ 8. retrato de don Gaspar de Guamán, aguafuerte $0.205 \times 0.150$ 9. retrato de un enano, aguafuerte 0.205 0.150 . Picart, Bernard 10. El gobierno de la Reina, aguafuerte y buril $0.44 \times 0.81$. Jacques Rigand 11. vista del palacio de Versalles, aguafuerte $0.25 \times 0.473$. Louis Desplaces 12. presentación de la Virgen en el templo, aguafuerte $0.263 \times 0.340$. Jacques Philipe Le bas 13. conversación galante, aguafuerte $0.415 \times 0.27$ Jean Georges Wille 14. retrato del marqués de Marigny, grabado a buril $0.48 \times 0.325$. Robert Daudet 15. escena campestre, grabado a buril $0.162 \times 0.217$ 16. escena campestre, grabado a buril $0.153 \times 0.216$. Jacques Dassonnville 17 . grupo de 4 personas, grabado a buril $0.09 \times 0.079$. Armand Queyroy 18. un patio abandonado, aguafuerte $0.22 \times 0.143$. Augusto Blanchard 19 . campesino comiendo, aguafuerte y buril $0.18 \times 0.148$. Charles Daubigny 20 . paisaje, aguafuerte $0.15 \times$ 0.22 . Julien 21. Lit. ním. 140, Lit. núm. 153, nucvas acadenias del curso elemental. Escuela Inglesa. Joseph Collyer 22. retrato de Sir Felife Stephens, aguatinta, $0.18 \times 0.12$. James $T$. Willmore 23 . panorama de Niza, aguafuerte $\mathrm{y}$ buril. Benjamin ' $T$. Pouncy 24. paisaje, aguafuerte $0.21 \times 0.255$. Thomas $A$. Prior 25. paisaje, aguafuerte $0.19 \times 0.255$. William Say 26. retrato del duque de Cloucester, aguatinta, $0.705 \times 0.44$. Meyer Henrich 27. escena inglesa del s. XVIII, aguafuerte y aguatinta, $0.425 \times 0.61$. Thomas Williamson 28. Telémaco relata sus aventuras a Calypso, aguafuerte y aguatinta $0.58 \times 0.72$. Escuela Italiana. Francisco Rosaspina 29. nacimiento de Alejandro, aguafuerte $207 \times 0.10$. Fabio Berardi 30. paisaje y figuras, aguafuerte $0.345 \times 0.44$. Pablo Fidanza 31. cabeza de Safo, aguafuerte $0.39 \times 0.29$. Giuseppe Vasi 32. Basilica de San Pedro, aguafuerte $0.69 \times 0.96$ 33. vista de la Ciudad de Roma, aguafuerte. Nicola Cavalli 34. paisaje, aguafuerte $0.33 \times 0.40435$. salvamento de náufragos, aguafuerte 0.335 × 0.43, col Gastón García Cantú. Manuel Manilla 36. 94 hojas de grabados, Editor: Arsacio Vanegas Arroyo 1969. Col. Martín Kiek. Egerton 37. la ciudad de Puebla, 12 litografías iluminadas a mano de $60 \times 41.5 \mathrm{~cm}$. Editadas en Londres, abril de 1840. Imp. de James Holmes: Phillips y Ryder 38. litografías iluminadas a mano de la serie "México ilustrado con impresos descriptivos". Impresor: E. Atchley. Imprenta: Day \& Son Lith. to the Queen de $22.5 \mathrm{x}$ $38 \mathrm{~cm}$. Captain Lyon 39. Grabados del libro: "Sketch Book of Capt. G. F. Lyon during eight months' residence in the Republic of Mexico." Litógrafo: R. J. Lane. Impresor: C. Hullmandel $12 \times 13 \mathrm{~cm}$. W. Bullock 40. Litografías iluminadas a mano -pluma y agua-. Litógrafo: I. Clark. Editor: I. Murray. Londres, 1824. Augustine Aglio 41. Exposición sobre el México Antiguo en el 
Salón Egipcio de Piccadilly. Litografia iluminada a mano, dibujo e impresión del mismo autor $16 \times 27.5 \mathrm{~cm}$. Mrs. H. G. Ward 42. Grabador: John Pye Editor: H. Colburn, Londres, $1829,35.5 \times 15.5$. Catherwood 43. Cromolitografías de la seric "Views of the Ancient Monuments in Central America". Chiapas y Yucatán $38 \times 28 \mathrm{~cm}$. Audubon 44. dibujo: J. W. Audubon A.N.A. Én piedra: C. Gildenesiter Litógrafo: Nagel Weingartner. T. Jas. Dunphy 45. Ciudad de México, dibujo del natural tomado desde el camino del Niño Perdido. Ackermann 46. aguatintas, grabado: R. C. Reeves $50 \times 35.5 \mathrm{~cm}$. Colección Lore Stavenhagen (Propiedad del Dr. Kurt Stavenhagen) 47. anónimo Jardines flotantes de $M e ́$ xico, grabado en metal. J. Chapman 48. Teocalli y templo de los Idolos en México con un saccrdote ofreciendo un sacrificio humano. Grabado para la Enciclopedia Londinensis $1817,23 \times 18 \mathrm{~cm}$. C. Brighty y T. Kinnerfly 49 . Vista de la ciudad y pucrto de Acapulco en Hispano América, Bungay, junio de $1805,17.5 \mathrm{x}$ $12.5 \mathrm{~cm}$. Anónimo 50. Iodo a Wigne (Martirio de Cuauhtémoc) grabado núm. 55 de una serie sobre Centroamérica, buril $13 \times 19.3 \mathrm{~cm}$. A.A. Payne 51. Veracrus, buril $16.5 \times 11.4$. H. G. Ward/John Pye 52. Tlalpachec, aguafuerte $22 \times$ $15.5 \mathrm{~cm}$. Anónimo 53. Casas Grandes-México, aguafuerte, Aus \& Kunstandt D. Bibl. 15.5 x $10.5 \mathrm{~cm}$. Delamain 54. México, grabado. Editor: Le Coeur, París. J. M. Moreau Le Jeune 55. los españoles se proclaman amos de Moctezuma en la misma ciudad de México, buril, grabador: L. Delignon $30 \times 40 \mathrm{~cm}$. Solís 56. Cortés y los embajadores plenipotenciarios de Moctezuma, buril $25 \times 40 \mathrm{~cm}$. Colección Manuel Alvarez Bravo. Jacques Callot 57. Tentaciones de San Antonio, aguafuerte. Adrian van Ostade 58. Músico ambulante, aguafuerte. Daumier 59. el mandarín, aguafuerte. Hokusai 60 . aguilillas, grabado en madera a color. Goya 61. Qual la descanionan, aguafuerte, Hirosijc-Toyokuni 62. hombre y paisaje, grabado en madera a color. Kuni-Chica 63. la coqueta, grabado en madera a color. Colección Gustavo Pizarro (Propiedad de la Sra. Beatriz Corcuera Vda. de Pizarro) C. Nebel 64. Litógrafos: Courtin, Cuvillier, Benard. Litografía: Lemercier, Arnouth, Lelinert 65. Paris $52 \times 63 \mathrm{~cm}$. Pictro Gualdi 66. Impresión y Litografía: Massey Decaen, París $68 \times 56 \mathrm{~cm}$. Ximeno Raphael 67. Grabado: Bouquet, Impresor: Langlois. México. G. Ackermann 68. México/ Vista de la Plaza y de la Catedral, grabador: R. G. Reeve 79 x $64 \mathrm{~cm}$. Grabados Italianos de autor desconocido 69. Navegación sobre el lago de México y paso por el rio, iluminado a mano $25 \times 19 \mathrm{~cm}$. Menard 70 . Ilustraciones del libro: Atlas Pintoresco, litógrafo: Sabathier. Impresor: Litográfica de Thierry Frères. París, 1837-1839, 73 × $61 \mathrm{~cm}$. C. Castro 71. Ilustraciones del libro: México y sus alrededores. Litografía: J. Campillo, G. Rodríguez y del mismo C. Castro. Empresas Tláloc o Tezcatlipoca, grabado iluminado a mano $33 \times 28 \mathrm{~cm}$. Colección Ing. Anselmo Carretero 73. Libro: Schola Italica Pintorae sive Selectae Quaedam. Summorum e Schola Italica Pictorum Tabulae Aere... Hamilton Pictoria. Romae Litográficas: Decaen México $50 \times 39 \mathrm{~cm}$. B. Picart-Liancourt 72. HuitzilopochtliCIC. 74. Libro: Caprichos de Goya. Colección de 150 estampas. Grabados al aguafuerte, con aguadas de resina 1868 75. Libro: Grabados sobre Roma, Desseine Francois Halina 1704. Amsterdam. Colección Alfonso Soto Soria. Kuni Sada 76. el bonzo, madera. Ho Ku Sai 77. abanico. Shun Yo Sai 78. Bonzo. Kuni Yoshi 79. Samurai, madera. Yoshi Tura 80. Dama, madera. Yoshi Nor 81. Serie "Los Caudillos" (28 láminas) madera. Toyo Kuni 82. mujer, madera. Uta Maru 83. pareja, madera. Toyokuni 84. personaje, madera. Kiyo Naga 85. Serenata, madera. Anónimo 86. Buda, impresión sobre tela. Colección Paul Antebi. Wateau 87. mujer sentada, aguafuerte. Horace Vernet 88. Mohamed Ali Pacha-Vise-Roi D'Egypte, litografía. Colección Instituto Nacional de Bellas Artes. José Guadalupe Posada 89. Calavera de Don Quijote, grabado en metal

J. TElio, F. CoRpus y J. Martínez Saucedo. Exposición de treinta obras, presentada por la Galería del Instituto de Arte de México, Puebla 141, el 14 de marzo. tipo.

Escribo estas lineas con la satisfacción de acompañar la obra primigenia de tres 
jóvenes artistas que viven su gran aventura de la creación plástica. No deseo adelantar un juicio que debe ser el resultado del encuentro que propicia esta exposición con la crítica y el público y que en mi caso no escaparía al entusiasmo que provoca este anhelo de tránsito y de búsqueda por esos mundos presentidos de la forma y el color en que el arte de nuestro tiempo ofrece tantas posibilidades de expresar.

La vida y la obra del artista muestra diversas etapas en las que manifiesta sus inquietudes, las influencias y aun las tendencias en las que a lo largo del existir va desarrollándose la personalidad. Los artistas que nos ocupan han participado ya en exposiciones colectivas y hasta recibido premios como recompensa a su talento; pero creo que en esta ocasión van a recoger valiosas experiencias que contribuirán a nuevas valoraciones, porque en esta confrontación individual es donde todo aquel que ha dedicado largas horas a la meditación estética y al trabajo en una entrega sincera y apasionada, se percata de lo que su obra transmite o comunica a los demás.

He aquí tres pintores que une el mismo paisaje y que hermana por ahora la misna idea de evadir la representación naturalista; pero tres seres que se distinguen entre sí por lo que ya subraya en cada cuadro su propio temperamento.

\section{Alfredo Guati Rojo}

Catálogo: 1. Via del Canto Rivolto 2. Faaone 3. Tautira 4. Moorea 5. picos saje 5. mecanización 6. el guerrillero 7. vida marina 8. retrato de una familia feliz 9. el hombre y el tiempo 10. el cosmonauta, Acrílicos 11. bosque 12. pensamiento 13. circulos con flores 14. flor con capullo 15. mariposa 16. raices 17. caracol 18. flores 19. semillas 20. pétalos 21. recuerdos 22. composición I 23. composición II 24. movimiento 25. flora 26. composición III 27 . composición IV 28. ciudad 29. rocas 30. vida de la ciudad.

ENRIQUE Miguel DE LA VEGA. Exposición de Esculturas, presentada por el Organismo de Promoción Internacional de Cultura, de la Secretaria de Relaciones Exteriores, Galería de Arte Teatro Casa de la Paz, Cozumel núm. 33, el 14 de marzo.

GRABADo EN MÉxico. Exposición Homenaje a Leopoldo Méndez, presentada por el Instituto Nacional de Bellas Artes (SEP) Galería José Ma. Velasco, Peralvillo 55, el 14 de marzo.

Nombre de los expositores: Ignacio Aguirre, David Alfaro Siqueiros, Carlos Alvarado Lang, Luis Arenal, Abelardo Avila, Octario Bajonero, Angelina Beloff, Alberto Beltrán, Angel Bracho, Celia Calderón, Susana Campos, Federico Cantú, Fernando Castro Pacheco, Elizabeth Callett, Erasto Cortés Juárez, Lola Cueto, José Luis Cuevas, Antonio Chávez C., Gonzalo de la Paz Pérez, Francisco Diaz de León, Francisco Dosanantes, Manuel Echauri, Arturo Estrada, Arturo Garcia Bustos, Carlos García Estrada, Lorenzo Guerrero, Manuel Herrera Cartalla, Elena Huerta, Javier Iñiguiz, Saral Jiménez, José Julio, Amador Lugo, Roberto Malfavón, Ma. Luisa Martín, Leopoldo Méndez, Adolfo Mexiac, Francisco Mora, Francisco Moreno Capdevila, Isidoro Ocampo, Pablo O'Higgins, Carlos Olachea, Trinidad Osorio, Mariano Paredes, Feliciano Peña, Angel Pichardo, León Plancarte, José Guadalupe Posada, Antonio Pujol, Adolfo Quinteros, Fanny Rabel, 
Everardo Ramirez, Benjamin Romero, Guillermo Silva Santamaria, Juan Soriano, Leticia Tarragó, Ma. Teresa Toral, Paulina Trejo, Fernando Vilchis, Mariana Yampolsky, Alfredo Zalce, Angel Zamarripa.

EXPosición Grupo de amigos DE LAS bellas artes. Presentada en las calles de Horacio núm. 1703, del 15 al 30 de marzo.

Nombre de los expositores: Dolores Danzig, Alfonso Dominguez, Enrique Echeverria, Elizabeth B. de León, Bernardo Navarro, Lee Parker, Ana Luisa Ramos Prida, Kirby Rogers, Saul Steinlauf. Escultores: Adir Ascalón, Gloria Benedetti Seneres, Armando Ortega, Socorro Ortega, Zipora. Nota: se presentarán 5 obras de cada artista.

EXPosición DEL LiBro ARGentino. Presentada por el Instituto Nacional de Bellas Artes, Embajada de la República Argentina, vestibulo del Palacio de Bellas Artes, el 17 de marzo.

Clemente lococo H. Exposición de obras presentada por la Galería Misrachi, Londres 158 , del 18 de marzo al 11 de abril.

Catálogo: 1. Vía del Canto Rivolto 2. Faaone 3. Tautiva 4. Moorea 5. picos de Moorea 6. tormenta 7. frascos de laboratoiro 8. ananás y frutas 9. hojas secas y frutas 10. agapanthus 11. jacarandaes 12. maraña 13. bosque luminoso 14. ritmos en verde 15. ceibos en dia gris 16. oscuros y claros 17. bosque de miramar 18. en el barrio de la boca 19. hacia lo alto 20. desde el balcón 21. Vallata del Dragone 22. casa de pescadores 23. salumeria 24. arco naturale 25. Ses negres 26 , calle del rio.

LA MUjer en LAS artes plásticas DE MÉxico. Exposición presentada por el Departamento del Distrito Federal, Dirección General de Acción Social, Galerias de la ciudad de México, en el Centro Social Popular Leandro Valle, Sur 8 y Oriente 241, Col. Agricola Oriental, del 19 de marzo al 12 de abril.

Expositores: Sofia Bassi, Celia Calderón, Beatriz Caso de Solórzano, Dina Frumin, Silvia H. de González, Angela Gurria, Macrina Krauss, Julia López, Rina Lazo, Fanny Rabel, Leni de Servin, Lupe Sierra, Leticia Tarragó, Beatriz Zamora.

RUDOLF RAY. Exposición de pintura, paisajes anímicos (soulscapes), presentada por el Instituto Nacional de Bellas Artes, Sala Internacional, Galerías del Palacio de Bellas Artes, el 19 de marzo.

10 pintores mexicanos. Exposición presentada por el Comité de Actividades Generales del Centro Deportivo Israelita, Av. Manuel Ávila Camacho 620, Lomas de Sotelo, del 20 de marzo al 20 de abril.

Nombre de los expositores: Carrillo, Coen, Corzas, Felguérez, García Ponce, Gironella, Ramirez, Rojo, Toledo, Von Gunten.

ÁNGEL BoLIver. Exposición de pinturas, presentada por el Instituto Nacional de Bellas Artes (SEP), Salón de la Plástica Mexicana, Havre núm. 7, del 24 de marzo al 14 de abril. 
MaRILyN. Exposición presentada por la Dirección General de Difusión Cultural (UNAM), Galería Universitaria Aristos, Locales 1 y 2 del Edificio C. del Conjunto Aristos, Insurgentes Sur 421, el 26 de marzo.

Augusto pecors. Exposición de tapices del Brasil, presentada por el Organismo de Promoción Internacional de Cultura, de la Secretaría de Relaciones Exteriores y la Embajada de la República Federativa de Brasil en México, Sala de Arte Opic, Av. Juárez 42, el 26 de marzo.

exploraciones EN EL CENote SAgRado de chichén itzÁ. Exposición Temporal, presentada por el Museo Nacional de Antropología (INAH). SEP, el 28 de marzo.

$1^{2}$ Exposición internacional de instrumentos musicales. Presentada por el Instituto Nacional de Bellas Artes, Galerias del Palacio de Bellas Artes, Salas 4 y 5 , durante los meses de marzo a abril.

Catálogo: atemania 1. Acordeón Höhner modelo Morino $V$. Casa Veerkamp, S. A. 2. Cembalet, piano electrónico. Casa Veerkamp, S. A. 3. Citara, Casa Veerkamp, S. A. 4. Clarinete Schreiber sistema Boehm de 17 llaves y 6 anillo. Embajada de la República Federal de Alemania 5. Contrabajo electrónico Framus. Casa Veerkamp, S. A. 6. Contrabajo alemán. Casa Veerkamp, $S . A .7$. Corno doble en Fa y Sib marca Hücttl Majestic. Casa Veerkamp. S. A. 8. Cuarteto de flautas dulces. Embajada de la República Federal de Alemania 9. Fagot Schreiber sistema Hecke. Casa Veerkamp. S. A. 10. Flauta travesera barroca. Colección Roberto Rivera y Rivera 11. Guitarra electrónica Framus. Casa Veerkamp, S. A. 12. Instrumental para el sistema de enseñanza musical de Karl Orff. Embajada de la República Federal de Alenania 13. Laúd alemán, Embajada de la República Federal de Alemania 14. Laúd alemán. Casa Veerkamp, $S$. A. 15. Melódica "alto", marca Höhner. Casa Veerkamp, S. A. 16. Melódica "piano", marca Höhner. Casa Veerkamp, $S$. A. 17. Organo de boca, marca Höhner. Casa Veerkamp, S. A. 18. Organo electrónico con pedal de volumen y pedalier, marca Höhner modelo Symphonic. Casa Veerkamp, S. A. 19. Orlo o Cromorlo "alto". Colección Roberto Rivera y Rivera 20. Sousafón en Do y Sib, Marca Majestic. Casa Veerkamp, S. A. 21. Viola Höfner. Embajada de la República Federal de Alemania 22. Viola alemana. Embajada de la República Federal de Alemania 23. Violin Höfner. Embajada de la República Federal de Alemania 24. Violonchelo Höfner. Embajada de la República Federal de Alemania 25. Colección "Música Instrumental" (fotomurales). Embajada de la República Federal de Alemania. austratia 26. Didgeridoo. Embajada de Austria. BRasit 27. Agogo. Embajada de Brasil 28. Berimbau de barriga. Enbajada de Brasil 29. Cuica. Embajada de Brasil 30. Pandeiro. Embajada de Brasil 31. Reco-Reco. Embajada de Brasil 32. Afuche Embajada de Brasil. CAMBOYA 33. Insirumento monocore con arco. Colección Juan José Osorio. CoLombia 34. Cuatro. Embajada de Colombia. cuBA 35. Abre, Chequeré o Güiro. Fmbajada de Cuba 36. Bongó. Embajada de Cuba 37. Claves. Embajada de Cuba 38. Guitarra, Embajada de Cuba 39. Marimbula. Embajada de Cuba 40. Tambor Batá. Embajada de Cuba 41. Tres cubano. Embajada de Cuba 42. Tumbadora. Embajada de Cuba. Cinrcoslovaquia 43. Cimbal. Embajada de Checoslovaquia 44. Dudy. Embajada de Checoslovaquia 45. Flauta. Museo de las Culturas. INAH 46. Flauta. Museo de las Culturas. INAH 47. Fletna, Embajada de Checoslovaquia. cHINA 48. Cheng. Embajada de China 49. Da-lo. Embajada de China 50. Erh-hu. Embajada de China 51. Hu-ch'in. Embajada de China 52. Kuan. Embajada de China 53. Kwang-shiao. Embajada de China 54. P'i P'a. Embajada de China 55. San-Hsien. Embajada de China 56. Sheng. Embajada de China 57. Tang-ku. Embajada de China 58. Ti-tze. Embajada de China 59. Yueh-ch'in. Embajada de China. espaÑa 60. Bajón o Sordón bajo. Colección Roberto Rivera y Rivera 61. Bandurria. Casa Veerkamp, S. A. 
62. Gaita. Centro Gallego de México, A. C. 63. Laúd español. Casa Veerkamp, S. A. 64. Pandeiro. Centro Gallego de México, A. C. 65. Pandereta. Centro Gallego de México, $A$. C. 66. Timple canario. Colección INBA 67. Viciras. Contro Gallego de México, $A$. C. 68. Viola de rueda. Colección Roberto Rivera y Rivera 69. Txistu. Círculo Vasco Español, A. C. estanos unidos 70. Banjo. Casa Veerkamp, S. A. 71. Bateria, marca Rogers. Casa Veerkamp, S. A. 72. Flauta de bambu, de la tribu Sioux. Colección INBA 73. Ili-Ili, piedras sonoras de Hazvai. Colccción Alicia Molina de Cabrera 74. Ipu, de Hawai. Colección Alicia Molina de Cabrera 75. Kala-an, de Hawai. Colección Alicia Molina de Cabrera 76. Lapa, de Samoa. Colección Alicia Molina de Cabrera 77. Puili, de Hawai. Colección Alicia Molina de Cabrera 78. Trombón de varas. Casa Veerkamp, S. A. 79. Trompeta, marca Conn. Casa Veerkamp, S. A. 80. Ukulele. Casa Veerkamp, S. A. 81. Uli-Uli, de Hawai. Colección Alicia Molina de Cabrera. eTTopía 82. Flauta de caña. Embajada Imperial de Etiopía 83. Flanta de caña. Embajada Imperial de Etiopia 84. Flauta de caña. Embajada Imperial de Etiopia 85. Lira de madera, piel y esmalte. Embajada Imperial de Etiopia 86. Lira Embajada Inperial de Etiopia 87. Lira de 10 cuerdas. Embajada Imperial de Etiopia 88. Masinko. Embajada Imperial de Etiopía 89. Masinko. Embajada Imperial de Etiopía 90. Masinko. Embajada Imperial de Etiopia 91. Masinko. Embajada Imperial de Etiopía 92. Tambores de cerámica y piel Einbajada Imperial de Etiopía 93. Tambor de metal y cuero. Embajada Imperial de Etiopía 94. Tambor Kokima. Embajada Imperial de Etiopia 95. Tambor de madera y piel. Embajada Imperial de Etiopia 96. Tambor de madera y piel. Embajada Imperial de Etiopia. Finlandia 97. Kantele, Embajada de Finlandia. Francia 98. Clarinete alto, marca Selmer, Paris. Casa Veerkamp, S. A. 99. Corno inglés, marca Cabart modelo Conservatoire, Paris. Casa Veerkamp, S. A. 100. Flauta Selmer, Paris, Casa Veerkamp, S. A. 101. Oboe Thibouville Cabart, París, Casa Veerkamp, S. A. 102. Oboe barroco. Colección Roberto Rivera y Rivera 103. Ondas Martenot, Paris 1969. Colección INBA. 104. Piano Erard, mim. 2731. Colección José Antillón 105. Pochette, París 1690. Colección INBA 106. Saxofón barítono, marca Selmer, París. Casa Veerkamp, S. A. 107. Saxofón soprano en Sib, marca Selmer, Paris, Casa Veerkamp, S. A. 108. Tambor provenzal. Colección Carlos Luyando. GHANA 109. Instrumentos cordófono. Colección Museo de las Culturas, INAH 110. Instrumentos cordófono. Colección Museo de las Culturas, INAH 111. Tambor. Embajada de la República de Ghana 112. Tambor. Colección Museo de las Culturas, INAH. GRAN BRETANA 113. Bagpipes. Embajada de Gran Bretaña 114. Flauta de Pan inglesa de fines del siglo XIX. Colección INBA 115. Piano cuadrilongo, marca Muzio Clementi y Cía, num. 26, Cheapside, London. Colección José Antillón 116. Trompeta heráldica de fines del siglo VII. Colección INBA. HAITí 117. Tambor. Embajada de Haití. INDIA 118. Flauta alto. Colección José Guerrero 119. Flauta soprano. Colección José Guerrero 120. Instrumento aerófono libre. Colección Museo de las Culturas, INAH 121. Sârangî́. Colección Museo de las Culturas. INAH 122. Tabla (Par de tanobres). Colección Yolotl González de Lezur 123. Tumbura. Colección Museo de las Culturas, INAH. IsRaEL 124. Argul. Embajada de Israel 125. Darbuka. Embajada de Israel 126. Hod. Embajada de Israel 127. Shofar. Embajada de Israel. ITALIA 128. Corneta recta renacentista. Colección Roberto Rivera y Rivera 129. Mandolina. Colección INBA 130. Spinetta. Fabricada en México en el taller de Martín Seidel. méxico 131. Arpa de dieciseisavos de tono. Colección $y$ creación de Julián Carrillo 132. Arpa-mandolina. Creación y manufactura de Bandelio García 133. Arpa virreinal. Colección INBA 134. Caja de afinación en forma de guitarra, que sirve como tal, con 29 sonidos en la octava. Creación $y$ manufactura de Augusto Novaro 135. Donovar. Creación y manufactura de Augusto Novaro 136. Guibarrón. Creación y manufactura de Mariano Barrón 137. Huéhuetl precortesiano. Colección Amalia Millán 138. Lanozar. Creación y mamufactura de Augusto Novaro 139. Minovar. Creación y mamufactura de Augusto Novaro 141. Octazina. Colección y creación de Julián Carrillo 142. Piano de dieciseisavos de tono. Colección y creación de Julián Carrillo 143. Teponaxtle. 
(Reproducción de un modelo prehispánico). Colección INBA 144. Violo. Creación y manufactura de Baudelio García. NORUEGA 145. Hardingfele. Real Embajada de Noruega 146. Lur. Real Embajada de Noruega 147. Munnharpe. Real Embajada de Noruega. PAÍses BAJos 148. Hari Kawina, tambor de Surinam. Embajada Real de los Paises Bajos 149. Hari seki-seki, sonaja de Surinam. Embajada Real de los Países Bajos 150. Koti Kawina, tambor de Surinam. Embajada Real de los Paises Bajos 151. Koti seki-seki, sonaja de Surinam. Embajada Real de los Países Bajos 152. Kwakwa bangi, instrumento percutor de Surinam. Embajada Real de los Países Bajos 153. Midwinterhoorn, instrumento aerófono holandés. Embajada Real de los Países Bajos perú 154. Carachunchu. Colección Amalia Hernández 155. Quena. Colección José Guerrero. Rumania 156. Nai. Colección Museo de las Culturas, INAH 157. Siringa. Colección Museo de las Culturas, INAH 157. a. Pandereta gitana. Colección Carlos Luyando 157 b. Salterio. Casa Veerkamp, S. A. SENEGAL 158. Raspador. Embajada de Senegal 159. Tamborcillo. Embajada de Senegal. suecia 160. Nyckelharpa (Tiorba) Real Embajada de Suecia. Turqufa 161. Crótalos. Casa Veerkamp, S. A. 162. Flauta de pico de Esmirna. Colección Carmen Sordo Sodi 163. Laúd malati de Estambul. Colección Carmen Sordo Sodi 164. Platillos para banda. Casa Veerkamp, S. $A$. venezuela 165. Arpa criolla. Embajada de Venezuela 166. Cuatro de 4 cuerdas. Embajada de Venezuela 167. Cuatro doble. Embajada de Venezuela 168. Mandolina del tipo del cuatro. Embajada de Venezuela 169. Maracas. Embajada de Venezuela 170. Minas. Embajada de Venezuela. zambia 171. Sonaja. Colección INBA 172. Sonaja del brujo o del "shaman". Colección INBA 173. Tamborcillo ritual. Colección INBA.

romeo tabuena. Exposición presentada por la Tasende's Gallery, Calzada Costera M. Alemán y V. Yáñez Pinzón, Acapulco, Gro., durante el mes de marzo.

ABR1L

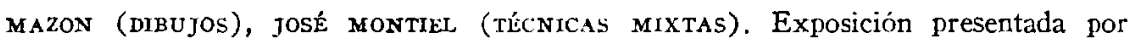
el Instituto Nacional de Bellas Artes, Galeria Chapultepec, Insurgentes sur 11 bis, el 8 de abril.

julıo montes. Exposición presentada por el Instituto Francés de América Latina. Nazas 43, el 8 de abril.

Catálogo: 1. la virgen teje pañales con rayos de luna clara, óleo 2. el camino del miedo, óleo 3. Sodoma, la ciudad avergonsada, tintas imprenta 4. noveno círculo del infierno, tintas imprenta 5. la luna mira curiosa, tintas imprenta 6 . en Bankgok se vende un rio, tintas imprenta 7. la anunciación, tintas imprenta 8. proyección de Adán y Eva, tintas imprenta 9. Monólogo de Medea tintas imprenta 10. entre el Eufrates y el Tigris, tintas imprenta 11. la piedra labra un paisaje, tintas imprenta 12. la caricia del estío, está matando la nieve, tintas imprenta 13. en donde se oculta el miedo, tintas imprenta 14. a Taxco, le falta un mar, tintas imprenta 15. un atrio para la yerba, tintas imprenta 16. la luna anclada en el Puerto, tintas imprenta 17. con un ambiente de cólera, tintas imprenta 18. el rio, historiador de siglos y de ciudades, tintas imprenta 19. y, legó una Náo China, tintas imprenta 20 . diálogo de don Quijote y los molinos sin brazos, tintas imprenta 21. Adán, Eva, y... la sorpresa, tintas imprenta 22. hacia el norte de los mares, tintas imprenta 23 . olas de piedra, tintas imprenta 24 . el pueblo verde, tintas imprenta 25. la llaman la costa azul, tintas imprenta 26. un pueblo para una cantera, tintas imprenta 27 . en la región de los lagos, tintas imprenta 28. ensueño y realidad de los violetas, tintas imprenta 29. luz espectral; tintas imprenta 30 . la presa ahoga al pueblo, tintas imprenta 31. paisaje angustiado para Semana Santa, tintas imprenta 32. manifestación de violencia, tintas imprenta 33. poesia del agua, tintas imprenta 34. marquetería, tintas imprenta 
35. el mezquital, sólo el agua de su llanto, tintas imprenta 36. el Samuray perdido, tintas imprenta 37. cuando el agua se hace hiclo, tintas imprenta 38. cuando el agua se hace hillo, tintas imprenta 39. donde emprenden sa huida los arroyos, óleo 40. el río habla con gentc, tintas imprenta.

SALVADOR ORTIz. Exposición de fotografías en color, presentada por el Instituto Francés de América Latina, Nazas 43, del 9 al 25 de abril.

EL gRabado intTiRnacional. siglo xx. Exposición presentada por el Museo Liniversi. tario de Ciencias y Artes, UNAM. Dirección General de Difusión Cultural, Depto. de Artes Plásticas, del 9 de abril al 15 de mayo.

La presente Exposición Internacional de Grabado del Siglo XX estuvo prececlitlat por otra sobre semejante asunto, pero dedicada a los siglos xvrri y xix, de manera que las dos, en conjunto, forman una amplia visión sobre esa injportante rama de la listoria del arte.

En los íltimos tiempos se ha venido considerando dentro del grabado en general a la litografía, si bien son artes cuyos procedimientos las hacen diferentes, en cuanto a las técnicas. El grabado tradicional, ya sea en madera o en lámina, éste llamado también "de talla dulce", ha tenido su propia evolución, y así también la litografía, hasta llegar a las reproducciones mecánicas.

Uno de los aspectos más interesantes de la presente exposición es la variedid de técnicas desarrolladas por los artistas del siglo $\mathrm{xx}$. Tal parece que así como no se lan conformado con, antes han rechazado, los conceptos tradicionales del arte, también en los aspectos técnicos han buscado y logrado nuevas posibiliclades expresivas.

Es de lo más sugestivo contemplar, por el lado de la creación misma, las formas naciclas en nuestro siglo, que van desde las libertades postacalémicas hasta las abstractas, con toda clase de combinaciones intermedias entre las que se encuentra un poético expresionismo.

En cuanto a los temas pucde decirse que aparecen en variedad tal que reflejan la vida misma, pues los laay dramáticos, trágicos, líricos, de sentido político-social $y$ en general, de interés humanista.

Se han reunido en esta exposición obras europeas, anglo e lispanoamericanas y de otras partes, nas es interesante constatar la excelente calidad de este acervo de grabados y litografías, lo que indica que, además de tratarse de artistas de valía, existe un cierto cspiritu verdaderamente internacional en cuanto a los varios conceptos del arte de nuestro tiempo.

Los grabados mexicanos lucen, por su propia categoría y dramatismo, a la altura de los mejores. Se advierte, por otra parte, que los artistas, siendo por lo general sabios y sensibles en el uso del color, no lo hayan empleado con la profusión y el encanto con que lo han hecho los extranjeros. Ello se debe, quizá, a que se lian ateniclo más bien al señero concepto tradicional de la técnica del grabado, ya sea en madera o en metal. Ha sido Tamayo el primero que se ha expresado nuyormente en litografías a color: de Siqueiros pueden verse en esta exposición algums muestras magníficas en esa técnica. El grupo de grabados del gran artista recientemente desapareciclo, Leopoldo Méndez, es prueba de su fuerza expresiva; la serie de Francisco Díaz de León tiene la sabiduría y delicadeza propias de su personat- 
lidad; estas cualidades se encuentran también en los grabados de Carlos Alvararlo Lang.

No sería posible reunir obras de todos los artistas del siglo $\mathrm{xx}$ que ya sea exclusiva $u$ ocasionalmente se han expresado en el grabado o en la litografía, sin embargo en la exposición están representados muchos de los más importantes. Bastan los nombres de Orozco, maestro insigne en las artes gráficas tanto como en la pintura; de Rivera, cuyo autorretrato en litografía es excelente; de Picatsso, maestro en las más variadas técnicas $y$ disciplinas, para dar prestigio a cualquier colección. Sería largo considerar a otros maestros cuyos nombres se elıcontrarán en el catálogo, no obstante hay que mencionar siquiera a Dufy, a Léger, a Carzou.

El acervo de obras de grabado y litografía que se exlibe en esta exposición es de la más alta categoria y permite al espectador cobrar conciencia de gran marte de la producción de nuestro siglo.

\section{Justino Fernindez}

Catálogo: Aguilar, Roger. 1. serie de siameses III, litografía, col. Sr. Orlando Suárez 2. después del desastre IV, litografía, col. Sr. Orlando Suárez. Aguilera Vicente, José Julián 3. Avance, litografía, col. Sra. Raquel Tibol. Aguirre, Ignacio 4. soldaleras, linóleo, eol. Instituto Nacional de Bellas Artes 5. Emiliano Zapata, linóleo col. Instituto Nacional de Bellas Artes. Nicasio Aguirre 6. amor, litografía, col. Sr. Orlando Suárez. David Alfaro Siqueiros 7. vértigo, litografía a color, col. del artista 8. sin titulo, grabado, col. Sra. Raquel Tibol 9. sin título, grabado, col. Sra. Raquel Tibol 10. mujer arrodillada, litografía, a cotor, col. Sra. Teresa Feibelman 11. Zapata, grabado metal, col. Galerías Mer-Kup 12. El centauro de la conquista, grabado metal, col. Galerias Mer-Kup 13. cobeza de Moisés Sáenz, grabado metal. col. Galerías Mer-Kup 14. madre con miño, litografía a color, col. del artista 15. mujer, litografía a color, col. del artista 16. bailarina, litografía a color, col, del artista. René Alis 17. paisaje hunar, monografía técnica mixta, col. Galerías Mer-Kup 18. estructura, monografia, técnica mixta, col. Galerías Mer-Kup. Francisco Almonasi 19. anhelo, linografia, col. Taller de la Gráfica Popular 20. lucha, linografía, col. Taller de la Gráfica Popular. Harold Altman 21, parque con figuras, metal, col. Sr. Fredrik Kirsebon 22. caminante, metal, col. Fredrik Kirsebon. Carlos Alvarado Lang 23. res muerta. linóleo, col. Instituto Nacional de Bellas Artes 24. cedros, linóleo, col. Instituto Nacional de Bellas Artes. Jestis Alvarez Amaya 25. la muerte joven, linografia, col. Taller de la Gráfica Popular 26, astronauta, xilografía, col. Taller de la Gráfica Popular. E. Amero 27. muchacha de Tehuantepec, grabado en madera, col. Galería de Arte Mexicano José Arellano Fischer 28. los enamorados, metal, aguatinta y buril, col. Instituto Nacional de Bellas Artes 29. figura junto a $l$ i ventana, metal, aguatina y buril, col. Instituto Nacional de Bellas Artes. Aremal, Luis 30. Cabeza de mujer, litografía, col. Instituto Nacional de Bellas Artes 31. la guerra, litografía, col. Instituto Nacional de Bellas Artes. Gustavo Arias Mulrueta 32. imágenes, intaglio, centro experimental de Arte Gráfica 33. la ciudad destruida, monotipo, col. Centro Experimental de Arte Gráfico. Doroteo Arnóis 34. el búho, aguafuerte, col. OPIC 35. bajo relieve, aguafuerte, col. OPIC 36 . tortura, aguafuerte, col. OPIC 37. sueño, aguafuerte, col. OPIC 38. cíclope, aguafuerte, col. OPIC. Raúl Anguiano 39. inujer sacándose una espina, litografía, Sra. Teresa Feibelman 40. sin título, litografía, col. Margarita Nelken 41. los chapulines, aguafuerte, col. taller Mario Reyes. Marina Anguiano 42. los dedos andantes, aguafuerte a color, col. taller Mario Reyes 43. elevación de cristo, agtaifuerte a color, col. taller Mario Reyes. Pedro Arrate González 44. victimas de la guerra, litografía, col. Raquel Tibol. Jean Michel Atlan 45. sin título, litografía, col. Juan Martín. Ugo Attardi 46. tiempo de furia, litografía, col. Raquel Tiboi 47. recuerdo del erotismo, litografía, col. Raquel Tibol 48, lo amarraron al árbol, litografía, col. Raquel Tibol. Milton Aupry 49. hombre, metal aguafuerte, col. 
Alfonso Soto Soria. A. Avila 50. troncos, grabado, col. Galerías Mer-Kup. Octavio Bajonero 51. en el mes del conejo, grabado en madera a cinco tintas, col. Sra. Teresa Feibelman. Yannik Ballit 52. el agua, aguafuerte, col. OPIC 53. Hyaster $I$, aguafuerte, col. OPIC 54. comabte, aguafuerte, col. OPIC 55. bajo el bosque, aguafuerte, col. OPIC 56. separación, aguafuerte, col. OPIC. Orlando Barral 57. maternidad, aguafuerte y aguatinta, col. OPIC. Teresa Basave 58. amanecer, taller Mario Reyes 59. baño de vapor, aguafuerte, col. taller Mario Reyes. Sofía Bassi 60. desolación, monotipo, col. Galerías Mer-Kup 61. viuda negra, monotipo, col. Galerías Mer-Kup 62. sin título, grabado en metal, col. Margarita Nelken, prop. Sra. Margarita Salas de Rivas. Angelina Beloff 63. la escalera, linóleo col. Instituto Nacional de Bellas Artes 64. bajo la lluvia, linóleo col. Instituto Nacional de Bellas Artes 65. los monotes, grabado linóleo, col. Margarita Nelken, prop. Sra, Margarita Salas de Rivas. Amold Belkin 66. TripticoSerie California, litografía a color, col. Galería Misrachi. Alberto Beltrán 67. Manuela Sánchez, linóleo, col. Instituto Nacional de Bellas Artes 68. entrega de poderes indigenas, linóleo, col. Instituto Nacional de Bellas Artes 69. la tierra, linóleo, col. Instituto Nacional de Bellas Artes 70. el éxodo, linóleo, col. Instituto Nacional de Bellas Artes 71. intentos de la dictadura de Victoriano Huerta de liquidar el Zapatismo, linóleo, col. Instituto Nacional de Bellas Artes 72. persecución del partido liberal por el régimen porfiristo, linóleo, col. Instituto Nacional de Bellas Artes. Roberto Berdecio 73. sin título, intaglio, col. del artista. Lena Berger 74. paisaje pedregal, grabado en linóleo, col. Leopoldo Méndez. Antonio Berni 75. Raniona bailarina, grabado metal, col. OPIC 76. Ramona se pone las medias, grabado, col. OPIC 77. pan y vino, grabado, col. OPIC 78 Ramona en el escenario. grabado metal, col OPIC 79. Ramona baila el tango. grabado metal, col. OPIC. Aldo Biglione 80 . preparando la riña, grabado metal, col. OPIC 81. muchos globos para los hijos de Pedro Changa, grabado metal, col. OPIC 82. desalojaron a Pedro Changa, grabado metal, col. OPIC 83. los que fueron postergados, grabado madera, col. OPIC 84. consultorio de la curandera, grabado metal, col. OPIC 85. después de la milonga, grabado, col. OPIC 86. tocado quenas, grabado, col. OPIC 87. la familia de Pedro Changa, grabado. col. OPIC 88. milonga en el conventillo, grabado, col. OPIC 89. tirando las cartas, grabado madera, col. OPIC 90. y zan cuatro lunas, grabado, col. OPIC Bonnard 91. escena campestre, grabado metal, col. Sra. Teresa Feibelman. Robert Block 92, muestro jardin salvaje, punta seca, col. Margarita Nelken. Iuan Boza 93. imágenes inclinadas de un radar, litografía, col. Orlando Suárez 94. sin título, litografía, col. Orlando Suárez. Angel Bracho 95. la niña Virginia Martínez, grabado en linóleo a color, col. Instituto Nacional de Bellas Artes 96. las rocas, grabado a tres tintas, col. Manuel Alvarez Bravo 97. Amistad con Guatemala, grabado a color, col. Instituto Nacional de Bellas Artes 98. Lombardo Toledano, linografía, col. taller de la gráfica popular 99. el chiclero, grabado a color, col. taller de la gráfica popular. Ennio Calabria 100. Africa, litografía, col. Raquel Tibol 101. no le gustaba, litografía, col. Raquel Tibol 102. pesadilla, litografía, col. Raquel Tibol. Celia Calderón 103. en busca de un camino, metal, col. Galeria Arte Mexicano 104. fuera de las sombras, intaglio col. Galería Arte Mexicano. Hilda Campillo 105. sin titulo, intaglio, col. taller Mario Reyes 106. ¿cuál problema?, aguatinta, col. taller Mario Reyes. Siusana Campos 107. sin titulo, grabado metal, col. Margarita Nelken prop. Margarita Salas de Rivas 108. paisajc urbano IV, grabado metal, col. Galerías Mer-Kup. Antonio Canct 109. Che, litografía, col. Sr. Orlando Suárez 110. paisaje en $P$., litografía col. Sr. Orlando Suárez. Federico Cantú 111. Cristo llevado por los ángeles, buril, cól. Instituto Nacional de Bellas Artes 112. ceres, punta seca. col. Galería Arte Mexicano 113. ángel tocando el cello, buril, col. Galeria Arte Mexicano 114. tríptico-Aurelia, grabado metal, col. Galería Misrachi 115. Moirés, grabado metal, col. Galeria Misrachi 116. pequeña huida a Egipto, grabado metal, col. Galería Misrachi Giulia Cardinale 117. laguna, aguafuerte y aguatinta, col. Margarita Nelken Prop. Margarita Salas de Rivas 118, pueblo de los reyes, grabado aguafuerte, col. Margarita Nelken, Prop. Margarita Salas de Rivas. Ican Caroou 119. Salomé, 
litografía en seis colores, col. Lic. Luis Carral y de 'Teresa 120. vence, litografía en seis colores, col. Lic. Luis Carral de Teresa 121. cartel para la exposición de Carzou, litografía en seis colores, col. Lic. Luis Carral y de Teresa 122. la bretona, litografía en diez colores, col. Lic. Luis Carral y de Teresa 123. Venice Le Zaterre, litografía en cuatro colores, col. Lic. Luis Carral y de Teresa. Vita Castro 124. pidiendo auxilio, aguafuerte aguatina, col. Galería Arte Mexicano 125. cascada, linóleo, col. Galería Arte Mexicano 126. cerro del aire, litografía, col. Galería Arte Mexicano. Fernando Castro Pacheco 127. figura, litografía, col. Galerias Mer-Kup 128. naturaleza muerta, litografía, col. Galerías Mer-Kup. Guillermo Ceniceros 129. paisaje en llamas, linóleo, col. del artista 130. mujer y tierra, linóleo, col. del artista. Eduardo Cerviño 131. cabeźa sideral I, litografía, col. Sr. Orlando Suárez 132. pareja sideral, litografía, col. Sr. Orlando Suárez. Josef Cielniak 133. viaje alrededor de una hoja de temperatura, litografía a tinta. col. OPIC 134. dedicad oa S. K. Dawaki, litografía a tinta, col. OPIC Clavé 135. sin titulo, litografía, col. Jorge Foechtwanger. H. Collins 136. sin título, litografía, col. Taller de la Gráfica Popular. José Contino 137. serie tradición (1) litografia, col. Sr. Orlando Suárez 138. serie tradición (2), litografía, col. Sr. Orlando Suárez $G$. Constant 139. naturaleza muerta, punta seca, col. Alfonso Soto Soria. Erasto Cortés Juárez 140. árboles, litografía, col. Instituto Nacional de Bellas Artes 141. el guerrillero Aurelio Rivera madera, col. Instituto Nacional de Bellas Artes 142. rancho sinaloense, linóleo, col. Galería Arte Mexicano. Carlos Cuéllar 143. maternidad, aguafuerte, col. Galeria Arte Mexicano 144. hombre en la cárcel, aguafuerte y aguatinta, col. Galería Arte Mexicano 145. figura núm: 2, metal aguafuerte, col. Galería Arte Mexicano. Dolores Cueto 146. figura de carnaval, metal, col. Instituto Nacional de Bellas Artes 147. animal fantástico, mesotinta, col. Instituto Nacional de Bellas Artes. José Luis Cuevas 148, estudio, litografía, col. Margarita Nelken, Prop. Margarita Salas de Rivas 149. Borgia. litografía, col. del Artista 150. historia del crimen, litografía, col. del artista Luis Chacón 151. niño con palonta, grabado a color, col. Taller de la Gráfica Popular 152. madres, grabado a color, col. Taller de la Gráfica Popular Marc Chagal 153. los novios, litografía a color, col. Sra. Lore Stavenhagen 154. ilustración para las fábulas de Lafontaine, edición especial (4 láminas) metal aguafuerte, col. Sra. Teresa Feibelman 155. Ecuycre, grabado mental, col. Sra. Teresa Feibelman 156. Pascual Cordero, aguafuerte. col. Manuel Alvarez Bravo 157. el sena, litografía, col. Jorge Foechtwanger 158, sin titulo, grabado metal, col. Sr. Jorge Foechtwanger. France Chancellor 159. el mensaje del pájaro, grabado, col. Galerías MerKup 160. Budoha, grabado, col. Galerías Mer-Kup. Jean Charlot 161. los primeros pasos (1) litografía, col. Instituto Nacional de Bellas Artes 162. los primeros pasos (2), litografía a color, col. Instituto Nacional de Bellas Artes 163. la cocina mexicana, litografía a color, col. Instituto Nacional de Bellas Artes 164. la lección de tortillas, litografía a color, col. Instituto Nacional de Bellas Artes 165. Zapatos domingueros, litografía a color, col. Instituto Nacional de Bellas Artes 166. preparándose para la danza, litografía a color. Col. Instituto Nacional de Bellas Artes 167. regreso del mercado, litografía a color, col. Instituto Nacional de Bellas Artes 168. peregrinos de Chalma, litografía a color, col. Instituto Nacional de Bellas Artes 169. descanso y trabajo, litografía, col. Instituto Nacional de Bellas Artes. Lourdes Chávez 170 , ritmo, metal, centro experimental de Arte Gráfico, Santos Cháves 171. un hombre en la playa, xilografía, col. OPIC 172, ausencia, xilografía, col. OPIC 173. buscando plantas del bien, xilografía, col. OPIC 174. niña, xilografía, col. OPIC 175. el beso, xilografía, col. OPIC 176. cabrita jugando con el viento, xilografía, col. OPIC 177. paloma alerta, xilografía, col. OPIC 178. creador de la vida, xilografía, col. OPIC 179. nace un sol, xilografía, col. OPIC José Chávez Morado 180. la ciudad de México, litografía, col. Instituto Nacional de Bellas Artes 181. Ia indomable América Latina, linóleo, col. Instituto Nacional de Bellas Artes. Halina Chrostozuska 182. las jarras, aguatinta y buril, col. OPIC 183. el hombre y los pájaros, aguatinta y buril, col. OPIC. Sal. vador Dali 184. litografía para ilustración de los cuentos de Andersen, col. Galeríi Juan Martín. Stanislaw Dawaki 185. K.S.A., grabado madera de hilo, col. OPIC. 
Sonia Delaunay 186. sin título, litografía a color, col. Sra. Dominique Grifouller. Hernóndes Delgadillo 187. sin título. aguatinta y aguafuerte, col. Margarita Nelken, prop. Sra. Margarita Salas de Rivas. Victor Delhez 188. "cordillera", estudio sin apoyo, madera, col. Instituto Nacional de Bellas Artes 189. retrato de Juan Manuel Acevedo, madera, col. Instituto Nacional de Bellas Artes. Gonsalo del Pozo 190. cintuón de castidad, aguafuerte, col. taller Mario Reyes 191. sueño inquieto, aguafuerte, col. taller Mario Reyes. Francisco Díaz de León 192. mujer en reposo, punta seca, col. del artista 193. maternidad, madera de hilo, col. del artista 194 crepúsculo en la Candelaria, aguafuerte con aguatintá, col. del artista 195 , en mi jardis, litografía, col. del artista 196. en el mercado, aguatinta, col. del artista 197. borracko con un perro, madera de pie, col. del artista 198, sueño de un marilutano, madera de pie, col. del artista. Luis Díaz Maurisset 199. sin titulo, grabado, col. Sra. Raquel Tibol. Otto Dix 200. niña scutada, litografía a color, col. Sra. Teresa Feibelman 201. gallo y gato, litografía a color. col. Sra. Teresa Feibelman. Domanguez 202. sin título, litografía a color, col. Sr. Jorge Foechtwanger. Francisco Dosamantes 203. mujeres zeracruzanas. litografía, col. Galería Arte Mexicano 204. inmigrantes, litografía a color, col. Galería Arte Mexicano 205. paisaic estratasférico, litografía a color, col. Galería Arte Mexicano. Dragutescu 206. sin títwlo, grabado en metal, aguafuerte, col. Margarita Nelkell, prop. Sra. Margarita Salas de Rivas. Raoul Dufy 207. sin titulo, grabado metal, col. Lic. Luis Carral y de Teresa. Jean Dufy 208. escena de circo, litografía a color, col. Sra. Teresa Feibelnan. Felipe Ehrenberg 209. andante exressino ad Libitum (en 3 hojas) stencil de fibracel impreso, col. del' artista 210. allegro quicto sempre ligato (en 3 hojas) stencil de fibracel impreso, col. del artista Max Ermst 211. ilustración del libro "El arte de ver el arte", aguafuerte, col. Sra. Teresa Feibelmaln. Jesuis Liscobedo 212. la noche, litografía, col. Mamel Alvarez Bravo 213. autorretrato, litogtafía col. Galería Arte Mexicano. A. España 214. sin titulo, aguafuerte, col. taller Mario Reyes. Arturo Estrada 215. sandía, aguafuerte, col. Galerias Mer-Kup. Fiersando Forulli 216. naturaleza muerta argrling I, litografía, col. Sra. Rapuel Tibol 217. naturaleza muerta argelina 2, litografía, col. Sra. Racuel Tibol 218. naturaleza muerta argelina 3, litografía, col. Sra. Raquel Tibol. Gabrid Ferníndes Jedesma 219. composición musical, grabado madera sobre papel periódico, col. Galería Arte Mexicino 220. el titiritero, madera, col. Gialería Arte Mexicano. 4.monio Ferrer Cabcllo 22t. cristo azotando a los mercaderes, litografía, col. Srá. Raquel Tibol. Luis Filcer 222. el lider, grabado aguatinta, col. Galerias Mer-Kup 223. mascarede, grabado aguatinta, col. Galerías Mer-Kup. Momro Flores 224. balcón grabado, col. Galerías Mer-Kup 225. ciudad grabado a color. col. Galerias Mer-Kup. Fridlander 226. sin titulo, técnica mixta, col. Sr. Jorge Foeclotwanger 227. sirs título. técnica mixta, col. Sr. Jorge Foechtwanger, Yukio Jukatair 228. sim titulo, grabado metal, col. OPIC. Galo Gal'cio 229: sin título, litografía a color, col. Taller de la Gráfica Popular 230. sin título, litografía, col. Taller de lát Gráfica Popular 231. Vicente Gardía 231. frutas amarillas, grahado metal, col. Galerías Mer-Kup 232. frutero, cuchillo y botella núm. 2, monotipo col. galerias Mer-K11, fielo Garcia 233. ciudad desde la ventana del tres, monocopia, col. OPIC 234. homenaje al Dr. Barnard, monocopia, col. OPIC 235. componentc estructural, monocopia, col. OPIC 236. reflerio de una ciudad, monocopia. col. OPIC 237. crucifijo rojo, monocopia, col. OPIC 238. explosión «mbasa, monocopia, col. OPIC. Sara Garía 239. módulo ocridental, intaglio, centro experimental de Arte Gráfica. Arturo García Bustos 240 el pcón acasillado, grabado en linóleo, col. Leopoldo Méndez. Prop. Sr. Pablo Méndez. Moshe Grat 241. madre con hijo, litografía, col. Sra. Lore Stavenlagen 242. cabra, punta seca. col. Sra. Teresa Feihelman 243, niño con flores, grabado metal, col. Galerías MerKup. Robin Gill 244. figura mirando a la luna, aguafuerte, col. Taller Mario Reyes 245. niña sentada, aguatinta, col. taller Mario Reyes 246. composición, aruafuerte, col. taller Mario Reyes. Gironello Aleshinsky 247. laberinto con reina y sapo aguainerte; col. Galeria Juan Martin. Miguel Goodman 248. sin título, litografia, col. laller de la Gráfica Popular. Marcolo Grassnian 249. núm. 13, grabado metal. col. galerías Mer-Kup 250. nim. 10, grabado netal, col. Galería Mer-Kup . Iherti 
Grounniuto 251. homonaje a Genesalt, litografía, col. Raquel Tibol 252. interrogatorio, litografía, col. Sra. Raquel Tibol 253. más allá de la noche, litografía, col. Sra. Raquel Tibol. Giuseppe Guerreschi 254. soldado y muchacha, litografia, col. Sra. Raquel Tibol 255. niña de Milán, Corea, litografía, col. Sra. Raquel Tibol. Piero Gucione 256. honores, para el tiltinto héroe, litografía, col. Sra. Raquel Tibol 257. libertad nocturna como pesadilla, litografía, col. Sra. Raquel Tibol 258. y si muere un hombre ..., litografía, col. Sra. Raquel Tibol. Ana Rosa Gutiérrez 259. flores $I I I$, litografía, col. Sr. Orlando Suárez 260. flores $I$, litografía, col. Sr. Orlando Suárez. Lilio Umberto Gutiérrez 261. sin título, grabado, col. Sra. Raquel Tibol. Renato Guttuso 262. masacre, litografía, col. Sra. Raquel Tibol 263. Argelia argelina, litografía, col. Sra. Raquel Tibol. Simo Hanmula 264. cuando empieza a desplegarse la niebla, grabado metal, col. Sr. Fredik Kirsebom. Miguel Hernández Urbán 265. Misión de paz, intaglio, col. Galerías Mer-Kup 266. iPor negrito?, intaglio, col. Galerías Mer-Kup. Elena Huerta 267. los ahorcados, xilografía, col. taller de la gráfica popular 268. V. Maiakovski, xilografía, col. taller de la gráfica popular. Isamu Ishikawa 269. México 63, grabado metal, col. del artista 270. México 63, grabado metal, col. del artista. Julián Jáuregui R. 271. la creación del maiz, aguafuerte, col, taller Mario Reyes 272. niña indígena, punta seca, col taller Mario Reyes. Sarah Jiménez $V$. 273. la ciencia para la paz, grabado en madera, col. Mariano Paredes 274. niño platanero, grabado en madera, col. Mariano Paredes. Lucas Johnson 275. Venus, litografía blanco y negro, col. Galería Misrachi 276. después de la guerra, litografía, col. Galeria Misrachi 277. la magia de la luna, litografía en blanco y negro, col. Galería Misrachi 278. sin título, grabado aguatinta, col. Margarita NelKen. Prop. Sra. Margarita Salas de Rivas. Miecyslaw Jurgielezvicz 279. el poeta, madera de pie, col. OPIC 280. cumpleaños, madera de pie, col. OPIC., Max Kahn 281. sin título, litografía a color, col. taller de la gráfica popular 282. sin título, litografía a color, col, taller de la gráfica popular Seymour Kaplan 283. sin título, litografía, col taller de la gráfica popular. Paul Klee 284. luz que se extingue, litografía, col: Sra. Teresa Feibelman. Kaethe Kolvoitz 285. encuentro familiar, aguafuerte, col. Sra. Teresa Feibelman. Krishna Reddy, H. 286. Jelly fish, grabado metal, col. Sra. Dominique Grifouller. Wilfrido Lam. 287. composición a color, litografía a color, técnica mixta, col. Sra. Teresa Feibelman 288. sin título, litografía, col. Sra. Dominique Grifouller 289. sin título, litografía, col. Juan Martín. María Lagunes 290. imágenes del hombre, grabado aguatinta, col. Margarita Nelken. Prop. Sra. Margarita Salas de Rivas 291. mirando como se van, grabado aguatinta, col. Sra. Margarita Nelken. Prop. Sra. Margarita Salas de Rivas. Tadeusz Lapinski 292. instrumento, litografía a color, col. OPIC 293. Ia imaginación, litografía a color, col. OPIC. Toulousse Lautrec 294. retrato de $M$. Moran, punta seca, col. Manuel Alvarez Bravo. Lucie Leblanc 295. impresión de noche, aguafuerte, col, OPIC. 296. la familia, aguafuerte, col. OPIC Leger 297. sin título, litografía, col. Sra. Doninique Grifouller 298. sin título, litografía, col. Sr. Jorge Foechtwanger. Luis López Loza 299. elocuencia de un maranjo, grabado en metal mesotinta, col. del artista 300. metamorfosis de una forma grabado en metal mesotinta y aguatinta, col. del artista. Amador Lugo 301. el valle bajo la tormenta, aguatiuta color, col. Galería Arte Mexicano 302. escena en Yucatán, litografía acuarelada, col. Galería Arte Mexicano 303. desnudo y paisaje, xilografía croyón, col. Galería Arte Mexicano 304. claustro en Oartepec, aguatinta col. Galería Arte Mexicano. Ercilla Luna 305. buenos aires de Piazzola, xilografía, col. OPIC. Francisco Luna 306. tejedores de redes, grabado a color, col. taller de la Gráfica Popular 307. abriendo caracoles, grabado a color, col. taller de la Gráfica Popular. Lurcart 308. sin título, litografía a color, col. Sra. Dominique Grifouller 309. sin título, litografía, col. Sr. Jorge Foechtwanger. Roberto Malfovon 310. presagio, linografía, col. taller de la gráfica popular 311. niño judío, xilografía, col. taller de la gráfica popular. Robert Mallary 312. sin título, aguafuerte, col. taller de la Gráfica Popular 313. sin título, litografía, col. taller de la gráfica popular. Cecile Martial 314. luna, aguafuerte y aguatinta, col. Taller Mario Reyes 315. casas, litografía, col. taller Mario Reyes. Ricardo Martines 316. dos mujeres y maguey, col. Galería 
Arte Mexicano. Matisse 317. sin titulo, litografía, col. Sr. Jorge Foechtwanger. Eliana Menasse 318. composición, monotipo, col. Galerías Mer-Kup 319. el circo, monotipo, col. Galerías Mer-Kup. Leopoldo Méndez 320. alegoria, grabado madera de pie, col. Leopoldo Méndez. Prop. Pablo Méndez 321. a las puertas de Madrid, litografía, col Instituto Nacional de Bellas Artes 322. buscando la tierra, madera de pie, col. Instituto Nacional de Bellas Artes 323. cocinero bailando, madera, col. Galería Arte Mexicano 324. carátula revista futuro (Nov. 1940), linóleo, col. Leopoldo Méndez. Prop. Sr. Pablo Méndez 325. coscomate, linóleo, col. Leopoldo Méndez Prop. Sr. Pablo Méndez 326. carnaval, madera de pie, col. Instituto Nacional de Bellas Artes 327. concentración e los yaquis, linóleo, col. Instituto Nacional de Bellas Artes 328. construcción, madera, col. Galería Arte Mexicano 329. danzante, litografía, col. Leopoldo Méndez. Prop. Sr. Pablo Méndez 330. duelo a Silvestre Revueltas, madera de pie, col. Leopoldo Méndez. Prop. Sr. Pablo Méndez 331. duelo en la selva, madera, col. Instituto Nacional de Bellas Artes 332 el soñador, linóleo, col. Leopoldo Méndez. Prop. Sr. Pablo Méndez 333. el mexicanismo de los fachistas (portada de Contra ataque), linóleo, col. Leopoldo Méndez. Prop. Sr. Pablo Méndez 334. el rayo, madera de pie, col. Leopoldo Méndez. Prop. Sr. Pablo Méndez 335. entrada a Madrid, litografía, col. Leopoldo Méndez. Prop. Sr. Pablo Méndez 336. el bruto, linóleo, col. Leopoldo Méndez. Prop. Sr. Pablo Méndez 337. Francisco Villa, madera, col. Instituto Nacional de Bellas Artes 338. graneros, litografía blanco y negro, col. Galería Misrachi 339. homenaje al heroico ejército de guerrilleros yugoslavos (La venganza del pueblo) madera de pie, col. Leopoldo Méndez. Prop. Sr. Pablo Méndez 340. ilustraciones de incidentes melódicos (serpiente), madera de pie, col. Leopoldo Méndez. Prop. Sr. Pablo Méndez 341. ilustración de incidentes melódicos (Doña Caracol), madera de pie, col. Leopoldo Méndez. Prop. Sr. Pablo Méndez 342. incidentes melódicos, madera en pie, col. Instituto Nacional de Bellas Artes 343. seis ilustraciones para el folleto "en nombre de Cristo", litografías, col. Leopoldo Méndez. Prop. Sr. Pablo Méndez 344. ilustraciones nums. 4 y 5 del libro "a orillas de este río", aguafuertes, col. Leopoldo Méndez. Prop. Sr. Pablo Méndez 345. los camisas doradas, madera de hilo, col. Leopoldo Méndez. Prop. Sr. Pablo Méndez 346. lo que puede venir, madera, col. Instituto Nacional de Bellas Artes 347. la carta, madera de pie, col. Instituto Nacional de Bellas Artes 348. Plan de Ayala, madera, col. Instituto Nacional de Bellas Artes 349. Pancho Villa, litografía en negro, col. Sr. Manuel Âlvarez Bravo 350. proyecto para óleo de Juárez, dibujo al carbón, col. Leopoldo Méndez. Prop. Sr. Pablo Méndez 351. reparando la escuela, madera de hilo, col. Leopoldo Méndez. Prop. Sr. Pablo Méndez 352. regalo a los niños de Vietnam para la Navidad de 1966, puntacolo, col. Sr. Manuel Alvarez Bravo 353. riña en el mercado, scratch, col. Leopoldo Méndez. Prop. Sr. Pablo Méndez 354. sin título, litografía, col. Leopoldo Méndez. Prop. Sr. Pablo Méndez 355. sin título, litografía, col Leopoldo Méndez. Prop. Sr. Pablo Méndez 355. sin título, litografía, col. Leonoldo Mćndez. Prop. Sr. Pablo Méndez 356. también la tierra bebe tu sangre, Tivilco, col. Galería Arte Mexicano 357. tengo sed, linóleo, col. Galería Arte Nexicano 358. tierra del chicle, madera de hilo, col. Instituto Nacional de Bellas Artes. Carlos Mérida 359. sin título num. 1, litografía, col. Sr. Manuel Alvarez Bravo 360. sin titulo num. 2, litografía, col. Sr. Manuel Alvarez Bravo 361. sin titulo núm. 3, litografía, col. Sr. Manuel Alvarez Bravo. Juan Messmacher 362. leones, metal, col. taller Mario Reyes 363. la lectura, aguafuerte, col. Taller Mario Reyes. Guillermo Meza 364. hombre maguey, litografía blanco y negro, col. Galería Misrachi 365. hoja de estudio, litografía, col. Sra. Teresa Feibelman 366. 8 y vendrá una gran guerra, litografía, col. Galerías Mer-Kup 367. 9 solamente por el tiempo loco, litografía, col. Galerías Mer-Kup. Lucjan Mianozeski 368. la catedral, litografía a color, col. OPIC. André Minaux 369. sin título, litografía a color, col. Sr. Jorge Foechtwanger. Miro 370. sin título, litografía a color, col. Sr. Jorge Foechtwanger Carmen Mones 371. la muñeca, metal, col. taller Mario Reyes 372. desnudo con gato, metal, col. taller Mario Reyes. Humberto Morales 373. 20 láminas originales, col. Sra. Raquel Tibol, Jesús Morales 374. los que ducrmen, grabado, col. Galería Arte Mexicano 375. gente del campo, grabado, col. 
Galería Arte Mexicano 376. puente del campanario, grabado, col. Galería Arte Mexicano. Francisco Moreno Capdevila 377. los rotos, litografía, col. Instituto Nacional de Bellas Artes 378. larga es la noche, punta seca y aguatinta s/papel, col. Instituto Nacional de Bellas Artes 379. parada de autobús, grabado, col. Galerías Mer-Kup 380. ama de llaves, grabado, col. Galerías Mer-Kup 381. en la playa, grabado, col. galerías Mer-Kup 382. paseo, grabado, col. Galerías Mer-Kup 383. exterminio, grabado, col. Galerías Mer-Kup 384. Lázaro, grabado, col. Galerías Mer-Kup 385. Prisioneros, grabado, col. Galerías Mer-Kup. Roberto Montenegro 386. calaveras, litografía, col. Instituto Nacional de Bellas Artes. Rogelio Naranjo 387. mujer de la trenza, litografía blanco y negro, col. Sr. Guillermo Ceniceros 388. árboles y pareja, madera, col. Sr. Guillermo Ceniceros. Robert Nicodsky 389. sin título, aguafuerte, col. OPIC 390. grabado verde, aguafuerte, col. OPIC 391. el bosque, aguafuerte, col. OPIC. Isidoro Ocampo 392. los minotauros, aguafuerte en color, col. Galería Arte Mexicano 393. la máscara del hombre moderno, aguafuerte en color, col. Galería Arte Mexicano 394. las calaveras toreras miedosas, aguafuerte en color, col. Galería Arte Mexicano 395. mujer y niño, punta seca, col. Galería Arte Mexicano 396. el deshollinador cansado, aguatinta, col. Galería Arte Mexicano. Pablo O'Higgins 397. día de raya, litografía, col. Galería Misrachi 398. hombre del siglo XX, litografía, col. Instítuto Nacional de Bellas Artes 399. en el mercado, litografía a color, col. Instituto Nacional de Bellas Artes 400. tienda de raya, litografía, col. Leopoldo Méndez. Prop. Sr. Pablo Méndez 401. Presidente municipal, litografía, col Sr. Manuel Alvarez Bravo 402. maguey, litografía, col. Sr. Manuel Alvarez Bravo 403. Don Lupito, litografía, col. Sr. Manuel Álvarez Bravo 404. retrato de hombre, litografía, col. Sr. Manuel Alvarez Bravo 405. mujer cocinando, litografía, col. Sr. Manuel Alvarez Bravo 406. mujer cosiendo, litografía, col. Sr. Manuel Álvarez Bravo 407. hombre del siglo $X X$, litografía, col. Sr. Manuel Alvarez Bravo 408. detalle del mural del Banco Exterior, litografía, col. Galería Arte Mexicano 409. la peleonera, litografía, col. Galería Arte Mexicano. Carlos Olachea 410. sueño, grabado meta], col. Galería Mer-Kup 411. el banquete, grabado a color, col. Galerías Mer-Kup. Alicia Orlandi 412. múcleo compuesto, litografía, col. OPIC. José Clemente Orozco 413. bocanal-fin de fiesta, litografía sobre papel, col. Instituto Nacional de Bellas Artes 414. dos cabezas-detalle de mural, litografía sobre papel, col. Instituto Nacional de Bellas Artes 415. muerto y mujeres, litografía sobre papel, col. Instituto Nacional de Bellas Artes 416. mujer llorando, litografía, col. Lore Stavenhagen 417. pedregal, litografía, col. Instituto Nacional de Bellas Artes 418. pleito-detalle' de mural, litografía, col. Instituto Nacional de Bellas Artes 419. presagio, punta seca, col. Instituto Nacional de Bellas Artes 420. pueblo mexicano (basurero), litografía sobre papel, col. Instituto Nacional de Bellas Artes 421. cabeza de mujer, punta seca, col. Instituto Nacional de Bellas Artes 422. las masas, grabado blanco y negro, col. Sra. Teresa Feibelman 423. mujer meditando ( $\sin$ terminar), punta seca, col. Galerías Mer-Kup 424. contorsionistas, aguatinta, col. Galerías Mer-Kup. Carlos Orozco Romero 425. figuras de mujer, punta seca, col. Instituto Nacional de Bellas Artes 426. mariposilla, punta seca, col. Instituto Nacional de Bellas Artes 427. retrato, aguatinta, col. Sr. Manuel Alvarez Bravo. Trinidad Osorio 428. hojas en el espacio, metal, col. Galerías Mer-Kup. Jerzy Panek 429. autorretrato con sombrero blanco (I), grabado, col. OPIC 430. autorretrato con sombrero blanco (II), grabado, col. OPIC. Mariano Paredes 431. descanso, grabado en madera a dos colores, col. del artista 432. grupo, grabado en madera en tres colores, col. del artista 433. la entrada a la mina, aguafuerte, col. Galería Arte Mexicano 434. el niño, grabado en madera, col. Galería Arte Mexicano 435. obrero, grabado en madera, col. Galería Arte Mexicano 436. Pazy, angustia, grabado, col. Galerías Mer-Kup 437. damas medievales, grabado, col. Galerías Mer-Kup. Ana Pellicer 438. la guerra, aguafuerte y aguatinta, col. taller Mario Reyes. Humberto Peña 439. no es el momento de rociarse, litografía, col. Sr. Orlando Suárez 440 . él puede echar porque él puede, litografía, col. Sr. Orlando Suárez. Picasso 441. buiho, grabado en linóleo, col. Juan Martín 442. Genevieve, grabado en metal, col. Sra. Dominique Grifouller 443. ilustración del perro para la historia natural de Buffon, 
litografía, col. Lic. Luis Carral y de Teresa 444. perro de Genevieve, grabado en metal, col. Sra. Dominique Grifouller 445. sin titulo, litografía, col. Sra. Dominiquo Grifouller 446. sin titulo, litografía, col. Sr. Jorge Foechtwanger 447. sin título, litografía, col. Sr. Jorge Foechtwanger. E. Pignon 448, sin título, litografía, col. Sra. Dominique Grifonller. Alberto Plaza 449. rostro, aguafuerte, col. OPIC 450. pas, aguafuerte, col. OPIC 451. circulos con rostro, aguafuerte, col. OPIC 452. vía láctea, aguafuerte, col. OPIC 453. figura, aguafuerte, col. OPIC. Poliakov 454. composición, litografía a color, col. Juan Martín. Mario Porras Villalba 455. viaje núm. 2, aguafuerte, col. Carlos Hernández Serrano 456. viaje núm. 1. lécnica mixta, col. Sr. Carlos Hernández Serrano 457, homenaje, aguafuerte, col. Sr. Carlos Hernández Serrano. François Portellete 458. figura, aguafuerte, col. OPIC. Liliana Porter 459. Monokini, grabado metal, col. Sr. Fredrik Kirsebom 460. 119 Sullivan Street, metal aguafuerte, col. Sr. Fredrik Kirsebom. José Guadalupe Posada 461. libro: José Guadalupe Posada, Ilustrador de la vida mexicana 1963, ejemplar núm. 180, fondo de la Plástica Mexicana, col. Sra. Iudith van Beuren 462. libro: Posada, monografía: 406 grabados de José Guadalupe Posada con introducción de Diego Rivera. Publicado por Mexican Folkways. Talleres Gráficos de la Nación 1938, col. Sra. Judith van Beuren 463. libro: José Guadalupe Posada, 36 grabados en hojas sueltas. Edición: Arsacio Vanegas Arroyo. México, D. F., 1943, col. Sra. Judith Van Beuren. Arturo Potestat 464, retrato litografía, col. Sr. Orlando Suárez. Pedro Preu.r 465. mar de noche, linóleo, col. Galería Misrachi 466. transportes al séptimo cielo, linóleo, col. Galería Misrachi 467. mar de dia, linóleo, col. Galeria Misrachi 468. el árbol de la vida, block print, col. del artista 469. no deberás olvidar, block print, col. del artista. Julio Prieto 470. el llawado de la muerte, linóleo, col. Instituto Nacional de Bellas Artes 471. ocalina ním. 2; litografía, col. Instituto Nacional de Bellas Artes. Antonio Pujol 472. la guerra, litografía, col. Instituto Nacional de Bellas Artes. Adolfo Quinteros 473. pescadores, linóleo, col. Instituto Nacional de Bellas Artes 474. Tarahumara, linóleo, col. Instituto Nacional de Bellas Artes 475. chinchorro, linóleo, col. Sr. Mariano Paredes 476. si vienen quedan, madera, col. Sr. Mariano Paredes. Fanny Rabel 477. juegos artificiales, linóleo, col. Instituto Nacional de Bellas Artes 478. hambre en España, linóleo, col. Instituto Nacional de Bellas Artes 479: juegos artificiales, linóleo, col. Instítuto Nacional de Bellas Artes 480. burocracia, litografía, col. Galerías Mer-Kup 481. los emigrantes, litografía a color, col. Galerías Mer-Kup. Alice Rahon 482. sin título, litografía a color, col. Margarita Nelken. Prop. Sra. Margarita Salas de Rivas. Jorge Ramirez 483. por la fuerza, xilografia, col. Taller de la Gráfica Popular 484. enajenados, xilografía, col. taller de la Gráfica Popular. Fernando Romírez Osorio 485. Zacatlán de las manzanas, linóleo, col. Margarita Nelken. Prop. Sra. Margarita Salas de Rivas 486. el hombre de la máscara, madera de pie, col. Margarita Nelken. Prop. Sra. Margarita Salas de Rivas. Fernando Ramos Prida 487. ella es asi, aguafuerte, col. Galería Arte Mexicano. Onar Rayo 488. forma horizontal, grabado s/metal, col. Sra. Nancy Vicens 489. hecho en Japón; intaglio, col. Sra. Nancy Vicens. Mario Reyes 490. hacer el amor no la guerra, metal a color, col. del artista 491. arleguin, mesotinta, col. del artista. Diego Rivera 492. autorretrato, litografía, col. Sra. Lore Stavenhagen. Julio Rodriguez 493. los eucaliptos, madera, col. Instituto Nacional de Bellas Artes 494. el misico, madera, col. Instituto Nacional de Bellas Artes. Ma. Isabel Rodríguez 495. neptuneo, aguafuerte, col. taller Mario Reyes 496. un mundo diferente, aguafuerte, coli taller Mario Reyes. Salvador Romero 497. Zapata, xilografía, col. taller de la. Gráfica Popular 498. la juventud lucha por la paz, xilografía, col. taller de la Gráfica Popular. Ignacio Romero P. 499. en el campo, intaglio, col. taller Mario Reyes 500. Galgo, aguatinta, col. taller Mario Reyes. Rowalt 501. sin título, metal, aguatinta y buril, col. Sr. Jorge Foechtwanger 502. sin titulo, metal, col. Sr. Jorge Foechtwanger 503. sin título, metal y aguatinta, col. Sr. Jorge Foechtwanger. Luis Rubestein 504. Semuana Santa en Tepoztlán, litografía, col. Leopoldo Méndez. Prop. Sr. Pablo Méndez. Andrzej Rudzinski 505. en el agua, aguatinta y buril, col. OPIC 506. en la orilla del lago, aguatinta y buril, col. OPIC. Marc Saint Saenz 507. sin título, 
lilografia a color, col. Sra. Dominique Grifouller. Ana Salinas 508, la puerta, srabado en madera a dos colores, col. Sr. Mariano Paredes 509. remanso, yrabado en madera a dos colores, col. Sr. Mariano Paredes. Carlos Scannapieco 510. rodaballo, serie del mar, aguafuerte, col. OPIC. Olivier Seguin 511. sin título, grabado metal y aguatinta, col. Margarita Nelken. Prop. Sra. Margarita Salas de Rivas. Guillcrmo Silva Santamaria 512. fusilamiento do la serie El hombre contra el hombre, metal en bajo relieve a color, col. Sra. Milena Esguerra 513. toros, grabado metal, col. Galerías Mer-Kup. Waldemar Sjolander 514. sin título, litografía, col. Margarita Nelken. Prop. Sra. Margarita Salas de Rivas 515. bal nogro niin. 1, litografía, col. Galería Arte Mexicano 516. ferias, litografia, col. Galería Arte Mexicano. Esperanza Solis. 517. doce técnicas, intaglio, col. Centro experimental de Arte Gráfica. Iuan Soriano 518. sin título, grabado aguafuerte, col. Margarita Nelken. Prop. Sra. Margarita Salas de Rivas. Alfredo Sosa Bravo 519 . micromasoquistas, litografía, col. Sr. Orlando Suárez 520. para un trabajo perfecto, litografía, col. Sr. Orlando Suárez, Jorgc Sotret 521. pausa, xilografía a color, col. OPIC. Arturo Souto 522. mujeres, litografía blanco y negro, col. Sra. B. Fernández Muñiz 523. iglesia, litografía blanco y negro, col. Sra. B. Fernánidez Muñiz. Konrad Srzednicki 524. el paraíso de los caballos, metal técnica mixta. col. OPIC 525. sin nowbre, grabado madera, col. OPIC. Y. Sasson 526. arraigo religioso, aguafuerte, col, taller Mario Reyes 527 . supe que tw cerchro se estaba convirtiendo en engranajes fríos y metálicos, punta seca, col. taller Mario Reyes. Rufino Tamayo 528. coyote ladrando a la luna, litografía a color, col. Sra. Teresa Feibelman 529. hombre mirando al firmamento, litografía a color, col. Sra. Teresa Feibelman 530. pájaros, litografía a color, col. Sra. Teresa Feibeluran 531. loombre al sol, litografía a color, col. Galerías Mer-Kup. Leticia Tarragó 532 . balcón, metal a color, col. Instituto Nacional de Bellas Artes 533. la gallina mensaicra, metal a color, col. Instituto Nacional de Bellas Artes 534. las ánimas honditas, grabado aguafuerte, col. Margarita Nelken. Prop. Sra. Margarita Salas de Rivas. Fictorina $R$. de Tarragó 535. claro en el bosque, agiafuerte, col. taller Mario Reyes. C. Terekovich 536. navidad, litografía a color, col. Lic. Luis Carral y de Teresa. Ma. Teresa Toral 537. el patito que soñaba con ser pes, grabado metal. col. Margarita Nelken. Prop. Sra. Margarita Salas de Rivas. Adela Truetu 538. reina virgen, aguatinta y aguafuerte, col. del artista 539. sin titulo, aguatinta $r$ aguafuerte, col. del artista. Francisco Vásques 540 . desco, madera aguatinta, col. Galería Arte Mexicano 541. desesperanza, aguada de tilta, col. Galería de Arte Mexicano. Lorenzo Vespignani 542. cualquiera festeja, litografía, col. Sra. Raquel Tibol 543. televisión, litografía, col. Sra. Raquel Tibol 544. encuentro, litografía. col. Sra. Raquel Tibol. Ma. Teresa Vicyra $R$. 545. lluvia, aguafuerte y aguaLinta, col. Margarita Nelken. Prop. Sra. Margarita Salas de Rivas. I. Villón 546. sin título, grahado metal iluminado a mano, col. Sra. Dominique Grifouller, Micsyslace Wciman 547. sin nombre (azul, negro), metal, técnica mixta, col. OPIC. 548. sin nombre (ocre, siena), metal, técnica mixta, col. OPIC. Charles White 549. sin titulo, litografía, col. taller de la Gráfica Popular. Stanislaze Wojtozericz $550 . \mathrm{dl}$ stucño, grabado madera, col. OPIC 551. la ciudad, grabado madera, col. OPIC. Marysole Worner Bas 552. pandilla, grabado madera, col. Galerías Mer-Kup 553. barrenderos, grabado madera, col. Galerías Mer-Kup 554 sin titulo (mujer), grabado madera de hilo, col. Margarita Nelken. Prop. Sra. Margarita Salas de Rivas 555. sin titulo (mujeres), grabado madera de hilo, col. Margarita Nelken. Pron. Sra. Margarita Salas de Rivas. Héctor Xavict 556. calaveras, litografía col. Galería Arte Mexicamo 557. judas y magueves, litografia, col. Galería Arte Mexical1o 558. cabeza, litografía, col. Galería Arte Mexicano. Xochitiotzin 559. la familia Xochitiotsin, grabado en linóleo, col. Margarita Nelken. Prop. Sra. Margarita Salas de Rivas. Mariana Yampolsky 560. agua para el pueblo, linóleo, col. Instituto Nacional de Bellas Artes 561. la paz, linóleo, col. Instituto Nacional de Bellas Artes. Hodaka Yoshida 562. cinco grabados numerados del 1 al 5 , madera técnica mixta, col. OPIC. O. Zadkine 563. sin título, litografia, col. Sra. Dominique Grifouller. Alfredo Zalce 564. arrastre de henequén (serie de Yucatán), litografía, col. Sr. Manuel Alvarez Bravo 565. sin título (serie de Yucatán), talla dulce, col. 
Sr. Manuel Alvarez Bravo 566. sin título (serie de Yucatán), punta seca, col. Sr. Manuel Alvarez Bravo 567. campesino herido, punta seca, col. Sr. Manuel Álvarez Bravo 568. desembarco de locos en el puerto de Manzanillo, litografía, col. Sr. Manuel Alvarez Bravo 569. el criminal se adueña del poder (Victoriano Huerta), grabado en linóleo, col. Leopoldo Méndez. Prop. Sr. Pablo Méndez 570. ingenio de azúcar, litografía, col. Sr. Manuel Alvarez Bravo 571. playa, grabado a color, col. Galería Arte Mexicano 572. pasaron por la calle principal, litografía, col. Leopoldo Méndez. Prop. Sr. Pablo Méndez 573. río palizada, litografía, col. Galería Arte Mexicano 574. sin título, litografía, col. Sr. Manuel Alvarez Bravo 575. libro: El sombrerón, 40 grabados originales, col. Sr. Manuel Alvarez Bravo. Angel Zamarripa 576. mujer de Texistepec, litografía, col. Instituto Nacional de Bellas Artes 577. templo de la cruz enramada de Palenque, litografía, col. Instituto Nacional de Bellas Artes. Javier Zamayoa 578. animales, intaglio, col. Centro experimental de Arte Gráfica. Zañartu 579. paisaje tangible, grabado metal, col. Margarita Nelken. Prop. Sra. Margarita Salas de Rivas. Wu-Ki-Zao 580. sin titulo, litografía a color, col. Sr. Jorge Foechtwanger 581. sin título, litografía, col. Sr. Jorge Foechtwanger. Rafael Zarza 582. lección de veterinaria, litografía, col. Sr. Orlando Suárez 583. tauromanía, litografía, col. Sr. Orlando Suárez. Francisco Zum Felde 584. fuente, metal y aguatinta, col. Instituto Nacional de Bellas Artes 585. rincón del Zócalo, metal y aguatinta, col. Instituto Nacional de Bellas Artes.

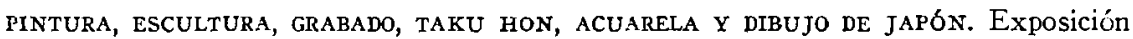
presentada por el Departamento del Distrito Federal, Dirección General de Acción Social, Galerías de la ciudad de México (Alameda Central), del 9 al 30 de abril.

Las autoridades del Departamento del Distrito Federal, al través de la Dirección General de Acción Social en sus Galerías de la ciudad de México, se enorgullecen en presentar al público mexicano la exposición de un grupo de artistas japoneses que han destacado notablemente en las artes plásticas de su país.

Goro Kakei, escultor que ha expuesto en la Octava Bienal de São Paulo, en la Exposición de Arte Moderno de Japón en Río de Janeiro y en la exposición de Arte Moderno japonés. El fue el ganador en su país del premio "Joven Artista" en la exposición "Shinseisaku". Actualmente es profesor de la Universidad Veracruzana, en Xalapa.

Minoru Kurazawa, graduado en la Universidad de Arte de Tokio y egresado en México de la Escuela Nacional de Bellas Artes. Premiado en la Exposición de Arte Contemporáneo de Japón. Participó en la Exposición de Arte Internacional de Japón.

Akira Hirakaz'a, extraordinario realizador de Taku Hon. Actualmente se encuentra en Tokio. El año pasado visitó México con motivo del programa cultural de los juegos de la XIX Olimpiada.

Yasushi Homoto, estupendo grabador que radica en Japón y que ha enviado a las Galerías de la ciudad de México nueve estupendas muestras de su extraordinario trabajo.

Shinzaburo Takeda, graduado en la Universidad de Arte de Tokio que ha expuesto en la Bienal Internacional de Grabado de Tokio, en la exposición "Grandes Maestros Modernos de Grabado" de Tokio; en la exposición "Modernos Grabados de Japón", realizada por los miembros de la Asociación de la Paz en París; invitado desde 1962, a la fecha, a las exposiciones bienales de grabado de Japón; uno de los 200 participantes en la exposición mundial de grabado de Vancouver, Canadá, realizada en 1967 y que el año pasado participó en la exposición, montada en esta capital, "Japan Art Festival". 
Y, Syuzo Wakiya, representante de la joven pintura japonesa que ha venido a nuestro país atraído por la tradición artística de México.

Las autoridades del Departamento del Distrito Federal agradecen profundamente la colaboración desinteresada que ha prestado para el logro de esta importante nuestra, la señorita Yoshico Shirata, representante en México de la Asociación de Arte de Asia.

ALFREDO HLITo (pintura 1946-1969). Exposición presentada por el Instituto Nacional de Bellas Artes, Sala Internacional, Galerías del Palacio de Bellas Artes, el 9 de abril.

La variedad de tentativas que revela esta muestra no es expresión de una feliz versatilidad; todo lo contrario. Hubiera deseado ser el pintor de un solo tema. Por qué no he logrado serlo no me corresponde a mí elucidarlo.

La decisión de dar un carácter retrospectivo a esta exposición - la primera que realizo en México- obedece al propósito de ofrecer una visión más o menos completa de mi itinerario como pintor; secundariamente, al de presentar en una perspectiva más favorable lo poco que he logrado realizar desde que no me siento depositario de ningún deber ajeno al mero gusto o disgusto que depara el ejercicio de la pintura.

Esta muestra abarca más de veinte años de una labor trabajosamente suspendida y reanudada. Desde luego, no se trata de todo lo que he realizado en este lapso; la muestra se limita al material que tengo a mano en estos momentos. Las influencias que me sirvieron de estímulo son demasiado obvias para mencionarlas; sólo puedo añadir que creí fervientemente en las cosas mientras las estaba haciendo y que no ignoro lo que significa continuar haciendo algo sin contar con las seguridades que suelen procurar las creencias.

Los cuadros que llevan el título de Espectros, realizados entre 1959 y 1963 -de los que aquí se da una muestra parcial一, me parecen hoy la solución más consistente a los problemas que me preocupaban entonces: la abolición del tema sin pérdida del rigor, refugio en la visualidad pura.

Lo que he hecho desde entonces, quizás no sea otra cosa que el resultado del relajamiento de una tensión orientada exclusivamente en el sentido de las disyuntivas formales.

Alfredo HLivo

Alfredo Hlito, nace en Buenos Aires, Argentina, en 1923.

Catálogo: 1. construcción, $1945, .70 \times .50$, óleo s/tela 2 2. construcción, $1945, .74 \times .56$, óleo $\mathrm{s} /$ tela 3. ritmos cromáticos $I$, $1947, .70 \mathrm{x} .70$, óleo s/tela 4. ritmos cromáticos II, $1947, .70 \times .70$, óleo s/tela 5. estructura con ritmos cromáticos, 1949 , $1.00 \times 1.00$, óleo s/tela 6 . estructura con planos, $1950, .55 \times .45$, óleo s/tela 7 . sobre la horizontal, $1952,1.00 \times .70$, óleo s/tela 8 . tema en dos circulos, 1954, $1.00 \times .50$, óleo s/tela 9 . en el rombo, $1954, .50 \times .50$, óleo s/tela 10 . posiciones, $1956, .65 \times .54$, óleo s/tela 11. tena suspendido, $1957, .65 \times .45$, óleo s/tela 12. derivación del cuadrado, $.55 \times .45$, óleo s/tela 13 . tema central, $1958, .65 \times .55$, óleo s/tela 14. volutas, $1955, .33 \times .55$, óleo s/tela 15 . tema simétrico, $1957,1.19 \times .70$, óleo s/tela 16. simetría, 1958, $.45 \times .35$, óleo s/tela 17 , volutas $I I, 1958, .45 \times$ .35 , óleo s/tela 18 . espectro $I, 1959, .70 \times .50$, óleo s/tela 19 . espectro $I I, 1959$, 
$1.00 \times .70$, óleo s/tela 20 en el óvalo $I, 1959,1.00 \times .70$, óleo s/tela 21 . en el óvalo $I I, 1959, .91 \times .72$, óleo s/tela 22 . espectro $I I I, 1960,1.84 \times .89$, óleo $\mathrm{s} / \mathrm{tela}$ 23. espectro $I V, 1959,1.80 \times .60$, óleo s/tela 24 . pintura, $1963,1.00 \times .80$, óleo $\mathrm{s} /$ tela 25 . figuras, $1963,1.10 \times .80$, óleo s/tela 26 . ritmo lineal, $1964, .45 \times .35$, óleo s/tela 27. figura suspendida, $1964, .80 \times .60$, óleo s/tela 28 . tres temas, 1965 , $1.00 \times 1.30$, óleo s/tela 29 . tema vertical, $1964,1.00 \times .70$, óleo $\mathrm{s} / \mathrm{tela} 30$. pintura, $1964, .80 \times .60$, óleo s/tela 31. tema lineal, $1965,1.20 \times .80$, óleo s/tela 32 . tema en el óvalo, $1966,1.50 \times 1.00$, óleo s/tela 33 . tema vertical, $1966,1.50 \times 1.00$, óleo $\mathrm{s} /$ tela 34. ejercicio $1,1967, .18 \times .21$, acrílico 35 . ejercicio $2,1967, .38 \times .51$, acrílico 36. ejercicio $3,1967, .38 \times .51$, acrílico 37 ejercicio $4,1967, .38 \times .51$, acrílico 38. ejercicio $5,1967, .38 \times .51$, acrílico 39 . ejercicio $6,1967, .38 \times .51$, acrílico 40. ejercicio $7,1967, .38 \times .51$, acrílico 41 . ejercicio $8,1968, .38 \times .51$, acrílico 42 . ejercicio 9, 1968, .38 x .51, acrílico 43 . ejercicio $10,1968, .38 \times .51$, acrílico 44. ejercicio $11,1968, .38 \times .51$, acrílico 45 . ejercicio $12,1968, .60 \times .50$, acrílico 46. ejercicio $13,1968, .38 \times .51$, acrílico 47 . ejercicio $14,1968, .38 \times .51$, acrílico 48. ejercicio $15,1968, .38 \times .51$, acrílico 49 . ejercicio $16,1968, .38 \times$ .51 , acrílico 50 ejercicio $17,1968, .67 \times .51$, acrílico.

antonio serna. Exposición presentada por el Instituto Cultural Mexicano Israelí, A.C., Ometusco 15, el 9 de abril.

IRENE ARIAs. Exposición de óleos y dibujos, presentada por la Galería de Editl Quijano, Paseo de la Reforma 412-A, el 10 de abril.

Ya desde su primera exposición esta joven pintora mexicana se impuso a nuestra atención por la fuerza de su expresividad. Ahora, en el conjunto de óleos y dibujos que nos presenta (Galería de Edith Quijano, Reforma 412-A), esa impresión primera se afianza y nos hace ver en su autora a uno de los valores ya seguros de la nueva generación.

Tintas a color: el colorido siempre limpio, vibrante en cada uno de sus tonos dentro de una composición definidamente figurativa, o muy sintetizada. Una obra cual la titulada "Toda la noche", se impone a la vez por la penetración del carácter de sus dos figuras y por la solidez de su síntesis. En los óleos, la angustia de un rostro fijada con certera simplicidad, tiene unos toques encendidos distribuidos con verdadero acierto. Asimismo, en "Huida", las manchas violetas asociadas a lo blanico de la parte superior del rostro, subrayan, en apariencia con espontaneidad, la mirada que podría decirse percutiente, que procura salvarse de la hostilidad de un mundo sentida con una sensibilidad de lerida abierta. Y es que hay, en el arte de Irene Arias, la afloración de una como devastación interior, cuya inagen más comunicativa es quizá la de ese rostro blanco de "La Gran Ciudad", apuntalado en unas geometrizaciones, expresión del automatisıno que lo cerca. Y esta impresión aparece especialmente en los autorretratos, abiertamente proclamados en obsesiva reiteración en la ristra de cuatro rostros valientemente presentados de frente, o en el disimulo de la figura titulada "Gasi y yo", con sus tonos claros resaltando sin brusquedad de un fondo contrastado muy bien trabajado.

Originalidad en la composición, como en el barroquismo del rostro lunar entre sus adornos "a la antigüita" de "Toda la Noche, Todo el Día", o del "Mercado", de tan convincente raigambre popular, lia cual reaparece en las divisiones de otras composiciones, como la de "El juego de las Parcas", con sus carretas ligadas por fragmento románticamente decorativo, sobre un fondo rígidamente cuadriculado que aquí 
cobra valor de simbolo inhumano. Una exposición, ésta de Irene Arias, deveras interesinte.

\section{Margarita NelkeN}

FRANCISCA DURÁn-Reynals. Exposición de collages, presentada por el Organismo de Promoción Internacional de Cultura de la Secretaría de Relaciones Exteriores, Galería de Arte del Teatro "Casa de la Paz", Cozumel núm. 33, el 11 de abril.

JUAN LuIS BŨ̃uel. Exposición de esculturas, presentada por la Galería de Arte Misrachi, Génova 20, el 11 de abril.

Datos biográficos: Juan Luis Buñuel, nació el 9 de noviembre de 1934 en París, Francia.

Catálogo: 1. máquina solitaria 2. comuto machine 3. unas cuantas ruedas 4. monja dos 5. carta a Smith III 6. carta a Smith $L V$ 7. carta a Smith VI 8. carta postal a Smith 9. desmodus rufus (vampire) 10. perro muy antiguo 11. carta a Smith $V$ 12. Place de la Contrescarpe 13. mier I 14. mujer II 15. formas no muy abstractas (Half moons) 16. cirque d'Hiver 17. caballo con dos jinetes 18. judas christ 19. naturaleza muerta y viva 20. naturaleza indiferente 21 . el pescado de mi madre 22. L'Année Dernière à Tlatelolco 23. la cámara silenciosa de Arturo 24. un huevo 25. un momento (swing) 26. más ruedas 27. solución (small).

PETER KNigge. Exposición de esculturas, presentada por la Galería Pecanins, Hamburgo 103 , del 15 de abril al 3 de mayo.

LUIS FEDERICO TRAMA (Uruguay). Exposición de acrílicos, presentada por el Organismo de Promoción Internacional de Cultura de la Secretaría de Relaciones Exteriores, Galeria de Arte Dr. Atl, anexo de exposiciones del teatro Antonio Caso, Reforma Norte 668, el 15 de abril.

viCENTE kojo. Exposición presentada por la Galería Juan Martín, Amberes 17, del 15 de abril al 3 de mayo.

Fanny Rabiz. Exposición de 40 tintas, presentada por la Galería Plástica de México, Londres 139, del 16 de abril al 15 de mayo.

Catálogo: 1. el perro del beduino 2. el maldito mirón 3. scñor, la mesa está servida 4. pareja vegctal 5. la bella y la bestia 6. los intrusos 7. un hombre de veras preocupado 8. ave maligna 9. maternidad subdesarrollada 10 . los anantes 11. también los feos tienen su corazoncito 12. tres sabios en el café 13. los globos 14. happy ncw year 15. la alcgre dana del colchón 16. retrato de novios 17. mujer al agna 18. doliente 19. una mujer desnuda 20. las consecuencias de hablar 21. planta citadina 22. el espejo 23. dama en azules envuelta 24. dama casquivana 25. planeta maltrecho 26. baño en la selva 27. a la maestra con cariño 28. desde las sombras 29. un profeta 30. una familia muy unida 31. poeta con musai 32. confesión 33. cl domador 34. Leonora y sus visitantes 35. el catador 36. flores asules 37. flores para los amigos 38. felicitación a namá 39. flores del bien 40. pareja sombria. 
ÁNGEL zÁRRAGA (1886-1946). Exposición homenaje, presentada por el Instituto Nacional de Bellas Artes, Galería de Exposiciones Temporales, Museo de Arte Moderno el 17 de abril.

Ilatos biográficos: nace en Durango, Dgo., el 16 de agosto de 1886.

La pintura de Angel Zárraga: En la vasta producción pictórica de Angel Zárraga cabe advertir cuatro épocas: la inicial, que en cierto modo justifica el pensamiento de Leonardo de Vinci: "la pittura é cosa mentale"; la etapa cubista, en que el pintor explora las posibilidades de su arte y enriquece su técnica con recursos que utilizará después con impecable acierto: la manera post-cubista, serena y expresiva, se manifiesta principalmente en bellas telas de caballete; su obra mural, en fin, al fresco y a la encáustica.

Lá primera época se inicia propiamente en 1905. Zárraga está en Toledo y tiene diecinueve años. ¿Qué hacer en esta ciudad, en ese momento y a esa edad, sino pintar mendigos? Sus cuadros trascienden el subgrequismo difuso en el ambiente artístico de entonces. En 1908 va a Italia. Florencia y Asís lo retienen dos años. Hasta 1912 es el periodo de las composiciones "que ilustran casos a veces literarios e inquietantes", dice en excelente estudio Mme. Louise Hervieu. El artista se busca a si mismo, no sin lograr bellas realizaciones, tal el San Sebastián, con el que llega a la notoriedad. En las pinturas de esa primera época, cargadas de intenciones expresivas, las oposiciones de la torturada carne - ancianos, mendigos, mártiresy del cuerpo femenino que es casi siempre la figura principal, juegan en el plano estético igual que en el plástico los negros y blancos de un aguafuerte. El pintor crea esos contrastes movido por un sentimiento pictórico. Opone a una forma bella otras que no los son tanto, como emplearía una iluminación de foco visible para lograr juegus de sombra. No pocos de sus cuadros mantienen ese propósito de contraste, atenuándolo a equilibrio entre la forma viva y la inerte: llama de un cuerpo desnudo y fría quietud del mar; y a oposiciones de color: gustará de poner vecinos, o en correspondencia, acres rojizos y puros ultramares, o avivará un rincón de un cuadro -iluminado por la albura rosa de un desnudo- con una mancha cadmio o limón: cubierta de libro o gorro de bañista.

La formación del artista - dice Mme. Hervieu- es, hasta entonces, de museo. Sin embargo, o por eso mismo, como reacción, apenas vuelto a Francia, en donde triunfan los neo-impresionistas entre los primeros rugidos de las fieras, Zárraga va a la vanguardia, sin titubeos: "a riesgo de que el éxito le abandone, deja sus cuadros de santidad y de aparato; construye en color ; rechaza la premeditación en el arte".

Esto, naturalmente, le lleva al cubismo -tras de pintar en España (1912) los últimos mendigos y de hacer un viaje a México. Su cubismo fue amable, sin dogmatismo, atemperado de poesía y de mesura. Más que de creación, fue ése un periodo de estıdio, de análisis. El cubismo le ensefió a disecar la forma, a desmenuzar el volumen, a descomponer el color, y a reanimarlo todo en cabal síntesis. Algunos de sus painales religiosos, y aun de sus cuadros de futbolistas, son la culminación de bocetos cubistas, que depuró quitando a la realización lo que el original pudo tener frialdad geométrica; la concepción estructural por planos de color, propia del cubismo, persiste, pero la obra definitiva tiene la firmeza de la afirmación frente a la preliminar incertidumbre 
de la búsqueda. La disciplina cubista, stı desinterés anstero, dieron a su pintura mayor salud.

Cabe aplicar al cubismo lo que del periodismo se ha dicho: "Conduce a todo, a condición de salir de él." Y Zárraga salió del cubismo para buscar, una vez más, la verdad humana. Sería muy interesante analizar en su obra ese periodo de tránsito hacia su nueva manera. Antes de que Picasso proclamara "el retorno a Ingres", ya nuestro pintor estaba de regreso al clasicismo. Sus obras poscubistas son el coronamiento —en la medida en que esto puede decirse de un artista que seguirá inventando mientras la vida le dure- de una evolución netamente marcada. Es ahora la época en que Zárraga es más él, la que nos interesa especialmente como objeto de este comentario.

Esa tercera etapa comienza poco después de la pasada guerra. Los temas que el pintor prefiere son de alta calidad plástica. Le atrae el deporte por su color, por su dinamismo, hasta por el problema de conciliar el movimiento con la estabilidad propia de la pintura. A la vez, pinta desnudos: cuerpos, casi siempre, a los que dio plenitud y euritmia la maternidad. La epidermis rosa y nácar de sus modelos francesas se presta, cual ninguna otra, a las delicadas magias del pincel. Así lo entendía Renoir, para quien era el desnudo tema de auroras deslumbrantes. Sólo que en Renoir el artista - genial sin duda, con la robustez, un no sé qué peyorativamente popular, en tanto que en Zárraga el buen gusto es congénito, herencia de afinamientos sucesivos. $\mathrm{Y}$ lo que en Renoir obedecía a su prodigioso instinto, se debe en el mexicano a su cultivado talento.

Las obras de Zárraga en esa época trascienden aquella impresión de paz sonriente que nos da la contemplación de un lento río en un paisaje veraniego; o la que causa el nobilísimo comienzo del andante en la Quinta Sinfonía de Beethoven: paz, serenidad; pero no serenidad olímpica, lindante con la indefenrencia: serenidad humana, impregnada de vida; calma, pero con latente fuerza; reposo, más con toda la acción inmediata en potencia.

Ese arte noble y alto, de profundo humanismo y sólido sentido arquitectónico, tenía que encontrar en la pintura mural sus más brillantes realizaciones.

A fines de 1932, a petición del gran diario parisiense Excelsior, Zárraga realiza una encuesta entre arquitectos célebres - Auguste Perret, Maller-Steven, Le Corbusier, Siclis y otros-, mediante la cual define las bases de la colaboración entre el arquitecto, el pintor y el escultor para lograr unidad de concepción y de realización en los edificios. Llevando al extremo, en efecto, la lógica constructiva, los arquitectos habían acabado por abolir la decoración, dejando desnudos los muros, hasta que descubrieron -y a ello no poco ayudó la encuesta de Angel Zárraga-- que la arquitectura moderna con sus vastas superficies lisas, se presta mejor que otra alguna a recibir pinturas murales.

No por capricho ni menos aún por casualidad llevó Zárraga a cabo tal encuesta. Si fue a oir de boca de arquitectos famosos la afirmación de la armonía y complemento de aquellas artes, es porque ésa era su teoría estética, y porque desde 1922 había comenzado a ponerla en práctica, con las pinturas para el castillo de Vert-Coeur, en Chevreuse, cerca de Versalles, en las que trabajó hasta 1928. En 1924 decora a la encáustica la cripta de Nuestra Señora de la Salette, en Suresnes, y pinta en sus tres capillas vastas composiciones: la Anunciación, la Asunción, el Coronamiento de 
María. Zárraga toma del cubismo, para estos bellos paineles, la riqueza decorativa y los recursos - superposiciones de halos, interpolación de haces de color, etcéteraque permiten inteponer, con materia generosa y densa, lo abstracto, y situar las figuras -mediante una serie de convenciones, por supuesto, pero que responden a nuestro sentimiento si no a nuestra intuición- en un plano suprarreal, en el camino de lo ideal.

En 1926 decora la iglesia de los Minimos en Rethel. Todo, en esas pinturas, exaltaba simbólicamente la Resurrección, porque la Iglesia, había sido reconstruida de las ruinas en que la dejara la guerra de 1914-1918. Nuevamente la guerra la ha destruido, en 1940, y con ella las pinturas de Zárraga.

En 1927, don Alberto J. Pani, a la sazón Ministro de México en Francia, le encomienda la decoración de la Sala de Fiestas de la Legación, vasta serie de dieciocho paineles alegóricos, entonados en un vivo ritmo de color.

En 1932 decora la iglesia de Fedhala, en Marruecos. Un año más tarde, el gran arquitecto Auguste Perret construye expresamente un hall para encuadrar un fresco de Zárraga sobre un tema de Paul Valery. En la capilla del Redentor, en Guébriant, comienza unas pinturas al fresco, que termina entre julio de 1933 y octubre de 1934; la Anunciación, el Redentor, las Bienaventuranzas, un Viacrucis.

De 1933 es también su fresco en la Casa del Café, en la plaza de la Ópera, de París - y una fotofrafía le muestra subido en un andamiaje de tubos de hierro y tablones, ante el muro en donde ya aparece su Don Quijote, que él ha tenido la malicia de pintar visto de espaldas, en lo que podría encontrarse un símbolo: el buen hidalgo desdeña nuestro mundo cotidiano, la nada aliciente realidad; Don Quijote sólo puede estar de espaldas a lo actual; su mundo está más allá, en la perspectiva irreal de la pintura.

Las obras murales se suceden: en 1934 decora la cúpula del Mal Paso en Mégeve; en 1935, la iglesia de la Ciudad Universitaria, de París. Pinta más tarde las Fábulas de La Fontaine en una casa de campo, en Meudon. En vísperas de la guerra y durante sus primeros tranquilos meses, Zárraga decora la sala de sesiones del Consejo de Administración y los despachos del director y del administrador de la Compañía de Fosfato de Constantina, en París, con alegorias de las estaciones y de los trabajos y recreo rústicos, y con evocaciones paganas: Nausícaa y Ulises, el Juicio de París. La Venus de este último painel es quizás la figura más fina, la más deliciosa de cuantas ha creado su pincel. En fin, en plena guerra, ocupada ya Francia por los invasores, pinta Zárraga un dramático Viacrucis en la iglesia de Meudon, y un vasto fresco, de más de sesenta metros cuadrados, en la iglesia inferior de San Fernando de las Ternas, en Paris, dedicada a Santa Teresita del Niño Jesús.

El Viacrucis de Meudon es de intenso pathos y de sorpredente sobriedad. Deja una inolvidable impresión de fuerza, lograda con un minimo de elementos, mediante la selección de lo característico, de lo más expresivo. Zárraga reserva el detalle para los rostros y trata las figuras en amplias masas. Con el mismo espíritu que los pintores del Renacimiento, Van Orley por ejemplo, pone a los sayones repulsivas facies. La composición, tan arbitraria como la de Mantegna, es en general de medias figuras, lo que permite darles mayores dimensiones $y$, por tanto, obtener mayor intensidad de expresión. Innova radicalmente en las actitudes; en el painel de Simón Cirineo, es no más la corona de espinas, el resplandor en torno al cabello, la túnica y las crispadas manos, lo que vemos de la víctima, desplomada en el suelo. En todos los tableros el 
profundo sentido arquitectónico da a la composición, sin perjuicio del movimiento de las figuras, gran estabilidad.

No debe verse en esas cuatro etapas de la evolución de Angel Zárraga - mal esbozadas aquí por la cortedad del espacio, que nos veda asimismo hablar de sus expresivos retratos y de sus bellos paisajes- incertidumbre en el camino. La variación no es juego, ni menos aún acatamiento a la moda: el pintor ha resguardado siempre la independencia de su ruta. La evolución de Zárraga es impulso creador, aunado al desdén por la facilidad de la repetición: no quiere -como Picasso no quiere- que el público llegue a formarse de él una idea definitiva. Ningún esquinazo, sino la rapidez. de un viaje a lo largo de la vida, cambiando de paisaje según las ondulaciones del terreno. Cada obra tiene para el artista un valor de realización: el presente, y ur valor de busca: el futuro. Pero el lógico que hay en Zárraga se contiene siempre para no llegar al límite extremo de sus descubrimientos. Todos ellos son para él, medios. $\mathrm{Y}$ a la vez, si audacia sonriente, ninguna aventura. Se desdobla en su pintura, no se agota en ella. Asi son sus obras llenas, de graves, de tan alta y clara nobleza. Obras honradas y francas - porque puede aplicársele lo que él mismo ha dicho de Seurat: "Con él, todo es claro, todo es neto como una palabra de honor. Su obra es la de un hombre."

A ese valor expresivo le ha llevado el dominio de la técnica. Sabe, como pocos, advertir las relaciones sutiles que son, diríamos, el esqueleto de la belleza. En su espiritu las impresiones se transmutan por la misteriosa alquimia del arte, y al exteriorizarse en la tela aparecen depuradas, traspuestas a un plano superior, recreadas. Lo accesorio y circunstancial queda eliminado. El pintor, constreñido a limitarse, elige. $\mathrm{Y}$ de esa concentración la obra toma su vuelo lírico. El milagro -que es el de toda creación artística - se logra naturalmente. Pero entre ese proceso y la obra, está el medio material: la mano con el pincel, el ojo juez. Ahí intervienen sus conocimientos técnicos: la ciencia de los valores, la seguridad en el tratamiento plástico de los volúmenes, la caligrafía firme y segura, el acierto en la síntesis, la franqueza sin rudeza de la pincelada, la justa proporción en el empleo de la pasta, la amplitud y nobleza de la composición. "Su dibujo dice lo esencial -expone uno de sus más perspicases comentarios- sin desviarse en vano arabescos. Va derecho a su fin, enérgico, voluntarioso allí donde necesita serlo, pero se dispensa de ser, siempre, tenso. Sabe expresarlo todo, pero también sabe sugerir sin apoyar, sin insistir. De este dominio perfecto de su escritura resulta una impresión de equilibrio, de armonía, de ritmo."

Su modelado es firme y de relieves eficazmente traducidos. Así tienen sus desnudos tal lozanía; sus figuras de deportistas, tal fuerzi. Su color es potente al par que matizado; opone con valentía unos, tonos a otros, logra afinaciones perfectas. Todo ello, normado por un principio al que es fiel. "Ell la pintura lo primordial es la arquitectura interna"; la del conjunto no menos que la de cada figura. Zárraga sabe siempre lo que quiere decir -en el artista esto es indispensable-; y lo dice con total claridad y precisión. $Y$ esto, en el artista, es no menos indispensable. Y Zárraga lo dice $\sin$ reticencias, sin trampas, lealmente, en un lenguaje expresivo. Le guía en 
ello -y se dijo- el espíritu sereno, ardientemente cultivado. Pero la técnica, por cabal, se hace olvidar; asi la emoción, cualquiera que ésta sea, se incorpora a la obra con exactitud, y la anima. Todos sus cuadros, todos sus frescos, llevan por signo distintivo una misma nobleza: ni énfasis ni timidez. Tranquila gravedad, que no es enigma de la alegría ni se alarga hasta el pesimismo: tranquila gravedad de humanidad mejor. Nada que no sea natural, sencillamente limpio. Es el suyo arte de claridad, de equilibrio y de medida. Pintura con aquel "segundo sabor" -rico y, a la vez, fino- de que habla León Daudet, sin el cual la obra de arte no tiene valor verdadero y perdurable; y basándose a sí misma, sin necesidad de explicaciones: franca, limpiamente Pintura.

Enero de 1942.

\section{J. M. González di: MendozA}

Catálogo: 1. rincón de pueblo con capilla, 1898, .15 x .05, col. Francisco Zárraga 2. paisaje, 1902, óleo s/tela $.60 \times .50$, col. Dr. Fernando Coalla 3. Cirano, 1903, pastel $.60 \times .50$, col. Arq. Jorge Durón H. 4. mi buhardilla en Bruselas, 1905, óleo s/tela $.40 \times .32$, col. Fernando y Clara Zárraga 5. mujer en oración, 1906, óleo s/tela $.73 \times .45 \mathrm{col}$. Sra. Adelaida Argüelles Vda. de Santa Fé 6. la señora del abanico, 1906 óleo s/tela $.80 \times .75$, col. Sra. Adelaida Argüelles Vda. de Santá Fé 7. el hombre del paraguas, 1906, óleo s/tela $1.90 \times 1.20$, col. Instituto Nacional de Bellas Artes 8. mafalda, 1909, óleo s/tela .63 x .45, col. Arq. Guillermo Zárraga 9. alegoría de septiembre, 1909 , óleo s/tela $1.80 \times 1.80$, col. Instituto Nacional de Bellas Artes 10. el pan y el agua, 1911, óleo s/tela $1.88 \times 2.06$, col. Arq. Guíllermo Zárraga 11. la adoración de los Reyes Magos, 1911, óleo s/tela $2.10 \times 2.10$, col. Sra. María Teresa de Sánchez Navarro 12. ex-voto, 1910-1912 (San Sebastián), óleo s/tela $1.84 \times 1.34$, col. Instituto Nacional de Bellas Artes 13. el circo, 1915 , óleo s/tela $1.08 \times .84$, col. Francisco Zárraga 14. dama en verde, 1915, óleo s/tela $.92 \times .73$, col. particular 15. majer con batea de frutas, 1915, óleo s/tela .80 $\mathrm{x} .73$, col. Fernando y Clara Zárraga 16. Chango pintor, 1916, óleo s/tela $.91 \mathrm{x} .72$, col. Francisco Zárraga 17. merienda de dos niñas, 1916, óleo s/tela $.91 \times .71$, col. Francisco Zárraga 18. muchacha con frutas, 1916, óleo s/tela $.50 \times .40$, col. Francisco Zárraga 19. chango músico, 1916, óleo s/tela .92 x .73, col. Francisco Zárraga 20. merienda, 1917 , óleo s/tela $.80 \times .65$, col. Francisco Zárraga 21. el lector, 1917 , óleo s/tela .91 x .71, col. Francisco Zárraga 22. septiembre, 1917, óleo s/tela 1.31 x 90 , col. Fernando y Clara Zárraga 23. composición, 1917, óleo s/tela $1.00 \times$ $.99 \mathrm{col}$. Fernando y Clara Zárraga 24. retrato cubista, 1917, óleo s/tela $.47 \times .38$, col. Lic. Antonio Luna Arroyo 25. Virgen de la Victoria, 1918, óleo s/tela $1.00 \mathrm{x}$ .80 , col. Pedro Licona García 26. naturaleza muerta, 1919 , óleo s/tela $.56 \times .51$, col. Francisco Zárraga 27. vendedora de frutas, 1922, óleo s/tela .65 x .81 , col. Pedro Licona García 28. mujer dormida, 1922, óleo s/tela $.74 \times$.61, col. Lic. Antonio Luna Arroyo 29. retrato de mi madre, 1922, óleo s/tela $.92 \times .73$, col. Arq. Guillermo Zárraga 30. futbolistas, 1922, óleo s/tela $.94 \times .75$, col. Srita. Guadalupe Luna Arroyo 31. bañista, 1923, óleo s/tela $.91 \times 12$, col. Arq. Guillermo Zárraga 32. triptico, 1924, óleo s/tela $.80 \times 2.40$, col. Arq. Guillermo Zárrag 33. desnudo, 1925, óleo s/tela $.95 \times .75$, col. Arq. Guillermo Zárraga 34. deportista (Ramón Novarro), 1925, óleo s/tela $1.30 \times 1.00$, col. Francisco Zárraga 35. jugada de futbol, 1925, óleo s/tela $.65 \times .53$, col. Francisco Zárraga 36. San Jorge, 1925, óleo s/tela $1.80 \times 1.80$, col. Francisco Zárraga 37. jugada de futbol, 1920-25, óleo s/ tela .81 x 1.01, col. Fernando y Clara Zárraga 38. jugada de futbol, 1920-25, óleo s/tela ,.92 x.60, col. Fernando y Clara Zárraga 39. futbolista I, 1922-25, óleo s/tela $1.49 \times .89$, col. Fernando y Clara Zárraga 40. futbolista II, 1926, óleo s/ 
tela $1.45 \times .90$, col. Fernando y Clara Zárraga 41, paisaje en Bretaña, 1926, óleo s/tela $.91 \times .73$, col. Arq. Guillermo Zárraga 42. desnudo, 1926, óleo s/tela $1.14 \mathrm{x}$ .88 , col. Arq. Guillermo Zárraga 43. piel tostada, 1926, óleo s/tela $1.00 \times .82$, col. Sr. Jorge Dipp 44. Limberg, 1927, 1.57 x .85, col Fernando y Clara Zárraga 45. futbolistas en el llano, 1924-28, óleo s/tela $1.75 \times 1.23$, col. Fernando y Clara Zárraga 46. retrato de una pintora, 1930, óleo s/tela $1.00 \times .80$, col. Fernando y Clara Zárraga 47. dos mulatas, 1930, dibujo a lápiz $.38 \times .30$ col. Ing. Marte $R$. Gómez 48. domingo, 1931, óleo s/tela $.63 \times .78$, col. Francisco Zárraga 49. estudio del pintor Zárraga en París, 1935-36, óleo s/tela .80 x .65, col. Francisco Zárraga 50. desnudo, 1936, óleo s/tela $.80 \times 1.65$, col. Sr. Alberto Fuentes 51. pesca, (naturaleza muerta), 1937, óleo s/tela $.63 \times 1.10$, col. Arq. Gustavo M. Saavedra 52. estudio, 1937, dibujo a lápiz $.35 \times .45$ col. Sra. Ana Caraza de Ramírez 53. Cyrano, 1938, dibujo a lápiz $.75 \times .55$, col. Sra. Ana Caraza de Ramírez 54. la solterona, 1938, óleo s/tela .81 x .60, col. Arq. Guillermo Zárraga 55. futbolista, 1941, tinta y aguada $.31 \times .24$, col. Ing. Marte $\mathrm{R}$. Gómez 56. retrato de la Sra. Hilda de Gómez, 1942, óleo s/tela $1.20 \times .80$ col. Ing. Marte R. Gómez 57. la fuente de la salud, 1942, dibujo a lápiz .55 × .38, col. Ing. Marte $\mathrm{R}$. Gómez 58. réplica de la mujer simbolizando el placer, 1942 , dibujo $1.45 \times 1.65$, col. Lic. Antonio Luna Arroyo 59. la niña de la lima, 1942, óleo s/tela $.80 \times .61$, col. Srita. Mariana Morillo Zafa 60. niño Carlos Prieto, 1943 , óleo s/tela $1.40 \times 85$, col. Sr. Lic. Carlos Prieto 61 . siete dibujos con temas clásicos, 1943, dibujo a sepia $.35 \times .28$, col. Ing. Marte $\mathrm{R}$. Gómez 62. mujer con caracol, 1943, óleo s/tela $1.15 \times 95$, col. Lic. Antonio Luna Arroyo 63. retrato de Eugenia Souza, 1943, óleo s/tela $1.15 \times .65$, col. Sra. Eugenia Souza de Martín del Campo 64. retrato de la Sra. Luz Souza de Souza, 1943, óleo s/tela 1.30 x 1.10, col. Sr. Antonio Souza 65. Liliane en el taller, 1944, óleo s/tela, 1.57 x 1.12, col. Mariana Morillo Zafa 66. desnudo de mujer, 1944, tinta y aguada .30 x .48, col. Ing. Marte R. Gómez 67. retrato de la Sra. Eulalia Orendáin de Rendón, 1944, óleo s/tela $1.10 \times 1.10$, col. Sra. Eulalia Orendáin de Rendón 68. desnudo, cuerpo entero, 1944-45, óleo s/tela $1.84 \times .59$, col. Arq. Guillermo Zárraga 69. cabeza de mi modelo, 1945, óleo s/tela $.50 \times .36$, col. Francisco Zárraga 70. autorretrato, 1946, dibujo a lápiz .38 x .32, col. Ing. Marte R. Gómez 71. Nausicac y Ulises, $5 / \mathrm{f}$, temple $2.55 \times 2.30$, col. particular 72 . mi vecinita, $\mathrm{s} / \mathrm{f}$, óleo s/tela $.32 \times .32$, col. Francisco Zárraga 73. negrito futbolista, s/f, óleo s/tela .91 x .62, col. Francisco Zárraga 74. la mancha, s/f, óleo s/tela $.49 \times .33$, col. Francisco Zárraga 75. mujer a la orilla de un pozo, s/f, óleo s/tela $.55 \mathrm{x}$ .38, col. Francisco Zárraga 76. Carnaval, s/f, óleo s/tela .73 x .70, col. Francisco Zárraga 77. retrato de mujer, s/f, óleo s/tela $1.08 \times .80$, col. Francisco Zárraga 78. retrato de varón con perro, $\mathrm{s} / \mathrm{f}$, óleo $\mathrm{s} /$ tela $1.15 \times .90$, col. Francisco Zárraga 79. el geógrafo, s/f, óleo s/tela $.60 \times .37$, col. particular 80 . trajinera, s/f, óleo s/tela $1.58 \times .79$, col. particular 81 . retrato de Juana, $\mathrm{s} / \mathrm{f}$, óleo s/tela $.72 \times .55$, col. particular 82. desnudo, s/f, óleo s/tela 1.13 x .88, col. Arq. Guillermo Zárraga 83. desnudo, s/f, óleo s/tela $.65 \times .54$, col. Arq. Guillermo Zárraga 84. paisaje, $\mathrm{s} / \mathrm{f}$, óleo $\mathrm{s} /$ tela $.81 \times .65$, col. Arq. Guillermo Zárraga 85 . mujer en la hamaca, $\mathrm{s} / \mathrm{f}$, óleo s/tela $.50 \times .72$, col. Lic. Antonio Luna Arroyo 86. retrato de Sarita, s/f, óleo s/tela .55 x .46, col. Lic. Antonio Luna Arroyo 87. soldado de los Andes de Flandes, $\mathrm{s} / \mathrm{f}$, óleo s/tela $.27 \times .19$, col. Pedro Licona García 88. bañistas, $\mathrm{s} / \mathrm{f}$, óleo $\mathrm{s} / \mathrm{tela}$ $.65 \times .54$, col. Marcelo Javelly 89. mujer en la fuente, s/f, óleo s/tela $1.15 \times 1.45$, col. Sra. María Teresa de Sánchez Navarro 90. la monja, s/f, óleo s/triplay $.42 \times .33$, col. Sra. Isabel $\mathrm{R}$. de Flores 91. mujeres del mundo, s/f, óleo s/tela $1.58 \times 2.28$, col. Sra. Isabel $R$. de Flores 92. bañistas, óleo s/tela $.97 \times 1.31$, col. Francisco González de la Fuente 93. pescadores, s/f, óleo s/tela $1.64 \times 1.30$, col. Francisco González de la Fuente 94. alegoria de Francia, s/f, óleo s/tela $1.64 \times 1.30$, col. Francisco González de la Fuente 95. las futbolistas, s/f, óleo s/tela $1.45 \times 1.13$, col. l'nstituto Nacional de Bellas Artes 96. en la playa, s/f, s/tela $1.25 \times .95$, col. Sra. Ana M. de Somlo 97. el hombrc solitario, s/f, carbón s/papel $1.20 \times 1.00$, col. Arq. Agustín Landa 98. desnudo, s/f, óleo s/tela $.82 \times 1.82$, col. Alberto Fuentes. 
IRENE EECERRIL. Exposición de óleos y dibujos recientes, presentada por la Galería Iosć Ma. Velasco, Peralvillo 55, INBA/SFP, el 18 de abril.

Catálogo: OLEOS: 1. ensueño 2. estrella de David 3. plenilunio 4. angelitos negros 5. pirotecnia 6. follaje 7. nacimiento 8. segando 9. poesía azul 10. arco iris 11. jacarandas 12. mulitas 13. bendición de los animales 14. autorretrato 15. retrato de Eva Vastari 16. retrato de Gury Truby. DIBUJOS: 17. angustia 18. abandonadas 19. blanco y negro 20. sacrificio 21. hombre 22. mestizaje 23. nadre 24. paisaje núm. 125 . paisaje núm. 2 26. ilustración del libro de Eva Vastari 27. ilustración del libro de Eva Vastari.

1.UIS GARcía RoBledo. Exposición de litografías, presentada por la Escuela Nacional (ie Artes Plásticas (UNAM), Sala de Exposiciones, Academia 22, el 18 de abril.

Lurs lópez loza. Exposición de pinturas, presentada por la Galería de Arte Mexi(ano, Milán 18, del 21 de abril al 17 de mayo.

Catálogo: 1. presencia nocturna 2. calendario de formas num. I 3. calendario de. formas núm. II 4. sótano espacial 5. formas devorándose 6. metamorfosis de un zapato núm. I 7. metamorfosis de un zapato núm. II 8. euforia de un zapato 9. zapato concreto nim. I 10. zapato concreto nim. II 11. zapatillas, deformaciones arquitectónicas serie $I$ del 12 a 19 20. deformación de una casa roja, deformaciones arquitectónicas serie II del 21 a 29. Grabados, buril y mezzo-tinta del 30 a 35 , grabados, mezzo-tinta del 36 al 41.

ALFREDo MEneses. Exposición de obras recientes, presentada por la Galería Edvard Munch, Paseo de la Reforma 489, el 21 de abril.

TONI SBERT. Exposición obra reciente, presentada por la Galería Jack Misrachi, Londies 158, el 22 de abril.

Carlos scannapieco. Exposición de xilografías y técnicas mixtas, presentada por el Organismo de Promoción Internacional de Cultura, de la Secretaría de Relaciones Exteriores y la Embajada de la República de Argentina en México, Sala de Arte Opic, Av. Juárez 42, Edificio “C”, 2a Mezzanine, el 23 de abril.

TRINIDAD osorio. Exposición de obras, presentada por la Galería de Arte Nieto, Av. Iuárez 4, esq. con San Juan de Letrán 1, del 25 de abril al 21 de mayo.

Catálogo: 1. día de campo 2. mujer 3. niña con perro 4. joven músico 5. el gran salto 6. cabaña en la playa 7. naturaleza muerta 8. niños jugando 9. niña con palomas 10. naturaleza muerta 11 . figuras 12 . naturaleza merta 13 . los pájaros 14. paisaje 15. ciudad iluminada 16 a 25. dibujos.

LU1S goLLAND. Exposición de 20 fotografías (la piscina lustral), presentada por el Instituto Nacional de Bellas Artes, Galerías del Palacio de Bellas Artes, Sala 3, el 24 de abril.

Datos biográficos: Luis Bolland, nació en México, D. F., en el año de 1920. 
ClARA kJINGHOFFER. Exposición de pinturas y dibujos, presentada por el Instituto Mexicano Norteamericano de Relaciones Culturales, A.C., Galería Nabor Carrillo, Hamburgo 115, el 24 de abril.

Catálogo: 1. woman puring tea 2. back of a woman 3. ray, leaning head on hand 4. head of a woman 5. baby, facing 6. San Jacopo Gate, S. Gemignano (Italy) 7. woman ironing (wash) 8. two babyheads 9. Lucy 10. woman asllep (chalk, sepia) 11. study of a girl 12. Fortin de las flores, study 13. Mike looking at $T V$ 14. Rachel (back study) 15. a page of Mexican figures 16. baby on its stomach 17. head of a young woman 18. girl (backview) 19. sleeping baby boy 20. Amy, drawing (original drawing for a litlo) 21 . baby on its belly (sanguine) 22. seated woman 23. the pasha, baby study 24. girl at a table 25. pen drazing of ray 26. sleeping woman 27. venetian beggar (pen) 28. venetian beggar (pen) 29. leah, asleep 30. basilica at Patzcuaro (flo-nen) 31. baby study 32. sheila 33. at lake Patzcuaro (gouache) 34. Jacopo Gate, S. Gemignano, Tuscany 35. Rosalind (pencil drawing) 36. head of a woman (black chalck) 37. mude, foreshortened (sanguine) 38. standing mde, back vieze 39. nude, resting 40. mude study 41. mude figure 42. sleeping baby 43. sick girl 44. Erica, asleep 45. pencil study of leah 46. little Angela 47. seated mude, hand at face 48. two nude studies (sepia) 49. back veize of a mude 50. Susan 51. mude (line drawing) 52. nude reading 53. two nude figures 54. Ray (red chalk) 55. woman sleeping 56. girl sleeping. PINTURAS: 57. a girl in a red blouse at a table 58. brown jug and apples 59. women at market 60. Ernestine parying 61. interior, with two figures 62. guitar player 63. spring flowers 64. small mude, backview 65. girl drinking tea 66. girl, seated (hand at head). LITOGRAFIAS: 67. old scholar 68. little dancer, resting 69. mother and child 70. mexican market 71. little seamstress 72. woman pouring tea, backview 73. woman pouring tea, 2 colors 74. amy, drazeing 75. the story book.

AleX ANDer Bogen, LIOR ROTH, MOSHE GAT. Exposición presentada por la Galcria MerKup, artistas de la Plástica Mexicana, A.C., bajo el Patrocinio de la Embajada de Israel, Molière núm. 328-C, el 24 de abril.

homenaje a JaIMe nunó. Exposición de fotografías, presentada por el Instituto Cultural Hispano-Mexicano, A.C., Tabasco núm. 68, el 24 de abril.

El padre Juan Bautista Bertrán s.j., es uno de esos raros poetas que escriben su poesía viviéndola, es decir, que sin negar realidad a cada uno de los actos de la vida, descubren en ellos un sentimiento que va más allá de lo aparente.

En su libro Hay un valle en mi infancia el poeta nos muestra todo un mundo de evocaciones, de vivencias, tanto espirituales como físicas, de recuerdos, que se mezclan al presente que es quien los ordena, y de cuyas resonancias nos hace partícipe.

Por una feliz coincidencia para nosotros, este valle del padre Juan Bautista Bertrán, es el mismo en que viera la luz primera Jaime Nunó, el autor de la música del Himno Nacional Mexicano.

San Juan de las Abadesas, que en esta ocasión podremos conocer en su esencia gracias al lenguaje de la poesía, es un lugar de la provincia de Gerona, España, y también, en cierta medida, un lugar espiritual de mestra patria.

Salvador Moreno 
NotA: en la sala de conferencias serán expuestas algunas fotografias de San Juan de las Abadesas, de Eudaldo Esteve, y los proyectos del Arq. José Blas Ocejo, de la fuente que será erigida en dicha población por el Comité Bilateral España-México, en honor del Himno Nacional Mexicano y de sus autores.

PINTURa y ESCUltura. Exposición colectiva, presentada por la Galería Selene, Parroquia $105-\mathrm{H}$, esquina con Insurgentes el 25 de abril.

Nombre de los expositores: Alfonso Ayala, Fernando Botas, Fernando Buitrón, Héctor Correa Zapata, Nicolás Moreno, Marín Bosquet S., Pedro G. Montes, Mariano Paredes, Angelina Vértiz, Juan Cruz, Tosia.

GERARDo CANTú. Exposición presentada por el Instituto Nacional de Bellas Artes (SEP)/Salón de la Plástica Mexicana, Havre núm. 7, del 25 de abril al 15 de mayo.

SHOSHANA LI-ON. Exposición de pintura Israclí, presentada por las Galerías del Centro Deportivo Israelita, Manuel Avila Camacho 620, Lomas de Sotelo, del 27 de abril al 20 de mayo.

Datos biográficos: En 1936, emigró de Yugoslavia a Israel. Fue miembro del Kibutz Afikim, iniciándose alli mismo en la pintura. En 1939, ingresa a la asociación Nacional de pintores y escultores en Israel. Toma parte en varias exposiciones colectivas. En 1940 presenta su primera exposición individual en Tel-Aviv en la Galería Katz.

SUZANNE DroRio. Exposición de obras recientes, presentada por el Instituto Norteamericano de Relaciones Culturales, A. C., Galería Nuevos Valores, Hamburgo 115, del 29 de abril al 20 de mayo.

RICHARD UPTON. Exposición de ilustraciones, presentada por el Instituto Nacional de Bellas Artes, Galerías del Palacio de Bellas Artes, Sala Internacional, el 30 de abril.

El mayor atractivo de esta notable exhibición de trabajos recientes de Richard Upton consiste en tres espléndidas carpetas: Impresiones de París (1965), Credo, basado en El paraíso perdido de Milton (1968), y Eros Thanatos con poemas alemanes medievales en traducción original al inglés de Helga Doblin.

Desde 1964, Upton ha realizado un gran número de exposiciones en galerías de universidades e institutos de los Estados Unidos. Además ha participado tanto en la mayoría de las exposiciones de grupos nacionales reconocidos, como en las exhibiciones que han viajado bajo el patrocinio del Instituto Smithsonian y la Federación Americana de Arte. Está representado en las más grandes colecciones de gráfica como las de la Biblioteca Nacional de París, el Museo de Bellas Artes de Montreal, la Biblioteca del Congreso de Washington, el Museo de Arte Moderio de Nueva York y el Museo de Arte de Filadelfia, la Colección Nacional de Bellas Artes en Washington y la Universidad de Siracusa.

El significado particular de la obra de Upton aquí expuesta es la relación sensitiva entre la figura y el espacio que el artista parece haber redescubierto en el mundo circundante, y la imagen lírica del poeta que, en alguna forma, ha adquirido nuevo significado a través de una yuxtaposición. El origen parece haber sido la inspiradora atmósfera de París en 1964-65, donde Upton gozó de una Fullbright Research 
Grant, pero sobre todo los famosos talleres de Clot, Casse, Lacouriere, y Stanley Hayter's Atelier 17. Fue la devoción artesanal y la rica tradición de grandes libros acumulada en estos talleres (especialmente Jacques Frelaut y Lacouriere, que editaron los famosos portafolios de Segonzac, Picasso, Miró, Rouault, Tanguy y Debuffet) lo que marcó a Upton el curso de su propio desarrollo.

La idea y su evolución, como puede verse en la obra de Upton, así como en el de algunos de sus colegas, tiene en el arte americano contemporáneo un profundo significado que aún no se capta del todo. En ese momento Upton sentía que casi toda la pintura se estaba despersonalizando y había perdido el contacto vital con el pueblo y la sociedad. A decir verdad se puede argüir que, en un sentido amplio, la pintura ya no posee ninguna justificación ideológica y técnica para ocupar una posición dirigente. Posiblemente ésa es la razón del renacimiento incomparable del grabado actual y la inspirada vitalidad de esta nueva generación.

\section{LAURENCE SCHMECKEBIER}

Richard Upton nació en Hartford, Connecticut, 1931. Hizo estudios de pintura y grabado en el College of San Mateo (California), Universidad de Connecticut, Universidad de Indiana, el Taller de Provincetown, la Academia de la Grand Chaumerie de París, los talleres de grabado de Auguste Clot, Casse, Lacouriere y Hayter's Atelier 17. Ha recibido los siguientes galardones: Indiana University Foundation Grant, el premio Brigham de dibujo, el premio adquisición en pintura del MunsonWilliam-Proctor Museum of Art; la Fullbright Research Grant; Ford Foundation. Ha realizado dieciocho exposiciones individuales en los Estados Unidos y en el extranjero. Sus obras han participando en exposiciones en el Museo de Arte de Boston; el Museo Nelson Gallery-Atkins; el Speed Museum; el Museo de Arte de Filadelfia; así como también en Grandes Grabados, Universidad Fstatal de Nueva York; Dibujos Americanos, Filadelfia (uno de los 10 artistas invitados) ; Dibujos, EUA 1968-1969, exposición itinerante; Grabados Actuales, EUA, Consejo de Artes del Estado de Nueva York; Instituto Smithsonian, Washington, D.C., en la Galería Jacques Casanova, París; en la Federación Americana de Artes, Nueva York. Ha realizado tres portafolios que son los que ahora se exponen aquí.

En la obra de Richard Upton no existen línites entre lo real y lo irreal. Ambos están mezclados para crear un sentido más intenso de la realidad en que la naturaleza está modificada, fragmentada, destilada. Figuras, paisajes, interiores y estructuras inventadas parecen correr unas dentro de otras, volverse símbolos los unos de los otros. Particularmente en los grabados, las imágenes parecen sobreponerse en capas transparentes o volverse parte de imágenes adjuntas en staccato, en una manera descontinuada de creat series de planos mutables.

En las pinturas, las figuras están modeladas con más peso y los ángulos y los espacios, se definen con mayor claridad. De esto resulta otro tipo de ambigüedad que abarca desnudos monumentales y su perturbador escenario. Las figuras, simplificadas hasta el punto de la anonimidad, sugieren algo más allá de la vida cotidiana. El 
tono emocional es de una crisis espiritual. Es esa grandeza de sensibilidad lo que da su extraordinaria calidad de la obra de Upton.

\section{JACOB KaINEN}

José garcía oCEjo. Exposición presentada por la Tasende's Gallery, Calzada Costera M. Alemán y V. Yáñez Pinzón, Acapulco, Gro., durante el mes de abril.

LEONARD NIERMan. Exposición, presentada por la Safrai Gallery, 171 Newbury Street, Boston, Massachusetts, EUA, durante el mes de abril.

Datos biográficos: Leonardo Nierman, nació en México, D. F., en el año de 1932.

MAYO

DENELLY FABRE. Exposición obra pictórica, presentada por la Galeria Kusak, Génova 2 J-bis, el 2 de mayo.

HERNÁNDEZ SUÁREZ (Hersua). Exposición presentada por el Instituto Francés de América Latina, Nazas 43, del 6 al 20 de mayo.

JUdith gutrérrez. Exposición de óleos, acrílicos y dibujos, presentada por la Galería Pecanins, Hamburgo 103, del 6 al 21 de mayo.

JUAN REYES (óleos y dibujos). José Lazcarro (grabados). Exposición presentada por el Instituto Nacional de Bellas Artes, Galeria Chapultepec, Insurgentes Sur 11bis, el 6 de mayo.

RODOLfo NIETo. Exposición de óleos y acrílico, presentada por la Galería Mer-Kup, Molière núm. 328-C, y Artistas de la Plástica Mexicana, A. C., el 7 de mayo.

héctor Xavier. Exposición (punta de oro y punta de plata), presentada por la Galería Mer-Kup, Molière núm. 328-C, y Artistas de la Plástica Mexicana, el 7 de mayo. Catálogo: los desmudos, "las azules" y los perros.

alfredo ramos martínez. Exposición Homenaje (1875-1946), presentada por el Instituto Nacional de Bellas Artes, Salas 1 y 2, del 8 de mayo, al mes de agosto.

La obra visionaria de Alfredo Ramos Martínez, por Alfonso de Neuvillate.

Alfredo Ramos Martínez fue un gran artista de su tiempo, al cual revaloramos hoy con la intención de darle un sitio definitivo en la historia del arte mexicano.

Existe en su producción varias épocas que se determinan por inquietudes, estados anínicos, modas y gustos teñidos de reminiscencias románticas y una profunda sensualidad.

Su primera producción comprende las obras realizadas de 1890 a 1900: trabajos académicos en que ostenta su habilidad como dibujante, su preocupación por la compo- 
sición y su correcto empleo de tonos, medios tonos, veladuras, texturas, claroscuro y, en general, su amplia visión de la plástica del fin del siglo y de las posibilidades de enriquecerla introduciendo en ella, las complejidades de dos difíciles géneros: el paisaje y el retrato.

A estos años corresponden gran número de copias de yesos, recreaciones del natural, tiernos y a la vez bucólicos paisajes nostálgicos, y alegorías de esa alegría de vivir que fue un tema reiterado al través de su vida y obra.

De 1900 a 1910, después de haber viajado por Europa absorbiendo las novedades estéticas del momento, cambia de rumbo en su expresión e imprime a sus obras delicadeza y símbolos sutiles que van desde paisajes oníricos hasta obras que resumen los ideales espirituales de los simbolistas. Influyen en él artistas como Rosseti, Waterhouse, Manet, Turner y Van Dongen, así como los decoradores de la Regencia: Watteau, Audran y Fragonard.

Sin embargo, puede hablarse de un Ramos Martinez inclinado hacia los temas y las formas caras al posimpresionismo. El detalle se diluye en manchas cromáticas, el todo se desvanece en la sugerencia. Los trajes, los rostros, anatomias femeninas, poseen una luminosidad interior que responde a un vehemente deseo, casi lujuria, por hacer sentir, por hacer palpable la decadencia de una pintura a la que sólo interesan problemas de belleza, entendida ésta, como copia fidedigna de sucesos y arquetipos perfectos.

Su obra maestra es La primavera, puesto que es en ella donde resume estudios, influencias, deseos, preocupaciones e ideales románticos $\mathrm{y}$, a la vez, filosóficos. El cuadro se exhibió en 1910 en las salas de la antigua Academia y tuvo éxito crítico sin parangón.

El cuadro, de tamaño monumental, es una alegoría jubilosa de la vida y sus placeres cotidianos, así como una exaltación de ciertos valores propios de ese momento histórico: cinco mujeres parecen bailar al compás de valses imaginarios y son como moldes de una belleza decadente. Sus vestidos transparentes, graciosos, las flores que llevan, así como las gasas y los tules, trabajados a la perfección por el artista, hacen patente, además de la maestría del pintor, una cierta frivolidad que cierra definitivamente una época y abre senderos a otra más dinámica y profunda.

El goce de la vida, la antítesis del drama, la glorificación de las virtudes, el efectismo difícil, el apenas sugerido paisaje que sirve de fondo a las damiselas parecen presagiar - por lo que hace a México- el fin de la llamada "paz porfiriana". No en balde su exhibición coincidió con las fiestas del Centenario. Empero, esta obra maestra de la pintura nacional, sublima ciertos conceptos plásticos así como algunas ideas fundamentales de la estética finisecular: su mismo alegorismo y simbolismo de carácter descriptivo ostentan visible el signo de su tiempo y evidencian la comprensión que Ramos Martínez tuvo de artistas como Renoir y Nonell.

La primavera es una obra majestuosa pero es también, un callejón sin salida de la pintura mexicana, exactamente como el Autorretrato y La odalisca de Gedovius; los retratos y las rosas de Ignacio Rosas; El San Sebastián, La adoración de los Reyes, Las futbolistas y El retrato de Ramón Novarro de Ángel Zárraga; Los espiritistas, Las hilanderas y La Manola de Juan Téllez Toledo, más los numerosos paisajes realizados a la acuarela de Gonzalo Argüelles Bringas, las miniaturas de Mateo Herrera; El torero muerto y los dibujos blanco y negro (prologados por Henri de Regnier) de Roberto Montenegro; y las chinas poblanas y trajineras de Saturnino Herrán. 
Estas obras - calles sin rumbo-- fin de una época, pertenecen a un género inclasificable de la pintura del siglo $\mathrm{xx}$. Por una parte incapsularon su simbolismo en románticas ensoñaciones, o por la otra cayeron en la languidez de una frivolidad decadente con puntos de coincidencia con la vuelta de la filosofía hacia la nada y el vacio.

Cuenta José Clemente Orozco en su autobiografía que: "Los pensionados a Europa tenían la obligación de mandar a México algunos cuadros anualmente, para ser exhibidos en grupo." Así conocimos los paisajes de Las Baleares de Montenegro, La casa sobre el puente de Rivera, los cuadros de Ramos Martínez, Angel Zárraga, Téllez Toledo y Goitia.

"Ramos Martínez lanzó su candidatura para Director de la Academia y pidió el apoyo de los estudiantes huelguistas prometiendo acabar con el monstruo académico y hacer grandes reformas en los métodos de estudio." Nos mostró una rica colección de vestidos de seda tornasolada que lucieron las modelos para el cuadro de La primavera. Nos habló largamente de Renoir, de Matisse, de Claude Monet, de Pissarro $y$, en fin, de todos los impresionistas franceses y de la aldea que hicieron famosa: Barbizón. Los muchachos pintores cayeron definitivamente, para no levantarse más en el embrujo parisiense de La primavera.

"Ramos Martínez fue director; lo primero que hizo fue fundar en Santa Anita, D. F., una escuela de pintura al aire libre llamada pomposamente 'Barbizón', que erá como fundar sobre el río Sena, cerca de París, un Santa Anita con trajineras, pulque, charros, enchiladas, huaraches y cuchilladas. A dos pasos de la Torre Eiffel.

"Esto no quiere decir que Ramos Martínez hizo mal; al contrario, era la reacciói natural contra la Academia, ya en completa descomposición. Porque los buenos métodos académicos de orden y disciplina habían desaparecido y sólo quedaban la ineptitud y la rutina. Lo malo estuvo en las consecuencias de esta innovación. J_os barbizonianos al aire libre pintaban muy bonitos paisajes, con los reglamentarios violetas para las sombras y verde nilo para los cielos, pero a mí me gustaba más el negro y las tierras que habían sido excluidas de las paletas inıresionistas. En vez de crepúsculos rojos y amarillos pinté las sombras pestilentes de los aposentos certados y en vez de indios calzonudos, damas y caballeros borrachos."

Todas estas pinturas de Alfredo Ranus Martínez son visionarias y proféticas en la medida en que sus formas, el mundo que plasmó y la atmósfera que fijó en pasteles, tintas, bosquejos y óleos, trascienden los conceptos de la hermosura para convertirse en signos de una transición.

Era lógico que, después de esta pintura, viniera el gran cambio hacia los temas: sociales y la problemática del liombre contemporáneo.

Alfredo Ramos Martínez, a lo largo de su obra, actúa sobre el supuesto de que todo es poesía, representacion (Vorstellung), de vivencias y espera de algo infinito: ideas y conceptos trascendentes sobre las probabilidarles de una metáfísica de carácter heideggeriano.

Su especulación estética aspira a quitar un velo a lo desconocido y con ello, a entrar en la revelación de las premisas poéticars de un todo imposible de cleslindar. (das begegnende). 
En Ser y tiempo, Heidegger trata de "mantener una posición entre el idealisıno Y la realidad del realismo y del naturalismo para que el hombre se proyecte como «r en el mundo". Alfredo Rannos Martínez, plásticamente hablando, coincide con estos postulados filosóficos; sin embargo, cae en los límites del vacío; interpreta, más bien, lo benal, con elementos de lo cursi, y se mantiene en una línea descriptiva, mejor diclio narrativa, del romanticismo tardío y del arte del cartel.

Hay en Ramos Martínez una concepción ideal de lo que lo envolvía: lo cotidiano como factor indispensable.

Kaerlegraard decía que: "Cuando planteamos objetivamente la cuestión de la verdad, la reflexión se clirige a la verdad como si fuera un objeto... Si sólo el objeto con quien el sujeto se relaciona es verdad, entonces el sujeto está en la verdad... Cuando nos planteamos subjetivamente la cuestión de la verdad, la reflexión se dirige subjetivanente a la naturaleza de la relación individual; si sólo el modo de esta relación ustá en la verdad, el individuo está en la verdad aun cuando estuviera relacionado con lo que no es verdad..."

Alfredo Ramos Martínez se instala en esa corriente del subjetivismo ya que, al plantearse en su obra una finalidad ideal y otra de carácter poético, circunscribió todo a ese afán que motivó, nás adelante toda una serie de obras con motivos florales.

A partir de 1920 su obra cambiah, en cuanto a la representación, para abordar tenas puramente decorativos, también llamados menores: flores, retratos de damas noctámbulas, escenas mexicanistas y conjunciones de orientalismos con descripciones de interiores lujosos y mujeres fatales.

Nada descleñable es este periodo plástico de Ramos Martínez ya que da una visión txacta del momento histórico.

Las damas se engalanan con misteriosos atuendos, con velos y sombreros emplumados, los trazos describen la moda de los años veintes y treintas con sus peculiarísimas manifestaciones: todos los rostros son nostálgico, pálido, perdidos en la bruma a velados entre los cortinajes lúbricos que la técnica del pastel podía dar.

También retornó a ciertos tipos del antaño pictórico: caballeros de gola y señoras vestidas como en tiempos de los Luises. Sin embargo, son evidentes la técnica y la perfección de caria una de estas obras como evidente fue su gusto por plasmar no innto la superficialidad de un rostro, sino los conceptos abstractos que toda "biografia dramática" debe llevar consigo: ternura, desconcierto, misterio, preocupación, melancolía, poesía, dramatismo, etcétera.

La pintura de Alfredo Ranos Martínez posterior a 1930 es débil puesto que, además de reiterar sus preferencias por determinados "tipos" de belleza, cayó irremediablemente en u1r arte cartelístico con sus connotaciones de banalidad y extemporaneidad.

Existe, además, un paralelisno, una correspondencia entre el pintor y las expresiones plásticas de la Escuela de París. Sus flores son comparables con las de Pierre Bonnard, sus alegrías de vivir con las que ejecutó Roussel, sus paisajes con los de Jean Metzinger, las naturalezas muertas con las de André Derain, Amédée de la Patellière y Marie Laurencin; y sus mujeres desconcertantes como las que pintaron Klee, Van Dongen y Chaim Soutine.

Lo "exquisito fallido" en Alfredo Ramos Martínez es una sublimación de ciertos 
seres que lo sedujeron y lo inspiraron en su oportunidad. Pocos, muy pocos por cierto son los modelos varones; en cambio son sinnúmero las mujeres de grandes ojos, con sombras azules o verdes y envueltas en las modas ocasionales de ese tiempo.

Ignoramos si Ramos Martinez pretendió, conscientemente, con su obra, dejar el testimonio fidedigno de la época en que radicó en los Estados Unidos. Lo cierto es que cada una de sus últimas pinturas, casi todas ellas al pastel, técnica de la que fue maestro consumado, son reflejo de la moda o gusto colectivos y también del idealismo con que siempre especuló: la mujer como meta de belleza y ejemplo artístico.

El arte de Alfredo Ramos Martínez resulta importante al enfocarlo con posterioridad a los ismos que le sucedieron en el acontecer histórico-plástico.

Fue el suyo un arte aislado, completamente distinto de lo que se hizo posteriormente, en el mundo de la pintura. Una obra contradictoria cuyo afán de perfección fue su misma finalidad.

Sus grandes dotes de dibujante, la temática escasa y afición por la "buena cursilería" lo colocan en sitio preferente dentro de los artistas visionarios que dejaron constancia estética de su momento con cuestionarios insolubles y premisas sin respuesta por efecto de su paradoja.

Los retratos de ladies inglesas, damas de sociedad mujeres incógnitas, señoritas de opereta, así como sus "estados del alma", es decir, sus paisajes de inconmensurable hermosura, y fundamentalmente, La primavera, son muestras de lo que fue como creador de emociones y reinventor de imágenes del romanticismo poético.

Su autorretrato es severo, casi monocromo, pero deja ver, con imaginación y sensibilidad, al tipo de creador de imaginaciones y sensibilidades ajenas a nuestro momento.

Artista siempre refinado trató de alcanzar esa rara perfección artística: sus aciertos son indiscutibles como indefendibles son los errores en que incurrió.

La descendencia o cauda que dejó, la herencia de las escuelas al aire libre, fue un mal estético, dado su carácter folklorista y su limitada cosmovisión. El experimento de la "Barbizón Mexicana" tiene interés exclusivamente como eso: investigación del paisaje y en la caracterología de la idiosincrasia. Los pasteles que realizó en Santa Anita y Coyoacán son magníficos, puesto que en ellos describió los paisajes urbano y rural.

Sin embargo, sus tintas, los dibujos sobre temas indígenas son pobres, precisamente por lo que Orozco señaló la falsificación de lo real.

Los ramos, los búcaros de rosas, amapolas y violetas, los jarrones colmados de pétalos y capullos de claveles y nomeolvides, los chícharos puestos amorosamente en vasos y copas de cristal tornasolado, las anémonas iridiscentes así como las mujeres sensuales con eróticas ojeras del ayer, del inmediato pasado, son temas que trató Alfredo Ramos Martínez con sin igual amor y delectación.

Los carbones y pasteles con molinos de viento de Holanda, los viejos bretones, los seres comunes del sur de Francia, fueron plasmados por el artista con tanta maestría como los de Ponce de León y Germán Gedovius.

Los retratos de Ramos Martínez simbolizan el esplendor y el ocaso de una época de transición. A lo delicado de su dibujo se une la imaginación y la evocación: tibia evocación de ese pretérito ya tan lejano en la historia y en el arte. 
La primavera basta para colocar al artista como inventor de realidad: no le falta ni le sobra detalle alguno. Es uno de los grandes logros de la pintura nacional.

Dentro del arte característico del siglo $\mathrm{xx}$, los productos estéticos realizados por esos maestros, artífices de lo real, descubren el lado poético de la vida y encierran el enigma de lo que llegó a pertenecer a lo metafísico.

Sus últimas obras, deleznables, quizá frutos de la decadencia, aportan, empero, razones de ser en la plástica del género cartelístico.

Indudablemente algunos de los últimos cuadros de Ramos Martínez poseen el signo de lo intrascendente. Pero, igualmente intrascendentales fueron ciertas obras de artistas como Forain y Burne-Jones: mismas que ahora cobran encanto y seducen por su sabor pretérito.

Ramos Martínez: un pintor desigual pero siempre seductor. Su obra de caballete (que es enorme) así como su producción mural conservada en domicilios particulares de Los Angeles, en la Santa Bárbara Chapel, en la Chapel of Mary Star of the Sea y en el Café de la Avenida, del Estado de California; los vitrales para la Saint John Catholic Church; y los muros inconclusos para el Scripps College de Claremont ponen de relieve su dedicación por la pintura y el aventurarse por todos los caminos o manifestaciones que ella depara.

Esta exposición-homenaje es doblemente importante. Se descubre a un pintor visionario y se muestra, por segunda vez, después de cincuenta y nueve años de no ser exhibida, y sesenta y cuatro de haberse pintado, su obra capital : La primavera.

Datos biográficos: Alfredo Ramos Martínez, nació en 1875, en Monterrey, Nuevo León.

Catálogo: 1. la primavera, París 1905, $188 \times 286$, óleo s/tela. Col. Sra. Amalia Mascareñas de Salcedo 2. dama con sombrero y rosa, pastel, $80 \times 66$ 3. mujeres en el campo con vestidos antiguos, $70 \times 90$, óleo 4 . mujer con niño, $37 \times 27$, técnica mixta 5. molino de viento holandés, $58 \times 48$, pastel 6 . molino de viento holandés, $58 \times 48$, pastel 7. paisaje chico con figuras y mar, $47 \times 32$, pastel 8 . cara de mujer con fondo veneciano, $72 \times 75$, pastel 9. paisaje chico con figuras, $46 \times 35$, pastel 10. paisaje de San Angel, $79 \times 122$, pastel 11. apaches parisinos, $47 \times 38$, pastel 12. holandeses con fondo de mar, $62 \times 57$, pastel 13. molinos de viento, $46 \times 40$, pastel 14. mujer con niño, $60 \times 47$, carbón 15. mujeres, $46 \times 33$, pastel 16. cinco figuras, $38 \times 32$, dibujo a lápiz 17. dibujo, $12 \times 10$, dibujo a tinta. 18. paisaje con tres árboles, $17 \times 12$, acuarela 19. paisaje de San Angel, $47 \times 36$, pastel 20. florero con rosas, $48 \times 63$, pastel 21 . búcaro de rosas, $53 \times 42$, paste 22. holandesas, $43 \times 37$, tinta china 23. mercado ambulante, $31 \times 23$, dibujo 24 . paisaje de Holanda, $39 \times 45$, pastel 25 . campesinos holandeses, $47 \times 37$, pastel 26. mujeres bretonas, $35 \times 26$, pastel 27. iglesia a contraluz-crepuisculo, $61 \times 46$, pastel 28. iglesia a contraluz-nocturno, $54 \times 44$, pastel 29 . las torres de Churubusco, $50 \times 35$, acuarela 30. paisaje europeo, $33 \times 27$, pastel 31. paisaje, $31 \times 22$, acuarela 32. mujer de perfil con naranjas, $64 \times 40$, pastel 33. triptico de Paris, $17 \times 12, \mathrm{c} / \mathrm{u}$ 34. retrato de la señorita con velo, $54 \times 44$, pastel 35 . dos mujeres bretonas, $36 \times 24$, técnica mixta 36. florero con malvones, $44 \times 29$, pastel 37 . retrato de indígena, $57 \times 53$, pastel 38. florero con rosas, $52 \times 45$, pastel 39. hombre con gola, óvalo, pastel 40. mujer con gola, óvalo, pastel 41. reunión de mujeres, $24 \times 18$, técnica mixta 42. molino de viento, $36 \times 36$, carbón 43. paisaje mexicano, $17 \times 14$, tinta 44 . iglesia, $12 \times 14$, tinta 45 . cabeza de hombre, $34 \times 25$, pastel 46. indigena con ollas, $35 \times 25$, dibujo a color 47 . cabeza de gato, $33 \times$ 28, pastel 48. figuras sentadas, $48 \times 4049$. paisaje, $14 \times 22$, acuarela 50. mujer bretona, $32 \times 40$, tinta 51. cabeza de dama, $38 \times 36$, pastel 52. mujer con sombrero, óvalo, pastel 53. ramo de rosas, $57 \times 53$, pastel 54. dos cabezas de cabritos, 
$39 \times 30$, pastel 55. vaso con flores, $31 \times 23$, pastel 56. rosas flotantes, $91 \times 51$, pastel 57. patio de casa, 71 x 55, pastel 58. cuatro pinturas en un cuadro, $53 \times 43$, pastel 59. paisaje mexicano, $41 \times 34$, pastel 60 . copia, $60 \times 48$, óleo $\mathrm{s} /$ tela 61 . retrato de un hombre, $53 \times 40$, óleo $\mathrm{s} / \mathrm{tela} 62$. ramo de flores con florero talavera, $55 \times 41$, óleo s/tela 63. ramo de flores con florero de loza, $47 \times 37$, óleo s/tela 64. interior del convento de Churubusco, $93 \times 63$, óleo s/tela 65. dama en azul, óvalo, pastel 66 . paisaje, $26 \times 18$, acuarela 67. paisaje, $26 \times 18$, acuarela 68. ramo de flores, óvalo, pastel 69. dama en rosa, óvalo, pastel 70 . rostro, $20 \times 27$, tinta 71 . holandesa, $27 \times 54$, acuarela 72 . actriz del cine mudo, $34 \times 44$, pastel 73. paisaje de brujas, $31 \times 35$, pastel 74. dos damas antiguas, $71 \times$ 55 , óleo s/tela 75. jarrón con rosas blancas, $70 \times 56$, óleo s/tela 76. rosas rosas, $40 \times 50$, pastel 77. cara de mujer con velo, $46 \times 33$, pastel 78. jarrón de cristal con hortensia, $69 \times 53$, pastel 79. mujer romántica, óvalo, pastel 80. mujeres en el campo, $70 \times 55$, óleo s/tela 81 . odalisca oriental, $45 \times 32$, pastel 82 . cara de mujer con flores en el pelo, $34 \times 27$, pastel 83. florero con rosas, $77 \times 57$, óleo $\mathrm{s} /$ tela 84. Franciscano, miniatura, acuarela 85 . cabeza de vieja, $10 \mathrm{x} 15$, técnica mixta 86. florero con azucenas, $61 \times 35$, pastel 87. niño, $9 \times 20$, tinta 88. figura mexicana, $10 \times 16$, acuarela 89. carreta, $16 \times 12$, carbón 90. árboles y hombre a caballo, $17 \times 13$, técnica mixta 91. reminiscencia, óvalo, pastel 92. retrato, $69 \times 54$, pastel 93. autorretrato, $61 \times 49$, pastel 94. mujer con limonero, $45 \times 60$, pastel 95. hombre, $48 \times 59$, carbón 96. retrato de señora, $53 \times 63$, pastel 97. muchacha rubia, $35 \times 44$, pastel 98. alegoría, $48 \times 37$, pastel 99 . estudio, $40 \times 60$, pastel 100. la democracia, $28 \times 35$, pastel 101. muchacha nostálgica, $44 \times 44$, pastel 102 . muchacha con moño verde, $42 \times 58$, pastel 103. Lola Montes, $59 \times 44$, pastel 104. hombre con gola, $58 \times 74$, pastel 105. impresiones, $106 \times 86$, óleo s/tela 106 . retrato de la Sra. Beatriz Inigo de Ramos Martinez, $65 \times 80$, pastel 107. Beethoven, $50 \times 57$, pastel 108. Becthoven, $47 \times 36$, pastel 109. estudio académico, $30 \times 40$, dibujo 110. paisaje, $39 \times 47$, pastel 111. dos figuras, $30 \times 36$, tinta 112. carta, $12 \times 18$, acuarela 113. bretones, $32 \times 57$, óleo s/tela 114 . figura, tinta, $20 \times 36$ 115. paisaje, $43 \times 55$, pastel 116. mascarada, $58 \times 80$, pastel 117. estudio académico, $39 \times 35$, lápiz 118. hombre, $21 \times 30$, tinta 119. molinos de viento, $127 \times 76$, pastel 120. paisaje, $16 \times 12$, carbón 121. florero, óvalo, pastel 122. paisaje, $13 \times 16$, acuarela 123. mujer europea, $54 \times 65$, óleo s/tela. Col. Sr. Diego Moreno 124. retrato de la Sra. Dolores Rubín de Parada, $177 \times$ x 84, pastel 125. perro, $49 \times 39$, pastel sobre periódico. Col. Sres. Madrazo Serrano 126. paisaje con rosas, $100 \times 75$, pastel 127. rosas, $75 \times 46$, pastel. Col. Sr. Abelardo Carrillo y Colón 128. retrato de dama con moño amarillo, $39 \times 38$, pastel. Col. Sr. Carlos Pellicer 129. retrato de Lady inglesa, 133 y 113, pastel. Col. Museo de Arte Moderno 130. retrato de la Sra. Belinda $H$. de Palavicini, $188 \times 88$, pastel, donado por la Sra. Belinda $H$, de Palavicini.

zAPATA, 50 años EN EL ARTE de México. Exposición de grabado, litografía y pintura, presentada por el Taller de Gráfica Popular. (Confederación Nacional Campesina), Mariano Azuela 121, el 8 de mayo.

shuzo wakiya. Exposición de óleos, presentada por el Organismo de Promoción Internacional de Cultura de la Secretaría de Relaciones Exteriores y la Enbajada del Japón en México, Galería de Arte Dr. Atl, anexo del teatro Antonio Caso, Reforma Norte 668, el 9 de mayo.

ARTE INDUSTRIal dE FINLANDIA. Exposición, presentada por el Museo Universitario de Ciencias y Arte, UNAM y la Embajada de Finlandia, Dirección General de Difusión Cultural, Depto. de Artes Plásticas, el 14 de mayo. 
ANTONIO JIMÉNEz núf̃ez. Exposición de esculturas, presentada por el Instituto Mexicano Norteamericano de Relaciones Culturales, A.C., Galería Nabor Carrillo, Hamburgo 115 , el 15 de mayo.

Dutos biográficos. Antonio Jiménez Núñez nació en México, D. F., en 1932; estudios: de 1951 a 1956, estudió pintura, en la Escuela Nacional de Artes Plásticas. 1957-58, diseño de muebles y hierros coloniales. 1958-59, investigación de trabajos en metal en Santa Clara del Cobre, Amozoc, Taxco y San Miguel Allende. 1959-61, cerámica. 1963, esmalte sobre metales. 1964, vitrales. 1965, estudio e investigación de materiales plásticos.

clatre evangelista. Exposición de esculturas, presentada por el Instituto Mexicano Norteamericano de Relaciones Culturales, A.C. Galería Nabor Carrillo, Hanburgo 115 , el 15 de mayo.

Datos biográficos. Nacida en Italia, Claire Evangelista ha trabajado y expuesto sus obras tanto en los Estados Unidos, del que hoy tiene la ciudadanía, como en Europa. Ultimamente ha hecho su residencia en México.

100 miniaturas. Exposición presentada por la Galería Edvard Munch, Paseo de la Reforma 489, el 19 de mayo.

Nombre de los expositores: Antragne, Byron, De la Rosa Hurtado, Kristin, Menese's, Millioud, Victor, Villagrán, Zavala.

Alfredo castañeda. Exposición de pinturas, presentada por la Galería de Arte Mexi(ano, Milán 18, el 19 de mayo, al 21 de julio.

(atálogo: 1. el hombre de las condecoraciones 2. el que se lleva a si mismo 3. el hacedor de palomas 4. el que tiene el secreto 5. la madona rel río 6 . torre 7. abstracto 8. autorretrato con sombrero 9. la casa de la primera infancia 10 . la casa de la mariposa 11. muro habitado 12. aromas 13. abstracto 14. amiga mía 15. rostro olvidado 16. el hombre interior 17 . meditabundo I 18. meditabundo II 19. soñador 20. exégeta 21. hombre con pertenencias 22. mago 23. Cristo 24. rostro antiguo 25 . querubin 26. correligionarios 27 . abstracto 28. abstracto.

jOSEPH HOGAN. Exposición de 15 acrílicos, presentada por el Instituto Mexicano Norteamericano de Relaciones Culturales, A.C., Galería Nuevos Valores, Hamburgo 115, del 22 de mayo al 11 de junio.

Datos biográficos: Joseph Hogan, nació en el año de 1936, en Troy, Ohio.

SALVADOR MAGAÑa (TERRACOTAS) LEONEL MACiel (dibujos). Exposición (escaparate zoológico), presentada por el Instituto Nacional de Bellas Artes, Tienda de Arte del Palacio de Bellas Artes, el 29 de mayo.

Un afortunado entronque de coincidencias afluye en esta doble exposición de terracotas y dibujos. En primer lugar, Magaña y Maciel han concordado en crear sendos bestiarios; en segundo, se han inspirado al alimón en un magnífico tono de humor.

Luego, semejan haberse puesto de acuerdo en unificar los conceptos mediante administrarse una ligera dosis de criterio próximo - oriental. La corporeidad de unos ani- 
males y la doble dimensión de otros agitan el recuerdo, una y otra vez, de aquella prolijidad y vergonzante reverencia que los artistas del complejo sumario - y, posteriormente, los del complejo bizantino- aplicaron al tratamiento de los bestiarios diseminados en grandes monumentos y pequeños capiteles o libros de evangelización.

Sólo que allí el humor surgió a pesar del artista, y que aquí comparece como deliberado factor creador. Aquél fue un humor atribuido, por nosotros calificado de tal; éste, por contra, es humor a todas luces, manifestado en una franciscana, una tierna imantación por la gracia, sumisa o feroz, de los animales, con la que se suprime cualquier agresividad y se concede la superior domesticidad del platónico binomio belleza-bondad.

El conjunto constituye una espléndida unidad formalístico-moral con la que Magaña y Maciel coinciden asimismo en lo que podría ser el inicio de un tratado de psicologia zoológica.

Enrique F. Gual.

Colectiva. Exposición de pintura, dibujo y escultura, presentada por el Centro Cívico Cultural de Cuernavaca, Salón de la Plástica Morelense, Cuernavaca, Mor. del 3 de mayo al 10 de junio.

Nombre de los expositores: Armando Anguiano Valadez, Cruz Badillo España, Irene Becerril, Rafael Bonilla, Jorge Cázares, Goergia Choruhas de García, Carmen Cook de Leonard, Porfirio Diaz Cruz, Jesús Franco, José Luis Franco, Francisco Guerrero Garro, Guillermo Martinez, Yolanda Quijano, Kirby Rogers, Miguel Ange! Rubio, René del Salvador Cecilio, Enrique Sánchez, Adrián Silva, Charlot Stol, Valetta Swan, Rafael Ximenez.

\section{JUNIO}

valetta. Exposición de óleo, acrílico, pastel, presentada por la Galería Kusak, Gérova 2-J bis, el 3 de junio.

Miguel cervantes. Exposición presentada por el Instituto Nacional de Bellas Artes, Galerías del Palacio de Bellas Artes, Salas 4 y 5 , el 3 de junio.

Miguel Cervantes, el viaje a lo otro. La relación entre el arte y la cultura, en especial en nuestro mundo $y$ en lo que se refiere al arte vivo, al arte que se hace en estos momentos, y la cultura oficial, la cultura que quiere nacer de antemano como continuación de un pasado y no como renovación e inauguración de un nuevo, posible presente, es $y$ ha sido siempre precaria, tirante, marcada con el signo de la desconfianza mutua y en muchas ocasiones imposible. Por su propia naturaleza, por su relación estricta e indispensable para él, con lo primigenio, lo auténtico, lo primitivo, lo que se encuentra en los orígenes y sólo puede partir de ellos, en vez de apoyarse en cualquier supuesto histórico, aun cuando es consciente de la historia y reconoce sus exigencias, la obra de arte quiere permanecer siempre fiel a esa libertad original en la que se encuentra su propia razón de existir y le repugna la posibilidad de 
ponerse al servicio de cualquier orden establecido, precisamente porque aspira a ser su propio orden y a crear su propia respuesta. No necesita por lo tanto ni de la respuesta establecida de antemano que puede entregarle la cultura como hecho anterior a la obra, ni de la que puede entregarle los espectadores, en tanto que es ella la que define sus propias proposiciones y no admite adiciones exteriores, venidas de un campo que no sea el de su propia realidad. Al contrario, si tiene algún deseo, éste es entregar la respuesta que ella misma contiene, resolviendo las interrogaciones que se plantea, en un estado puro, sin ningún añadido que nos aparte de esa respuesta. $\mathrm{Y}$ precisamente, la cultura la requiere para integrarla a ull orden exterior, que puede y debe enriquecerse con el contenido de la obra de arte, pero necesita clasificarlo y ponerlo a su servicio. Esto es lógico y natural. Al abrirse al mundo exterior, entregándose a la contemplación, ofreciendo la oportunidad de convertirla en cultura, la obra de arte realiza un movimiento que le es inevitable y que la traslada a otro campo. Pero cuando lo es auténticamente, cuando es una obra que ha puesto a su servicio la multiplicidad de fuerzas que alimentan al artista, y a través de su ordenamiento formal nos abren un nuevo campo de realidad, la obra de arte realiza este movimiento que la incorpora a la cultura conservando sus características originales. Y lo maravilloso es que estas caracteristicas guardan en si el poder de subvertir los términos de la cultura a la que se incorporan, transformándolos. En este sentido, la fusión entre arte y cultura sólo se realiza no cuando ésta absorbe al 2rte, sino cuando el arte cambia la cultura. Y si la cultura, en su proyección como fuerza e instrumento social, no está dispuesta a aceptar esta transformación, la obra de arte simplemente se mantiene aparte, crea su propia cultura y la proyecta como una posibilidad utópica tal vez, pero no menos real por esto, sobre la cultura que la sociedad ha estratificado para defenderse, cerrándose sobre sí misma. En esta capacidad de acción, aun cuando la cultura que representa a una sociedad determinada intente negársela se encuentra el poder subversivo de toda obra de arte.

Cuando el arte entra al campo de la cultura oficial es para imponer este riesgo. Ella nunca será la que defina a la obra, sino que la obra siempre actuará sobre ella. Este es el sentido profundo de toda actividad artística que materializada en la obra se abre y solicita la atención de los espectadores dentro del marco de lo establecido. Viene, muy concretamente, a romper este marco, a abrirle nuevos horizontes y ponerlo en movimiento. El escritor, en tanto que artista también, que se vo en la situación de actuar como crítico y presentar una obra en estas condiciones, tiene que estar plenamente consciente de estas exigencias para darle sentido a su propia actividad. Su responsabilidad no está relacionada con la cultura, sino con la obra. Es en las posibilidades de acción de ésta, en su verdadero valor como obra, en la que deben pensar, $y$ es a la obra que debe actuar sobre el marco cultural que la recibe a la que se encuentra dirigida su propia fidelidad. Desde esta conciencia es desde la que yo deseo presentar la obra de Miguel Cervantes en el Instituto Nacional de Bellas Artes dentro de ciclo Exposiciones de los Críticos.

En estas condiciones, nada puede ser más coherente con las exigencias de la función como crítico que presentar a un nuevo pintor, a una obra que se conservaba inédita y que sólo ahora se entrega a la atención de los espectadores y se arriesgh a imponerle sus propios términos a la cultura. Miguel Cervantes es un pintor joven. Nació el 23 de julio de 1942. Su obra, sin embargo, no se nos nucstra como el 
principio de una búsqueda, como un primer intento de hallar su propio lenguaje, de encontrar la forma que corresponda a su voz, sino como la expresión de esa voz, como un producto maduro y acabado que no busca, sino que ha encontrado, que es ya una realidad. Cualquier intento de definir esa obra sería una redundancia; ella es su propia definición. Uno de sus méritos fundamentales, incluso en tanto que es una primera exposición, es la seguridad y la claridad de su lenguaje. Creados desde el máximo rigor y la máxima libertad, esto es, con plena conciencia de las exigencias que el juicio crítico le impone, a la libertad creadora y con plena conciencia de las infinitas posibilidades de expansión de ésta aun dentro de las aparentes limitaciones que el juicio crítico le impone, los cuadros de Miguel Cervantes se crean libre y voluntariamente un círculo de exigencias que sólo les permite viajar en profundidad. A primera vista, su pintura puede verse como una exacerbada serie de variaciones sin término alrededor de una sola posibilidad. Sus cuadros se cierran, se limitan, se imponen reglas, quieren un orden anterior a ellos y se obligan a obedecerlo. Pero es muy importante darnos cuenta desde el principio de que se trata de un orden ficticio, de un orden formal, nacido del arte mismo, de su necesidad de artificio, que por tanto el pintor elige y crea para imponérselo a sí mismo como base indispensable. Esto, en otras palabras, no quiere decir más, ni menos por supuesto, que Miguel Cervantes quiere que sus obras no partan de la realidad, sino de la realidad de la pintura, no surjan de lo indefinido, sino de la verdad de un orden, de una serie de órdenes que el artista se impone desde afuera, anteior a ellas. En esta dirección podría ellas. En esta dirección podría decirse que los cuadros de Miguel Cervantes son cuadros pensados de antemano. $\mathrm{Y}$ sin embargo, ninguna de estas características se conserva en la obra terminada. Ella nos las deja entrever precisamente porque kas lia superado, porque ya es otra cosa, ya es una obra de arte y como todas las verdaderas obras de arte, permite, desde su propia realidad abierta un viaje de decirse que los cuadros de Miguel Cervantes son cuadros pensados de antemano. $Y$ sin embargo, ninguna de estas características se conserva en la obra terminada. Ella nos las deja entrever precisamente porque las ha superado, porque ya es otra cosa, ya es una obra de arte y como todas las verdaderas obras de arte, permite, desde su propia realidad abierta un viaje de regreso hacia sus fundamentos, es el tereno en el que juegan y se muestran contraponiéndose, la luz de lo acabado y la oscuridad de los orígenes. La necesidad de este fundamento se encuentra en un supuesto básico e indispensable para la pintura de Cervantes que es el que el permite ser tan puramente sólo pintura, lenguaje plástico, voz del color, en una época en que la pintura alardęa una y otra vez de su imposibilidad y su propio agotamiento. Al partir de la realidad de la pintura, de la posibilidad de orden formal que ella ofrece en tanto que tradición viva, Cervantes hace en principio a un lado las presiones y exigencias de la realidad inmediata para apoyarse en una base ajena y anterior a ella. Este no es más que cl fundamento de toda la llamada pintura abstracta o en última instancia de toda la pintura vista en tanto que pintura pura, orden formal que se realiza en sí y por sí mismo. Por esto, Cervantes, que como nos lo dicen sus cuadros, conoce y vive $y$ sufre y goza la tradición de la pintura, sabe que sólo puede imponerse un orden cle base que descansa en las últimas esencias y en el más extremo rigor, en las zonas límites que la , intura ha llegado a tocar en su inevitable ensimismamiento en su propia contemplación. Pero lo verdaderamente significativo, lo que le da su verdad a través de str 
profundidad a la obra de Miguel Cervantes, es que el pintor, el artista, no se detiene en esa base original, no se queda en ella, sino que la utiliza para dar el salto hacia la libertad, hacia el mundo cerrado y ausente de definiciones, hacia la realidad, $y$ convertirse en un auténtico creador, un artista que abre el espacio de su obra a esa callada revelación en la que el silencio se vuelve voz. Es por esto que deciamos que los cuadros de Cervantes viajan en profundidad. Dentro de su tamaño reducido en términos del inútil gigantismo de tantas obras contemporáneas, dentro de sus formas estrictas y casi buscadamente frías a base de rigor, ante ellos sentimos contradictoriamente que la obra, que cada cuadro, pierde todo límite, se sale de sí mismo $y$ se extiende infinitamente como una posibilidad siempre renovada. Pero este movimiento no es una acción exterior; al contrario, se recoge sobre sí mismo y desde su propia expansión nos obliga a centrarnos en el cuadro y a viajar hacia adentro. Es allá, adentro, donde se encuentra el secreto manifiesto, el misterio abierto, de estas obras tan aparentemente exteriores de Miguel Cervantes. Y el pintor logra haccrlo existir y mostrárnoslo, logra más bien el mostrárnoslo demostrar que ese secreto, ese misterio siempre la existido, mediante la dirección que su acción creadora le inpone a sus medios expresivos.

Entregándonos una nueva contradicción, una más de las muchas en las que se e11cuentra su riqueza, estos cuadros que son toda luz, que nos deslumbran hasta enconirar su unidad en la ausencia de límites que nace de su propia rigurosa nitidez, st aparentemente calculada construcción, su ardiente frialdad, se abren a través de esa misma luz a la más remota oscuridad. Son lo Abierto. Pero ¿a dónde conduce to Abierto cuando to es en verdad? Lo Abierto es el campo que se ha despejado, el terreno que se ha liberado de los obstáculos que nos impedían ver, es el espacio en el que reina la claridad. En los cuadros de Miguel Cervantes ese espacio vive y se lnce posible no como un vacío, cono un puro campo neutro, sino como un objeto concreto, dueño de su propia materia, con una realidad en la que la visión encuenträ el obstáculo que hace posible su propia capacidad de ver, de mostrarse a sí nisma como acción de la vista, a través del color. Mediante su juego interior, su capacidau de mostrar las cliferencias, los matices que se abren en el paso de una tonalidad a otra, el sutil camino que lleva de un verde a un rojo, de un amarillo a un azul, de tal manera que, como ocurre en el disco de Newton, nosotros sólo sabemos que hemos pasado de una tonalidad a otra y el color que veíamos ya no es el mismo, se ha transformado convirtiéndose en una realidad distinta que, sin embargo, aunque exteriormente nos muestre lo contrario, tiene el mismo origen que la anterior, lo que cada uno de los cuadros de Miguel Cervantes es en verdad una ventana, un paso abierto hacia ese origen común que se hace posible precisamente por medio de la cerrada matcrialidad del cuadro. Así, el obstáculo, la materia concreta que es cada obra y sobre la que se detiene la visión, encontrando el límite que la materializa también, es en un sentido profundo una vía de acceso hacia el más allá en el que la jropia visión debe encontrar su sentido más profundo, su propia capacidad de ver, de hacer visible lo que de otra manera permanecería invisible, se quedaría cerrado, incapaz de mostrarse. Esta es la profunda revelación espiritual que hacen posible al constituirse como auténticas obras de arte los cuadros de Miguel Cervantes. Llevados de la mano por ellos, guiados por el sereno equilibrio, por la callada armonía en la que la voz de los valores se hacen partícipes de un silcucio único que contiene todo: 
los llamados con lo que acentúan sobre nuestra atención, entramos a ese otro espacio que está más allá del cuadro, pero que es hecho posible por él, en el que se encuentra la verdadera revelación interior. Asi, la pintura comple con su más alta función: mostrarnos el otro lado de las apariencias, llevarnos hacia lo Otro, hacia la verdadera existencia de lo existente.

De allí que pueda decirse que no hay nada menos puramente decorativo que estas obras, inclinadas reverentemente hacia su pura realidad interior, ajenas a todo elemento que distraiga del sentido profundo de la visión que ellas mismas hacen posible y en la que encuentran su razón de ser, pero que a primera vista - sólo a primera vista- no se nos muestran más que como una serie de combinaciones y juegos cromáticos elaborados sobre una estructura elemental. Como todas las combinaciones de sonidos, ya Rimbaud nos mostró que cada vocal tiene su equivalente en color, estas combinaciones cromáticas de Miguel Cervantes quieren conducimos al sonido original, el que nace del y desemboca en el silencio. Es entonces cuando sentimos, porque, como todas las auténticas obras de arte, lo importante de los cuadros de Miguel Cervantes es que nos hacen comprender, por medio de lo que nos obligan a sentir al mostrársenos como obras, que el espacio creado por el pintor es un espacio abierto. En su claridad, en ese ámbito despejado de todo obstáculo por el carácter esencial de la forma, por su voluntad de constituirse a sí misma como el fundamento en el que encontrará acomodo natural del color, la presencia de la luz que se manifiesta en ella crea el camino hacia la oscuridad de los orígenes. Pero éste es un camino de ida y vuelta. Por él regresamos de nuevo a la realidad de la luz dotada ya de un verdadero sentido. No es gratuitamente que el artista ha incluido en su obra un cuadro cuyo título concretiza su voluntad de rendirle homenaje a Delaunay, el pintor de las ventanas, esos objetos cuya realidad es su ausencia de realidad, su carácter de vía de acceso. Por la ventana, desde nuestro lugar, sin desplazarnos de nuestro propio centro, permaneciendo inmóviles y concentrados en nosotros mismos, pasamos a otro lado, al otro lado, y el otro lado llega a su vez hasta nosotros, se adentra en nosotros. Ellas son el punto medio, el obstáculo puesto entre nosotros y lo exterior o entre lo interior y nuestra extrerioridad que precisamente se elimina como obstáculo y se convierte en vía de acceso, en el camino que nos conduce de un lado a otro. Para cumplir esta función, es indispensable su neutralidad, su no intervención, lo que podríamos llamar su función pasiva que sin embargo da lugar a la actividad, al más profundo de los movimientos posibles. A esta neutralidad es a la que aspiran y esta neutralidad es la que alcanzan los cuadros de Miguel Cervantes. Su belleza exterior, toda la sabiduría instintiva de pintor nato, que se muestra en ellos, toda la libertad con que el artista se deja llevar por su pasión por el color y por la particularidad de cada uno de ellos para llegar a mostrar su esencia única, alcanza su significado profundo, no en sí misma, sino en lo que al constituirse como tal hace posible. Sin embargo, esa belleza es indispensable, del mismo modo que la ventana es necesaria para marcar el más allá y el más acá. La capacidad de crearla es la que hace de Miguel Cervantes el artista que es. El como artista logra mostrarnos esa claridad que define a lo abierto. Pero una vez cumplida esta función desaparece. Ante nosotros queda la obra. Ella es todo y es nada. Simplemente reconoce $y$ asume su función. La visión, nuestra mirada, debe entregarse a 
ella para que cumpla su maravillosa tarea. El creador se retira y nos deja frente a la Creación.

Catálogo: 1. Stella nova $I I, 41 \times 41$, acrílico s/papel 2. Casitería azul, $41 \times 41$, acrílico s/papel 3. Osiria, $41 \times 41$, acrílico s/papel 4. Cuadrivio púrpura, $41 \times$ 41, acrílico s/papel 5. Bizantina, $32 \times 32$, acrílico s/papel 6. hoja del libro de los árboles, $40 \times 46$, acrílico s/papel 7. Quaternio, $40 \times 40$, acrílico s/papel 8. metástasis, $44 \times 40$, acrílico s/papel 9. Quaternio, $40 \times 40$, acrílico s/papel 10. Cuadrivio I. $30 \times 30$, acrílico s/papel 11. Cuadrivio $I I, 30 \times 30$, acrílico s/papel 12 . Cuadrivio, $40 \times 40$, acrílico s/papel 13. lienzo mandálico, $44 \times 44$, acrílico s/papel 14. Mandala, $44 \times 44$, acrílico s/papel 15. la noche de Danae, $35 \times 52$, acrílico s/papel 16. homenaje a Robert Delaunay, 53 x 53, acrílico s/papel 17. cristalización, $41 \times 60$, acrílico s/papel 18. la cámara de Delft $I, 26 \times 26$, acrílico s/papel 19. la cámara de Delft $I I, 26 \times 26$, acrílico s/papel 20. la cámara de Delft III, $26 \times 26$, acrílico s/papel 21. paisaje $I, 40 \times 62.5$, acrílico s/papel 22. paisaje $I I, 42.5 \times 70$, acrílico s/papel 23. estrella de Delft, $50 \times 50$, acrílico s/papel 24. oxidaciones, $47 \times 65$, acrílico s/papel 25. Isthar, $26 \times 26$, acrílico s/papel 26. sino azul, $50 \times 50$, acrílico s/papel 27. río dorado, $42.5 \times 60$, acrílico s/papel 28 . floración, $30 \times 42$, acrílico s/papel 29. reflejos, $39 \times 44$, acrílico s/papel 30. silenciario, $43 \times 60$, acrílico s/papel 31. Origenesia, $44 \times 65$, acrílico s/papel 32. la hoja I, 31 x 44, acrílico s/papel 33. homenaje a Harry Callahan, $36 \times 50$, acrílico s/papel 34. Thalassa, $37 \times 52$, acrílico s/papel 35. "Gegenströmung bei Vollmond", 37 x 52.5, acrílico s/papel 36. aguas amansadas, 37 x 52.5, acrílico s/papel 37. archipiélago, $40 \times 62.5$, acrílico s/papel 38. lemurias, $42.5 \times 62.5$, acrílico s/papel 39. Demeteria, 40 x 62.5, acrílico s/papel 40 . invasión, $41 \mathrm{x}$ 68 , acrílico s/papel 41. arcana, $40 \times 62.5$, acrílico s/papel 42 . la hoja $I I, 45 \times 40$, acrílico s/papel 43. gran triada, $42 \times 60$, acrílico s/papel 44. la cámara roja $I$, $30 \times 30$, acrílico s/papel 45 . la cámara roja $I I, 30 \times 30$, acrílico s/papel 46 . metástasis verde, $50 \times 50$, acrílico $\mathrm{s} /$ papel 47. metástasis solar, $50 \times 50$, acrílico s/papel 48, cantata, $42.5 \times 47$, acrílico s/papel 49 . Jericó, $40 \times 70$, acrílico s/papel 50. Jericó $I I, 40 \times 67.5$, acrílico $\mathrm{s} / \mathrm{papel} 51$, verde lacustre, $42.5 \times 60$, acrílico s/papel 52. campo áurico, $42.5 \times 60$, acrílico s/papel 53 . umbral, $50 \times 45$, acrílico s/papel 54. Momentum, $52.5 \times$ x 42.5, acrílico s/papel. DIBUJOS. 55 . Ia gaviota, $38.5 \times 38.5$, lápiz s/papel 56. dibujo 2, $38.5 \times 33$, lápiz s/papel 57. dibujo $3,38 \times 40.5$, lápiz s/papel 58. dibujo 4, $38 \times 42$, lápiz s/papel 59. dibujo 5, $35 \times$ 38, lápiz s/papel 60. el nudo, $30 \times 30$, lápiz s/papel 61. dibujo 7, $28.5 \times 26$, lápiz s/papel 62. dibujo $8,18 \times 18$, lápiz s/papel 63 . dibujo $9,18 \times 18$, lápiz s/papel 64. dibujo $10,18 \times 18$, lápiz s/papel.

voroshilov vazante. Exposición de óleos, presentada por el Organismo de Promoción Internacional de Cultura de la Secretaría de Relaciones Exteriores y la Embajada de la República del Ecuador en México, Sala de Arte Opic, Av. Juárez 42, edificio C, 2a. Mezzanine, el 3 de junio.

GoUlveN Elies. Exposición (Electrart XXI), presentada por el Instituto Francés de América Latina, Nazas 43, el 4 de junio.

HÉCTOR Xavier. Exposición de 25 obras, presentada por el Instituto Mexicano Norteamericano de Relaciones Culturales, A.C., Galería Nabor Carrillo, del 5 al 25 de jumio (Hamburgo 115). 
Datos biográficos del artista: Héctor Xavier. Nació en Tuxpan, Veracruz, en 1921.

Catálogo: 1. naturaleza, 1944, lápiz 2. el hombre y el perro, 1945, lápiz 3. mujer de vestido blanco, 1946, lápiz 4. desnudo hombre, 1947, lápiz 5. desnudos (dos figuras), 1948, tinta 6. Orozco, 1949, lápiz 7. tres mujeres, 1950, tinta color 8 . retrato del Dr. Morones, 1951, tinta 9. desnudo, 1952, crayón 10. retrato de Brancusi, 1953, (cabeza), tinta 11. los árabes, 1954, tinta 12, el rabino, 1955, tinta 13. el judio, 1956, acrílico 14. tres figuras, 1957, tinta y acrílico 15. puerco espin, 1958, tinta color 16. el gato, 1959, tinta 17. desnudo vitral, 1960, tinta color 18. el buho, 1961, tinta color 19. serie de los viejos, 1964, tinta 20. serie de lo. viejos, 1963, tinta 21. serie de los viejos, 1965 22. pumas, 1966, acrílico 23. León Felipe, 1967, tinta 24. Kudu, 1968, tinta 25. niño, 1969, tinta.

laGAN. Exposición de pinturas y dibujos, presentada por la Galería Antonio Souzal, Reforma 334-A, el 5 de junio.

iv BIENAL nacional de escultura. Exposición presentada por el Instituto Nacional de Bellas Artes, Museo de Arte Moderno, Galería de Exposiciones Temporales, el 5 de junio.

Silvia H. González. Exposición obras recientes, presentada por la Galería Mer-Ku1 y artistas de la Plástica Mexicana, A.C., Molière 328-C, el 5 de junio.

Colecriva. Exposición presentada por la Galería de Arte, Plástica de México, Londres 139 , el 6 de junio.

Nombre de los expositores: Jorge González Camarena, Jesús Guerrero Galván, Trinidad Osorio, Diego Rivera, José Clemente Orozco, Roberto Montenegro, Fanny. Rabel, Francisco Zúñiga, Cordelia Urueta, Adrián Silva, Raúl Anguiano, Carlos Orozco Romero, José Reyes Meza, Feliciano Peña, Froylán Ojeda, Luis Nishizawa, Olga Costa, José Chávez Morado, Celia Calderón, Fernando Castro Pacheco.

edgaruo coghlan. Exposición ("Israel 5728"), presentada por el Comité de Actividades Generales del Centro Deportivo Israelita, Galerías C.D.I., Boulevard Manuel Avila Camacho núm. 620, Lomas de Sotelo, del 8 de junio al 30 del mismo mes.

MANUEL FeLGUÉRez. Exposición presentada por la Galería Juan Martín, Amberes 1j, del 10 al 28 de junio.

párricia padilla de corcuera. Exposición de óleos y dibujos, presentada por la Galería de Arte, Nieto, Av. Juárez 4, esq. con San Juan de Letrán, del 10 de jumio al $1^{\circ}$ de julio.

FRANCISCo coello. Exposición de pintura, presentada por el Instituto Nacional de Bellas Artes, Embajada del Ecuador, Galerías del Palacio de Bellas Artes, Sala Internacional el 11 de junio.

VERna RINGer. Exposición presentada por el Instituto Mexicano Norteamericano de Relaciones Culturales, A.C., Galería Nuevos Valores, Hamburgo 115, el 12 de junio. Datos biográficos. Verna Ringer, nació en Nueva York, en 1945. 
KITTY KAUPP. Exposición presentada por el Instituto Mexicano Norteamericano de Relaciones Culturales, A.C., Galería Nuevos Valores, Hamburgo 115, el 12 de junio.

MARTo PÉREZ orona. Exposición de acrílicos, presentada por la Galeria Misrachi, Génova 20, el 12 de junio.

Datos biográficos: Mario Pérez Orona, nació en Miami, Arizona, el 3 de julio de 1929. Estudios: University of Arizona, Tucson, Arizona, College of Arts and Crafts, Oakland, California, México City College (Bachillerato en Artes Plásticas), University of the Americas (Maestría en Artes Plásticas).

Catálogo: 1. el prestidigitador 2. Babel 3. Minerva 4. cacería 5. conquistador 6. el arco 7. el templo 8. la danza de los pájaros 9. el viaje 10. el profeta 11 olimpo 12. el cazador 13. Elías 14. en el huerto 15. pajarera 16. el barco 17. recolección 18. los pájaros 19. el cuento 20. el constructor de mitos 21 . el embajador 22. el rapto 23. los peregrinos 24. las damas 25. la aldea 26. nocht y música 27. iniciación 28. el puente 29. en una noche de luna 30. el ave cautiva 31. el árbol rosa 32. el ángel 33. el gato 34. el consejo 35. huida.

luis lópez loza. Exposición presentada por el Instituto Cultural Mexicano Israelí, A.C., Ometusco 15, el 12 de junio.

DIBUjo-1969. Exposición presentada por la Galería Edvard Munch, Paseo de la Reforma núm. 489, el 16 de junio.

Nombre de los expositores: Antragne, Aréralo, Belain, Byron, E. Cruz, De la Rosa, Falfan, H. Delgadillo, Hurtado, Kristin Kubli, Melesio, Meneses, Messeguer, Pardo, P. Orona, Victor, Villagrán, H. Xavier, Zavala.

Alberto de trinidad solís. Exposición de óleos, dibujos, grabados e ilustraciones, presentada por la Escuela Nacional de Artes Gráficas, del 16 de junio al 14 de julio.

frinnano vilchis. Exposición de tapices y grabados, presentada por el Salón de la Plástica Mexicana, INBA/SEP/Havre núm. 7, del 16 de junio al 6 de julio.

AkIra kirakawa. Exposición de calcas, presentada por el Museo Universitario de Ciencias y Arte/UNAM/Dirección General de Difusión Cultural, Departamento de Artes Plásticas, Ciudad Universitaria, el 17 de junio.

Colectiva, Exposición de la Selección de artistas mexicanos ex-becarios del Gobierno Francés, presentada por el Instituto Francés de América Latina, Nazas 43, el 18 de junio.

Nombre de los expositores: Fernando Caballero, Lilia Carrillo, Amaldo Coen, Francisco Corzas, Jorge Dubon, Manuel Felguérez, Alberto Gironella, José Hernándes Delgadillo, María Lagunes, Emilio Ortiz, Mariano Rivera Velázquez, Vicente Rojo. Vlady.

nueva imagen Plástica, grupo 65. Exposición presentada por el Organismo de Promoción Internacional de Cultura, de la Secretaría de Relaciones Exteriores, Galería de Arte del Teatro Casa de la Paz, Cozumel núm. 33, el 20 de junio. 
ARTURo Estrada. Exposición presentada por el Salón de la Plástica Mexicana, INBA/ SEP/Havre núm. 7, del 20 de junio al 9 de julio.

JOAQUín MARTÍNEz NAVARRETE. Exposición de acuarelas, presentada por la Galería José Ma. Velasco, INBA/SEP/Peralvillo 55, el 20 de junio.

Catálogo: 1. Tepotzotlán 2. la ciudad perdida 3. paisaje con pájaros 4. plaza de la conchita 5. convento del Carmen 6. vecindad 7. plasa de Coyoacán 8. estación Insurgentes del metro 9. otoño 10. estación de San Lázaro 11. paisaje 12. valle de Las Monjas 13. huitzilac 14. trigal 15. ciudad en grises num. 116. muelle 17. amaneciendo 18. aldea 19. humos 20. estampa invernal 21 . crepúsculo en rojos 22. mi ciudad 23. tarde lluviosa 24. contraluz 25 . ciudad en grises núm. 2 26. Texcoco 27. naturaleza muerta 28. reflejos 29. campanario del Carmen 30. crepúsculo.

ARTE pOPUlaR DE LA URSS. Exposición temporal presentada por la Embajada de Ja Unión de Repúblicas Socialistas Soviéticas en México. El Museo de las Culturas, INAH/SEP/Moneda núm. 13, el 26 de junio.

Exposición DE inbujos. Presentada por la tienda de Arte del Palacio de Bellas Artes, el 26 de junio.

Nombre de los expositores: A. Martínez, S. Alcázar, C. Cuéllar, A. Chacón, A. Pastrana, J. A. Pérez Vega, J. Martinez, A. Antuna.

PINTURA IMPREsionista. Exposición presentada por el Departamento del Distrito Federal, Dirección General de Acción Social, Museo de la ciudad de México, Pino Suárez 30 , el 26 de junio.

MIGUEL HERNÁNDEz URBÁN. Exposición de grabados, presentada por el Instituto Mexicano-Norteamericano de Relaciones Culturales, A.C., Galería Nabor Carrillo. Hamburgo 115, del 26 de junio al 16 de julio.

Exposición colectiva. Exposición de óleos, grabados, esculturas, presentadal por la Constructora Move, S. A., Calle de Filadelfia 109, esq. Nebraska, Col. Nápoles, el 27 de junio.

Nombre de los expositores: Feliciano Béjar, Federico Cantú, Francisco Corzas, Germán Cueto, Xavier Esqueda, José García Ocejo, Heriberto Juárez. Luis Lópẽ Loza.

José CLEMENTE OROzco y LA MUJER. Exposición presentada por la Sala Revolución, ubicada en Av. Revolución núm. 1608, 3er. piso, el 28 de junio.

olga costa. Exposición de pinturas, presentada por la Galería de Arte Mexicano, Milán 18 , del 30 de junio al 26 de julio.

Catálogo: 1. frutas 2. paisaje 3. después de la cosecha 4. alfajor 5. tres canas tillas con fruta 6. geometria agraria 7. biznaga 8. campos labrantios 9. vista del jardin 10. Tata Chipe 11. paisaje 12. charamuscas 13, flor de cebolla 14. paisaje dorado 15. campo de cempasúchiles 16. cerro de La Bufa 17. pasionaria 
18. pitahayas 19. fruterito 20. calabazas 21. varas de lima 22. naturaleza muerta con mandarinas.

reliciano béjar. Exposición de 25 años de dibujo, presentada por la Galería de Arte Arvil, Hamburgo 241, durante el mes de junio.

Carlos JURADo. Exposición presentada por la Galería del Casino de la Selva en Cuernavaca, Mor., el 7 de junio.

JULIO

iv CONCURSO NACIONAL dE ESTUdiANtes de ARTES PLÁSTICAS EN AGUASCALIENTES. Exposición de obras seleccionadas, presentada por el Instituto Nacional de Bellas Artes, Galería Chapultepec, el $1^{\circ}$ de julio.

Nuevos valones. Exposición presentada por la Galería Kusak, Génova 2-J-Bis, del $1^{\circ}$ a] 20 de julio.

GABRIEl RAMíREz. Exposición presentada por la Galería Juan Martín, Amberes 17 , del $1^{\circ}$ al 19 de julio.

SERgio Moyano. Exposición presentada por el Instituto Nacional de Bellas Artes, Embajada de la República Argentina, Galerías del Palacio de Bellas Artes, Sala Tnternacional, el 2 de julio.

HERNICE KOLKo. Exposición de imágenes de Trinidad y Jamaica, presentada por la Casa del Lago, Difusión Cultural/UNAM (bosque de Chapultepec), el 6 de julio.

MARYSOLE WÖRNER BAz. Exposición homenaje a León Felipe, presentada por las ralerías Mer-Kup, Artistas de la Plástica Mexicana, A.C., Molière núm. 328-C, 7 de julio (obras recientes).

l.oRRAINE rinto. Exposición (Luz y Sonido por el Ing. Leonardo Visking), presentada por Galerías Mer-Kup, Artistas de la Plástica Mexicana, A.C. (obras recientes), Molière núm. 378-C, el 7 de julio.

Querida Lorraine: La visita a tu estudio me ha conmovido. Con enorme autenticidad me has hecho partícipe de tus dudas, de tu inseguridad $y$, al mismo tiempo, en tu obra he captado un optimismo y una humildad que estimo más que necesarios, imprescindibles, en las búsquedas humanas actuales.

La problemática que te has planteado en la exposición es tratar de ensamblar tus valores personales (sujeto) con los valores exteriores del mundo de la técnica (objeto). Y yo sentí en tu angustia, reflejada la mía y la de todos los que queremos llegar a ser, con conciencia, hombres de nuestro tiempo y superar la enajenación en que parcce hahernos colocado el mundo de la técnica y sus consecuencias como sistema de vida.

Tú sabes muy bien que nuestra época, eminentemente tecnológica, ha dejado atrás a lenguaje "artístico" de las galerías. Fuera de unos cuantos pioneros (Moholy- 
Nagy, Gabo, Calder, etcétera) que abrieron las brechas de un arte cinético y "al día" en cuanto sus preocupaciones técnicas es, hasta años muy recientes, cuando la búsqueda de integración de estas dos formas -arte y técnica- que se nos habian presentado como opuestas, se está realizando.

La intervención del tiempo, las aperturas espaciales, la estandarización, la ambientación, la limpieza e impersonalidad del material, la animación y fluctuación de lá forma son, entre otros muchos, los cambios con que el mundo de la técnica ha transformado nuestras visiones físicas y psíquicas.

Iil ritmo de nuestro tiempo fluctuante e inaprehensible está aún en pugna con mestra realidad interior; y el artista, habiendo perdido el paso ante la excesiva velccidad del mundo técnico, luclia por alcanzarlo.

El reflejo de tu disputa interior lo vi claramente en la división de las obras que presentas:

Por una parte nos dejas huellas de tu mano -esa parte de nosotros que consideramos sacrosanta- en la serie de "dibujos" sobre aluminio, donde sientes proyectarte con mayor evidencia. Por la otra nos ofreces sólo ideas plásticas. Tomas diversas materiales del rendimiento tecnológico y creas con ellos un mundo en el que te apropias de la luz, el sonido, la electricidad y los conocimientos de los ingenieros con quienes trabajas y por esto lo sientes más ajeno. Pero, es a mi juicio, justo ahí en el liecho de enfrentarse con entusiasmo a la sensación de amenaza de despersonalización, donde se abre la vía de salida a la generosidad del hombre íntegro de hoy, del próximo futuro.

Cuando me despedi de ti me pediste que te escribiera algo para tu Catálogo y, créeme que no puedo decirte nada que tu no sepas ya. Lo único que puedo darte es la afirmación y apoyo a tus búsquedas de comunicación humana que es lo que tú, con tu obra me diste a mí.

Me afirmaste en la creencia de que la pérdida del elemento irracional, de lit constatación psicológica, y en fin del individualismo y sus valores personales son los que están en vías de mutación. Que es el deber del artista aprovechar al máximo el mundo exterior y transformarlo en lenguaje motor para no seguir hablando un lenguaje muerto y anquilosado. Sólo así estaremos vivos y cumpliendo nuestra mínimát misión de servicio.

Para ni es innegable que solamente con el establecimiento de nuevas formas de comunicación y relación humanas; con el nacimiento de una sensibilidad captadora de ondas más amplias será factible la actualización de los valores éticos sobre los que se Iormarán los estéticos. De esta manera podremos establecer el diálogo interrumpido no sólo entre artista, técnica y sociedad, sino entre todos como hermanos.

Uno a mis felicitaciones mi cariño.

IDA RODRÍGUEZ

Catálogo: 1. expansión, plástico, luz y sonido, $1.24 \times 0.98$ 2. reloj espacial, plástico, movimiento, kalliroscopios, diámetro 0.95 3. pirámides, plástico y luz, $1.50 \times 0.63$ 4. sobre el basurero, elementos mixtos, luz y sonido, $1.83 \times 1.10 \times 1.22 \quad 5$. yo hombre, yeso, madera y luz, $2.00 \times 1.10 \times 1.60$ 6. juguete, plástico y movimiento, $0.40 \times 0.25$ 7. yo y yo, plástico, poliestereno y luz, $0.65 \times 0.45$ 8. jungla, plásticr 
y luz, $1.20 \times 1.51$ x 1.52 9. Mini-universo, plástico y luz 0.63 y 0.6310 tetraedro, plástico, luz y música, $0.58 \times 0.50-25$ placas : dibujos en aluminio $0.49 \times 0.24$.

EjFMPLOS DE SIMBIOSIS PLÁSTICA EN PINTURA. Exposición presentada por el Instituto Nacional de Bellas Artes, Galerías del Palacio de Bellas Artes, Salas 1 y 2 , el 8 de julio.

Nombre de los expositores: Guillermo Ceniceros, Byron Gálvez, Leonel Maciel.

FRLIPE ORLANDo. Exposición de acrílicos, presentada por la Galería Pecanins, Hamburgo 103, del 8 al 28 de julio.

ChaRles Douglas JoNes. Exposición de pinturas, presentada por el Instituto Mexicano-Norteamericano de Relaciones Culturales, A.C. Galería Nuevos Valores, Hainburgo 115 , el 10 de julio.

zufino tamayo. Exposición de 20 litografías, presentada por la Galería de Arte Misrachi, Génova 20, el 10 de julio.

Habiendo nacido en Oaxaca, México, en 1899, Tamayo, a la edad de ocho años fue a vivir con una tía en la ciudad de México. Allí la ayudaba en un puesto de fruta que ésta tenía en el mercado; esta experiencia habría de influenciar definitivamente su obra. Sus temas muy a menudo son frutas o naturalezas muertas y sus colores se han comparado con los vivos tonos de la fruta madura. Estudió en la Escuela de Bellas Artes durante un año, pero ha sido principalmente autodidacta. En 1921 fue nombrado jefe de diseño del Museo Nacional de Antropología y estc contacto con la arqueología ha influenciado su concepto de la pintura, que combina a ésta con el cubismo y algunas tendencias de la pintura abstracta.

La primera exposición de Rufino Tamayo fue en la ciudad de México el1 1926, labiendo tenido ese mismo año una exposición individual en Nueva York. Ha participado en numerosas exposiciones internacionales incluyendo la Bienal de Venecia, en donde se le dedicó un salón completo a su obra; en 1952, el Museo de Arte Moderno de París presentó una exposición individual y la Panamerican Union, una retrospectiva. Está representado en las colecciones permanentes de los museos más importantes del mundo, incluyendo el Museo de Arte Moderno de la ciudad de México, al Museo de Arte Moderno de Nueva York, el Museo de Arte Moderno de París y otros, que conservan su obra como parte importante de su acervo.

Catálogo: 1. dos cabezas de mujer, 54 x $69 \mathrm{~cm}$. más márgenes, lila, verde, blanco, negro 2. dos cabezas, $54 \times 69 \mathrm{cr}$. más márgenes, lila, rosa, azul, blanco 3. torso de mujer, $54 \times 69 \mathrm{~cm}$. más márgenes, azul, amarillo, rosa, blanco, negro. 4. lir negra, $54 \times 69 \mathrm{~cm}$. más márgenes 5. venus negra, $54 \times 69 \mathrm{~cm}$. más márgenes 6. mujer con mallas negras, $54 \times 69 \mathrm{~cm}$. más márgenes 7 . torso de joven, $54 \times 69$ $\mathrm{cm}$. más márgenes 8. mujer en lila, $54 \times 69 \mathrm{cin}$. más márgenes 9. carnavalesquc, 54 x $69 \mathrm{~cm}$. más márgenes 10. mujer con medias malva, $54 \times 69 \mathrm{~cm}$. más márgenes 11. mujer con mallas rosa, $54 \times 69 \mathrm{~cm}$. más márgenes 12 . medio pescado, $54 \times 69 \mathrm{~cm}$. más márgenes, naranja, bistre, amarillo, blanco, negro 13. sandía múm. 1, $54 \times 69 \mathrm{~cm}$. más márgenes, verde, lila, rojo, blanco, negro 14. sandía núm. 2, $54 \times 69 \mathrm{~cm}$. más márgenes, verde, rojo, lila, blanco, negro 15. la campesina, 54 × $69 \mathrm{~cm}$. más márgenes, naranja, café, rosa, blanco 16. mujer en rojo, 54 × 69 cm. más márgenes, rojo, amarillo, blanco, negro 17. affiche, $54 \times 69 \mathrm{~cm}$. más 
márgenes, negro y lila 18 . mujer sonriente, $54 \times 69 \mathrm{~cm}$. más márgenes 19 . múscaria roja, $54 \times 69 \mathrm{~cm}$. más márgenes 20 . retrato de mujer, $54 \times 69 \mathrm{~cm}$. más márgenes.

ENRIQUE CLIMENT. Exposición Homenaje presentada por el Instituto Nacional de Bellas Artes, SEP/Salón de la Plástica Mexicana, Havre núm. 7, del 10 al 31 de julio.

Enrique Climent nació en Valencia, España. Hizo sus primeros estudios de pinturit en la Escuela de San Carlos de su ciudad natal. En Madrid, fue ilustrador de libros y de revistas, y el Gobierno le otorgó una beca para pintar paisaje en el Monasterio de Paular. De 1922 a 1924 se dedicó a la escenografía en París. La Galería Nancy, de Madrid, presentó su primera exposición individual en 1924. Por oposición, fue designado maestro de arte en el Instituto Salmerón de Barcelona en 1930. Vino a México en 1939. Algunas de sus exposiciones han sido en la Galeria de la Universidad (1941) y en la Galería de Arte Mexicano. Ha participado en certámenes internacionales en Pittsburgh (1952), Tokio $(1955,1957)$ y ha expuesto en Nueva York $(1960,1966)$ y Madrid (1964). Sus obras se hallan en importantes colecciones del pais $y$ del extranjero.

Desde 1939, Enrique Climent vive en México dedicado a contribuir con su trabajo al ennoblecimiento de la pintura nacional. Durante esos treinta años transcurridos entre nosotros, no ha descansado en su tarea de of recer, con singular maestría, muestras constantes de un talento que, sobre toda otra intención, se define por sus propósitos eminentemente plásticos. Entregado en un principio a la práctica de las formas tradicionales progresivamente fue modificando su vocación mediante la búsqueda de nuevas maneras de concebir los propósitos de su oficio. Así, a partir de ese incesante impulso renovador, apoyado en experiencias que han hecho variar su sentido estético, en ocasiones atraído por cierta predisposición hacia el abstraccionismo, ha llegado a señalarse como uno de los pintores que aúnan firmemente la capacidad expresiva y el vuelo de la imaginación.

En muy pocos artistas como en él, el gusto por el color se identifica tan armónicamente con la arquitectura de la composición, y en muy pocos tambiér la naturaleza adquiere, por obra y magia del pincel, ese misterio característico con que se vierte en sus telas. Por propia decisión, no ha querido ser sino el hombre que da testimonio de la belleza que a su lado triunfa, captada en su interno resplandor, desde la intimidad de sủ entrafia, para volcarla al través de la gracia de los sentidos. De ali que en sus cuadros la sensación visual nos haga percibir una encendida trama donde la alegría, entrelazada con rasgos melancólicos, forma un sorprendente juego de luces.

Tal es el artista a quien el Salón de la Plástica Mexicana se honra en rendir homenaje - a seis lustros de su arribo a México- con esta exposición en que advertimos cómo la realidad y el mito, el sueño y la vigilia, los objetos y la fantasía, sc dan la mano para crear otro mundo animado por s11 extraordinaria sensibilidad.

Lourdes Chumaceko

Catálogo: Oleos: 1. naturalesa muerta con mantel a cuadros 2, naturalesa merla con gran samovar 3. naturaleza muerta persa 4. naturaleza muerta en asules 5. naturaleza muerta en mesa negra 6 . naturaleza muerta en tonos marfil 7 , b:- 
tellas y copas en mesa blanca 8. frutero con uvas y botellón rojo 9. formus blancas 10. frutero y frasco granate 11. naturaleza muerta con plátano negro 12. naturaleza merta con firma en la botella 13. naturaleza muerta en tonos verdes 14. naturaleza muerta con cerámicas 15. samovar blanco 16. objetos hebreos 17. casas en la costa 18. iglesia 19. casas de Ibiza 20. plaza antigua 21. pueblo de Levante 22. cortijo 23. ajedrez 24. cáliz 25. pequeña composición en ocres 26. restos de puerta 27. signos musicales. TEMPLES 28. paisaje de San Miguel de Allende 29. composición en ocres 30. Imagen de Venecia 31. Muro con tronera 32. escudo. ACUARELAS 33. naturaleza muerta 34. casas encimadas CRAYOLAS. 35. ánfora verde 36. forma de totem 37. iglesia. BATIKS. 38. paisaje castellano 39. juegos 40. lápidas 41. hermitas rojas 42. arcón y cerámicas 43. Dío. 44. naturaleza muerta con mantel 45. mostrador con balanza 46. pequeño puerto 47. ánforas blancas 48. naturaleza muerta en óvalo 49. nocturno plateresco. TECNICA MIXTA. 50. nocturno.

SAnros. Exposición presentada por la Galería Plástica de México, Londres 139, del 11 de julio al 6 de agosto.

Catálogo: 1. móscara 2. Hippic 3. personajes de Circo 4. ave disecada 5. gestación geométrica 6. génesis 7. tablero de ajedrez 8. algo del signo piscist 9. guardianes del templo negro 10. ángel crucificado 11. umbral 12. personaje pisciano 13. composición núm. 1 14. el astronauta 15. paisaje urbano 16. serpientc en Acecho 17. serpiente atacando 18. composición núm. 2 19. cruz barroca 20. máscara riendo 21. humor negro 22. gestación poética de un ave.

beNJAMin manzo. Exposición presentada por Difusión Cultural/UNAM, Casa del Lago, Galería del Lago, Bosque de Chapultepec, el 12 de julio.

Carlos kohn-Kagan. Exposición de dibujos de Israel, presentada por el Comité de Actividades Generales del Centro Deportivo Israelita, Galerías C.D.I. Av. Manuel Avila Camacho 620, del 13 de julio al 4 de agosto.

El arquitecto y profesor universitario, Carlos Kohn-Kagan, nació en Praga, Checoslovaquia, donde desarrolló una brillante carrera profesional que traspasó las fronteras de su país. Acerca de sus realizaciones arquitectónicas se publicaron dos obras.

Egresado en 1920 de la Academia de Arte de la misma capital checoslovaca, el profesor Kohn viajó por toda Europa exponiendo sus obras pictóricas con muclw, éxito.

Ante el avance nazi, abandona con toda su familia su país e inmigra a Quito, Ecuador, donde enseña en la escuela de Bellas Artes y en la Universidad de Quito. E11 1940 es premiado en la Exposición del Riverside Museum de Nueva York. Sus cuadros se encuentran en museos y colecciones particulares del mundo entero.

En 1958, regresa a Europa; expone en Zurich; viaja a Israel donde se queda pintando durante dos años.

La exposición de dibujo con temas israelíes que será presentada en la Galería C.D.I. es parte de la gran cantidad de dibujos que el artista realizó en el Estado de Israel y que lamentablemente han sido extraviados.

JaCoro gLANTz. Exposición (detrás de las formas), presentada por Difusión Cultural/ UNAM. Casa del Lago, Galería Dionisos, Bosque de Chapultepec, el 13 de julio. exposictón colectrva. Presentada por la Galería Pablo Picasso, Avenida Coyoacán 931 , el 15 de julio. 
Nombre de los expositores: Allis, Arias Murueta, Arévalo, Hermández Delgadillo, Hornández Uróán, Maciel, Mion, Sarasúa.

Considerando que una galería de Arte no solamente está destinada a la exposición de obras, sino a difundir tanto las artes plásticas como otras disciplinas artísticas y la cultura, la Galería Pablo Picasso, del Centro de Artes Plásticas EGA, abre sus puertas para recibir e impulsar a los artistas jóvenes y talentosos que son, en este momento transcedental, el nuevo impulso; y más tarde, la realización plástica de México.

Construir un real y verdadero centro de exposición, sin distinción de escuelas y tendencias, será la responsabilidad de esta Galería que se obliga a promover toda clase de actividades en el máximo nivel, iniciando con la evidente calidad de los expositores con que inaugurarán, todo ello, para fomentar el espíritu creador de sus integrantes y la comunicación que de su arte se haga a todo el público.

Sea nuestro propósito la firme decisión de servir honestamente a la superación social y conceptual de la colectividad, construir y aunar este organismo y nuestras voluntades, a otros que han iniciado esta nueva trayectoria.

Leopoldo Ayala

El Centro de Artes Plásticas inicia sus labores consciente de su obligación de ser una institución seria y eficaz para la formación de artistas plásticos, en un marco de respeto a la individualidad y la libertad humanas.

Como consecuencia de los cambios que se han operado en las Artes Plásticas, la actual enseñanza de las mismas requiere de un Programa de Estudios que responda a estos requerimientos además de permanecer siempre abierta a la investigación de nuevas formas de expresión; es por eso que la dinámica preside el ejercicio de cada lisciplina para hacer que la asistencia a la escuela sea una verdadera fuente de (xperiencias, conocimientos y conceptos que permitan al futuro artista contar con todos Ios recursos posibles en el inicio de su ardua tarea.

Estos propósitos incluyen a maestros y alumnos, pues la actividad docente debe poseer esas virtudes para no incurrir en vicios anacrónicos y limitaciones contrarias a la naturaleza del arte.

José Hernández Delgadiljo

I UAAN JOSÉ ARREOLA. Exposición Eros Cosmogónico, presentada por la Galeria Edvard Munch, Paseo de la Reforma 489, del 14 de julio al 9 de agosto.

Iurs Jaso. Exposición de óleos, presentada por la Galería Pecanins, Hamburgo 103. ef 15 de julio.

intragne. Exposición presentada por el Instituto Francés de América Latina, Nazas +3 , del 16 de julio al $1^{\circ}$ de agosto.

Antragne se equipara misteriosamente al prodigioso hacer minucioso y siempre inrencionado de aquellos dibujantes y pintores para quienes su arte era la válvula de escape de un pensamiento no en todas ocasiones sociable, y mucho menos declarable. 
Un demoniaco, un enigmático y apasionante monólogo es esta exposición de dibujo que el autor desarrolla, al parecer, en beneficio de su exclusiva exégesis. Obviamente imposible que sólo signifique lo que aparenta. Los millones de puntitos y rayitas ensamblados orgánicamente componen escenas de una, diríamos, perversa belleza que, una de dos: o provoca la benevolente sonrisa con su más epidérmica realidad, o queda uno atrapado en la inasequible tarea de interpretarla extra-artísticamente.

Versión moderna de un Bosch, de una Mandyn, Antragne lanza su imaginación al clima fenoménico de la actualidad, que en su alma viene investida de mil cosas viejas desprendidas de augustas senectudes plásticas; del arte sumerio, de mitos paganos y renacentistas, del lenguaje sicoanáliticos, acentuado por las delirantes interpretaciones propias de la actividad paranoicocrítica. Sin embargo -y he aquí lo pasmoso-, ese volumen de complicaciones adquiere un sobresaliente carácter de actualización, de donde proviene el hecho de que esa organizada multitud de imágenes y signos nos llegue como un notable intento revisionista, cuyas consecuencias serian perfectamente imprevisibles.

El espectador debe autodefinirse ante la presente obra de Antragne, y admitir como admitiera el monarca español respecto a Bosch que se trata de una obra moralizante y ejemplar, o suponer, como to han hecho críticos posteriores a Felipe II, que contemplan un conglomerado de intenciones de las que no anda muy lejos una cierta disimulada perfidia.

EnRIQUe F. Gual

LEONORA CARRINGTON. Exposición de 22 de nuevos dibujos, presentada por la Galería de Arte Mexicano Florencia, Florencia 35-E, el 17 de julio.

Catálogo: 1. they made mermaids into fish cakes 2. computer to reform an original vacuum 3. la octava sonrisa 4. synapsis 5. Charriot 6. sarcófago del torero 7. monad with a window 8. pura firma 9. hatha yoga class 10. scream 11. ipso facto 12. núm. 13. lemurs 14. swimmers 15. snake 16. Joseph 17. como dos 18. smog 19. llamada a veces la gallina negra 20 . crozes head 21. quinta essentia 22. the joker.

HELF.N LUITJENS. Exposición de obras, 2 temas y una inspiración=un deseo, presentada por el Instituto Mexicano Norteamericano de Relaciones Culturales, A. C., Galería Nabor Carrillo, Hamburgo 115, del 17 de julio al 6 de agosto.

Graduada de la Universidad de California del Sur, Estado del que es nativa, Helen Luitjens continó sus disciplinas artísticas en la Universidad de ese mismo Estado en Los Angeles y, más tarde, en el Instituto de Allende de San Miguel y en la Universidad de Hawai de la que recibió una beca.

"Veo el mundo que me rodea - dice la artista- a través de su color, de su diseño y de sus patrones arquitectónicos. Probablemente éstas son las razones de que las hermosas casas victorianas me hayan servido como inspiración en mis expresiones artísticas. También aquí en México, las iglesias barrocas que llenan el paisaje me han sugerido los temas de muchas de mis pirituras. Mi deseo es de comunicar al espectador el gozo y el placer de ver el mundo a través de los lentes rosas de una artista." 
ESCULtura CLÁstCa. Exposición presentada por el Museo de las Culturas, INAH/SEP, Moneda 13, el 17 de julio (con 20 reproducciones donadas al pueblo de México por el Gobierno de la Rep. Italiana). El acto estará presidido por el Excmo. Sr. Embajador de Italia en México, Enrico Guastone Belcredi.

melesto galvín. Exposición de obras, presentada por la Galería Antonio Souza, Reforma núm. 334-A, el 17 de julio.

Elizabeth millioud. Exposición de doce tapices, presentada por el Instituto Mexicano Norteamericano de Relaciones Culturales, A. C., Galerías Nabor Carrillo, del 17 de julio al 6 de agosto.

En el campo de las inquietudes artisticas de Elizabeth Millioud ha brotado otra flor que se agrega a las anteriormente cosechadas.

Trátase ahora de la original creación de tapices saturados de color, de imaginación formal, exhibidos por vez primera en las galerías de este l'nstituto.

En toda ocasión en que la artista emprende otra actividad, suponemos en mestro fuero interno que ella va a concentrarse en aquélla con carácter exclusivo, en menoscabo de otras empresas brillantemente iniciadas. Un poco de resignación nos embarga, hasta que el transcurrir de los dias viene a manifestar que lo temido queda en simple sobresalto. Posee, por lo visto, facultades e ideas para todo lo vinculado al arte.

Los tapices de reciente manufactura constituyen, pues, otra faceta de la multipersonalidad de la autora. Si nos atenemos a su historial, no desplazarán a otras actividades igualmente creadoras, y sólo nos indicarán que otra sensibilidad ha despertado en el vasto horizonte de Elizabeth Millioud, en el cual esas piezas de telar agregan otra cifra positiva a lo ya muy positivo de su inquieta carrera plástica.

ENRIQUe F. Gual

NUEVA VISIÓN SOBRE LA CULTURA PRECOLOMBINA DE AMORENo. Exposición presentada por el Organismo de Promoción Internacional de Cultura de la Secretaría de Relaciones Exteriores, Galería de Arte del Teatro Casa de la Paz, Cozumel núm. 33, el 18 de julio.

ANTonio Ramírez. Exposición de 20 óleos, presentada por la Galería Kusak, Génova $2 \mathrm{~J}$-Bis, del 18 de julio al 9 de agosto.

Exposición nacional DE GRABAdo. Exposición presentada por la Galería de Arte, Edificio del CEN del PRI, Insurgentes Norte 59, el 18 de julio.

Pablo picasso. Exposición de cerámica y litografía, presentada por la Galería 33, Amberes 33, del 21 de julio al 2 de agosto.

COLETte holder dE MARCillac. Exposición presentada por el Instituto Nacional de Bellas Artes, la Embajada de Francia, Sala Internacional, el 23 de julio.

ETnografía de POLONIA. Exposición temporal, presentada por el Museo de las Culturas, Embajada de la República Popular de Polonia en México, INAH/SEP, Moneda núm 13, el 24 de julio. 
Thomas mann. Exposición presentada por la Universidad Nacional Autónoma de México y el Instituto Cultural Alemán (Goethe-Institut), Dirección General de Difusión Cultural, Departamento de Artes Plásticas, Museo Universitario de Ciencias y Arte (entre la Escuela de Arquitectura y terminal de camiones) el 25 de julio.

Xavier lavalle. Exposición homenaje de óleos, pasteles y dibujos presentada por el Instituto Nacional de Bellas Artes, Galería José María Velasco, Peralvillo 55, el 25 de julio.

TRES EN UNO. LA OSA MAYOR, EQUIPO GOERITZ-MONTIEL. PINTURAS, MANUEL MONTIEI BLANCAS. PRESENCIA DE LOS HARTOS. Exposición presentada por el Instituto Nacional de Bellas Artes, Galerías del Palacio de Bellas Artes, Salas 4 y 5, el 25 de julio.

Tovar. Exposición presentada por la Galería Pecanins, Hamburgo 103, del 29 de julio al 18 de agosto.

TOLEDo. Exposición obra gráfica, presentada por la Galería Juan Martín, Amberes 17 , del 29 de julio al 16 de agosto.

\section{AGOSTO}

RINA LAzo. Exposición de óleos, presentada por el Organismo de Promoción Internacional de Cultura, de la Secretaría de Relaciones Exteriores, Sala de Arte OPIC, Av. Juárez 42 , el $1^{\circ}$ de agosto.

PINTURA EN MOVImiento (14 nuevos valores). Exposición presentada por la Galería de Arte Misrachi, Génova 20, el 7 de agosto.

Michael Carver (realismo e imaginación). Exposición presentada por el Instituto Mexicano Norteamericano de Relaciones Culturales, A. C., Galería Nabor Carrillo, Hamburgo 115, del 7 al 27 de agosto.

Las obras de Michael Carver pueden considerarse insólitas en una época en la que el artista se ha entregado al tema de la desilusión y la angustia, mientras que las de Michael Carver son una declaración de fe en la realidad.

Con firmeza y pasión, Carver afirma la tangibilidad de los seres y de los objetos en el espacio tridimensional. Sus composiciones maestras, atravesadas por relampagueantes negros y blancos, proyeccciones del drama y del sentido trágico de la existencia, reiteran una y otra vez que hay belleza en la solidez y ternura en la fuerza. Estas pinturas que representan una carrera de casi 30 años, son las expresiones de un hombre que ha buscado encarnar al espíritu renacentista -humanista, intelectual y artista que resiste hundirse en la desesperación y que no se deja engañar por la sensación superficial.

Aunque nacido en Palestina, es norteamericano y ha pasado casi toda su vida en la ciudad de Nueva York, excepto por unos breves viajes al extranjero. En esa ciudad empezó sus estudios de pintura en la School of Fine and Industrial Arts, colocándose después bajo la dirección de Hans Hofmann. Más tarde, pasó unos años estudiando con el gran expresionista alemán Max Beckmann, de quien tuvo una fuerte influencia. La obra Carver se ha expuesto en numerosas galerías tanto en Nueva York como en 
otras ciudades estadunidenses, mientras que varias de sus pinturas hoy forman parte de'colecciones particulares. Esta es la primera presentación de su obra en México. Otras exposiciones se abrirán en Italia e 1srael. Michael Carver es también profesor de pintura, conferencista y director de la escuela de arte que fundó hace 20 años en East Village. Su libro de instrucción sobre pintura, Painting in Oil by the 5-Color Method, que publicó la editorial McGraw-Hill en 1961, sigue siendo uno de los más populares de su tipo. Indiscutiblemente, los asistentes a la exposición encontrarán que no falta destreza ni maestría del oficio, el dibujo explícito, escueto, forma un tejido de lạzadas y jalones; el color vibrante, inequívoco, dramático, funcional, pero sobre todo el moderno aficionado del arte encontrará que a través de los desnudos, las lanchas, las naturalezas muertas, y demás temas convencionales, trasmite un sentido vigoroso de la vida, oirá una voz que asevera, en medio de una época de desengaños y dudas, que el mundo es real y que el hombre sí es significativo.

IRENE G. DE SÁYAgo

Desde el punto de vista de Carver, el arte no puede completamente desasirse de la vida y ser al mismo tiempo un medio vigoroso de comunicación. Hoy, cuando las antiguas concepciones de la realidad artística se confrontan con medios como la fotografía $y$ el cine, este punto de vista es particularmente pertinente en cuanto a las preocupaciones modernas del arte, actitud que apoyan las obras que se exhiben.

El artista no está preocupado por las relaciones espaciales como tales, o con las formas precisas de los objetos. Estas han sido sacrificadas ante una preocupación por el objeto y por la humanidad de las figuras mismas. Para aquellos que no les importe, ser un poco heterodoxos, el resultado vale la pena.

JAMES CASEY

Catálogo: 1. hombre con pipa 2.-discusión talmuidica 3. muchacha sobre silla de caña 4. arlcquin 5. joven bailarina 6. naturaleza muerta con mandolina 7. tres bailarinas jóvenes 8. muchacha de vestido blanco 9. en la galería 10. naturaleza merta con guitarra 11. naturaleza muerta con trompeta 12. lanchas varadas 13. escena invernal 14. iuego de damas 15. lanchas blancas 16. peinado 17. naturaleza muerta con tablero de damas \# 2 18. hombre con chaleco rojo 19. hermanas mayor y menor 20. pescador con redes 21 . tocando la concertina 22. música en la calle 23. muchacha con tiras cónicas 24. naturaleza muerta con flor de nochebuena 25. homenaje a Cezanne 26. en la playa 27. en la cantina \# 128 , muchacha vestida de rojo 29. payaso 30 . muchacho 31 . en el parque \# 1 32. bañistas 33. niños en la escalcra 34. tres monjas 35. naturaleza muerta con cafetera italiana 36 . el festejo.

gutllermo castaño ramírez. Exposición de bronce y aluminio, presentada por la Galería Mer-Kup, Artistas de la Plástica Mexicana, A. C., Molière 328-C, el 7 de agosto.

Datos biográficos: nació en México, D. F., el 17 de abril de 1938.

Catálogo: 1. desnudo, bronce y coral 2. Cuauhtémoc I, bronce 3. Cuaulitémoc II, bronce 4. Cuauhtémoc III, bronce 5. crisálida I, bronce 6. crisálida II, bronce 7. crisálida $I I I$, bronce y cerámica 8. sueño $I$, aluminio 9. vida $I$, bronce 10 . ella y él, aluminio 11. delfines, aluminio y bronce 12. astorel, aluminio y coral 13 astrom, aluminio y bronce 14. atamantis, aluminio y bronce 15 . atyra, alunininio y 
bronce 16. augea, aluminio y bronce 17. athos aluminio y bronce 18, azov, aluminio y bronce 19. astrea, aluminio y bronce 20 . moises, piedra bronce y aluminio, 15 bocetos bronce a la cera perdida.

eyron Gálvez. Exposición de óleos 69, presentada por las Galerías Mer-Kup, artistas de la Plástica Mexicana, A. C., Molière núm. 328-C el 7 de agosto.

Datos biográficos: Byron Gálvez, nació en Mixquiahuala, Hgo., el 28 de octubre de 1941, Ingresó a la Escuela Nacional de Artes Plásticas en el año de 1958.

DANielle wolfowitz. Exposición de dibujos, presentada por las Galerías Mer-Kup, Artistas de la Plástica Mexicana, A. C., Molière núm. 328-C el 7 de agosto.

Dotos biográficos: Danielle Wolfowitz, autodidacta, nacida en París, se educó en Francia, México y Estados Unidos.

Catálogo: 1. encuentro 2. amor 3. adolescentes 4. estudio 5. le Bois Maudit 6 . manos 7. niobee 8. cabeza 9. ilusión 10. séptimo circulo 11. absesión 12. el bosque 13. plenitud 14. figura.

MARÍA teresa tORAL. Exposición de grabados, presentada por el Instituto Nacional de Bellas Artes, SEP, Salón de la Plástica Mexicana, Havre núm. 7, del 8 de agosto al 10 de septiembre.

exposición final. Exposición de platería, cerámica, cestería, cocina internacional presentada por el Museo de las Culturas, INAH/SEP, Moneda núm. 13, el 9 de agosto.

JULIO PRIETO. Exposición de bocetos de escenografía y pintura, presentada por el Comité de actividades generales del centro deportivo Israelita, Galerías C.D.I., Av. Manuel Avila Camacho núm. 620, Lomas de Sotelo, del 10 de agosto al 5 de septiembre.

Datos biográficos: Julio Prieto, nació en la ciudad de México, en el año de 1912, estudió sin concluir, la carrera de Arquitectura en la Universidad Nacional Autónoma de México. Grabador, sobre todo en madera, ilustró numerosos libros hasta el año de 1942, cuando empieza su carrera de escenógrafo en el Teatro de Bellas Artes con el pintor Julio Castellanos y el tramoyista Marcelino Jiménez, a quienes considera sus maestros. Desde esa fecha ha diseñado las escenografías de más de 500 obras.

KEN NISHI. Exposición de pintura, presentada por el Instituto Nacional de Bellas Artes, Sala Internacional, el 13 de agosto.

FROYLÁN OJEDA. Exposición con el tema "Signos" de 20 obras, presentada por la Galería de Arte Plástica de México, Londres 139, el 14 de agosto.

gustavo arangures. Exposición de pintura y dibujo, presentada por el Instituto Nacional de Bellas Artes, Galerías del Palacio de Bellas Artes, Salas 1 y 2, el 15 de agosto.

SI sólo 3 pfas. Exposición presentada por la Galería Pecanins, Hamburgo 103, del 15 al 17 de agosto (venta anual del Salón Independiente). 
exposictón de trajes del extranjero. Presentada por la señora arqueóloga, Josefina Lomeli Quirarte, Museo de las Culturas, Moneda núm. 13, el 16 de agosto.

Apocalipsis. Exposición presentada por 4 pintores, en la Galería Edvard Munch, Reforma 489, el 18 de agosto.

Nombre de los expositores: José Luis Cuevas, Victor, Friedeberg, Francisca.

Los ANimales EN EL ARTe popular. Exposición presentada por la Galería Universitaria Aristos, UNAM. Difusión Cultural, Edificio C del Conjunto Aristos, Insurgentes Sur 421, el 19 de agosto.

grabado internacional. Exposición presentada por la Galería Pablo Picasso, Centro de Artes Plásticas, S.C., Centro Experimental de Arte Gráfico, Avenida Coyoacán núm. 931, del 19 de agosto al 5 de septiembre.

Nombres de países participantes: Argentina, Costa Rica, Japón, México, Polonia, URSS.

CRISTINA RREMER. Exposición de 24 pinturas, presentada por la Galeria de Arte Mexicano Florencia, Florencia 35-E, el 20 de agosto.

Catálogo: 1. proceso I 2. proceso II 3. el elegido 4. personaje $A$ 5. los alquimistas 6. punto de cruz 7. mi torre 8. yo torre 9. falso paisaje (tríptico) 10. liga nostálgica 11. tendedero 12 . torre de proceso o la vitrina de mi abuela 13. hacedora de marionetas 14. el intruso 15. la herida 16. desprendimiento (díptico) 17. desplome 18. invasión de transparencia 19. torre desde la ventana de mi cuarto 20. la ventana de mi cuarto 21. cámara de transparencias (tríptico) 22. cuarto de meditación 23. Guillermo en muerte (caja) 24. mi torre desde el fondo del patio.

RAFAEL JTMÉnez (Raxim). Exposición presentada por las Galerías Escudero, Valencia 20 , el 20 de agosto.

Rafael Jiménez (Raxim), como tantos elegidos, nace y crece en el seno de una familia en la que el arte no es un pasatiempo, sino una función vital.

Desde niño observa con pasión el mundo que lo rodea. Espíritu, manos y vista inquietos, lo llevan a intentar sus primeros trazos, el lápiz se transforma para él en una prolongación de su propio cuerpo.

Artista en esencia, le interesan todas las disciplinas. Así termina una carrera de leyes, pero los libros de Derecho, y el título de abogado, mágicamente, con decisión poco común, se transforman en pinturas y pinceles.

San Carlos le abre sus puertas. Avido, de dominar las técnicas, de ver y de irse encontrando a sí mismo es discipulo y amigo, en la UNAM y el Colegio Nacional de Diego Rivera, Justino Fernández, el Dr. Atl, Juan de la Encina, etcétera, lo liga una amistad inolvidable a Goitia. Se refugia en Tepoztlán, en donde además de pintar, van brotando los gérmenes de muchos de los cuadros de esta exposición.

Su manantial de estudio es inagotable: desde las Grutas de Altamira, hasta la más reciente producción de todo el mundo; pero sigue siendo el hombre y su esencia misma, su dolor, su preocupación y su felicidad.

Hace años ganó por oposición una cátedra en la Escuela Nacional de Artes Plás- 
ticas, imparte las clases de Desnudo, Dibujo preparatorio, Iniciación a la pintura y Dibujo publicitario.

Su obra puede encontrarse, aparte de México, en Holanda, Canadá, Estados Unidos y Francia. Es nutrida su colaboración en revistas y carteles y Rafael Jiménez, no se esconde tras el seudónimo de Raxim, acorta su nombre porque siempre le hará falta espacio para terminar, si algún día lo logra, la desgarradora poesía que lleva dentro.

\section{Manuel Cosfo V.}

Catálogo: 1. relicarios germinales 2. libélulas 3. azoro espectral 4. el adiós 5. callẹión sin salida 6. crisálida 7. L'Emprise (abrazo que se ahoga) 8. floración rítmica 9. escape onirico 10. apología del amor 11. laguna azul 12. laguna rosa 13. laguna magenta 14. laguna verde 15. jaula de cristal 16. asceta 17. música sorda 18. eterno cautivo 19. entrega animica 20. comunión humano-vegetal 21. ligaduras 22. umbral del destino 23. autorretrato 24 . ascetismo alucinante 25. mascarade 26. la cosecha 27. fatalismo pictórico 28. candelabro esotérico 29. resurrección 30. placenta espacial 31. el dolor de envejecer 32. voracidad vegetal 33. ensueño creativo.

ARTESANÍAS DE ISRAEL. Exposición temporal, presentada por el Museo de las Culturas, INAH/SEP/Moneda núm. 13, el 21 de agosto.

exposición de trabajos ivealizados en el ciclo escolar 1968-69. Presentada por la Escuela de Diseño y Artesanías, INBA/SEP/Balderas 125, el 22 de agosto.

ADolfo MENchacA. Exposición de grabados, presentada por el Organismo de Promoción Internacional de Cultura, de la Secretaría de Relaciones Exteriores, Sala de Arte OPIC, Av. Juárez 42, el 26 de agosto.

exposición de pintura. Presentada por el Molino de Santo Domingo, Av. Observatorio 139 , del 27 de agosto al 15 de septiembre.

Muchos años tuvieron que esperar los muros del Molino de Santo Domingo de Tacubaya, para recibir la obra de jóvenes pintores, un poco arriba de la mitad del siglo el siglo xx. El nuestro, cuando el hombre acaba de volver de la luna, y aquí están estas excelentes colecciones en el gran salón de lo que fue hace dos centurias la troje mayor de la hacienda.

Adaptadas sus viejas unidades para instalar tiendas y talleres de artes, artesanías y antigüedades, quienes hemos soñado en convertir su tradición de granero en una tradición de arte y cultura con lugares propicios para la creación joven y nueva del arte mexicano, no hemos tenido gran fortuna. Ha habido empeño de hombres y mujeres por lograr esa ilusionada empresa, pero ha sido duro el camino. El propietario de cstos espacios, Lic. José Angel Ceniceros, no ha escatimado esfuerzo por estabilizar al grupo fundador $y$ hacer de este hermoso y ensolerado lugar un emporio artístico: El Arq. González del Sordo, es el autor de todas las edificaciones y adaptaciones, con el buen gusto y el enlace armónico de sus unidades, y yo he configurado la idea infundiendo el contagio y el entusiasmo, con sugestiones e insistencias para lograr el conjunto, los tres hemos sorteado con optimismo las contingencias de un centro lleno de atractivos que ha venido ensanchando sus actividades, y ahora las diversifica al ofrecer sus espacios para exhibiciones de arte. 
La presencia de un numeroso y calificado grupo de pintores en una exposición de sus obras recientes viene a vigorizar ese empeño, y abre una etapa que con ellos empieza el capítulo singular y trascendente de las exposiciones, en el viejo molino, habitado ahora por el joven talento de la plástica de México. Nos complace contar con la solidaridad de quienes se expresan con el idioma del color y de la forma para definir la creación artística de nuestra época. No puedo referirme, individualmente al acervo de esta exposición, pues aunque conozco su inventiva y los frutos de su talento, el propósito medular de esta presentación es consignar lo grato que resulta recibirlos dentro de estos muros viejos, hoy iluminados con su juvenil presencia. Basta con señalar que a todos es común la inquietud, la indagación, el ensanchamiento de su lenguaje que su variada sensibilidad ha escogido para expresarse libremente, y con ello está casi definida una generación con vigencia de una o dos décadas. Bienvenidos a esta casa de esperanza, que con su presencia puede confiar más fundadamente en las luces del éxito y el abierto camino hacia el mañana.

Miguei. Alvarez Acosta

Nombre de los expositores: Arévalo, Aries Marueta, Byron, Chessal, De la Rosa, Dominguez, Falfán, Gochez, Kazekubo, Maciel, Manzo, Malfabon, Montiel, Pescina, Sauret, Tomás Ortiz, Yamandu, Zalathiel, Zamora, Zepeda, Zinniga.

hugo chávez. Exposiciön de cobres, óleos, dibujos, recubrimientos, murales, presentada por el Instituto Nacional de Bellas Artes, Galería José María Velasco, SEP/ Peralvillo 55, el 29 de agosto.

EL PAISAJE EN LA palabra y EN la pinTURA. Exposición presentada por el Instituto Nacional de Bellas Artes, Sala Verde, el 29 de agosto.

Nombre de los expositores: Acosta, Ayala, Echáti, Herrera, Lugo, Moreno, Nishizawa, Peña, Pichardo, Suárez.

17 obras DE BAYA. (Argelina). Exposición presentada por el Organismo de Promoción Internacional de Cultura, de la Secretaría de Relaciones Exteriores, Galería de Arte del Teatro, Casa de la Paz, Cozumel núm. 33, el 29 de agosto.

GRABADo soviÉtico. Exposición presentada por la Escuela Nacional de Artes Plásticas/ UNAM/Sala de Exposiciones, Academia núm. 22, el 29 de agosto.

SALón dE GRABado 1969. Exposición presentada por el Salón de la Plásitca Mexicana, Havre núm. 7, del 29 de agosto al 17 de septiembre.

ANTONIO BERNi y AIDO BIGLIONE. Exposición de grabados, presentada por la Escuela Nacional de Artes Plásticás/UNAM/Sala de Exposiciones, Academia núm. 22, el 29 de agosto.

FRANCIsco MOYao. Exposición de pinturas y esculturas, presentada por la Escuela Nacional de Artes Plásticas/UNAM/Sala de Exposiciones, Academia núm. 22, el 29 de agosto. 
FRANK KYLE. Exposición de Escultura, presentada por el Departamento Cultural del Municipio del Centro, Museo de Querćtaro, Sala de Exposiciones Temporales, Corregidora núm. 7, Querétaro, Qro., durante el mes de agosto.

HILDA CAMPILLO. Exposición de grabado, presentada por el Departamento Cultural del Municipio del Centro, Museo de Querétaro, Sala de Exposiciones Temporales, Corregidora núm. 7, Querétaro, Qro, durante el mes de agosto.

OLGA DONDÉ. Exposición de pintura, presentada por el Departamento Cultural del Municipio del Centro, Museo de Querétaro, Sala de Exposiciones Temporales, Corregidora núm. 7, Querétaro, Qro., durante el mes de agosto.

\section{SEPTIEMBRE}

GRUPO ESPIRAL. Exposición de obras recientes de pintura y escultura, presentada por la Galería Kusak, Génova 2 j-bis, del 2 al 22 de septiembre.

Nombre de los expositores: Barrios, Camps Ribera, Casas Castaños, De las Casas, Getulio, Muñoz López, Nierman, Pérez Barrios, Sabattini, Sisto.

LUIS TORRLBLANCA. Exposición de escultura, un punto en fuga, presentada por el Departamento del Distrito Federal, Dirección General de Acción Social, Galerías de la ciudad de México, Alameda Central, Sala Hidalgo, el 3 de septiembre.

Catálogo: 1. punto en giro 2. punto en el espacio 3. punto convexo 4. punto en fantasia 5. punto lunar 6. punto en consonancia 7. punto en acorde 8. punto infinito 9. punto en perspectiva 10. puntos cardinales 11. punto céntrico 12. prunto crudo 13. punto apoyo 14. punto de caramelo 15. punto galáxico 16. punto de partida 17. punto equinoccial.

BETTy sCHNeIDER. Exposición de obras, presentada por el Instituto Nacional de Bellas Artes, Galerías del Palacio de Bellas Artes, Sala Internacional, el 3 de septiembre.

DAvid Pimentel. Exposición retrospectiva, presentada por el Departamento del Distrito Federal, Dirección General de Acción Social, Galerías de la citudad de México, Alameda Central, Sala Juárez, el 5 de septiembre.

jaime villa. Exposición ecuatoriana de pinturas, presentada por el Organismo de Promoción Internacional de Cultura, de la Secretaría de Relaciones Exteriores, la Embajada de la República de Ecuador en México, Almacenes Nacionales de Depósito, S. A., Galería de Arte del Teatro de Cámara ANDSA, Plaza de la Constitución núm. 7 , el 5 de septiembre.

ERNESTO CARREón. Exposición de obras recientes, ciclo NADI, presentada por las Galerías Mer-Kup, Artistas de la Plástica Mexicana, A.C., Molière núm. 328-C, el 8 de septiembre.

grtpo arte fotográftco, $6^{a}$ exposición. Presentada por el Instituto Mexicano-Norte- 
americano de Relaciones Culturales, A.C., Galerías Nabor Carrillo, Hamburgo 115, del 9 al 30 de septiembre.

Nombre de los expositores: Antonio Pla Miracle, Carlos Fernández, Blas Cabrera, Raúl Diaz González, Arênas, Figueras, Warman.

I EXPosición DE MAestros. Presentada por el Instituto Nacional de Bellas Artes, Escuela de Diseño y Artesanías, SEP/Vestíbulo del Palacio de Bellas Artes, el 9 de septiembre.

josé manuel schmil.. Exposición de dibujos, gouaches y tintas, presentada por la Plástica de México, Londres 139, el 12 de septiembre.

PAL KePENyes. Exposición de escultura, joyería, escultura en Alta costura, presentada por la Galería Pablo Picasso, Centro de Artes, Plásticas, A.C., Avenida Coyoacán núm. 931, el 17 de septiembre. Catálogo: "El Retorno de la Esperanza."

KISHIo mUizata. Exposición de 17 pequeñas pinturas, presentada por la Galería de Arte Mexicano, Florencia 35-E, el 19 de septiembre.

Catálogo: 1, flor del desierto 2, la nieve de la mañana 3. tiempo silencioso 4. jardín en mayo 5. paseo por la noche 6. una historia del Japón 7. la primavera en Japón 8. tiempo pasado del Japón 9. un arroyo 10. la playa 11. luz y som bra 12. la brisa 13. una canción por la luna 14. arena blanca 15. la ventana 16. el otoño del Japón 17. ave en el mar.

16 voces de la Plástica. Exposición presentada por la Galería Edvard Munch, Reforma 489, el 22 de septiembre.

Nombre de los expositores: Arévalo, Arias Murueta, Byron, Susana Campos, Capdevila, Pilar Castañeda, Guillermo Ceniceros, Falfán, Silvia González, Hernández Delgadillo, Hernández Urbán, Carlos Jurado, Eliana Menasse, Messeguer, Carlos Olachea, Mario Orozco Rivera.

SALÓN DE PINTURA 1969. Exposición presentada por el Salón de la Plástica Mexicana, INBA/SEP/Havre núm. 7, del 22 de septiembre al 16 de octubre.

Nombre de los expositores: Ignacio Aguirre, Ernesto Alcántara, Raull Anguiano, Javier Arévalo, Gustavo Arias Murueta, Héctor Ayala, Alfonso Ayala Díaz, Sofía Bassi, Feliciano Béjar, Arnold Belkin, Angelina Beloff, Roberto Berdecio, Celia Calderón, Gloria Calero, Gerardo Cantú, Federico Cantú, Pilar Castañeda, Guillermo Ceniceros, Enrique Climent, Héctor Cruz, Roberto Donis, Francisco Dosamantes, Manuel Echauri, Enrique Echeverria, Arturo Estrada, Alfredo Falfán, Byron Gálvez, Arturo García Bustos, Silvia H. González, José Hernández Delgadillo, Miguel Hernández Urbán, Carlos Jurado, Rina Lazo, Julia López, Amador Lugo, Maka, María Marin, Eliana Menasse, Guillermo Meza, Francisco Mora, Nicolás Moreno, Francisco Moreno Capdevilla, Luis Nishizawa, Isidoro Ocampo, Pablo O'Higgins, Froylán Ojeda, Carlos Olachea, Mario Orozco Rivera, Carlos Orozco Romero, Trinidad Osorio, Xavier Oteyza, Feliciano Peña, Angel Pichardo, Fanny Rabel, Antonio Ramirez, Antonio Serna, Adrión Silva, Helena Talmacs. 
Catálogo: 1. agraristas, $70 \times 92 \mathrm{~cm}$, óleo s/masonite 2 . el espejo, $130 \times 80 \mathrm{~cm}$, óleo s/tela 3. jugador núm. 2, $151 \times 121 \mathrm{~cm}$, ólco s/tela 4. pintura 1969, $149 \times$ $149 \mathrm{~cm}$, óleo s/tela, premio-adquisición 5. lucha por la libertad, $270 \times 150 \mathrm{~cm}$, óleo s/papel 6. abstracción, $239 \times 149 \mathrm{~cm}$, óleo s/tela 7 . el cardenal, $76 \times 122$ $\mathrm{cm}$, encáustica s/masonite 8 . juicio somero, $77 \times 57 \mathrm{~cm}$, óleo s/tela 9 . formas, $81 \times 121 \mathrm{~cm}$, óleo s/tela 10. figura sentada, $180 \times 180 \mathrm{~cm}$, óleo s/tela 11. ranio de flores, $60 \times 80 \mathrm{~cm}$, óleo s/tela 12. composición de perspectiva kinética (visión lateral de izquierda-derecha), en espacio no-euclidiano, $220 \times 250 \mathrm{~cm}$, técnica mixta/ masonite 13. caligrafía de oro $y$ luz en el tiempo, $110 \times 132 \mathrm{~cm}$, técnica mixta/mazonite 14. madona, $60 \times 50 \mathrm{~cm}$, óleo s/tela 15 . clasificación inconclusa (cuernos de luna), óleo/tela, $150 \times 200 \mathrm{~cm}$, premio adquisición 16. palenque, $105 \times 135 \mathrm{~cm}$, óleo s/tela (fuera de concurso) 17. personajes, $90.5 \times 150 \mathrm{~cm}$, óleo s/tela 18. figura, $541 \times 200 \mathrm{~cm}$, acrílico s/tela 19 . naturaleza muerta con tonos marfil, $24 \times 54 \mathrm{~cm}$, óleo/tela/triplay 20 . paisaje, $150 \times 163 \mathrm{~cm}$, óleo s/tela, premio-adquisición 21. prisión invisible, $148 \times 104 \mathrm{~cm}$, técnica mixta s/masonite 22. botellas, $60 \times 50 \mathrm{~cm}$, óleo s/tela 23. paisaje, $60.5 \times 90 \mathrm{~cm}$, óleo s/masonite 24 . Uxm, $108 \times 140 \mathrm{~cm}$, óleo s/tela 25. Las Marias, $128 \times 98.5 \mathrm{~cm}$, óleo s/tela 26. cvocación, $110.5 \times 130.5 \mathrm{~cm}$, óleo s/tela 27. amor en los trigales, $95 \times 120 \mathrm{~cm}$, óleo s/tela 28.7 de noviembre en Moscú, 110 x $98.5 \mathrm{~cm}$, mosaico/triplay 29. jardín, $69.5 \times 50 \mathrm{~cm}$, óleo/triplay 30. el ángel exterminador, $203 \times 143 \mathrm{~cm}$, técnica mixta s/tela 31. paisaje, $169.5 \times 122 \mathrm{~cm}$, acrílico s/masonite 32 . figuras con cometa, $148.5 \times 350 \mathrm{~cm}$, óleo s/tela 33 . el día y la noche, $40 \times 112 \mathrm{~cm}$, óleo s/tela 34. la mujer del viento, $120 \times 244 \mathrm{~cm}$, óleo s/tela 35 . paisaje urbano, $61 \times 122.5$ $\mathrm{cm}$, óleo s/triplay 36. homenaje a Stan Getz, $120 \times 140 \mathrm{~cm}$, óleo s/tela 37. naturaleza nuerta (botella blanca), $37 \times 57 \mathrm{~cm}$, óleo s/masonite 38 . regreso, $80 \times 120$ $\mathrm{cm}$, óleo s/tela 39. figura y árbol, $106 \times 80 \mathrm{~cm}$, (fuera de concurso), óleo s/tela 40. plástico en la lluvia, $152.5 \times 76 \mathrm{~cm}$, técnica mixta s/tela 41 . el árbol caído, $122 \times 242 \mathrm{~cm}$, encaústica s/madera 42 . canto negro, $150 \times 150 \mathrm{~cm}$, acrílico s/tela 43. naturaleza muerta, $71 \times 96.5 \mathrm{~cm}$, acrílico s/tela 44 . el tapado del diablo, $66 \mathrm{x}$ $51 \mathrm{~cm}$, tinta gráfica-pastel 45. paisaje del valle de México, $65 \times 100 \mathrm{~cm}$, óleo s/tela 46 . reglamentos para el sueño, $60 \times 90.5 \mathrm{~cm}$, acrílico s/masonite 47 . reflejos, $112 \times 76 \mathrm{~cm}$, acrílico s/madera 48. así en la tierra como en el cielo, $122 \times 92$ $\mathrm{cm}$, técnica mixta 49 . el fantasma, $50 \times 40 \mathrm{~cm}$, (fuera de concurso), óleo s/tela 50. cofre de ilusiones, $70.5 \times 100 \mathrm{~cm}$, óleo s/tela 51 . jarras y frutas, $30.5 \times 66 \mathrm{~cm}$, óleo/triplay 52. pueblo abandonado, $80 \times 135 \mathrm{~cm}$, óleo s/tela 53 . bosque, $135.5 \mathrm{x}$ $154.5 \mathrm{~cm}$, óleo s/tela 54. caperucita y la Cía., $120 \times 76$, técnica mixta s/tela 55. jaulas, $110 \times 80 \mathrm{~cm}$, óleo s/tela 56 . el aquelarre, $100 \times 150 \mathrm{~cm}$, óleo $\$ /$ tela 57 . el tercer principio, $100 \times 80 \mathrm{~cm}$, técnica mixta s/tela 58 . flora sintética, $80 \times 70 \mathrm{~cm}$, óleo s/tela.

Antonio rodríguez luna. Exposición de 10 obras recientes, presentada por la Galería de Arte Mexicano, Milán 18, del 22 de septiembre al 25 de octubre.

Dibujos de escultores y esculturas pequeñas: de rodin a NUESTros días. Exposición presentada por el Instituto Nacional de Bellas Artes, Embajada de Francia, Museo de Arte Moderno, Galería de Exposiciones Temporales, el 23 de septiembre.

María lagunes. Exposición de dibujos y esculturas, presentada por la Galería de Arte Misrachi, Génova 20, el 23 de septiembre.

Los ANImales DE MARTA ADAMs. Exposición de 29 dibujos a lápiz y tinta, presentada por la Galería de Arte Misrachi, Génova 20, el 23 de septiembre.

george lOOMER. Exposición de pintura, presentada por el Instituto Nacional de Bellas Artes, Galerías del Palacio de Bellas Artes, Sala Internacional, el 24 de septiembre. 
Ligia urvina dávila. Exposición de témperas, presentada por el Instituto Cultural Hispano Mexicano, A. C., Tabasco 68, del 24 de septiembre al 7 de octubre.

Datos biográficos: Ligia Urbina Dávila... Nació en Quito y realizó estudios generales en el Colegio 24 de Mayo, Estudios Artísticos, Autodidacta.

Catálogo: 1. deslumbramiento en negro 2. la arcilla intemporal 3. los utensilios del gran gozo 4. el barro resonante 5. las pirámides del silencio 6. los danzantes del sol 7. castillo de las armas 8. el circulo embriagado 9. vibración ancestral 10. fortaleza y leyenda 11. montaña del padecimiento 12. la cárcel del verano 13. al encuentro del pasado 14. agonia Cañari 15. la soledad quebrada 16. fiesta del estilo 17. presencia de una raza 18. vegetación de piedra 19. simbolo de piedra 20. el regreso del sol 21. arcillas perpetuas 22 . el descanso del sol 23. las piedras eternales 24. tierra fria 25 . regreso a la tierra propia 26 . la gran batalla 27. las huellas del Inca 28. vigilia de la contienda 29. presencia de los dioses 30 . la danza de granito 31. el ave de los festejos.

ALLEN CARTER. Exposición de Fotografías, presentada por el Instituto Mexicano Norteamericano de Relaciones Culturales, A. C., Galería Nuevos Valores, Hamburgo 115 , el 25 de septiembre.

JEsÚs contreras PEÑA. Exposición de xerigrafías, presentada por la Galería Chapultepec, Insurgentes Sur núm. 11, bis, el 25 de septiembre (comenzó el día $1^{\circ}$ del mismo mes).

hrrminio Álvarez. Exposición de técnica mixta, presentada por la Galería Chapultepec, Insurgentes Sur núm. 11, bis, el 25 de septiembre (comenzó el día $1^{\circ}$ del mismo mes).

RDA : 20 AÑos DE CONSTRUCCIón DEL ESTAdo DEMOCRÁtico Y ANTIFASCISTA. Exposición presentada por el Club de Periodistas de México, A. C., Filomeno Mata 8, el 25 de septiembre.

José pantlla carlin. Exposición de tintas y dibujos, presentada por el Instituto Nacional de Bellas Artes, Galería José María Velasco, Peralvillo 55, el 26 de septiembre.

Luis garcía robledo. Exposición de litografías, presentada por el Comité de Actividades Generales del Centro Deportivo Israelita, Galerías CDI. Manuel Avila Camacho 620, Lomas de Sotelo, del 28 de septiembre al 17 de octubre.

Ante el número cada vez mayor de exposiciones que muestran con descaro los productos de la improvisación y el oportunismo, resulta placentero y en particular reconfortante, escribir unas líneas en relación con la obra sensible y vigorosa de un artista que se comunica con verdadera maestría a través del interesante y noble arte litográfico. Concebida con fines utilitarios, la litografía desde su invención fue bien acogida por el arte - Goya, Daumier, etcétera- convirtiéndose en nuestros dias en uno de los procedimientos gráficos más apreciados por los artistas. 
Luis García Robledo a cuya exposición me refiero, es fundamentalmente un dibujante y con plena conciencia de esto, escogió la litografía como principal medio de expresión, ya que este oficio se apoya en un conocinniento del dibujo que ha de ser tail seguro como el propio y natural vocabulario, el que se usa a diario, pero que es necesario depurar, limpiar y pulir para lograr una comunicación mejor con el mundo.

Hace algún tiempo que LGR no mostraba su obra en público; pero durante este receso aparente, el artista se dedicó infatigablemente a la indagación y la búsqueda, experimentando toda clase de medios y recursos gráficos que ahora practica y domina. Unas veces los utiliza con pureza ortodoxa, y en otras, la mayoría, los mezcla con agilidad y poderío sorprendentes, logrando unidad y armonia de efectos sienipre justos con respecto a lo que representan y expresan sus obras. Para valorar mejor esto que acabo de señalar, baste recordar que la litografía, durante su ejecución, no es un procedimiento directo como es el dibujo; resulta indirecto, esto es: hay que concebir y planear el efecto final, antes de verter y plasmar algo sobre la piedra litográfica, pero con tal certidumbre y dominio, que asegure, hasta cierto punto, la respuesta requerida.

En resumen, se trata de un maestro de la litografía cuya obra impregnada en profundo sentido humano, invita a meditar sobre ese tema de dimensión infinita que es el Hombre, y cuyo espíritu encierra toda la gama de sentimientos que van desde la alegría a la desesperanza; de la ternura al amor y la piedad, llegando en su recorrido hasta las más graves notas que acompañan la rebeldía, el dolor o la nuerte. Pero todo esto dicho al mismo tiempo con énfasis y dignidad, con vigor y equilibrio. No se encuentra en esta obra algo pueril, discordante ni grandilocuente; no se ven tampoco posturas teatrales; no hay gestos lacrimosos ni retorcimientos de mal gusto. Obra inteligente, esencialmente humana y por ende comunicativa, cuyo simbolismo no es obvio en virtud de cierta dosis de misterio que se consubstancial a la poesía, a la obra de arte.

Para concluir sólo me resta señalar que reitero mi confianza en la ruta que sigue García Robledo, porque tengo la convicción de que su obra, no obstante su indiscutible carácter de madurez, no deja presentir alguna declinación. Al contrario, todo hace pensar que empieza, que va en ascenso. $Y$ cabe evocar aquí la frase que se atribuye a Picasso en relación con los pintores: El artista empieza después de los cuarenta años...

RAFAel A NzTURES

rostros 1900. Exposición presentada por la Dirección General de Difusión Cultura, UNAM/Depto. de Actividades Cinematográficas, Galería del mismo, Insurgentes Sur 1838, esp. Juventino Rosas, el 29 de septiembre.

david alfaro sigueiros y artistas colaboradores. Exposición presentada por la Galería del Arte la Selva, Hotel Casino de la Selva, Cuernavaca, Mor., el 15 de septiembre.

miguel aldana. Exposición presentada por la Galería Municipal, Av. Chapultepec y España, Guadalajara, Jal., el 12 de septiembre. 
X BIENal de são paulo. Brasil 1969. Exposición presentada por el Instituto Nacional de Bellas Artes, del 27 de septiembre al 31 de diciembre de este año. Expositores:

Pedro Friedeberg. Los Enigmas en la obra de Pedro Friedeberg. Tanto la pintura como la escultura de ese extraño "artista que es Pedro Friedeberg, es sucesión de formas e ideas que persisten en el ánimo del espectador, aún después de que finaliza la intensidad del impacto emocional". Las ideas son mucho más reales, más genuinas, en los horizontes ópticos, en el humor satírico y en el espacio en perspectiva, que el propio pintor que los realiza, es decir, que trascienden al inventor y se sustentan en sus propias posibilidades estéticas.

En esta pintura caligráfica, original por su atracción o repulsión, como en las obras singulares de todos los tiempos, no hay ninguna verdad objetiva ni signo alguno. Todo es subjetividad ideal y consumación del proceso intelectual, que da vida al razonamiento que prosigue $y$ a la vez contradice, los postulados surrealistas y del arte fantástico.

Friedeberg va idealizando, inventando o concibiendo - que es lo mismo- universos mágicos identificados con la verdad absoluta y con el enigma de la proyección artística universal.

La idea hegeliana del devenir, del supuesto de la existencia y el idealismo metafórico, innatos del arte; tienen sus correspondencias lógicas y coherentes, en esas acepciones formales de Pedro Friedeberg que, al llenar un espacio y crear otro distinto, concomitante con lo contemporáneo, desgaja el subjetivismo en otros conceptos como son la idea de la vida y la muerte, la realidad con el misterio, la mentira con lo genuino, objetivos como subjetivos temáticos, orden y desorden sintomáticos.

Jean Paul Sartre, al referirse a! arte y su destinatario, que es el conglomerado de hombres que hacen la élite de la sociedad, afirmó: il n'y a pas de signes dans le monde; puesto que el hombre, en este caso el artista, es libre de concebir, in mente, su real significado y significación, de antemano.

Dentro del caos al cual ha llegado la plástica de nuestros días, proponiendo una enigmática respuesta con humor, drástica, dolorosa y poética, eslabonando antecedentes e influencias que parten de Dadá y del posterior arte mágico de los surrealistas, como Ray, Tanguy y Magritte; sustentando teorías que especulan con las vivencias de lo real y los significados del sueño; concretando un mundo cerrado, críptico, aterrador por su propia inestabilidad o inmovilidad; dejando que el dibujo sea la base radical de la idea y después elaborando una nueva filosofía sobre un arte que lleve lo espiritual por senderos inexplorados, oníricos, alucinantes, carentes de sentido común, sintetizando las partículas geométricas que hieren a la vista $y$ dan el espectro de enigmas nunca mirados con la razón; la obra poética de Pedro Friedeberg se presenta como tendencia nueva, saludable y gozosa, dentro de las muchas tentativas estéticas de esta década de los años "sesentas" que cierran su ciclo en el cabalístico 1969.

La magia y un cierto aspecto romántico ciñe, constriñe toda la producción del artista: los jeroglíficos persas, el torot de los egipcios, los signos extraños, la numeración arábiga y los símbolos numerales de los pueblos remotos, así como la sucesión de formas caprichosas, que ondulan graciosamente, y que son consecuencia de un tardío Art-Nouveau nuevo, mezclados con sintomáticas reverberaciones de una mente apasionada y alucinada en el arte de la minia es, por decirlo en unas cuantas líneas, el 
enigma en la pintura de Friedeberg, al cual debemos ver con la conciencia liberada; no contaminada de las gélidas razones de los muchos ismos actuales.

El Erotismo cerrado, silenciosamente disimulado en transparentes paredes que dan el trompe l'ocil, los vegetales y los frutos que se guardan, misteriosamente, en cajas decoradas con volutas, grutescos, esferas, circunvoluciones, concavidades y convexidades de la óptica; los melones que constituyen cementerio y monumentos, la construcción imaginaria de ciudades completamente fantásticas, lo que siempre se adelanta al juicio de la historia, como es la imposible posibilidad de dialogar con la materia, hacen de Friedeberg, artista sutil, sin parangón en el arte de este tiempo.

Pero, por sobre todas las especulaciones, esta pintura tiene lo que casi todo el arte contemporáneo carece, que es el sentido, la idea o el invento del amor, y por ello, parte su sinceridad $y$ el afán de conmover, de hacer sensibles todas las fibras secretas del ser pensante. Aun el sexo, cuando es pintado por el artista, adquiere una categoría distinta: se transforma en sentido de la vida, toma mil formas iridiscentes, llena de vegetales y de frutos encantados la sentencia de lo sagrado, lo moral y lo anecdótico. Como bien escribió Gore Vidal: "En esta era neo-romántica el sexo sin amor es considerado uno de los aspectos más repugnantes de la naturaleza humana, algo que debe situarse entre el asesinato y el robo a mano armada. Y los hombres y las mujeres que hacen concesiones a sus sentidos suelen ser considerados débiles en el mejor de los casos y canallescos en el peor, capaces de las otras dos infracciones" (E1 juicio de París.)

Pedro Friedeberg con su arte miniatural, con sus esquemas de imágenes vitales, extraordinarias por su factura, por su paciencia de alquimista medieval; por sus razones que nunca excluyen la belleza, sea la forma que adquiera, y por supuesto, por presentar algo o mucho del arte espiritual, del que tanto escribió y preconizó Kandisky; además de la genial manera de objetivar los enigmas de la vida, y su respuesta en la manifestación artística, lo colocan en sitio de honor de los creadores con talento poético y de ideas profundas.

\section{Alfonso de Neuvillate}

Datos biográficos: Pedro Friedeberg, nació en 1937, vive en la ciudad de México desde 1940. Hizo sus estudios con Mathias Goeritz.

Catálogo: 1. la silla elécirica de Madame Pompadour, acrílico s/cartón, 1967, 0.38 $\mathrm{x} 0.38$, col. Sr. Alfonso de Neuvillate. 2. tres pirámides hipersensitivas, 1969, tinta y acrílico $0.60 \times 0.60$, col. del autor 3. mi perro toca su violín perfectamente, tinta y acrílico, $1969,0.60 \times 0.60 \mathrm{col}$. del autor 4. cuatro monumentos para cinco paquidermos, 1969 , tinta y acrílico, $0.60 \times 0.60 \mathrm{col}$. del autor 5 . la cocina de Bau delaire, 1969 , tinta y acrílico $0.60 \times 0.60 \mathrm{col}$. del autor 6 . orfanatorio para tehuanas, 1968 , mixta sobre cartón $76 \times 1.01$ col. Sr. José Castelló Iturbide 7 . te odio apestoso jazmin, mixta s/cartón, $0.60 \times 0.60 \mathrm{col}$. Club de Industriales 8 . finalmente han comprendido, 1965, mixta s/cartón, $77 \times 97$, col. del Sr. Stanley Weiss 9. viaje circular, collage, $50 \times 50$, col. Sra. Rosa Covarrubias.

Antonio Pelácz. La pintura absoluta. Antonio Peláez es un artista en el sentido que a este término otorgaba Paul Valéry. En sus manos y con su sensibilidad la 
pintura cobra significado absoluto: la perfecta concordancia entre realidad e imaginación, sugerencia de constelaciones percibidas en el telescopio imaginario de la geometría, con lo perfecto de la ilusión y la alucinación extraña.

Las formas convexas, las líneas paralelas, las hoquedades cóncavas, aquellas texturas de muros inexistentes; temas arrancados a lo más fino de la aspiración espiritual el proceso de las ideas que nos conducen al abismo de sus ideas; las rupturas líricas del orden cotidiano y la madurez con que se idealizan el silencio, el espacio y los signos mágicos, son lo que hacen de Antonio Peláez un artista contemporáneo de singular perfección. Lo que crea, re-crea, este pintor, es reflejo imaginario, histórico, de oraciones violentas, dramáticas, a punto de explotar dentro de aparente calma y tranquilidad. Todos los objetos, y lo que queda de ellos, los plasma Peláez con sentido ambiguo de la verdad absoluta, aquella que sólo logran alcanzar los mejores artistas de ciertas generaciones.

Su pintura es como rompecabezas a partir del cual hay que conformar nueva realidad, la que no excluye la identificación con la problemática social, histórica, política y fundamentalmente espiritual.

Antonio Peláez pinta rombos, sugestivos conos, pirámides, triángulos o rectángulos imperfectos; sigue, con esta idea, el supuesto euclidiano de la invención a priori de todos los objetos circundantes, aún antes de conocerse y tomar forma determinada en la mente, la razón o la palabra.

Para Antonio Peláez sus frases filosóficas son los ocres, los dorados, las superficies desconchadas, como apariciones cosmogónicas o espejismos y abstracciones de la mente. Ese lenguaje, asimismo, posee reglas gramaticales, estéticas que todo ser sensible podrá leer e interpretar o rechazar conforme su estado emocional y su sensación de realidad.

Dentro de los muros lóbregos, encerrados en laberintos volcánicos, desgastados por la herrumbre del tiempo sin espacio, los círculos, la idealización de lo inalcanzable, de lo metafísico: las esferas que se licúan y se esfuman en álgidas paredes incendiadas, los grafismos que irrumpen deformando la extraña naturaleza material, el clímax y la catarsis en esa agobiadora, aterrante e inquietante forma de manifestar la emotividad; hacen a un tiempo, de la pintura de Antonio Peláez, solución y enigma.

La solución se halla en la desconectante naturaleza deformada que encauza mil y una formas de deshacer lo conocido, y el enigma, en que todo no es ya más que supuesto ideal.

Esta naturaleza cósmica, estas desérticas y salitrosas paredes suplicantes, al decir de Octavio Paz "no conocen la historia pero en sus formas viven los cstilos del pasado, del presente y el porvenir".

Las esferas llameantes, las ráfagas luminosas, el incendio dorado, los destellos inmaculados, los rojos delincuentes, las formas esquematizadas, sintéticas que se sumergen en el silencio de la nada, que es lo otro, es, también el todo, que es lo nuevo y lo poético.

El emplea la poesía, la poiesis, como manera de crear utopías, fugaces imágenes de otros seres que son, a última instancia, su propio ser. El artista se retrata en cada obra. Deja gran parte de su ser y sentir. Absorto en las aberturas de su creación, Antonio Peláez se deja llevar por la necesidad expresiva, cuyo rigor y dinamismo estriban en su expansión y, precisamente por ello, cada una de sus telas no se limitan 
dentro de los cuatro lados superficiales; sino que se agigantan y salen, buscando otros limites, otros espacios, de la consternida forma tradicional. La obra de Antonio Peláez, como las pinturas de ese conglomerado de artistas - tan diversos unos de los otros-, que forman la Escuela Mexicana de Pintura son contestaciones frente al arte que trata de negar, ya no tan sólo la forma de la figura conocida sino también, las técnicas imperecederas del arte por el arte. Después de experimentos, tras lucubraciones tecnológicas y lo puramente mecánico, la pintura pura, la plástica que se vale de los medios antiguos para estipular sentencias verdaderas, es la que, después del análisis razonado y ontológico, es lo que da contestación al enigma de lo bello y los posibles lenguajes que el artista puede inventar con su cultura.

Antonio Peláez: creador sutil que, con finísimas y a la vez nostálgicas presencias misteriosas, llevan al encuentro con formas hermosas de la constelación utópica de la realidad transformada.

Todo su arte es la significación de la belleza y trasciende los límites del pensamiento, puesto que aborda aquellos elementos perfectos de lo ideal en el arte poético.

Su pintura es su principio, medio y fin. Un artista, pues, que emociona con la severidad, y aterra por ser portavoz de cálidas remembranzas de la ensoñación perversa. Su pintura, poesía sin fin, perdurará a través del tiempo, el espacio corporal, ya que hace valedera la sentencia de Hölderlin: "Was bleibet aber, stiften sie Dichter."

Alfonso de Neuvilifate

Datos biográficas: Antonio Peláez nace en Llanes, Asturias, en el año de 1921.

Catálogo: 1. Planificación del silencio núm. 1, 1969, óleo s/tela, $90 \times 1.60$, col. del autor 2. planificación del silencio núm. II, 1969, óleo s/tela $90 \times 1.60$, col del autor 3. planificación del silencio núm. III, 1969, óleo s/tela, $90 \times 1.60$, col. del autor 4 . planificación del silencio núm. IV, 1969, óleo s/tela $90 \times 1.60 \mathrm{col}$. del autor 5 . sugerencia lunar, 1968 , óleo s/tela, 1.50 × 2.00 col. Galería Misrachi 6 . sugerencica solar, 1968, óleo s/tela $1.50 \times 2.00$ col. Galería Misrachi.

Cordelia Urueta y su significación. La pintura de Cordelia Urueta pretende alcazar -y lo logra - además del misterio, mediante extraña alquimia, los ideales kantianos de belleza y el concepto de angustia estipulado por Kierkegaard.

Las apariciones, esquemas humanos, que presenta en sus lienzos, son dolorosas síntesis del mundo mitológico, ancestral, cósmico e ideal, por la metamorfosis del proceso creativo. La obra de Cordelia Urueta no copia nada de la naturaleza ni de los hechos cotidianos. Todas las sugerencias obedecen al principio que rige la profundidad filosófica de las investigaciones mágicas de las civilizaciones antiguas mexicanas.

Tanto el color, las tonalidades que confunden por las especialísimas significaciones y las formas remotas, son producto sublimado del amor, de la crueldad y la pasión que transtorna el orden frecuente en la manifestación-pintura.

La eterna dualidad entre estado de vigilia y sueño, la vida y la muerte, oscilan, gravitan, mejor dicho, en la obra de la artista como puntos de arranque y como conclusiones sentimentales-aparentes. 
La dureza de ciertas figuraciones asombrosas, asi como la potencial vitalidad de imágenes portadoras de signos axiomáticos, la especulación con los valores reales e irreales de la naturaleza, la concretan y significan como creadora, más que de sensaciones reales, de pensamientos inimaginables.

Todo ello, de manera angustiosa, asombrada, delimitada tan sólo por lo que se aprehenden de inmediato. Su obra circunscribe y aborda estados anímicos que se introduce en los linderos del "más allá" y en la poesía.

Los objetos son reconocibles después que el espectador inicia, asimismo, su creación interior. De ahí, en adelante, las conclusiones que se desprenden de la obra, no son otras que las premisas finales y finiseculares del arte contemporáneo.

Hombres y mujeres, niños, figuras que pueden ser humanas o mezcla zoológica, son necesarias para que el encanto surta efecto repentino: todo es continua metamorfosis, nada es estático, sino por lo contrario, dinámico y explosivo.

Cordelia Urueta enmascara, con atmósferas enrarecidas, adentro de ámbitos secretos, con intensísimos tonos violáceos, rojos, magentas y amarillos, a los hombres del inmediato mañana y las fieras terribles de la pesadilla casual. Ella llegó al punto climático en que se encuentra después de ir decantando, puliendo, sintetizando, tras muchos años de pintar; todo lo que nos rodea en vida diaria y en vida metafísica.

Los primeros trabajos no son diferentes, esencialmente hablando, de los actuales. Si antes presentaba formas de mujeres, pájaros y ambientes ambiguos, después fue procesándolos hasta llegar al esqueleto de éstos, a síntesis perfecta. Esto se debió a que la insatisfacción y angustia eran temas importantes de los cuales surgiría, como surgió ese desarrollo y desdoblamiento de la irrealidad de lo real y la realidad de lo irreal.

Incluso, ese hombre del futuro inevitable es el signo del orden nuevo en la jerarquía plástica, y dentro de la estética, síntoma de verdades absolutas y significados existenciales.

En el constante cambio radical de las imágenes, es donde se encuentran los rasgos, específicamente subjetivos, de toda su creación genuina. Ese subjetivismo se torna en objetividad, ya que, la fragmentación total, la desintegración fenoménica de sus caracteres, tanto como la pasión enervada y atrevida de Cordelia Urueta, le dan a su arte cariz de sensaciones severas y sui generis en el contexto cultural.

La angustia frente a la realidad histórica, el horror a la destrucción del arte puro, el ataque a la razón, en general, tienen su protagonista en Cordelia Urueta. Ella se deja arrastrar por lo angustioso de la soledad y, además, considera "los ataques de la angustia terminarán siendo, espantosos, pero, por muy tremendos que ellos sean, no se les rehuirá", por lo contrario, serán tomados como "partes de la eternidad" (Kierkegaard).

La creación plástica de Cordelia Urueta desconcierta por ser todo del cual se extraen enigmáticas soluciones estéticas. En su ambigüedad y en la solución a problemas angustiosos, su inagotable fuente de inspiración.

Cordelia Urueta, una de las más grandes artistas de México actual. Su significado es la trascendencia y su trascendencia los signos singulares de una época difícil de resolver. Su intuición y sus grandes dotes artísticos son capaces de hacer de la pintura, reflejo fiel de los sinsabores y el grito desconcertante de pasión que jamás llega a etiquetarse en ismo alguno. 
Su determinismo es la meta del arte, su verdad lo absoluto, su Leit motiv, la amalgama de valores poéticos, trágicos y dubitativos. Esta obra es una finalidad significativa y epifanía de color y motivos con los que se puede, aún, dialogar.

Alfonso de Neuvillate

Cordelia Urueta. Nació en México en septiembre de 1908. Fue su padre el Dr. Jesús Urueta, ilustre tribuno e intelectual mexicano. Pasó su infancia en medio de las grandes mudanzas que sobrevinieron con la Revolución Mexicana. Desde niña sintió inclinación por las artes plásticas que practicaba como pasatiempo.

Catálogo: 1. niños, 1967, óleo s/tela $1.00 \times 80$, col. Galería de Arte Mexicano 2 hombre gris, 1967, óleo s/tela $1.10 \times 1.40$, col. Galería de Arte Mexicano 3. secreto del bosque, 1967 óleo s/tela, 1.20 × 1.60 col. Galería de Arte Mexicano 4. tiempo, óleo s/tela $1.30 \times 1.70$, col de la autora 5 . signos, óleo s/tela $1.30 \times 1.70$, col de la autora 6. miradas, 1969 óleo s/tela $1.30 \times 1.70 \mathrm{col}$. de la autora 7. la torre, óleo s/tela $1.30 \times 1.70$ col. de la autora 8 . vigía, óleo s/tela $1.30 \times 1.70 \mathrm{col}$. de la autora 9. puerto, óleo s/tela $1.15 \times 85$, col. de la autora 10 . hombre rojo, óleo s/tela 1.25 x 85 col. de la autora.

José LUis cuevas. Exposición homenaje a Quevedo, presentada por la Graphic Gallery, One Jackson PL. 633 Battery St., San Francisco, Calif. 94111, Estados Unidos de Norteamérica, durante el mes de septiembre.

\section{OCTUBRE}

Retrospectiva del taller De la gráfica popular. Exposición presentada por el Departamento del Distrito Federal, Dirección General de Acción Social, Galerías de la ciudad de México en el Centro Social Popular' "Leandro Valle", Av. Sur 8 y Oriente 24l, Col. Agrícola Oriental, del $1^{\circ}$ al 31 de octubre.

Nombre de los artistas que pertenecen y han pertenecido al Taller de la Gráfica Popular: David Alfaro Siqueiros, Ramón Alva de la Canal, Jesús Alvarez Amaya, Ignacio Aguirre, Raúl Anguiano, Luis Arenal, Octavio Bajonero, Alberto Beltrán, Roberto Berdecio, Lena Bergner, Guillermo Bonilla, Angel Bracho, Celia Calderón, Gustavo Casillas, Fernando Castro Pacheco, Elizabeth Catlett, Erasto Cortés, Miguel Covarrubias, Jean Charlot, José Chávez Morado, Gonzalo de la Paz Pérez, Alberto Día, Francisco Dosamantes, Jesús Escobedo, Gabriel Fernández Ledezma, Juan Antonio Franco, Oscar Frias, Cutberto Galván, Arturo Garcia Bustos, Luis García Robledo, Moshe Gat, Andrea Gómez, Jesís Guerrero Galván, Lorenzo Guerrero Ponce, Xavier Guerrero, Jules Heller, Elena Huerta, Roberto H. Malfavon, Xavier Iñiguez, Sarah Jiménez, Marcelino Jiménez, Carlos Jurado, Iker Larrauri, Francisco Luna, Jesús Gutiérrez Martinez, Robert Mallary, Ma. Luisa Martinez, Norberto Martínez, Leopoldo Méndez, Carlos Mérida, Adolfo Mexiac, Hannes Meyer, Guillermo Monroy, Roberto Montenegro, Ma. Luisa Martín, Antonio Morales, Francisco Mora, Isidoro Ocampo; Pablo O'Higgins, Mariano Paredes, Máximo Prado, Antonio Pujol, Mercedes Quevedo, Adolfo Quinteros, Fanny Rabel, Everardo Ramirez, 
Jorge Ramirez, Ricardo Rivas, Guillermo Rodriguez, Alberto Rovira, Amado Salazar, José Sánchez, Koloman Sokol, Ramón Sosamontes, Héctor Ventura, Agustín Villagra Caleti, Isabel Villaseñor, Charles White, Mariana Yampolsky, Alfredo Zalce, José Guadalupe Zuno.

GILDARDo URIBE (grabados), JEsús ESCALERA (óleos), LuIs TORREBLANCA (esculturas). Exposiciones presentadas por la Galería Chapultepec, Insurgentes Sur 11-bis, INBA/SEP, el $1^{\circ}$ de octubre (al 25 del mismo mes).

las artes plásticas en la arquitectura moderna. Exposición de grabados, presenta tapicerías y maquetas, presentada por el Instituto Francés de América Latina, Río Nazas 43, el 2 de octubre.

ANTONio gutiérRez mendoza. Exposición de pinturas, presentada por el Instituto Mexicano Norteamericano de Relaciones Culturales, A. C., Galería Nabor Carrillo, Hamburgo 115, el 2 de octubre.

Datos Biográficos: Antonio Gutiérrez Mendoza nació el 16 de octubre de 1944, en la ciudad de México.

ROGER vON GUNTEN. Exposición presentada por la Galería Juan Martín, Amberes 17 , del 7 al 25 de octubre.

RODOLFo NIETo (Laboratorio en Papel). Exposición presentada por el Instituto Nacional de Bellas Artes, Sala Verde, Galerías del Palacio de Bellas Artes, el 7 de octubre.

colectiva. Exposición presentada por la Galería Pablo Picasso y el Centro de Artes Plásticas, A. C., Av. Coyoacán 931, col. del Valle, el 8 de octubre.

Nombre de los expositores: Mario Arellano Zajur, Guillermo Ceniceros, Benjawín Dominguez, Antonio Esparza, Enrique J. Estrada, Fernando Flores Sánchez, Byron Gálvez, José de Santiago.

la poesía en el grabado (Maria Teresa Toral), y este tiempo (Beatriz Zamora). Exposición presentada por el Departamento del Distrito Federal, Dirección General de Acción Social, Galerias de la ciudad de México (Alameda Central), Sala Juárez, del 10 de octubre al 7 de noviembre.

nieco rivera. Exposición de dibujos, presentada por las Galerías Mer-Kup-, Artistas de la Plástica Mexicana, A. C., Molière núm. 328-C, el 13 de octubre.

Will, gutmann. Exposición de esculturas, presentada por las Galerías Mer-Kup, Artistas de la Plástica Mexicana, A. C., Molière núm. 328-C, el 13 de octubre.

BRECHT Y EL TEATRo EN LA REPÚblica DEMocrática alemana. Exposición presentada por la Galería de Artes Plásticas, Eleuterio Méndez núm. 11, Coyoacán, el 13 de octubre. 
vibujos y Grabados. Exposición colectiva, presentada por la Plástica de México, Londres 139 , el 14 de octubre.

esteban cruz. Exposición de Gouaches, presentada por el Instituto Francés de América Latina, Nazas 43, el 15 de octubre.

ENRIQUE mónaco. Exposición presentada por el Instituto Nacional de Bellas Artes, Sala Internacional, Galerías del Palacio de Bellas Artes, el 15 de octubre.

SUSANA smrth. Exposición obras recientes, presentada por el Instituto Mexicano Norteamericano de Relaciones Culturales, A. C., Hamburgo 115, el 16 de octubre.

Antonio RocA. Exposición presentada por la Galería Marcos Fastlicht, S. A., Hotel Aristos Reforma 276, el 16 de octubre.

SALÓN INDEPENDIENTE 69. Exposición presentada por la Universidad Nacional Autónoma de México, Museo de Ciencias y Arte, Terminal de Autobuses, Ciudad Universitaria, el 16 de octubre.

Nombre de los expositores y Datos Biográficos: Gilberto Aceves Navarro. Nace en México, D. F. en 1931, hace estudios en la Esmeralda, de 1950-53, en 1954 estudios de grabado en la Esmeralda. Philip F. Bragar, nació en Nueva York en 1925, radica en México en 1954-1959, estudió en Esmeralda en 1960. Juan Luis Buñuel, nació en París, Francia en 1934, de 1939 a 1946 vive en los Estados Unidos, en 1957, hace estudios de Licenciado en Literatura Inglesa de Oberlin College, Ohio. Lilia Carrillo, nació en México, D. F. en 1930, estudia de 1947-1951 en la Escuela. de Pintura y Escultura La Esmeralda, de 1953-54, estudia en la Academia La Grande Chaumiere, de París. Arnaldo Coen, nace en México, D. F, el 10 de junio de 1940, estudia Artes Publicitarias en el taller del pintor norteamericano Lawrence Calcagno. José Luis Cuevas, nace en México en 1934, en 1944, presenta su primera cxposición individual, en la calle de Donceles. Felipe Ehrenberg, nace en la ciudad de México y estudia cuatro años en Ontario Canadá. Helen Escobedo, nace en la ciudad de México en 1951 obtiene beca de tres años para estudiar escultura en el Royal College of Art de Londres. Manuel Felguérez, nació en Zacatecas, en el año de 1928, estudia de 1949-55 con Ossip Zadkine, en París. Fernando Garcia Ponce, nació en Mérida, Yuc. en 1933, estudia de 1952-55 en la Escuela Nacional de Arquitectura, con Enrique Climent. Vita Giorgi, nació en Sicilia, Italia, reside en México en 1960, ha participado en numerosas exposiciones de grabado mexicano tanto en el país como en el exterior. Alan Glass, nació en Montreal, Canadá, en 1932, en l'École des Beaux Arts Montreal, Beca del Gob. Francés en 1952, París, Ecole du Musee de 1'Homme, de (1952-1961), École des Beaux Arts Lithographia, París. Leonel Góngora, nació en Colombia en Cartago en 1932, ciudad fundada en 1536 con un rio que era muy bello en su antigüedad que se llama La vieja. Raúl Herrera, nació en México en 1941. En 1963 presentó su primera exposición individual en París. Francisco Icaza, nació en 1930. Empezó a pintar en 1955. Luis Jaso, nació en México, D. F. en 1928, arquitecto de la UNAM. Myra Landau, nació en Rumania. Vivió en Brasil 20 años, en 1960 radica en Méxicl, autodidacta en pintura, 
en grabado alumna de Oswaldo Goeldi. José Muñoz Medina, nació en la ciudad de México, en 1930 estudios en la escuela de pintura y escultura La Esmeralda, donde ahora es maestro. Brian Nissen, nació en Londres, Inglaterra en 1939, estudió en la escuela de Artes Gráficas de Londres y en l'École des Beaux Arts de París. Viaje por Grecia, Turquía y Noráfrica. Radica en México desde 1963. Felipe Orlando nace en 1917 en un pueblo del Estado de Tabasco, se traslada a Cuba su familia en 1919, donde hace estudios primarios, secundarios y universitarios, al mismo tiempo que los de pintura, Marta Palau, nace en Lérida, Cataluña, España en 1934, estudia en La Esmeralda, grabado con Guillermo Silva Santamaría en la Ciudadela. Pedro Preux, nació en París, Francia en 1932, en 1942 llega a México en calidad de refugiado, estudia medicina 3 años y estudia textiles en "Textiles Zodiaco". Gabriel Ramírez, nace el 4 de enero en Mérida, Yuc., en 1938, autodidacta, comienza a pintar en 1959. Ricardo Regazzoni, nació en 1942, arquitecto de la Universidad Nacional Autónoma de México. Ricardo Rocha, nace en México, D. F. en 1937, estudia en la Academia de San Carlos, de 1956-57, estudia en la escuela de pintura y escultura La Esmeralda en 1958. Vicente Rojo, nació en Barcelona, España, en 1932, vive en México desde 1949, estudios en La Esmeralda en 1950. Kazuya Sakai, nació en Buenos Aires, se educó en Japón, residió en Nueva York de 1963-65, actualmente es profesor del centro de estudios Orientales en el Colegio de México y de la Facultad de Filosofía y Letras de la UNAM. Toni Sbert, nació en Perpignan en 1937. Olivier Seguin, nació en Montreuil sur Mer, Pas de Calais, Francia en 1927, estudia en la Escuela de Bellas Artes de Lille, Francia, escuela de Bellas Artes de París, Francia. Vlady, nació en Leningrado (URSS) en 1920, en 1936 sale de Rusia, en 1937 Bruselas, de 1937 a 1940 en París donde frecuenta asiduamente los museos. Luego Marsella-Antillas-México, autodidacta. Roger Von Gunten, nació en Zurich, Suiza en 1933, de 1948 a 1952 en la Escuela de Artes Plásticas de la ciudad de Zurich, en 1956 radica en México. Raúl Tovar Luna, nace en la ciudad de Querétaro en 1943, en 1961 inicia sus estudios en la Escuela Nacional de Artes Plásticas de San Carlos. Enrique Carbajal González, nació en Camargo, Chih., en 1947. Hizo estudios de pintura y escultura en la Escuela Nacional de Artes Plásticas de la UNAM. Roberto Realh de León, nació el 25 de noviembre de 1950, estudió de 1963-65 en la Escuela Nacional de Artes Plásticas. Antonio Scgui, nace en Córdoba, Argentina en 1934, vive en París desde 1963. Rafael Canogar, nació en Toledo, España, en 1935, comenzó a pintar a la edad de 14 años. Fernando de Szyszlo, nació en Lima, Perú, en 1925, inicia estudios de arquitectura que abandona poco después de 1943. Estudia pintura en la escuela de arte de la Universidad Católica, Lima.

Ayako tSURU. Exposición de esmalte y joyería, presentada por el Museo de las Culturas, INAH / SEP, Moneda 13, el 16 de octubre.

exposición nacional de arte Publicitario. Presentada por el Instituto Nacional de Bellas Artes, Salas 1 al 5, Galerías del Palacio de Bellas Artes, el 17 de octubre.

RAÚl ANGUiANo (30 años de labor). Exposición homenaje, presentada por el Salón de la Plástica Mexicana, INBA/SEP, Havre núm. 7, del 17 de octubre al 14 de noviembre. 
Al entrar al gran estudio del maestro Anguiano, todo se puso en movimiento. De los cuadros surrealistas los tonos fríos fueron saliendo lentamente, y del cuadro de Caín y Abel la mano de Caín huyó como una araña fatal. Los colores de los retratos se saludaron con esa cortesía tan comprensible de las personas que no se conocen y los desnudos femeninos amenazaron la tranquilidad de las mismas paredes. La mano que dibuja, mano maestra, organizó el orden que a veces destruye y las líneas de los dibujos estuvieron de acuerdo en todo. E1 sentimiento que hay en esas líneas es el más noble y el más hermoso. Esas líneas se quedaron para siempre. Los lacandones, perfectos hippies de la selva de Chiapas, último reducto de los mayas clásicos, habitaron las sombras de los árboles y no pudieron romper el silencio de las cincuenta maravillosas pequeñas esculturas de Mezcala. Éstas son de piedra viva y como detestan el movimiento no se movieron de su eternidad. El maestro Anguiano que ejerce la brujería - todo artista verdadero anda en eso-, le ciñó una cuerda a la Venus primitiva, la de hace muchos miles de años, y aprovechando sus formas y creyendo que era un trompo, tiró después de la cuerda, y la Venus giró, gira para siempre a una velocidad sideral. El grande artista se robó asimismo cuanto pudo de color y tocando lo abstracto con la mano realizó una de sus creaciones más admirables. La palabra México figura en la lista de socios activos de su talento. Yo confieso que esta cosa de la Pintura la entiendo como hechicería, como lo de los sonidos que llamamos Música.

Abandoné el Mundo-Anguiano después de treinta años de verle trabajar, héroe famoso e incansable como un árbol de una causa, que si no fuera de este mundo, todos infelizmente habríamos nacido muertos.

\section{Carlos Pellicer}

Sea lo primero decir su origen, solar y linaje. Alfa Ríos nació india, Juchitán. Si alguna otra sangre hubiera en sus venas, ésa sería tan poca que no logra teñirla. Hija del pueblo, de la multitud. Toda ella remite a sus paisanas: es el botón que sirve de muestra. La frente pequeña, el cabello de luto, los ojos que parecen hojas y los labios una hoja encendida. Tiene enanas las manos y tiene negros y pequeños los ojos. Los brazos, el color y la consistencia del pan recién y bien cocido. El rostro todo sereno y firme. Las cejas, las alas de una golondrina que volara por una ladera.

El Retrato está pintado muy sencillo, sin mayores problemas, casi a la manera primitiva. En el fondo se insinúa un muro; el piso de madera; la silla, una sillita mexicana. Viste a la usanza de Tehuantepec, de tehuana, quiero decir. Entre paréntesis: fuera del Istmo todas las mujeres son tehuanas; todos los hombres, juclitecos. Sólo cuatro colores: el blanco del olán, el negro de la enagua, el amarillo y rojo del huipil y de las joyas. El alba, la noche y el crepúsculo, como quien dice. De esa gama y regocijo de colores, emerge el rostro suave, armónico. El cabello se anuda en dos trenzas, sin adorno, que ya el resto de la indumentaria lo lleva.

Muchas obras perfectas ha realizado Raúl Anguiano. El Retrato de Alfa una de ellas. Acaso fuera el mejor retrato que hasta ahora haya pintado. Pese a la golosina que promueve la superabundancia de adornos y colores del traje istmeño, el artista supo contenerse: se valió de unos cuantos elementos, los más constantes de las 
tierras cálidas. El pincel, sobrio, la mano y el pulso suaves, el oficio hasta el limite Esa cara está pintada con primor, con deliquio, minuciosamente, al extremo que recuerda la delectación con que se realizan las pinturas chinas, las orientales. La obra de un pintor chino, en efecto, me parece este retrato. El instante, que luego fue eterno, de una actitud, de un estado del alma de una mujer, queda aquí preso. Una primera aurora, un primer medio día, una plenitud de la obra de Raúl Anguiano, eso representa el Retrato de Alfa.

\section{Andrés Henestrosa}

Raúl Anguiano es el portavoz de un país que regresa a las fuentes de su arte, pero que se niega a copiar la manera de los antiguos. Sin enajenar su personalidad estética y étnica, reivindica todas las principales conquistas de la pintura moderna. De esta forma dobla el cabo del provincialismo (o del regionalismo) y confiere a su obra un carácter de universalidad. No imita a los pintores occidentales. Sigue siendo indoamericano y se impone como tal. Pero, al mismo tiempo que utiliza los temas estrechamente ligados a la vida de México, a su alma, a su pueblo, a su historia y a su tragedia, se reúne a esos astros del arte europeo, los pintores alemanes de las Danzas de los Muertos, Jérome Bosch y Orcagna, Goya y James Ensor.

El espíritu cómico y el espíritu dramático coexiste en el extraño arte de Anguiano, cuyas figuras grotescas tienen un acento macabro. La magia de esas figuras fascina. Nunca está desprovista de grandeza. Las leprosas envueltas en sus rebozos, esos entes miserables que piden limosna, son furias de la antigüedad. La mujer que vela a un campesino asesinado es una Virgen de los Dolores: una Piedad medieval. Los personajes de un carnaval rural no son sino actores de la vieja comedia italiana. Los saltimbanquis, cuyos ejercicios gimnásticos y acrobacias evoca Anguiano, evolucionan en un espacio abstracto, el de los matemáticos del Alto Renacimiento. Las patéticas "dolientes" que siguen al féretro de un héroe de la Revolución están impregnadas de una belleza escultural. El volumen de sus cuerpos es macizo y pesado como los de un discípulo del florentino Masaccio. En cuanto a las composiciones que reproducen los combates de los guerreros mexicanos, son tan armoniosas como las pinturas de los vasos, los vasos griegos y etruscos.

Si la obsesión del vacío que preocupa (o que preocupaba) a los pintores surrealistas, de Chirico a Magritte, puede ser descubierta en la Melancolía, una de las obras más metafísicas y más inquietantes de Raúl Anguiano el Carnaval en Veracruz es una tela de expresión popular. Ensor, este pintor de las máscaras hilarantes, se refiere a las fiestas del martes de carnaval que se celebran en algunas ciudades de Flandes. Anguiano se inspira en el folklore de América Central. Pero el pintor de la Crucifixión no se limita a explotar el exotismo y el color local, sino que llega al fondo de las cosas. A las Saturnales de una muchedumbre delirante, mezcla las visiones de la muerte y las de las expiaciones. Opera las síntesis de estas dos antítesis; el culto cristiano y el culto mexicano, este culto espiritualista que los invasores, en su piadosa ignorancia, calificaban de pagano. Sus demonios y sus monstruos nos descubren todos los complejos que los pecadores revelan a sus confesores y cuyos misteriosos arcanos se esfuerzan en desentrañar los sicólogos y los sicoana- 
listas. Su simbolismo prueba su ciencia de iniciado, pero muestra su angustia. He aquí la razón de que Anguiano, pintor de los seres fabulosos, cuya anatomía y conformación son contrarios a las leyes de la naturaleza, sea el descendiente de Bosch y de Goya.

En el Tigre rojo y, particularmente, en su pintura mural, Creación del hombre maya, Anguiano reanuda voluntariamente la tradición del arte precolombino. Pero esta tradición, la trata libremente, la incorpora a su obra y le da una versión de originalidad llevada al extremo. Anguiano es en relación con sus lejanos antepasados, lo que Cézanne ha sido a Poussin.

El año 1967 señala en la obra de Raúl Anguiano el principio de las investigaciones que son testimonio de una nueva voluntad de expresión estética. El punto de mira es la Venus de Lespugue. Raúl Anguiano realiza, sobre el tema de este pequeño ídolo de la maternidad, aguafuertes, varias litografías e innumerables dibujos que son otros tantos bosquejos constructivos. Anguiano vuelve a blandir la antorcha del Cubismo regenerándolo e infiltrándole un elíxir de vida, al mismo tiempo que lo "cindianiza". Sus planos se erigen como arquitecturas de una geometría prestigiosa y sensible.

Gracias a la iniciativa de un pintor ecuménico, una divinidad de la prehistoria descubierta en un pueblo de Francia, se convierte en hermana de los formidables colosos levantados por los costructores mayas. Sin dejar de ser él mismo, el mexicano Anguiano exalta la unidad interior de la familia humana y de sus creaciones.

Waldemar George

Datos biográficos: Raúl Anguiano, pintor, muralista, litógrafo, grabador. Nace en Guadalajara, Jal., el 26 de febrero de 1915.

Catálogo: 1. melancolía, óleo/cartón, 1937, $40 \times 59.5 \mathrm{~cm}$ col. Dr. Diego González Terán 2. campesino asesinado, aguafuerte, $1940,14 \times 28 \mathrm{~cm}$ 3. la cirquera rosa, óleo/tela, 1941, $95 \times 75 \mathrm{~cm}$, col. Gral. Ignacio M. Beteta 4. cirqueros en gris, óleo/ mason te, 1941, $60 \times 47 \mathrm{~cm}$, col. Sr. Mariano Paredes 5. el hijo muerto, óleo/masonite, $1941,52 \times 71.5 \mathrm{~cm}$, col. Museo de Arte Moderno 6. Adán y Eva, óleo/tela, 1942,73 x $45.5 \mathrm{~cm}$, col. Dr. Federico Marín 7. nacimiento y muerte, óleo/tela, 1942 , $53.5 \times 73 \mathrm{~cm} 8$. la llamada del instinto, óleo/tela, 1942, $67.5 \times 88 \mathrm{~cm} 9$. flor de pato, óleo/tela, 1942, $80 \times 58 \mathrm{~cm} \mathrm{10.} \mathrm{Cain,} \mathrm{óleo/tela,} \mathrm{1943,} 66 \times 85 \mathrm{~cm}$ 11. retrato de Victoria Alonso, óleo/tela, 1944, $106 \times 85 \mathrm{~cm}$ 12. retrato de Agueda, óloe/tela, $1945,98.5 \times 78.5 \mathrm{~cm}$ 13. retrato de Alfa Henestrosa, óleo/tela, 1945-46, $159 \times 108$ $\mathrm{cm}$, col. Andrés Henestrosa y Sra. 14. azoteas de México, óleo/tela, 1946, $79 \mathrm{x}$ $99 \mathrm{~cm}$, col. Sr. Luis García 15. naturaleza muerta, óleo/tela, 1946, $88 \times 108 \mathrm{~cm}$, col. Dr. Raoul Fournier y Sra. 16. paisaje del Tepeyac, óleo/tela, 1946, 63.5 x 91 $\mathrm{cm}$ 17. la torre, óleo/tela, 1947, $109 \times 84 \mathrm{~cm}$, col. Sr. Juan C. Luttmann y Sra. 18. auctorretrato, óleo/tela, $1947,93.5 \times 80 \mathrm{~cm} 19$. día de muertos, óleo/tela, 1947-48, 93 x $69 \mathrm{~cm}$, col. Museo Nacional de Arte Moderno 20. Marina, óleo/ tela, 1949, $99 \times 69 \mathrm{~cm}$ 21. retrato de la Sra. Elisa Madrid de del Moral, 1950, $110 \times 74 \mathrm{~cm}$, col. Arq. Enrique del Moral y Sra. 22. la siesta de Na-Kin, óleo/ tela, $1950,100 \times 100 \mathrm{~cm}$, col. Sr. Ramiro Alatorre 23. Na-Kin, óleo/tela, 1951, $85 \times$ $70 \mathrm{~cm}$, col. Sr. Juan C. Luttmann y Sra. 24. la espina, óleo/tela, 1952, $119 \times 168$ $\mathrm{cm}$ 25. Chartres, óleo/tela, $1952,82.5 \times 69 \mathrm{~cm} 26$. anunciación, óleo/tela, 1954, $167 \times 112 \mathrm{~cm}$, col. Museo Nacional de Arte Moderno 27. maternidad, óleo/tela, 1954, $134 \times 93 \mathrm{~cm}$, col. Lic. Manuel R. Palacios 28. Na-Kin, litografía, 1955, $59 \times 52 \mathrm{~cm} \mathrm{29}$. la mujer de las iguanas, óleo/tela, 1956, $99 \times 64 \mathrm{~cm}$, col. Dr. 
Manuel Pesqueira y Sra. 30. redes, óleo/tela, 1956, $100 \times 80 \mathrm{~cm}$, col. Sra. Adela de Barona 31. sol del Istmo, óleo/tela, 1957, $109 \times 78 \mathrm{~cm}$, col. Sr. José Luis Ordóñez 32. los tres soles, óleo/tela, 1957, $123 \times 78.5 \mathrm{~cm}$, col. Ing. Marte R. Gómez 33. carnaval en Veracruz, óleo/tela, 1957, $110 \times 74 \mathrm{~cm} 34$. dolientes, dibujo a lápiz, 1957, óleo/tela, 1958, $90 \times 59.5 \mathrm{~cm}$, col. Arq. Carlos Solórzano y Sra. 35. retrato de la Sra. Beatriz Caso de Solórgano, $27.5 \times 21.5 \mathrm{~cm}$, col. Sr. José Luis Ordóñez 36. la espina, litografía, 1959, $54.5 \times 72 \mathrm{~cm} 37$. muchacha en reposo, dibujo a pincel y tinta, $1959,89 \times 72 \mathrm{~cm} 38$. $N$ ina, dibujo a pincel y tinta, 1960,89 × $70 \mathrm{~cm}$ 39. retrato de la Sra. María Becerra González, 1960 , $104 \times 79 \mathrm{~cm}$, col. Sra. María Becerra González 40. desmudo en azul, óleo/tela, 1960-61, $179 \times 74 \mathrm{~cm}$ 41. barco, apunte, óleo/tela, 1961, $34.5 \times 25 \mathrm{~cm}$, col. Ing. Marte R. Gómez 42, retrato de la Sra. Victoria Macías de Pizarro, 1961, 104 x $79 \mathrm{~cm}$, col. Sra. Victoria M. de Pizarro Suárez 43. negrita con fondo rosa, óleo/ tela, 1962, $140 \times 84 \mathrm{~cm}$ 44. puesta de sol, óleo/cartón, $1962,21.5 \times 26.5 \mathrm{~cm}$, col. Ing. Marte R. Gómez 45. negrita en un diván, óleo/tela, 1962, 114 x $155 \mathrm{~cm} 46$. Luisa Susana, óleo/masonite, $1963,109 \times 63 \mathrm{~cm} \mathrm{47.} \mathrm{Brigitte,} \mathrm{óleo/caseína,} \mathrm{1963,}$ $120 \times 63 \mathrm{~cm}$, col. Sr. Joaquín Catalá y Sra. 48. guerreros mayas, proyecto para mural, caseína/masonite, $1963,73 \times 119 \mathrm{~cm}$ 49. sacrificado, dibujo al carbón, 1964, $64 \times 100 \mathrm{~cm} 50$. después del baño, dibujo al carbón, $1964,100 \times 66.5 \mathrm{~cm} 51$. lo batalla, proyecto para mural, dibujo a la sanguina, $1964,64 \times 100 \mathrm{~cm} \mathrm{52}$. estudio de pies y figura yacente, dibujo al carbón y sanguina, $1964,100 \times 64 \mathrm{~cm} 53$. retrato de Marina, óleo/masonite, $1966,66 \times 44.5 \mathrm{~cm} 54$. Carole, óleo/tela, 1966, $119 \times 79 \mathrm{~cm} 55$. la guerra y la paz, óleo/tela, 1967, $174 \times 220 \mathrm{~cm} 56$. muchacha en ocres, óleo/tela, 1967, $130 \times 99 \mathrm{~cm} 57$. Venus Lespugue, óleo/tela, 1967, $99 \times 65$ $\mathrm{cm}$, col. Sr. Erwin Baitenmann 58. personaje, óleo/masonite, 1967, $64 \times 44 \mathrm{~cm}$ 59. cabeza africana, óleo/tela, 1967, $89 \times 64 \mathrm{~cm} \mathrm{60.} \mathrm{catedral} \mathrm{de} \mathrm{Amiens,} \mathrm{óleo/tela,}$ $1967,61 \times 45 \mathrm{~cm}$ 61. Venus en negro y gris, óleo/tela, 1968, $168 \times 120 \mathrm{~cm} 62$. desarrollo de Venus, óleo/tela, 1968, $110 \times 150 \mathrm{~cm}$ 63. Venus cinética, óleo/tela, 1968, $80 \times 99 \mathrm{~cm}$ 64. nave espacial, óleo/tela, 1968, $80 \times 130 \mathrm{~cm} 65$. anunciación, óleo/ tela, 1968, $114 \times 80 \mathrm{~cm}$ 66. venus primitivas, óleo/tela, 1968, $115 \times 115 \mathrm{~cm} 67$. deidad nocturna, óleo/tela, $1968,135 \times 75 \mathrm{~cm}$ 68. negrita con geranio, acrílico sobre masonite, $1968,115 \times 75 \mathrm{~cm}$ 69. jugador de jai-alai, acrílico sobre tela, $1968,150 \times 110 \mathrm{~cm} 70$. dolientes, aguafuerte, $1968,24 \times 19 \mathrm{~cm} 71$. jugador de jai-alai, aguafuerte-tríptico, 1968, $25 \times 68 \mathrm{~cm}$ 72. jugador núm. 2, acrílico sobre tela, $1969,149 \times 119 \mathrm{~cm}$ 73. jugador núm. 3, acrílico sobre tela, $1969,64 \times 49 \mathrm{~cm}$ 74. Pablo, dibujo al bistre, $1969,62.5 \times 48.5 \mathrm{~cm} 75$. caguama, aguafuerte, 1969 , $22 \times 34.5 \mathrm{~cm}$ 76. Alimentos para astronautas, aguafuerte-color, $1969,40 \times 28.5 \mathrm{~cm}$ 77. strip-tease, aguafuerte, $1969,35 \times 24.5 \mathrm{~cm} 78$. danza de la fertilidad, aguafuerte, $1969,38 \times 29 \mathrm{~cm}$ 79. desarrollo de Venus, aguafuerte, $1969,38 \times 30 \mathrm{~cm} \quad 80$. veinte de julio, acá en la tierra, aguafuerte, $1969,39.5 \times 34 \mathrm{~cm} 81$. Cristo en la cruz, aguafuerte, $1969,34.5 \times 21.5 \mathrm{~cm} 82$. eclipse, monotipo, $1969,37.5 \times 17 \mathrm{~cm} 83$. $V$ enus color madera, monotipo, $1969,38 \times 17 \mathrm{~cm}$.

DOLOR y violencia. Exposición presentada por la Galería Edvard Munch, Paseo de 1a Reforma 489, el 17 de octubre.

Nombre de los expositores: Leopoldo Ayala, Carlos Bracho, José Luis Cuevas, Carlos Fuentes, Hernández Delgadillo, Marcos Huerta, Oscar Menéndez, Alfredo Meneses, Carlos Monsiváis, Claudio Obregón, Carlos Olachea, Mario Orozco Rivera, Armando Ortega, Octavio Paz, Teresa Selma, René Villanueva, Armando Zallas.

zipora Ascalón. Exposición de obras presentada por el Comité de Actividades Generales del Centro Deportivo Israelita, Galerías C.D.I., Av. Manuel Avila Camacho 620, Lomas de Sotelo, del 19 de octubre al 14 de noviembre. Datos Biográficos: Ascalón Zipora, nació en Polonia en 1915. 
ESTEBAN RAMOS (esculturas), oliverio df́az (dibujos). Exposición presentada por la Escuela Nacional de Artes Plásticas/UNAM, Sala de Exposiciones, Academia 22, el 20 de octubre.

COEN. Exposición presentada por el Instituto Cultural Mexicano Israelí, A.C., Ometusco 15 , el 21 de octubre.

Los ACUARELISTAS. Exposición presentada por el Instituto Mexicano-Norteamericano de Relaciones Culturales, A.C., Galería Nabor Carrillo, Hamburgo 115, el 23 de octubre.

Nombre de los expositores: Rodolfo Aguirre Tinoco, Gustavo Alaniz, Manuel Arrieta, Ignacio M. Beteta, Edgardo Coghlan, Alfredo Guati Rojo, Erasto León Zurita, Luis López Canales, Juan B. Meana, Ma. Teresa Miranda, Jaime Oates, Martha Orozco, Angel Mauro Rodriguez, Leni de Servin, Rodolfo van Kurczyn, Hugo Zúñiga.

ARÉvato. Exposición presentada por la Galeria de Arte Mishachi, Génova 20, el 23 de octubre.

Datos biográficos: Nace en Guadalajara, Jal., en 1937, a la edad de 13 años hace sus primeros estudios de dibujo, pintura y caligrafía. En 1957 ingresa en la Escuela de Artes y Letras de Guadalajara, Jal. Durante un año recorre las costas de Nayarit y Jalisco pintando una numerosa serie de paisajes. Este viaje es decisivo para la carrera de Arévalo, se traslada, en 1961, a la ciudad de México e ingresa en la Escuela Nacional de Artes Plásticas (San Carlos), siendo alumno del maestro Antonio Rodríguez Luna.

Catálogo: 1. por primera vez 2. imagen directa desde la luna 3. por la lejana montaña 4. hoy si, mañana también 5. regresando por el mismo camino 6. dando y recibiendo 7. sucedió hoy 8. bestia citadina que aniquila voluntades 9. cada cabeza es un mundo 10. antes eran otros tiempos 11. madre de todas las cosas que hay en el agua 12. como será cuando tenga 15 años 13. animales debajo de la cama 14. muchos se multiplicaron 15. corazón del cielo 16. retoños que fueron miestos por estrellas 17. fueron llevados a la casa oscura 18. ninguno de los nombres olvidaron 19. recuerdo claramente que estuve alli 20 . sube a la tierra $y$ al mundo y no morirás 21. habitaron la ticrra 22. entra en él y en él reside 23. quedando sólo las señales 24. a donde iba todos los días 25. ocultos entre la hierba 26. todo, todo se menea 27. dispusieron ponerle vida 28. entre más se vive más se bebe 29. y así se crearon todas las cosas. 30. entre los hombres trataron de salvarse 31. el lobo satisfecho y la ovejita viviendo 32. los montes se estremecen 33. estaba untado de tierra 34. dividido en tres 35.4 caminos para el año 2,000 36. de un lado a otro 37. árbol muy antiguo 38. deseo de todo corazón 39. abrid todas las ventanas 40 . no me quiten la vida 41. mi corazón será desde ahora anunciar la vida 42. liquido rojo de la tierra 43. de donde vienes tú 44. basta esta señal 45. todos los días los dos 46. por la mañana al amanecer 47. ellos se transformaron en todo 48. mudaron de caras; se han vuelto animales 49. todos sembramos la tierra de un solo golpe 50. queriendo darse a conocer.

PLÁstica moderna del JAPón. Exposición presentada por el Instituto Nacional de Bellas Artes, Embajada del Japón, Museo de Arte Moderno (planta baja de la galería de exposiciones temporales), el 23 de octubre. 
ARTOREZ (técnica mixta), OCTAvio BAjONERo (grabados), HUMBERTo PERAZA (esculturas). Exposiciones presentadas por la Galería Chapultepec, INBA/SEP/Insurgentes Sur núm. 11-bis, el 27 de octubre.

IGNACIO BARRIos. Exposición presentada por el Colegio de Arquitectos de México y la Sociedad de Arquitectos Mexicanos, A.C., Av. Veracruz 20 y 24, Col. Roma, el 27 de octubre.

FRA NCISCo zú̃̃iga. Exposición de esculturas y dibujos, presentada por el Instituto Nacional de Bellas Artes, Museo de Arte Moderno, Galeria de Exposiciones Temporales, el 30 de octubre.

La escultura es indeslindable del sentimiento espiritual, en la acepción más estricta de la estética, dado que en ese arte se unen la idea, la aspiración ideal y la reinvención del cuerpo humano: las factores anatómicos, que provocan la sensualidad y el goce traducidos en la contemplación y el tacto. La obra escultórica mezcla, "brutal y objetivamente a la misma naturaleza" (Baudelaire) y a partir de ésta recomienza la interpretación individual, la aportación del creador.

La escultura es, además, "expresión de la idea romántica" (Gauthier) y reducto de la capacidad receptiva, además, el metamorfosear a un tiempo lo conocido y lo que se desconoce con las múltiples enseñanzas del factor intelectual: concreción de lo que el artista quiere expresar mediante lo que se reconoce y con las ausencias de preceptos lógicos y recuerdos inmediatos de sus deseos insatisfechos. Por todo ello, esta forma de manifestarse es unidad que conforma el estilo y las singularidades del genuino intérprete del acto creativo.

Hegel escribió sobre la escultura algunas frases relativas sỏlo a la estatuaria, mas no en lo que en esencia es la obra libre, despojada de aquel utilitarismo que lo primero debe satisfacer. El afirma que "la escultura es posterior a la pintura ya que no puede interpretar ni lo interior y subjetivo en su intimidad y su pasión particulares, ni tampoco una serie de manifestaciones exteriores como hace la poesía, limitándose al aspecto general de la individualidad, en la medida en que el cuerpo lo expresa".

Rodin, Maillol, Lehmbruck, Kolbe, Gerhard Marcks, Ernest Barlach y tantos otros demuestran las posibles interpretaciones poéticas de la escultórica, basándose para ello, precisamente en el cuerpo humano que es, a través de la historia del arte, lo más bello y a la vez lo más difícil de la pintura y la escultura contemporáneas.

Francisco Zúñiga es un tradicionalista y un clásico. Su herencia parte de la monumentalidad de las obras subjetivas del antaño académico pero con una dimensión totalmente nueva y significación metafísica, humanista y existencial. Su clasicismo estriba en que todas las obras que surgen de su espiritu sensitivo pretenden (y lo logran) establecer relación entre el binomio artista-espectador. Diálogo poético, una serie de lenguajes se establecen, de inmediato, por las imágenes concomitantes con cierto romanticismo analítico y por el signo metafórico (¿o paradójico?) resultante.

Zúñiga es artista y artífice a un tiempo. Su dedicación, el oficio-maestro adquirido en la talla directa, su percepción y la inclinación por todas aquellas lucubraciones del intelecto, lo han conducido a fincar una obra que exalta los motivos y los conceptos abstractos del individuo en su cotidianeidad. Así, más que simples obras imaginativas, estas esculturas son significaciones raciales de gran pureza de expresiones 
filosóficas. Las esculturas del gran artista echan por tierra las afirmaciones de George Santayana, puesto que éste afirmó que: "El problema de un escultor actual es que ni el alma ni el cuerpo han hecho nada bien porque no han hecho nada juntos". Zúñiga une ambos conceptos o ideas (el alma y el cuerpo) y realiza la tarea significativa de hermanarse con el expresionismo, la aspiración romántica y el deseo de comunicar el humanismo mediante figuras melancólicas, meditabundas, ensimismadas: mujeres que reposan en hamacas o que en su proximidad son ensoñaciones de vivencias y recreaciones de la sensualidad y el erotismo.

A Francisco Zúñiga debe otorgársele sitio de honor entre los escultores de mayor personalidad de la Kultur contemporánea: su obra es principio y es fin; explica todo y es ambigua, con la severidad del arte mayor.

Su grandiosidad es la sencillez, lograda después de investigar y sintetizar las formas de la anatomía y profundizar en la psiquis del modelo a reproducir, mediante la sensibilidad y la-fuerza dramática del ser comprometido ante él mismo y frente a la sociedad.

Veo un paralelismo entre sus moles escultóricas y aquellas luminosas de ese otro gran artista que es Ricardo Martínez. Hay concordancias, afinidades y gustos por las tentativas eróticas, extranaturales, y lo que se rastrea en la verdad absoluta de la humanidad. El perfecto equilibrio existente entre la mole en sí misma, lo que deja ver de realidad cambiada y la poesía demoledora que todo lo envuelve, hacen de este creador de emociones sutiles, brillante punto de partida de la nueva escultura : retorno a los orígenes e introducción a los ideales de la idiosincrasia, sin que esto quiera decir nacionalismo ni cualquier otro tipo de ismo conocido.

Si tratara de clasificar la obra de Francisco Zúñiga en alguna corriente estipulada con anterioridad no sabría qué dirección tomar; si el realismo del inventor o la invención de la realidad. Empero, lo catalogaría dentro del arquetipo de artista que ejecuta obras que sólo pueden tener el nombre del artista y nada más.

La obra de Zúñiga: vuelta a la pureza del arte y horizonte sin fin de la estética renovada. Elegía, canto al ser humano, oración y meditación en la problemática humanista y solución significativa: algo de lo mucho que nos brinda, para enriquecernos, la altísima y honrada obra de Francisco Zúñiga.

\section{Alfonso de Neuvillate}

Catálogo: 1. la hamaca, 1957, piedra xaltocan, $90 \mathrm{~cm}$, col. INBA/Museo de Arte Moderno 2. muchacha con guitarra, 1957, piedra, $60 \mathrm{~cm}$, col. INBA/Museo de Arte Moderno 3. madre indígena, 1957-58, piedra xaltocan, col. INBA/Museo de Arte Moderno 4. desmudo reclinado, 1958-59, piedra xaltocan, $1.05 \mathrm{~m}$, col. Arq. Enrique Carral 5. mujeres de pie, 1959, bronce, $1.85 \mathrm{~m}$, col. INBA/Museo de Arte Moderno 6. mujer del sureste, 1960 , bronce, $1.05 \mathrm{~m}$, col. INBA/Museo de Arte Moderno 7. madre con niño, 1961, bronce, $77 \mathrm{~cm}$, col Dr. y Sra. H. D. Prensky 8. desnudo acostado, 1961, piedra xaltocan, $1.05 \mathrm{~m}$, col. Sra. Olga Dondé 9. mujer con rebozo, 1962, bronce, $45 \mathrm{~cm} 10$ matrona, 1962 , bronce, $45 \mathrm{~cm} 11$. desnudo de Victoria, 1962, bronce, $22 \mathrm{~cm} \mathrm{12.} \mathrm{grupo} \mathrm{de} \mathrm{mujeres,} \mathrm{1962,} \mathrm{bronce}$ (boceto), $22 \mathrm{~cm}$ 13. grupo de tres mujeres, 1962, bronce (boceto), $23 \mathrm{~cm} 14$. madre e hija, 1963, bronce, $22 \mathrm{~cm}$ 15. implorante, 1963, bronce, $31 \mathrm{~cm} 16$. desmudo en cuclillas, 1964, bronce, $85 \mathrm{~cm}$, col. del autor 17. umbral, 1964, bronce (relieve), $52 \times 38 \mathrm{~cm}$ 18. mujer angustiada, 1964, bronce, $50 \mathrm{~cm}$ 19. desmudo en cuclillas, 
1965, bronce, $80 \mathrm{~cm}$, col. Dr. y Sra. H. D. Prensky 20. juchitecas de pie, 1965 , bronce, $40 \mathrm{~cm}$, col. Salomón Marcovich 21. juchiteca de pie, 1965, bronce (boceto), $30 \mathrm{~cm}$ 22. madre con niño de pie, 1965 , bronce, $70 \mathrm{~cm} 23$. mujer de pie con rebozo, 1965, bronce, $72 \mathrm{~cm} 24$. Soledad sentada, 1965, bronce, $38 \mathrm{~cm} 25$. juchiteca sentada, 1965, bronce, $35 \mathrm{~cm}$ 26. mujeres de pie, 1965, bronce, $57 \mathrm{~cm} 27$. torso de mujer, 1965, ónix, $60 \mathrm{~cm}$, col. Miss Isabel Burgess, Phoenix, Arizona 28. grupo de mujeres sentadas, 1965 , bronce, $23 \mathrm{~cm}$ 29. mujer sentada con rebozo, 1966, bronce, $32 \mathrm{~cm}$ 30. María, 1966, bronce, $64 \mathrm{~cm} 31$. desnudo reclinado de Silvia, 1966, bronce, $34 \mathrm{~cm}$, col. Sr. y Sra. Baril 32. Soledad de pie, 1966, bronce, $1.85 \mathrm{~m}$, col. Galería de Arte de coleccionistas 33. juchiteca de pie, 1966, bronce, $2.00 \mathrm{~m}$, col. del autor 34. retrato de Elena, 1966, bronce, $34 \mathrm{~cm}$, col. Sra. del artista 35 . muchacha grávida, 1967, bronce, $35 \mathrm{~cm}$ 36. Esperanza, 1967, bronce, $28 \mathrm{~cm} 37$. la espera, 1967, bronce (relieve), $55 \times 39 \mathrm{~cm}$ 38. anunciación, 1967, bronce (relieve), $55 \times 33 \mathrm{~cm}$ 39. desnudo de Silvia, 1967, ónix ámbar, col. Sr. Javier Bustos 40. yucateca en cuclillas, 1967, ónix, $40 \mathrm{~cm}$, col. Sr. Pablo Brener 41. yucateca de pie, 1968 , bronce, $45 \mathrm{~cm}$ 42. tehuanas con iguana, 1968, bronce, $65 \mathrm{~cm}$, col. Dr. y Sra. H. D. Prensky 43. maternidad en cuclillas, 1968, bronce, $80 \mathrm{~cm}$, col. José M. Tasende 44. desnudo agachado de Silvia, 1968, ónix, $55 \mathrm{~cm}$, col. Herbert Kassner y Sra. 45. yalalteca, 1968, ónix café, $60 \mathrm{~cm}$, col. Catherina Valente, Lugano, Suiza 46. Evelia sentada, 1969, bronce, $44 \mathrm{~cm} 47$. Evelia, 1969 , bronce, $40 \mathrm{~cm} 48$. desnudo recostado, 1969, ónix café, $95 \mathrm{~cm}$, col. Eric van Aro. Lugano, Suiza 49. yucateca sentada, 1969, ónix café, $39 \mathrm{~cm}$, col. Norman Blau. Pasadena, Calif. 50. mujer de pie, 1969, bronce, $1.90 \mathrm{~m}$, col. del autor 51. desmudo de Evelia, 1969, bronce, $80 \mathrm{~cm} 52$. la abuela, 1969, bronce, $32 \mathrm{~cm}$ 53. mujer en un banquillo, 1969, bronce, $80 \mathrm{~cm}$, col. del autor 54. cabeza de Evelia, 1969, bronce, $44 \mathrm{~cm}$, col. Dr. Dimitry Jodidio. Summit, New Jersey, EUA. 10 bocetos en bronce de obras realizadas. Dibujos en diferentes técnicas sobre papel, numerados del 1 al 50.

OFRENDAS CON MOTIVO DEL TRAdICIONAL díA DE MUERTOS. Exposición colectiva presentada por la Galería José María Velasco, Peralvillo 55, INBA/SEP el 31 de octubre.

Nombre de los expositores: Héctor Ayala, Octavio Bajonero, Tomás Bárcenas, Feliciano Béjar, Angel Boliver, Ernesto Carreón, José Concepción Cerón, Hugo Chávez, Margarita Chávez, Irma Escárzaga, Artuiro Estrada, Leopoldo Estrada, José Gómez Rosas, Ester Guerrero, Manuel Herrera Cartalla, Rosa Lie Johansson, Macrina Krauss, Julia López, Lauro López, Froylán Ojeda, José Padilla Carlin, Carlos Páramo, Mariano Paredes, Feliciano Peña, Angel Pichardo, David Pimentel, Yolanda Quijano, Mariano Rechy, Angel Mauro Rodriguez, Alicia Saloma, Alfredo Serrano, Leni de Servin, Adrián Silva, Luis Toledo, Ana Ugalde, Rodolfo van Kurczyn, Raúl Vilchis, Puri Yáñez, José Zúñiga.

EXPosición anual. Presentada por la Universidad Juárez del Estado de Durango, de la Escuela de pintura, escultura y artesanías, Auditorio del Pueblo, durante el mes de octubre.

Catálogo: 1. mujer joven 2. estudio de vieja 3. estudio de un joven 4. hombre verde 5. minero 6. el hombre y la gruta 7. tigrillo 8. hombre, tierra y fuego 9. el geólogo 10, el cautivo 11. Mauro 12. estudio concéntrico 13. hombre de paz 14. escape al exterior 15. esclavo 16. hombre receptor 17. estudio 18. estudio 19. estudio desnudo 20. el hombre y la urbe 21. cabeza de estudio 22. modelo posando 23. el hombre rojo 24. el tendero 25. doña Ramona 26. después del hombre 27. la abuela y su nieto 28. el peso de la convivencia 1 29. el peso de la convivencia 2 30. la calle 31. los dogmas 32. don Brunito 33. africano 34. luces 35. estudio 36. salteña 37. modelo joven 38. desnudo de adolescente 39. hallazgo 40. Alicia 41. cabeza de estudio 42. despedida 43. meditación 44. 
invierno 45. muchacha 46. cabeza de niño 47. Beatriz 48. estudio (desnudo) 49. estudio (desnudo) 50. estudio (desnudo) 51. estudio (desnudo) 52. doña Inés 53. desmudo 54. joven gris 55. el velorio 56. la muchacha y la nube 57. supersticiosa 58. campesino 59. estudio (desnudo) 60. estudio (desnudo) 61. estudio (desnudo) 62. estudio (desnudo) 63. orador 64. el reprobado 65. Alicia 66. cabeza de viejo 67. limosnera 68. muchacha mexicana 69. el niño dorado 70. Betty 71. santos 72. retrato de joven 73. desnudo en la gruta 74. desnudo 75. estudio 76. cabeza 77. estudio (desnudo) 78. estudio (desnudo) 79. tianguis 80. estudio (desnudo) 81. estudio (desnudo) 82. muchacha 83. estudio (desnudo) 84. desmudo en azul 85. estudio en rojo 86. torso 87. desnudo 88. busto de joven 89. busto de Nora 90. niña 91. minero 92. raices 93. Tlatelolco 94. niña tronco 95. cabeza de niño 96. desnudo 97. niña 98. muchacha 99. mujer meditando 100. cabeza de soldado 101. cabeza de viejo 102. figura de mujer 103. desnudo 104. niña 105. cabeza 106. astronauta 107. cabeza de niño 108. desnudo 109. Cleto 110. busto de muchacha 111. figura de joven 112. cabeza de niño 113. cabeza de viejo 114. estudio, aguatinta 115. efectos, aguafuerte 116. naturaleza muerta, linóleo 117 . peces, aguafuerte 118. cúpula, aguatinta 119. pájaro, aguatinta 120. viaje, aguatinta 121. calavera, madera 122. lider, aguafuerte 123. juego infantil, madera 124. estudio, aguafuerte 125. despojo, aguafuerte 126. recordando, agua tinta 127. mujer y ropa, aguatinta 128. estudio, linóleo 129. rostro, fibracel 130. ruego, aguatinta 131. estudio, aguafuerte 132. dibujante, linóleo 133. estudio, linóleo 134. interior, linóleo 135. labriego, aguafuerte 136. interior, aguafuerte 137. estudio, aguafuerte 138. en el agua, aguafuerte 139. niño, aguafuerte 140. florero, linóleo 141. cabeza, linóleo 142. estudio, linóleo 143. niña, linóleo 144. rostros, linóleo 145. estudio, linóleo 146. cabeza, linóleo 147. naturaleza muerta, linóleo 148. estudio, linóleo 149. fuente, linóleo 150. cabeza, linóleo 151. naturaleza muerta, linóleo 152. estudio, madera 153. lavandera, linóleo 154. estudio, aguafuerte 155. el átomo, linóleo 156. cerebros, madera 157. gran paso, aguafuerte 158. paisaje, madera 159. estudio, linóleo 160. estudio, linóleo 161. cristo cósmico, linóleo 162. Barrabás, linóleo 163. velorio, mixto 164. cara de joven, aguafuerte 165. gigante, aguafuerte 166. estudio, aguafuerte 167. grupo, aguafuerte 168. avance difícil, aguatinta 169. estudio, aguafuerte 170. naturaleza muerta, linóleo.

Nombre de los expositores: José Candelario Vázquez, Jesús Martinez, Elizabeth Linden Bracho, Yolanda Hernández Salas, Guillermo Salazar, Jesús Salvador Marrero, José Luis Rodriguez, Jesús Gómez, Dora Leticia Curiel, Arcadio Estevané H. Ignacio Jiménez, Martha Valdez, Francisco Espinoza, Julián Rocha Bayona, Juan Diego López, Juan Manuel de la Rosa, Sra. Magdalena Durán, Gloria Escalante, Candelario Vázquez, Marcia León, Joe Goodman, Alicia Manifacio, Trinidad Núñez, Pablo Ibarra B. Leoncio Arango, Jesús Soto M., Sergio Mar T., Salvador Avila, Manuel Nava R., Oscar Espinosa.

Leonardo nierman. Exposición de pintura, presentada por la Gallerie, Katia Granoff, Place Beauvau, Paris VIIIe, durante el mes de octubre.

plástica contemporánea de guadalajara. Exposición presentada por el Salón de Otoño 1969, Galería Municipal, Av. Chapultepec y España, Guadalajara, Jal., el 20 de octubre.

Nombre de los expositores: Miguel Aldana, Gustavo Aranguren, Thomas Coffeen, Shul, Estanislao Contreras, Guillermo Chávez Vega, Gabriel Flores, Mauro Flores, 
Angel Hernóndez, Ernesto Minakata, Héctor Navarro, Jorge Navarro, Francisco Rodriguez Caracalla, Sánchez Larrauri, Jesús Serna Maytorena, Torreblanca.

José luIs cuevas. Exposición de dibujos, de la colección de José Gómez Sicre, presentada por The College Art Gallery, State University College, New Paltz, New York durante el mes de octubre.

\section{NOVIEMBRE}

ANDREE BURG DE GENOVES (cerámicas), ANDREE VREBOS (tintas). Exposiciones presentadas por el Instituto Francés de América Latina, Nazas 43, el 3 de noviembre.

CARLOS A. GUERRERO B. (pinturas), luIS G. GUERRERo B. (grabados). Exposición presentada por el Instituto Cultural Hispano Mexicano, A. C. Sala de Exposiciones del Instituto, Calle de Tabasco núm. 68, el 5 de noviembre.

YORK WILSON (pinturas y dibujos). Exposición presentada por el Instituto Nacional de Bellas Artes, Embajada del Canadá, Sala Internacional, Galerías del Palacio de Bellas Artes, el 5 de noviembre.

luis torreblanca. Exposición de relieves en metal presentada por el Departamento del Distrito Federal, Dirección General de Acción Social, Galerías de la ciudad de México en el Centro Social Popular "Leandro Valle" (Av. Sur 8 y Oriente 241, Col. Agrícola Oriental), del 6 al 29 de noviembre.

Nicolás moreno. Exposición presentada por la Galería Plástica de México, Londres 139, del 6 al 26 de noviembre.

Catálogo: Óleos. 1. el mirador 2. los huexotes 3. sabinos del nacimiento I 4. sabinos del nacimiento II 5. desde el chiquihuite 6. el maguey viejo 7. cerros 8. rocas del chiquihuite 9. raices 10. troncos y raices I 11. raices de ahuehuete 12 . ahuehuete caído 13. las calderas 14. minas de arena 15. troncos y raíces II 16. lomerío 17. las flores y el valle 18. xochitepec 19. xochitepec y los volcanes 20. cañón de la huasteca I 21. cañón de la huasteca II 22. cañón de la huasteca III 23. cañón de la huasteca IV 24. la cañada 25. el olivar.

CECILE martiel. Exposición presentada por el Instituto Francés de América Latina, Nazas 43, del 6 al 27 de noviembre.

JUAN SORIANo (16 nuevas acuarelas). Exposición presentada por la Galería de Arte Mexicano Florencia, Florencia 35-E, el 7 de noviembre.

copias de maestros europeos (de la Colección de la Antigua Academia de San Carlos). Presentada por el Instituto Nacional de Bellas Artes, Salas 1 y 2, Galerías del mismo, el 7 de noviembre.

XAVIER GIRÓN DE LA PEÑa Y hUMBERTo CHAPA. Exposición de diseño gráfico, presentada por la Escuela de Diseño y Artesanías, Balderas 125, del 7 al 28 de noviembre. 
ALFREDO ZALCE. Exposición de pinturas y grabados, presentada por la Galería de Arte Mexicano, Milán 18, del 10 al 30 de noviembre.

Catálogo: Acrílicos 1. naturalesa muerta con roloj 2. ventana con florero 3. naturaleza muerta 4. hombre con perro 5. domingo 6. pedregal 7. ciudad 8. Morelia I 9. Morelia II 10. Morclia III 11. cocina 12. el modelo 13. toro 14. trastero. Grabados 15. mujer leyendo 16. en el muclle 17. cabeza 18. luz en el estudio 19. niña 20. mujer sentada 21. sandías 22. la noche 23. naturalcza muerta 24. pajarera 25. vendedora de pescado 26. poblado 27. en la playa 28 . desnudo 29. diálogo 30. ventana con florero 31. águila y serpiente 32. niño 33. girasoles 34. el pollero 35. naturalcza muerta 36. muchacha 37. muchacha leyendo 38. rapto.

FRANCISCO MúJiCa 1)EZ DE BONILLA. Exposición (20,000 elementos gráficos sobre el tesoro artístico e histórico de México: prehispánico, colonial, moderno, paisaje, tipos, trajes y costumbres, cartografía e historia). Presentada por la UNAM, Biblioteca Nacional de México y el Patronato de Honor, Sala José María Virgil de la nisma, Uruguay e Isabel la Católica, el 10 de noviembre.

TL HOMBRE EN EL ESPACIO. Exposición colectiva, presentada por la Galería Pablo Picasso, Av. Coyoacán 931, del 11 al 29 de noviembre.

Nombre de los expositores: René Alis, Javier Arévalo, Arias Muructa, Byron Gálzé, Guillermo Ceniceros, José Luis Cuevas, Manuel Felguérez, Gelsen Gas-Pardo, Hcrnández Delgadillo, Leonel Maciel, Orozco Rivera, Antonio Peyri, Josć I. Sarasúa, David Alfaro Siqueiros. Carlos Téllez.

ENRIQUE BRYANT. Exposición de dibujos, pinturas, estudios y proyectos, presentada por el Instituto Francés de América Latina, Foyer de la Salle Molière, Nazas 43, del 12 de noviembre al 8 de diciembre.

Catálogo: Pinturas 1. la siembra 2. la laguna 3. el puente 4. la costurcra 5. el alba 6. el jacalón 7. la fiesta campestre 8. odalisca 9. un hombre herido 10. cl sacate 11. un patio 12. nagueyes 13. los remedios 14. la familia campesina 15. el burro.

JREFABRICACIÓN DE ARQUI'TECTURA. Exposición I, presentada por la Universidad Nacional Autónoma de México, Escuela Nacional de Arquitectura, Depto. de Enlace y Cintura, del 12 al 26 de noviembre.

El aRTE DEl FUturo (arte-robot: pintura cinética con luz solar). Exposición presentada por el Instituto Nacional de Bellas Artes, Embajada de Israel, Instituto Cultural Mexicano-Israeli, Sala Manuel M. Ponce, Palacio de Bellas Artes, el 14 de noviembre.

ALABRTo sfmas. Exposición de acuarelas, presentada por el Instituto Nacional de Bellas Artes, Galería José Ma. Velasco, Peralvillo 55, SEP, el 14 de noviembre.

SOCILIDA MEXICANA DE GRABADORES, A. C. Exposición con demostraciones prácticas de grabado y litografía, presentada por el Instituto Nacional de Bellas Artes, Galerias del mismo, Sala Verde, el 14 de noviembre. 
Colectiva ANual. Exposición presentada por las Galerías Escudero, Valencia 20, el 14 de noviembre.

Nombre de los expositores: Luis Acosta, José Chavarria, Hortensia Dominguew, Manuel Echauri, Javier González Iñiguez, Manuel Guillén, Manuel Herrera Cartalla, Amodor Lugo, Adolfo Mexiac, Nicolás Moreno, Feliciano Peña, Yolanda Quijano, Fermin Rojas, Alicia Saloma, Guillermo Sánchez Lemus, Adrián Silva, Eduardo Tanariz, Héctor Trillo, Ana Waterland, Rafael Ximénez.

TORNEO DE MENTIRas. Exposición colectiva presentada por la Galería Edvard Munch, Reforma 489, el 14 de noviembre.

Nombre de los expositores: Durán Vázquez, Hagan, Hurtado, Zanabria, Zauil Peña.

Marco chilet. Exposición "payasos", presentada por el Departamento del Distrito Federal, Dirección General de Acción Social, Galerias de la ciudad de México, Alameda Central, Salas Juárez e Hidalgo, el 14 de noviembre.

MARIO OROzCo RIVERA. Exposición de medio-relieves, sobre tableros de asbestos cementopintura-escultura, presentada por el Instituto Nacional de Bellas Artes, SEP, Salón de la Plástica Mexicana, Havre núm. 7, del 17 de noviembre al 7 de diciembre.

Datos biográficos: Mario Orozco Rivera, nació en México, D. F., el 19 de enero de 1930. En 1952, ingresó à la Escuela de Pintura y Escultura del Instituto Nacional de Bellas Artes.

Catálogo: Obra mural. Mural en el Museo del Instituto de Antropología de la Universidad Veracruzana en la ciudad de Jalapa, Ver. 1. defensa, contimuidad y destino de nucstra cultura, $1959,13.33 \times 3.13 \mathrm{~m}$. acrílico s/aplanado de cemento blanco, polvo de unármol y cuarzo. Murales de la Facultad de Veterinaria de la Universidad Veracruzana en Veracruz, Ver. Tríptico formado por tres aspectos diferentes de la Ciencia Veterinaria. 2. la lucha por la existencia y la creación en la naturaleza: Caballo en Disección: La ciencia Veterinaria integrada a la vida social, 1960, acrílicos sobre planchas de concreto, dejando una cámara de aire de $20 \mathrm{~cm}$. de $7 \times 3.50$ m. $8 \times 4 \mathrm{~m}$. y $7 \times 3.50 \mathrm{~m}$. Mural en la Biblioteca Central de la Universidad Veracruzana en Jalapa, Ver. 3. Veracruz Revolucionario, 4 × $3 \mathrm{~m}$., 1961, acrílicos s/ aplanado de concreto. Mural en el Tribunal Superior de Iusticia del Estado de Veracruz. 4. liberación, $1962,10 \times 8 \mathrm{~m}$. acrílicos s/aplanado de concreio. Mural en el Sindicato de Obreros Textiles de "E1 Dique", Jalapa, Ver. 5. lucha de clases, 1962, $6 \times 4 \mathrm{~m}$. acrílicos s/aplanado de concreto. Mural en la Esc. Secundaria "Antonio Ma. de Rivera", Jalapa, Ver. 6. adolescencia, $1963,6.30 \times 2.47 \mathrm{~m}$, acrílicos s/aplanado de concreto. Mural para el periódico El Mundo, de Córdoba, Ver. 7. carta abierta, $1963,4.60 \times 3.40 \mathrm{~m}$. acrílicos s/cuatro paños de yute. Mural para li casa del Dr. Schettino en Orizaba, Ver. 8. integración elemental del hombre, 1963, acrílico s/lino, $3.60 \times 2.50 \mathrm{~m}$. Mural exterior en la Facultad de Ciencias Químicas de la Universidad Veracruzana en Orizaba, Ver. 9. microorganismos, 1964, acrilicos s/concreto, 14 × $7 \mathrm{~m}$. Murales para el "Hotel de México", del Parque de la Lama en la ciudad de México, D. F., realizados en forma de tríptico compuesto jor seis paisajes pintados en la parte frontal y posterior de tres paneles cuya medicla total es de 144 metros cuadrados 10. Cuauhnáhuac, 1967, $20 \times 3.60 \mathrm{~m}$. por c/lado, acrílicos s/madera comprimida. Mural para la casa del Sr. Tomás Marentes en México, D. F. 11. noche y día en el Valle de Cuautla, 1968, $5.50 \times 1.75$, acrílicos 
y óleo s/tela. Realiza el proyecto del Mural para las oficinas centrales de la Comisión Federal de Electricidad en la ciudad de México, 1968. Fuente Monumental para el Hotel de México, México, D. F. 13. La fuente de los genios, 1969, 6 $\times 8 \mathrm{~m}$. de diámetro de alto iluminado con un haz de luz policromado de $30 \mathrm{~m}$. de alto, hierro, plexiglás, asbesto-cemento, acrílicos e instalaciones eléctricas, de agua y mecanismos de movimiento. Cuatro medios relieves de hierro y asbesto-cemento policromados sobre tableros de los mismos materiales, para la fachada del Banco Agropecuario de Sinaloa en Culiacán, Sin. 14. de la agricultura a la industria, $2.40 \times 1.33 \mathrm{~m} .1969$.

paßro pICasso. Exposición de grabados, presentada por las Galerías Mer-Kup, Molière núm. 328-C, el 18 de noviembre.

GREGORIO GUTÍ́RREZ. Exposición de pinturas, presentada por el Instituto MexicarioNorteamericano de Relaciones Culturales, A. C., Sala Nabor Carrillo, Hamburgo 115, el 19 de noviembre.

MEXiac. Exposición de grabados, relieves, litografías, presentada por el. Instituto Nacional de Bellas Artes, SEP, Salón de la Plástica Mexicana, Havre núm. 7, del 19 de noviembre al 9 de diciembre.

JorGl: Quiroz. Exposición de óleos y dibujos reminiscentes, presentada por el Instituto Nacional de Bellas Artes, Galería Chapultepec, Insurgentes Sur núm: 11-bis, el 21 de noviembre.

José gakcía ocejo. Exposición de dibujos recientes, presentada por la Galería de Arte Arvil, Hamburgo 241, del 22 de noviembre al 15 de diciembre.

$11^{\circ}$ SALÓN DE NUEvos valones. Exposición presentada por el Comité de Actividades Generales del Centro Deportivo Israelita, Galerías CDI, Av. Manuel Ávila Camacho núm. 620, Lomas de Sotelo, del 23 de noviembre al 14 de diciembre.

Nombre de los expositores: Jeanctte Amkie, Elvira Amkie, Salomón Balas Cohen, Lily Barer, Rebeca Bronsoler, María R. de Borkou, Malbin Cogan, Evielyn Frid, Daniel Himelfarb, Georg Juliusburger, Matilde Lieberman, Fabián Margolis, Ignacio Mendel, Ironne Natjar, Sara Natjar, Moisés Nifco Cohen, Aurora Orzechovsky, Sara Sulkin, Regina Salomón, Lore Sommer, Katheleen Schweitzer, Irene G. de Sáyago, Kipi Turok, Jeanette Wurm, Silvia Zajdman. Fotografias Andrés Bogati, Bert Gold1nan, Boris Hale, Eduardo Kluk, Irving Kessler, Pedro Kleinburg, Sergio Leizorek Ishay Podgaetz, Salomón Stavchansky, Guillermo Sunursz, Fernando Wachnovetzki. Perry Weinstein.

FRANCisco ICAza. Exposición presentada por la Galería Pecanins, Hamburgo 103, el 25 de noviembre.

vickNTe kojo. Exposición señales en Nueva York, presentada por la Galería Juan Martín, Amberes 17, el 25 de noviembre.

5 litografías, 35 acrílicos y 1 artefacto. 
Fivza: Metagalaxia o la búsqueda de una meva dimensión. Exposición presentada por el Instituto Nacional de Bellas Artes, Galerías del Palacio de Bellas Artes. Sala 3 , el 26 de noviembre.

SAlJívar JAIME. Exposición de temas populares, presentada por la Galería de Arte Misrachi, Génova 20, el 27 de noviembre.

Calálogo: 1. la Virgen patrona 2. la Catedral 3. la villa de Guadalupe 4. el ángel 5. Chapultepec 1900 6. la ültima pulquería 7. chinampa de Jesusa Rizas 8. TPpotzotlán en pastorelas 9. domingo en la Marquesa 10. sólo Veracrus es bello 11. Maravatio 12. hospital de Santa $F$ c de la laguna 13. día 16 en Santa Ana Xaltoc 14. feria en los Altos 15. ribera del Papaloapan 16. suave Patria 17. el de las virgenes mexicanas 18. el de Sebastián de Aparicio 19. el de doña Jucuencia Lagos 20. el enmarcado 21. la alacena 22. el nacimiento 23. la vivienda 24. la adolorida. Un biombo con paisajitos. Acompañan esta exposición: el pulquero, anónimo, Apam, Hgo. la pulquera, anónimo, Apam, Hgo. la entrada de Madero, Joaquín Pérez, 1924. la charola, anónimo, siglo XIX, fiesta en Xochimilco, anónimo, siglo xıx, Batalla de Puebla, anónimo, siglo xix, la presentida, anónimo, siglo xıx, la .quedada, anónimo, siglo XIX.

las ARTES PLÁSTICAS AI. SERvicio DE. IA ARQUiteCTURA. Exposición presentada por la Universidad Nacional Autónoma de México, Dirección General de Difusión Cutural, Museo Universitario de Ciencias y Arte, Ciudad Universitaria, el 27 de noviembre.

Crḱ́mica maya. Exposición presentada por el Museo Nacional de Antropología e Historia, SEP, el 27 de noviembre. (Col. de Manuel Barbachano Ponce.)

li.l arte maya es la obra de un gran pueblo, desconocemos los nombres de los artistas individuales que to crearon, en cambio, reconocemos en estas formas prodigiosas el genio, la sensibilidad, los anhelos, quizás los temores, sin duda la memoriá y la imagen de toda una cultura.

¿Cómo pretender, elitonces, que estas obras estrictamente anónimas, que estas obras creadas por y para una comunidad, puedan tener el nombre de un coleccionista? El coleccionista, si en verdad ama lo que reúne, sabe que su posesión es transitoria, el coleccionista busca, rescata, ordena y no es ajeno al legítimo placer de los sentidos, nero sabe perfectamente que su función, si necesaria, también es fugaz, ha sido, por uin tiempo, el depositario de una herencia que no es suya : ha sido el guardián efímero del tesoro espiritual de su pueblo, quizás ha salvado algunas obras del olvido, de la destrucción física y anı de esa forma embozada de la destrucción que es la fuga de nuestro patrimonio cultural al extranjero, pero, finalmente, sabe que estits obras dehen regresar a los ojos, a las manos y al espíritu que las crearon.

Al agradecer al Museo Nacional de Antropología e Historia que loy exhiba parte de una colección en vías de integrarse, deseo afirmar que el destinatario real de estas obras es el mismo pueblo que las inaginó y les dio forma y que mi decisión es legarle a mi gente la colección final que logre reunir.

Ojalá que en este arte, Yucatán pueda, a un tiempo, recordar su original grandeż, reconocerse en aquello que lo solidariza y define, proyectarse al futuro que desea $y$ merece $y$, también encuentre en las formas del pasado los motivos para un orgullo en el presente y para una fe cada vez mayor en el porvenir.

Manuel Barbachano Ponce 


\section{Introducción}

Siempre he creido que de todas las artesanías, la más apasionante, por humana, es la cerámica, hecha de barro, trabajada con las manos y endurecida con el fuego, el objeto resulta entrañable, así, la cerámica, tierra y fuego, es continuación inmediata del ser humano, primero se bebió de bruces, después, ahuecando las manos y uniéndolas, tal vez un mediodía, a la orilla del agua, jugando con el barro, el hombre, torpemente, hizo la primera vasija que el sol endureció y después el fuego, se impuso la ley del menor esfuerzo y del cuenco de la mano nació la cerámica, por un proceso natural, del objeto útil realizado toscamente se llegó a la obra de arte.

La colección de cerámica maya que ha reunido Manuel Barbachano Ponce, es tan importante, cuanto hermosa, corresponde a los últimos tiempos de esa gran cultura que cubrió el sureste de México y parte de Centroamérica durante el primer milenio de la era cristiana.

Entre el grupo de vasos hay uno de gran belleza, lo clásico maya, por el movimiento y la composición de los personajes, hace de este objeto un testimonio de refinamiento a que llegaron esas gentes incomparables.

¿Qué palabra agregar a propósito de las figuras de la isla de Jaina, frente a 12 costa de Campeche? André Malraux, el gran escritor y crítico francés de arte, declara que hay días que no sabe qué admirar más: si una figura tanagra o una de jaina.

Pero es la Colección de platos lo que por ahora en esta colección más me impresiona, siempre decorados, frecuentemente sobre fondo anaranjado y rojo, representan un momento aislado del arte maya por lo que se refiere a la absoluta libertad de los artistas para expresarse sobre todo cuando se trata de animales, en gran medida, el arte maya es un homenaje a la realidad y al realismo, una realidad y un realismo de la más noble elegancia, es Palenque su ejemplo supremo, contrastado valerosamente con la grandiosidad del imperio vegetal, en estos platos, también la audacia es elegante, la audacia está desde luego en el trazo, y la audacia es resultado de la libertad, extrañas criaturas imaginadas a veces con cierto buen humor, o personajes semidesnudos, lujosamente desnudos, hay composiciones que parecen abstractas, por las que pasa una leve brisa animal, estos platos, generalmente trípodes, son la última revelación del genio pictórico de los mayas, sus representaciones, más allá de la realidad, nos confirman en la idea de la capacidad poética de sus autores, yo nací en esa región del área maya que antes fue magníficamente olmeca y me complazco en creer que viaja en mi sangre una gota, una sola gota de la sangre de esos cultísimos pueblos.

\section{Carlos Pellicer}

La Cerámica Maya. La alfarería fue uno de los medios preferidos por los anónimos artistas mesoamericanos, para el desarrollo de ciertos aspetos estéticos como el modelado, el dibujo y la pintura; de modo que al través de ella uno puede observar la imaginación y el espíritu creador, los estilos, las técnicas y aun varias ideas y costumbres de los pueblos prehispánicos al correr del tiempo.

Así, los mayas iniciaron su cerámica con una coloración monocroma: negra, crema, 
rojiza, blanca o grisácea; prefirienron luego la bicromía: rojo sobre blanco, rojo sobre café, blanco sobre rojo y rojo sobre naranja: y después pasaron a la policromía, a la decoración negativa y a la pintura al fresco o sobre estuco seco, creando una gran variedad de formas, muchas de ellas llenas de refinamiento y elegancia.

En la cerámica de los primeros tiempos se puede observar una serie de ollas para el acarreo del agua y para la cocción de los alimentos; cuencos o escudillas sencillas y de silueta compuesta; platos de base plana y de paredes divergentes; vasijas con efigies de animales o humanas, a veces con vertedera sencilla; botellones; patojos; copas con base anular; incensarios para quemar el copal y otras muchas formas tanto lisas como decoradas con incisiones, punzonado y pintura.

Los alfareros producían también sencillas figurillas modeladas a mano, por lo regular con ojos perforados y con aditamentos al pastillaje; y hacían sellos o pintaderas, tal vez empleadas en la decoración del cuerpo; lo mismo que silbatos representando aves, nonos y otros animales.

Con el tiempo la alfarería evoluciona y se vuelve predominantemente bicroma y policroma, pintada en diferentes colores, y surgen los vasos, platos, trípodes, vasijas tetrápodes, floreros, jarras silbadoras, vasijas efigies y otras formas, en las que se aprecian los soportes mamiformes, la vertedera sencilla o doble, los soportes carrete, las bases pedestales, anchos bordes acanalados, anillo basal; molduras labiales, mediales y basales; lo mismo que la decoración negativa y la pintura sobre estuco seco, esta última en colores verde, azul turquesa, amarillo, rosa y a veces negro.

La cerámica rojo sobre naranja, negra con borde blanco pintado, roja incisa, negativa usulután, estucada y pintada, blanco marfil, rojo y negro sobre naranja, etcétera, anuncian lo que será el típico estilo policromo de la alfarería maya; el cual caracterizará a la cultura durante su época de apogeo, tanto en los viejos centros del petén guatemalteco y campechano, como en sitios de la costa de Campeche y Yucatán.

Así alcanza la cerámica policroma su auge, en colores negro, naranja, rojo, amarillo, blanco, gris, café y crema combinados; en vasos, platos con rebordes basales y cuencos por lo general, y surgen los motivos naturalistas de animales y gentes; bandas de jeroglíficos y diseños geométricos; escenas de caza, de comercio, de guerra, de tributos y otros muchos temas que ayudan a comprender y explicar ciertos aspectos de la vida de esos tiempos. $\mathrm{Y}$ junto a esta extraordinaria producción alfarera aparecen también las figurillas de barro, moldeadas y modeladas a mano, que representan señores ricamente ataviados, sacerdotes, jugadores de pelota, enanos, dioses gordos, mujeres de elevada alcurnia, sacerdotisas, tejedoras y, en suma, a las gentes de esos tiempos; mostrando el uso de faldillas, bragueros, capas, abanicos, bolsas, sandalias, collares, pectorales y muchas otras prendas $\mathrm{y}$ joyas que permiten reconstruir varios aspectos de la cultura, desde luego las más bellas figurillas proceden de Jaina, Uaymil, Jonutla y Palenque.

Contemporánea a esta cerámica y figurillas se desarrolla en la península de Yucatán el estilo del Puuc o de la serranía, preocupado por la decoración de sus frisos con mosaico de piedra, tendientes a la geometrización; y con él aparece la cerámica pizarra, primero de color blanco o marfil con finas cuarteaduras, después en colorạciones grisáceas, anaranjada, verdosa, rojiza y cremosa, con bandas de pintura 
chorreada a partir de los bordes y en formas de cazuelas con anchos bordes, tiıajas, ollas, tazas, platos y vasos principalmente.

Después de la producción alfarera comienza a declinar, se introducen por comercio la cerámica anaranjada fina, generalmente en forma de vasos con base pedestal y paneles decorados, o con soportes de sonaja; la cerámica "plumbate" o plomiza, principalmente con efigies de animales o tipo tohil; la cerámica pizarra se vuelve fundamentaimente de color crema con pintura negra; y se elaboran una serie de braseros y urnas con adornos al pastillaje, representando sacerdotes y deidades, muchas de ellas con influencia mexicana y con pintura de varios colores aplicada directamente sobre el barro.

En este breve bosquejo de la evolución cerámica de los mayas, lay un periodo monocromo y bicromo que corresponde al preclásico medio y superior (namom y chicanel); un periodo con el inicio de la policromía y énfasis en la decoración negativa, correspondiente al protoclásico (matzanel); un periodo de ange de la policromía, de las figurillas y de la cerámica pizarra, que se relaciona con el clásico (tzacol y tepeu); $y$ un periodo de decadencia alfarera e introducción de otras cerámicas importadas, que corresponde al postclásico.

La selecta colección del señor Manuel Barbachano Ponce, incluye fundamentalmente ejemplares del periodo clásico y algunos del postclásico, procedentes también principalmente de la península de Yucatán; y constituyen una buena muestra de la producción alfarera de los antiguos mayas, quienes crearon una de las civilizaciones más avanzadas del nuevo mundo, sobre todo en el orden arquitectónico, astronómico y matemático.

Román Piña Chan

Catálogo: 1. vaso antroponnorfo, Kaminaljuyú, Guatemala, preclásico superior, attura $25.5 \mathrm{~cm}$ 2. plato trípode, Yucatán, clásico tardio, diámetro $35.5 \mathrm{~cm} 3$. plato tripode, Yucatán, clásico tardío, diámetro $33.0 \mathrm{~cm}$ 4. vaso con botones al pastillaje, Yucatán, clásico temprano, altura $14.0 \mathrm{~cm}$ 5. figurilla-sonaja, (femenina), Campeche, clásico medio, altura $10.0 \mathrm{~cm} \quad$ 6. vaso con decoración, Yucatán, clásico medio, altura $15.0 \mathrm{~cm}$ 7. vasija venenero o perfumero, Yucatán, clásico tardío, altura $07.0 \mathrm{~cm}$ 8. plato trípode, Yucatán, clásico tardío, diámetro $25.0 \mathrm{~cm} \mathrm{9.} \mathrm{cajete,}$ Yucatán, clásico tardío, altura $08.5 \mathrm{~cm}$ 10. cajete, Yucatán, clásico tardío, altura $08.0 \mathrm{~cm}$ 11. vaso, Yucatán, clásico tardío, altura $11.5 \mathrm{~cm} \quad 12$. varija venenero $o$ perfumero, Yucatán, clásico tardío, altura $05.0 \mathrm{~cm}$ 13. cajete. Yucatán, clásico tardío, altura $10.5 \mathrm{~cm}$ 14. vaso con decoración, Yucatán, clásico medio, altura $11.5 \mathrm{~cm} 15$. cajete, Yuatán, clásico tardío, altura $10.5 \mathrm{~cm} 16$. cajete, Yucatán. clásico tardio, altura $10.0 \mathrm{~cm}$ 17. vaso cilindrico, Yucatán, clásico tardio, altura $23.0 \mathrm{~cm}$ 18. vasija venenero o perfumero, Yucatán, clásico tardío, altura $06.5 \mathrm{~cm}$ 19. vasija venenero o perfumero, Yucatán, altura $10.5 \mathrm{~cm}$, postclásico temprano, altura $10.5 \mathrm{~cm} 20$. vaso cilíndrico, Yucatán, clásico tardío, altura $21.5 \mathrm{~cm} 21$. vaso. Yucatán, clásico tardío, altura $15.5 \mathrm{~cm}$ 22. plato tripode, Yucatán, clásico tardío, cliámetro $34.0 \mathrm{~cm}$ 23. plato trípode, Yucatán, cultura maya, diámetro 39.0 $\mathrm{cm} \mathrm{24.} \mathrm{zasija} \mathrm{zoomorfa,} \mathrm{Yucatán,} \mathrm{posclásico} \mathrm{temprano,} \mathrm{altura} 16.0 \mathrm{~cm} 25$. figurilla-sonajä, bicéfala, Campeche, clásico medio, altura $16.5 \mathrm{~cm}$ 26. figurilla femenina en posición sedente, Campeche, clásico medio, altura $19.2 \mathrm{~cm} 27$. figurillasonaja, femenina en posición sedente, Campeche, clásico medio, aitura $10.5 \mathrm{cn}$ 28. figurilla femenina en posición sedente, con tocado, Campeche, clásico medio. altura $18.0 \mathrm{~cm}$ 29. vaso cilindrico, Yucatán, clásico tardío, altura $17.0 \mathrm{~cm} 30$. figurilla-silbato, masculina y femenina; en posición sedente, Campeche, clásico 
medio, altura $13.5 \mathrm{~cm}$ 31. cajete, Yucatán, clásico tardío, altura $13.0 \mathrm{~cm} \quad 32 . c a-$ jete, Yucatán, clásico tardío, altura $11.0 \mathrm{~cm}$ 33. figurilla masculina de pie, Campeche, clásico medio, altura $20.0 \mathrm{~cm}$ 34. figurilla masculina cn posición sedente, Campeche, clásico medio, altura $13.0 \mathrm{~cm} 35$. figurilla femenina de pie, Campeche, clásico medio, altura $21.8 \mathrm{~cm}$ 36. figurilla fenenina de pic, Campeche, clásico medio, altura $16.5 \mathrm{~cm}$ 37. vasija venenero o perfumero, Yucatán, clásico tardio, altura $06.5 \mathrm{~cm}$ 38. plato trípode, Yucatán, clásico tardío, diámetro $26.0 \mathrm{~cm} 39$. vasija venenero o perfumero, Yucatán, clásico tardío, altura $04.5 \mathrm{~cm} 40$. plato trípode, Yucatán, clásico tardío, diámetro $26.0 \mathrm{~cm}$ 41. figurilla masculina en posición sedente, Yucatán, clásico medio, altura $16.0 \mathrm{~cm} 42$. figurilla femenina de pie, Compeche, clásico medio, altura $14.0 \mathrm{~cm}$ 43. figurilla silbato, femenina, Campeche, clásico medio, altura $14.0 \mathrm{~cm}$ 44. figurilla masculina de pie, Campeche, clásico medio, altura $15.8 \mathrm{~cm}$ 45. plato tripode, Yucatán, clásico tardío, diámetro $33.0 \mathrm{~cm}$ 46. plato, Yucatán, clásico tardío, diámetro $27.0 \mathrm{~cm} 47$. cajete, Yucatán, clásico tardío, altura $11.5 \mathrm{~cm}$ 48. cajete, Yucatán, clásico tardío, altura $11.5 \mathrm{~cm} 49$. vaso cilíndrico, Yucatán, clásico tardio, altura $13.5 \mathrm{~cm} \quad 50$. vaso, Yucatán, clásico tardío, altura $21.0 \mathrm{~cm}$ 51. vasija trípode, Yucatán, posclásico temprano, altura $17.0 \mathrm{~cm}$ 52. vaso cilindrico, Yucatán, posclásico temprano, altura $19.5 \mathrm{~cm}$ 53. vasija zoomor$f a$, Yucatán, posclásico temprano, altura $10.5 \mathrm{~cm} 54$. vasija trípode, Yucatán, posclásico temprano, altura $16.0 \mathrm{~cm} 55$. vasija zoomorfa, Yucatán, posclásico temprano, altura $07.5 \mathrm{~cm}$ 56. cabeza antropomorfa, Yucatán, posclásico tardío, altura $20.0 \mathrm{~cm}$ 57. fragmento de urna o incensario, masculino, Yucatán, posclásico tardio, altura $12.0 \mathrm{~cm}$ 58. plato trípode, Yucatán, posclásico tardío, diámetro $29.5 \mathrm{~cm}$ 59. vaso cilíndrico, Yucatán, posclásico temprano, altura $17.5 \mathrm{~cm} 60$. vaso cilíndrico, Yucatán, clásico tardío, altura $17.5 \mathrm{~cm}$ 61. figura zomorfa, Yucatán, posclásico tardío, diámetro $16.0 \mathrm{~cm} 62$. vasija incensario, Yucatán, posclásico tardío, altura $08.5 \mathrm{~cm}$ 63. vasija venenero o perfumero, antropomorfa, Yucatán, posclásico tardío, altura $08.2 \mathrm{~cm}$ 64. plato trípode, Yucatán, posclásico tardío, diánetro 26.0 $\mathrm{cm}$ 65. plato trípode, Yucatán, posclásico tardío, diámetro $31.0 \mathrm{~cm}$.

TRINIDAd osorio. Exposición presentada por la Galería Plástica de México, Londres 139, del 27 de noviembre al 13 te diciembre.

Catálogo: 1. mujer en reposo 2. cofre de ilusiones 3. baúl rojo con gato azul 4 . ciclistas en el bosque 5. adivino 1 6. la fuente 7. Tepoztlán 8. adivino 2 9. valle de Tepoztlán 10. valle de Cuernavaca 11. niña 12. paseo a caballo 13. amantes 14. naturaleza muerta 1 15. naturaleza muerta 2 16. paisaje 1 17. paisaje 218. figura.

aragón. Exposición de chapopote y oro en 16 pinturas, presentada por el Museo de las Culturas, INAH/SEP. Moneda 13 , el 27 de noviembre.

rGiresanos recientes de san carlos. Exposición presentada por la Escuela Nacional de Artes Plásticas/UNAM, Sala de Exposiciones, Academia 22, el 28 de noviembre.

LENI DE SERVIN Y SU ARTE. Exposición de acrílicos, acuarelas, bocetos, óleos, presentada por el Centro Cultural Provisional del BNOSPSA, el 29 de noviembre.

IRMA RENŚ KOEN. CARMEN coox. Exposición de óleos presentada por el gobierno del Estado de Morelos, Palacio de Cortés, del 20 de noviembre al 9 de diciembre en Cuernavaca, Mor.

Catálogo: 1. los volcanes 2. mercado de Ozumba 3. mercado de flures, Oaxaca 4. arrojando la red de pesca 5. tormenta 6. lluvia repentina 7 . corca de Pátz- 
cuaro 8. campanento en la montaña 9. las jacarandas 10 . mercado cerca de Toluca 11. nercado de árboles de navidad 12. lanchas de pesca en Pátzcuaro 13. mercado de Pátzcuaro 14. mercado con fuentes 15. rincón del mercado de Ozumba 16. la muerte de Kayyum 17. la hamaca 18. primavera 19. sostengo mi corazón 20. árbol es deseo 21. soledad 22. fin de un largo dia 23. río lacantun 24. de bruja a guajolote 25. los adúlteros 26. Kin Obregón.

GENaro NaCCI. Exposición presentada por la Galerie Libre a Le Plaisin 2100 Crescent, Montreal 107, Canadá, durante el mes de noviembre, Montreal, Canadá.

\section{DICIEMBRE}

venta ANual. 1970. Exposición de 100 obras de Pablo Picasso, y una colectiva de otros expositores, presentada por las Galerías Mer-Kup, Artistas de la Plástica Mexicana, A.C., Molière núm. 328-C, del $1^{9}$ de diciembre al 15 de enero.

Nombre de los expositores: René Alis, Raúl Anguiano, José Arias Murueta, Rolando Arjona, Dr. Atl, Sofía Bassi, Feliciano Béjar, Susana Campos, Francisco Capdevilla, Fcrnando Casas, Juan Castañeda, Pilar Castañeda, Guillermo Castaño, Guillormo Castaño Jr., Fernando Castro Pacheco, Ernesto Carrén, Miguel Cerz'antes, Olga Costa, Estanislao Contreras Colima, José Luis Cuevas, José Chávez Morado, Tomás Chávez Morado, France Chancellor, Vicente Gandia, Moshe Gat, Mathias Goeritz, Silvia González H., Angela Gurria, Willi Gutmann, José Herrández l'elgadillo, José Hernández Urbán, Julia López, Manabu Mabe, Jaime Mejia, Eliana Menasse, Benito Messeguer, Guillermo Meza, Julio Montes, Nicolás Moreno, Rodolfo Nieto, Leonardo Nierman, Juan O'Gorman, Carlos Olachea, José Clemente Orozco, Feliciano Peña, Lorraine Pinto, Fanny Ravel, Diego Rivera, Baruj Salinas, Guillermo Silva Santamaría, David Alfaro Siqueiros, Waldemar Sjöclander, Rufino Tamayo, I. on Ruhs Marlind, Pablo Weisz, Danielle Wolfowitz, Marysole Worner Bas, Híctor Xavier, Francisco Züñiga.

MANUEl Álvarez BRavo martínez. Exposición El tiempo lo hizo, presentada por la Galeria Edvard Munch, Reforma 489, el $1^{9}$ de diciembre.

EUGENIo BRITo (chileno). Exposición de obras, presentada por el Organismo de Promoción Internacional de Cultura, de la Secretaría de Relaciones Exteriores, Embajada de lá República de Chile en México y el Instituto Politécnico Nacional, Unidad cultural de Zacatenco del propio Instituto, el $1^{\circ}$ de diciembre.

fernando Casas. Exposición presentada por el Colegio de Arquitectos de México y la Sociedad de Arquitectos Mexicanos, Ciclo de Acuarelistas, Sala de las Instituciones, Av. Veracruz núm. 24, Col. Condesa, el $1^{\circ}$ de diciembre.

venta de Navidad, 1969. Exposición colectiva presentada por el Salón de la Plástica Mexicana, INBA/SEP, Havre núm. 7, del $1^{\text {"9 }}$ de diciembre de 1969 al 9 de enero de 1970 .

Nombre de los expositores: Gilberto Aceves Navarro, Ignacio Aguirre, Ernesto 
Alcántara, David Alfaro Siqueiros, Raúl Anguiano, Javier Arévalo, Gustavo Arias Murueta, Rolando Arjona, Alfonso Ayala, Héctor Ayala, Santos Balmori, Pedro Banda Salazar, Feliciano Béjar, Sofia Bassi, Arnold Belkin, Alberto Beltrán, Roberto Bcrdecio, Ignacio M. Beteta, Angel Bracho, Angel Boliver, Geles Cabrera, Celia Calderón, Susana Campos, Federico Cantú, Gerardo Cantú, Beatriz Caso de Solórzano, Pilar Castañeda, Fidencio Castillo, Rosa Castillo, Fernando Castro Pacheco, Guillermo Ceniceros, Enrique Climent, Pedro Coronel, Rafael Coronel, Erasto Cortés Iuáres, lirancisco Corzas, Olga Costa, Héctor Cruz, Dolores Cueto, Germán Cucto. Carlos A. Chávez, José Chávez Morado, Tomás Chávez Morado, María Elena Delgalo, Francisco Días de Lcón, Roberto Donis, Francisco Dosamantes, Manuel Echauri, Enrique Echeverria, Augusto Escobedo, Arturo Estrada, Alfredo Falfán, I.uis Filcer, Oscar Frías, Dina Frumin, Jesús Gallardo, Byron Gálvez, Ficente Gandia, Arturo García Bustos, Carlos García Estrada, José García Nareso, Juis Garcia Robledo, José Maria Jiménez Botey, Gastón González, Silvia H. Conzález. Iorge Gonsáles Camarna, Xavier Guerrero, Jesús Guerrero Galván, Lorenwo Gucrrero, Inycla Gurría, Iosé Hernández Delgadillo, Miguel Hernández Urbán, Desiderio I1. Xochitiotsin, Manuel Herrera Cartalla, Elena Huerta, Francisco Icaza, Sara Iincines, Carlos Iurado, Maria Lagunes, Agustin Lazo, Rina Lazo, Iulia López, Amador Lago, Maka, Francisco Arturo Marín, María Marin, Mary Martín, Héctor Martinez Arteche, Elaine Menasse, Leopoldo Méndez, Carlos Mérida, Benito Messeamcr, Adolfo Mexia, Guillermo Meza, Roberto Montenegro, Gustavo Montova, Francisco Mora, Nicolás Moreno, Francisco Moreno Capdevila, Nefero, Lconardo Niernan, Ituis Nishizawa, Isidoro Ocampo, Iuan O'Gorman, Pablo O'Higgins, Froylán Oicda, Carlos Olachea, Mario Orozco Rivera, Carlos Orozco Romero, Armando Ortega Orosco, Luis Ortiz Monasterio, Trinidad Osorio, Javier Otfyza. Mariano Paredes, Gonzalo de la Paz Pérez, Antonio Pelaéz, Feliciano Peña, Iais Péres llores, Angel Pichardo, Lorraine Pinto, Adolfo Quinteros, Fanny Rabcl. Antonio Romires, Everardo Ramirez, Aurora Reyes, Mario Reyes, José Reves Mesa, Iosí Inlio Rodriguca, Antonio Rodriguez Lunn, Manuel Rodríguez, José L. Ruiz, Carlos Sáncher, Antonio Serna, Artemio Sepúlveda, Alfredo Serrano Lara, Adrián Silva, Federico Silva, Guillermo Silva Santamaria, Waldemar Sjölander, Rosendo Soto. Iman Soriano, Rufino Tamayo, Leticia Tarrago, Ma. Teresa Toral, Helena Tolmacs, Jorgc Tovar, Paulina Trejo, Lucinda Urrusti, Cordelia Urueta, Ernesto Vázquez Beltrán, Alberto de la Vega, Fernando Vilchis, Luis Vizuet, Vlady, Héctor Xavicr, Alfredo Zalce, Angel Zamarripa, Francisco Zúñiga, Angelina Beloff.

minipinturas. Fxposición colectiva, presentada por la Galería Pahlo Picasso, Av. Coyoacán núm. 931, el 2 de dicienıbre.

PEDRo RANDA Y LUIS macf́as. Exposición de dos pintores testigos de su tiempo, presentada por el Instituto Nacional de Bellas Artes, Galerías del Palacio de Bellas Artes, Salas 4 y 5 , el 2 de diciembre.

ANDrea vrenos. Exposición de cerámica, presentada por el Instituto Francés de América Latina, Nazas 43 , del 3 al 19 de diciembre. 
SAlVAdOR valdÉs Galindo. Exposición de pintura onirica privada, presentada en la calle de Pedro Luis Ogazón núm. 98, San Angel, el 3 de diciembre.

GRACIELA MAKISCA1. (exposición de óleos). Exposición el tiempo aprisionado, presentada por el Organismo de Promoción Internacional de Cultura de la Secretaría de Relaciones Exteriores y Almacenes Nacionales de Depósito, S. A., Galería de Arte del Teatro de Cámara ANDSA, Plaza de la Constitución núm. 7, el 3 de diciembre.

artesanías pOPUlaRES DE checoslovaquia. Exposición presentada por el Museo de jas Culturas, INAH/SEP/ Embajada de la República Socialista de Clecoslovaquia en México, Moneda 13, el 4 de diciembre.

снгкиy. Exposición de pinturas a espátula, presentada por el Departanento del Distrito Federal, Dirección General de Acción Social, Galerías de la ciudad de México en el Centro Social Popular "Leandro Valle", Av. Sur 8 y Oriente 241, col. Agrícola Oriental, del 4 de diciembre al 3 de enero de 1970.

JoDy mC Gkath. Exposición presentada por la Galería de Antonio Souza, Paseo de la Reforma 334-A, el 4 de diciembre.

esculturas DE esteban Ramos. Exposición presentada por el Organismo de Proinoción Internacional de Cultura de la Secretaría de Relaciones Exteriores, Galería de Arte del Teatro Casa de la Paz, Cozumel núm. 33, el 5 de diciembre.

VII GRAN CONCURSo NACIONAL DE PIÑATAS. Exposición presentada por el Iustituto Nacional de Bellas Artes, Escuela de Diseño y Artesanías, Balderas 125, el 5 de diciembre.

mario rangel. Exposición presentada por la Galería de Arte Mexicano, Florencia 35-E, el 10 de diciembre.

Catálogo: 1. éxodo 2. violando las lejes 3. fragmentos de olvido 4. colección incompleta 5. fenomeno inexplicable 6. el sabio y el hombre común 7. tomor intstificado 8. cl artifice 9. naipes mágicos 10. concepción medicval 11. imagen compuesta 12. la trampa 13. resultado final 14. los pasatiempos del diablo 15. hipmosis 16. pasatiempo prohibido 17. antes del diluvio 18. desprendimiento 19. tinglado celeste 20. destino conuin 21. escena invernal 22. descubrimiento inútil 23. juego tetradimensional 24. el último diálogo 25. los ultimos preparativos 26. figura mitológica 27. mosaico mágico 28. extraña correspondencia 29 . recolección 30. la magia se justifica en sus creaturas 31. el tesoro 32. generando vida 33. reproducción 34. alguien lo tiene que hacer 35. sorpresa inceperada 36. desmićs del intigo.

exposición final de artesanías. Presentada por el Museo de las Culturas, INAH/ SEP Moneda 13, el 13 de diciembre.

venta dF navidal. Exposición colectiva, presentada por la Plástica de México, Londres 139 , el 15 de diciembre. 
Nombre de los expositores: Trinidad Osorio, Gilberto Aceves Navarro, Ernesto Alcantara, Raúl Anguiano, Dr. Atl, Pilar Castañeda, Rosa Castillo, Fidencio Castillo, lernando Castro Pacheco, Olga Costa, Francisco Corzas, Héctor Cruz, José Chávez Moreno, lrance Chancellor, Jorge González Camarena, Silvia H. Gonzáles, Manuel Herrera Cartalla, Maria Izquierdo, Jorge Stanyo Kaminiski, Amador Lugo, Luis Lópes Loza, Lconel Maciel, Roberto Malfavón, Francisco Marín, María Marín, İlaine Menasse, Nicolás Moreno, Leonardo Nierman, Luis Nishisawa, Isidoro Ocamfo, Juan O'Gorman, Pablo O'Higgins, Froylán Ojeda, Carlos Orozco Romero, Josí Clomente Orozco, ficliciano Peña, Angel Pichardo, Luis Pérez Flores, Fanny Rabel, José Reyes Meza, Diego Rivera, José L. Ruiz, Adrián Silva, José Manucl Schmill, I. aletta Swan, Gildardo Uribe, Cordelia Urueta, Lucinda Urrusti, Puri Yáĩes, Eduardo Zamora, Rafael Zepeda, Francisco Züniga.

Colectuva de invierno. Exposición de artistas seleccionados, presentada por la Galería Chapultepec, Insurgentes Sur 11-bis, el 15 de diciembre.

makía rlena delgado. Exposición presentada por la Galería Escudero, Valencia 20, del 15 de diciembre de 1969 al mes de enero de 1970.

Catálogo: 1. orrlación 3, recinto 2. ormlación 2, recinto 3. pirámide, mármol 4. elevación, cantera 5. capricho 1, cantera 6. espacial 2, fibra de vidrio 7. espacial 5, mármol 8. gruta 1, ónix 9. caracol, mármol 10. gestación, mármol 11. eros 1 , cantera 12. maternidad 2, recinto 13 . origen 1 , bronce 14 . ballet, bronce 15 . torso negro, mármol 16. génesis 1, mármol negro 17. génesis 2, mármol Carrera 18. esfera compucsta, bronce 19. eros 3, mármol 20. gruta 2, bronce 21. torso olimpico, mármol 22. sintesis, mármol 23. origen 2, mármol 24. protección 2, ónix 25. aerolito, bronce 26. éxtasis, bronce 27. el quijote, bronce 28 . nubes. bronce 29. penacho, bronce 30. máscara, bonce 31. foca, ónix 32. maternidad 3, ónix 33. ave, ónix 34. Selene, carreara 35. sublimación, ónix 36. torso sublimizado, ónix 37. impetu, ónix 38. flama, mármol 39. varón, ónix 40. Venus, mármol 41. gorgeo, ónix 42. silueta, ónix 43. el beso, ónix 44. espacial 1, ónix 45. pureza, mármol 46. constantes espaciales, grupo fibra de vidrio 47. constantes espaciales, maqueta 1 y 2, bronce 48. constantes espaciales $1,2,3,4,5,6$, fibra de vidrio. 49 bocetos espaciales 1,2 , fibras de vidrio 50 . boceto puerta monamental, fibra de vidrio 51. paisaje urbano 1,2 , fibra de vidrio 52 . elemento mural, fibra de vidrio y bronce.

JORGe wilmor. Exposición de cerámica y pinturas presentada por la Galería de Arte Mexicano, Milán 18, del 15 al 31 de diciembre.

FIESTA DE NAvIDAd. Exposición colectiva presentada por el Instituto Nacional de Bellas Artes, SEP, Galería José María Velasco, Peralvillo 55, el 16 de diciembre.

Nombre de los expositores: María Eugenia Alconero, Héctor Ayala, Octavio Bajonero, Feliciano Béjar, Ernesto Carreón, Hugo Chávez, Margarita Chávez, Irma Escárzega, Arturo Estrada, Leopoldo Estrada, José Luis Fernández Ledesma, José Gómez Rosas, Ester Guerrero, Rosa Lie Johansson, Macrina Krauss, Julia López, Froylán Ojeda, Tomás Ortiz, José Padilla Carlin, Carlos Páramo, Feliciano Peña, Angel Pichardo, David Pintentel, Yolanda Quijano, Mariano Rechy, David Romero, 
Angal Maniri Rodrigues, Alicia Saloma, Carlos Stampa, Alfredo Serrano, José Serrano, Adrián Silva, Luis Toledo, Ana Ugalde, Rodolfo van Kurcayn, Rail IVichis, Puri Yáñcz, José Zúñiga.

RINA lazo. Exposición de la reproducción de las pinturas nayas de Bonampak, presentada por el Departamento del D. F., Dirección General de Acción Social, Galerías (le la ciudad de México en el Centro Social Popular “Gral, Ignacio Zaragoza”, Av. Oriente 154 y Calle Sur 121, Col. Escuadrón 201, del 16 de diciembre de 1969 al 16 de enero de 1970.

JEAN-JACQUES MORvaN. Exposición presentada por el Instituto Nacional de Bellas Artes, Sala Internacional, Galerías del Palacio de Bellas Artes, el 17 de diciembre.

Nuevas pinturas Y esculturas latinoamericanas. Exposición presentada por el Center Inter-American Relations, 680 Park Avenue at 68th Street, New York, duraute el mes de diciembre de 1969 a enero de 1970 .

José Luis cuevas. Exposición de trabajos recientes presentada por la Tasende's Gallery, Calzada Costera Miguel Alemán y V. Yáñez Pinzón, en Acapulco, Gro., del 11 al 31 de diciembre. 
DOI: http://dx.doi.org/10.22201/iie.18703062e.1970.sup1 
DOI: http://dx.doi.org/10.22201/iie.18703062e.1970.sup1

En la Imprenta Universitaria, bajo la dirección de Jorge Gurría Lacroix, se terminó la impresión de Catálogo de las exposiciones de arte en 1969, el día 19 de diciembre de 1970. La composición se paró en tipos Old Style 8-10 y 8-8. Se tiraron 1500 ejemplares. 